
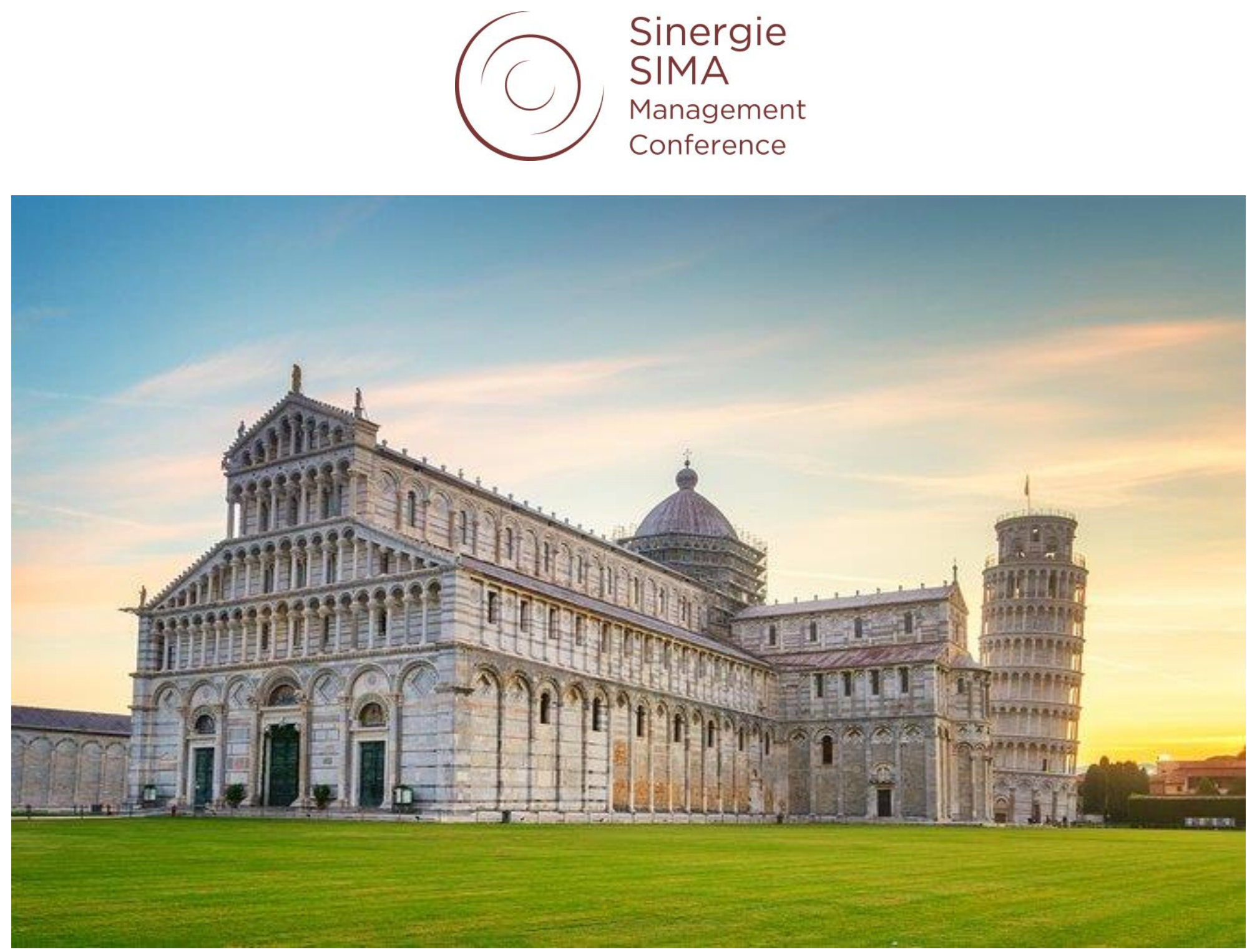

\title{
Grand challenges: companies and universities working for a better society
}

\section{Extended Abstracts}

University of Pisa - Sant'Anna School of Advanced Studies, Pisa 
Electronic Conference Proceedings of Sinergie - Sima Management Conference

Grand challenges: companies and universities working for a better society Pisa, 7-8 September 2020

University of Pisa - Sant'Anna School of Advanced Studies, Pisa

ISBN 97888943937-6-7

Gli Electronic Conference Proceeding sono pubblicati online sul portale di Sinergie Italian Journal of Management

http://www.sijm.it

(C) 2020 FONDAZIONE CUEIM

Via Interrato dell'Acqua Morta, 26

37129 Verona - Italy 


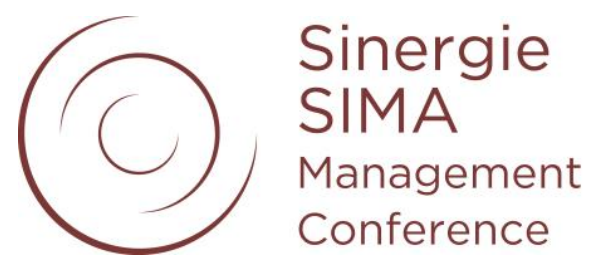

\title{
Grand challenges: companies and universities working for a better society
}

7-8 September 2020

\section{Electronic Conference Proceedings}

\author{
Extended Abstracts
}

a cura di

Sandro Castaldo, Elisa Giuliani, Marco Frey e Marta Ugolini 


\section{Conference chairs}

SANDRO CASTALDO

MARCO FREY

ELISA GIULIANI

MARTA UGOLINI

\section{Former Chairs}

Claudio BACCARANI

GAETANO M. GOLINELLI
Bocconi University

Scuola Superiore Sant'Anna

University of Pisa

University of Verona

University of Verona

Sapienza University of Roma

\section{Scientific and international coordination}

ANGELO BONFANTI

DANIELE DALLI

ARABELla MOCCIARO Li DESTRI

ANDREA PICCALUGA

\section{Scientific committee}

FEDERICO BRUNETTI

LUIGINO BRUNI

FRANCESCA CABIDDU

MARIO CALDERINI

MiCHELE CANO

PEgGy CHAUdRY

MARIA COLURCIO

VALENTINA DE MARCHI

IRENE HENRIQUES

CHARles HOFACKeR

GENNARO IASEVOLI

EMANUELE INVERNIZZI

BEATRICE LUCERI

Alberto MatTIACCI

PATRICIA MOURA E Sa

MARIA RoSARIA NAPOLITANO

ANTIGONI PAPADIMITRIOU

ROBERTO PARENTE

ALBERTO PASTORE

TONINO PENCARELLI

AlESSANDRA PERRI

FRANCESCO RIZZI

FRANCESCO RULLANI

ElITA SCHILlACI

PHILIP SHAPIRA

PAOLA SignORI

ANNALISA Tunisini

Alfonso Vargas

TIZIANO Vescovi

DONATA VIANELLI

ANTONELLA ZUCCHELLA
University of Verona

University of Pisa

University of Palermo

Scuola Superiore Sant'Anna, Pisa

University of Verona

LUMSA, Roma

University of Cagliari

Politecnico di Milano

University of West Scotland, UK

Villanova University, USA

University of Catanzaro

University Padova

York University, Canada

Florida State University, Usa

LUMSA, Roma

IULM University, Milano

University of Parma

Sapienza University of Roma

University of Coimbra, Portugal

University of Napoli Parthenope

Western Kentucky University, Usa

University of Salerno

Sapienza University of Roma

University of Urbino Carlo Bo

Ca' Foscari University of Venice

University of Perugia

Ca' Foscari University of Venice

University of Catania

Alliance Manchester Business School, UK;

Georgia Institute of Technology, USA

University of Verona

University Cattolica del Sacro Cuore, Milano

University of Huelva, Spain

Ca' Foscari University of Venice

University of Trieste

University of Pavia 
Organizing committee

ANTONELLA ANGELINI

ELEONORA ANNUNZIATA

MATTEO CORCIOLANI

ALBERTO Di MININ

ALESSANDRO GANDOLFO

CRISTINA MARULLO

FEDERICA NIERI

\section{Editorial staff}

FABio CASSIA AND NicOla COBElli

LAURA CIARMELA

ADA ROSSI

ADELE FERRAGAMO

Registration and invoicing

ANNALISA ANDRIOLO
University of Pisa

Scuola Superiore Sant'Anna, Pisa

University of Pisa

Scuola Superiore Sant'Anna, Pisa

University of Pisa

Scuola Superiore Sant'Anna, Pisa

University of Pisa

University of Verona

(laura.ciarmela@sinergieweb.it)

(redazione@sinergieweb.it)

(segreteria@societamanagement

(amministrazione@sinergieweb.it) 


\section{La Direzione e il Comitato Scientifico del Convegno di Sinergie sono riconoscenti ai Referee che hanno collaborato al processo di peer review dei paper}

TINDARA ABBATE

BARBARA AQUILANI

DANIELA BAGLIERI

ANTHONY BUONO

MARIA Rosita CAGNINA

ELENA CANDELO

RosSELla CANESTRINO

LUIGI CANTONE

FRANCESCO CAPONE

MARIA COLURCIO

LAURA COSTANZO

AlESSANDRA COZZOLINO

GIORGIA D'AlLURA

Augusto D'Amico

ALFREDO DE MASSIS

GIACOMO DEL CHIAPPA

SONIA FERRARI

MARIA ANTONELlA FERRI

FULVIO FORTEZZA

ALBERTO GRANDO

GENNARO IASEVOLI

FRANCESCO IZZO

TIZIANA LA RocCA

BEATRICE LUCERI

VITTORIA MARINO

JACQUES MARTIN

PIERO MASTROBERARDINO

MiCHELA MATARAZZO

ALESSANDRA MAZZEI

LAURA MICHELINI

PAOLA PANICCIA

ANTIGONI PAPADIMITRIOU

AlBerto PASTORE

GIOVANNA PEGAN

Anna Claudia Pellicelli

LUCA PETRUZZELLIS

TOMMASO PUCCI

YOSSI RAANAN

ANGELO RIVIEZZO

MARCELLO SANSONE

FRANCESCO SCHIAVONE

ALFONSO SiANO

PIERPAOLO SINGER

ERNESTO TAVOLETTI

ANTONIO TENCATI

FRANCESCO TESTA
Università di Messina

Università della Tuscia

Università di Messina

Bentley University

Università di Udine

Università di Torino

Università di Napoli Parthenope

Università di Napoli Federico II

Università di Firenze

Università Magna Grecia di Catanzano

University of Southampton

Sapienza Università di Roma

Università di Catania

Università di Messina

Università di Bolzano

Università di Sassari

Università della Calabria

Universitas Mercatorum

Università di Ferrara

Università Commerciale "Luigi Bocconi"

Università Lumsa di Roma

Università degli Studi della Campania Luigi Vanvitelli

Università di Messina

Università di Parma

Università di Salerno

Universite' Du Sud Toulon-Var

Università di Foggia

Università del Sannio

Libera Università di Lingue e Comunicazione IULM

Università Lumsa di Roma

Università di Roma Tor Vergata

Johns Hopkins School of Education, Baltimore, Western Kentucky

University, USA

Sapienza Università di Roma

Università di Trieste

Università di Torino

Università di Bari

Università di Siena

Levinsky College of Education, Yaffa-Tel Aviv, Israel

Università del Sannio

Università di Cassino e del Lazio Meridionale

Università di Napoli Parthenope

Università di Salerno

Università di Salerno

Università di Macerata

Università di Brescia

Sant'Anna Scuola Universitaria Superiore Pisa 
ROBERTA TRESCA

ANNALISA TUNISINI

MARIA VERNUCCIO

ROBERTO VONA

VINCENZO ZAMPI

LORENZO ZANNI
Università di Chieti e Pescara

Università Cattolica del Sacro Cuore

Sapienza Università di Roma

Università di Napoli Federico II

Università di Firenze

Università di Siena 



\section{Al Lettore,}

questo volume accoglie gli extended abstract del Convegno Sinergie-SIMA 2020, dal titolo Grand challenges: Companies and Universities working for a better society, Università di Pisa, Scuola Superiore Sant'Anna, Pisa, 7-8 settembre 2020.

Le società contemporanee si trovano di fronte a un bivio: da un lato i governi sono sotto pressione per raggiungere obiettivi ambiziosi di crescita economica, dall'altro tale crescita alimenta complesse sfide ambientali e sociali, parte degli obiettivi di sviluppo sostenibile, o Agenda 2030, delle Nazioni Unite. Ciò spinge verso un ripensamento del capitalismo così come tradizionalmente inteso.

Lo scopo del Convegno è di discutere del ruolo delle imprese e dell'università per affrontare queste sfide. Per quanto riguarda le imprese, un focus particolare è rivolto agli impatti positivi che esse possono esercitare sulla società e sull'ambiente attraverso varie iniziative: dagli investimenti responsabili al coinvolgimento degli stakeholder per affrontare rilevanti problematiche sociali. Altrettanto articolato è il contributo che le università possono offrire attraverso le proprie attività di ricerca, formazione e terza missione.

Gli Extended Abstract racconti in questo volume affrontano la tematica con una varietà di argomenti, punti di vista, prospettive.

Vengono altresì proposti studi e ricerche sul più ampio e generale capo del management, cui spetta un ruolo da protagonista anche al di fuori delle imprese.

Sandro Castaldo, Elisa Giuliani, Marco Frey e Marta Ugolini 

Cari Lettori e Convegnisti,

il call for paper del Convegno Sinergie-SIMA 2020 Conference dal titolo Grand challenges: companies and universities working for a better society ha previsto la possibilità di presentare extended abstract oppure full paper. In totale sono pervenuti in redazione 113 extended abstract $\mathrm{e}$ 35 full paper.

Per gli extended abstract, la valutazione dei contributi ricevuti è stata operata dai Chair e dal coordinamento scientifico in base alla coerenza con il tema del Convegno e/o con gli studi di management secondo l'articolazione dei Gruppi Tematici SIMA. Sono state altresì valutate la chiarezza e la rilevanza (anche potenziale) dei contenuti proposti.

Per i full paper, la procedura di valutazione dei contributi è stata condotta secondo il meccanismo della peer review da parte di due referee anonimi, docenti universitari ed esperti dell'argomento, scelti all'interno dei soci SIMA e della comunità di Sinergie.

In particolare, nella valutazione dei contributi i referee hanno seguito i seguenti criteri:

- chiarezza degli obiettivi di ricerca,

- correttezza dell'impostazione metodologica,

- coerenza dei contenuti proposti con il tema/track del convegno e/o con gli studi di management,

- contributo di originalità/innovatività,

- rilevanza in relazione al tema/track del convegno e/o agli studi di management,

- chiarezza espositiva,

- $\quad$ significatività della base bibliografica.

L'esito del referaggio ha portato a situazioni di accettazione integrale, accettazione con suggerimenti e non accettazione. In caso di giudizio discordante la decisione è stata affidata ai Chair. Ogni lavoro è stato poi rinviato agli Autori completo delle schede di referaggio per la attuazione delle modifiche suggerite dai referee.

A seguito del processo di valutazione sono stati accettati 23 full paper e 111 extended abstract, pubblicati in due distinti volumi.

Tutti gli extended abstract di questo volume sono stati presentati e discussi durante il Convegno e pubblicati online sul portale della rivista Sinergie ( $\underline{w w w . s i j m . i t})$. Quest'anno sono anche disponibili on line i video con le presentazioni registrate dagli Autori.

Nel ringraziare tutti gli Autori per la collaborazione ci auguriamo che questo volume contribuisca a fornire un avanzamento di conoscenze sul ruolo che le imprese e l'università possono svolgere per conciliare la crescita economica e la necessità di affrontare le complesse sfide globali ambientali e sociali.

I Chair e il Coordinamento Scientifico

Marco Frey, Elisa Giuliani, Marta Ugolini, Sandro Castaldo, Arabella Mocciaro Li Destri, Angelo Bonfanti 



\section{INDICE}

To go digital or not to go digital? the influence of board's digital expertise on strategic

change of the firm

CHIARA ACCIARINI, PAOLO BOCCARDELli, ENZO PERUFFO

New business ventures coping with COVID-19: the case of the MENA region

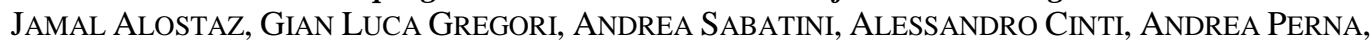

FARIS ALOSTAZ

Food literacy and food purchase behaviour

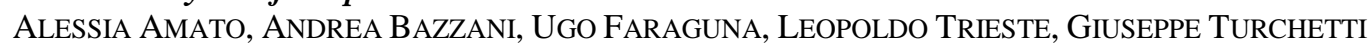

Declinazione dell'Agenda 2030 a livello locale. Il contributo dei FridaysForFuture

al processo di istituzionalizzazione

NORA ANNESI, MASSIMO BATTAGLIA, PATRIZIA GRAGNANI, FABIO IRALDO

The interplay of business models with sustainable innovations: evidence from Italian SMEs

in the energy sector

ElEONORA ANNUNZIATA, FRANCESCO RIZZI, MARCO FREY

Network collaborativi di trasferimento tecnologico dall'Università all'Industria per la sostenibilità

SILVIA BAIOCCO, FRANCESCO SCAFARTO, PAOLA M.A. PANICCIA

Exploring the main drivers of academic frustration: a systematic scale development

MARCo BALZANO, GUIDO BORTOLUZZI, MBIEKE STEPHEN NDULA

Do women promote environmental sustainability? A European patent analysis

MARIASOLE BANNÒ, MARCO TRAVERSI, GRAZIANO COLLER

Fair Trade and Universities: the case of certified fairtrade Universities in the UK

ROSSELLA BARATTA, FRANCESCA SIMEONI

Marketing GI products in the digital age. An exploratory study

CHIARA BARTOLI

Social innovation, community based tourism and place attachment. First insights from two Italian Experiences

Gianpaolo Basile, Mario Tani, Mauro Sciarelli, Maria Antonella Ferri

Una systematic literature review del turismo nautico: una prospettiva economico-manageriale

Clara BeneVolo, RicCARdo Spinelli, Agnese CARUSo

Distinctiveness in rural tourism: the case of Val d'Orcia

GIAIME BERTI, NICOLA BELLINI

SMEs@ Industry 4.0: A comparison between top and average performers

Marco BetTiol, Mauro CAPESTRO, EleONORA Di MARIA, STEFANO MicElli

Key Performance Indicators per una rete oncologica regionale. Verso modello multilivello

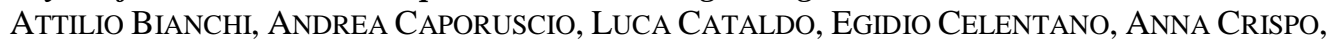

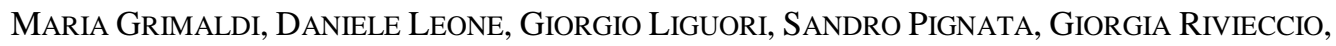
Francesco Schiavone, Michele Simoni, Cristina THIEBAUd

keyword research analysis: a new methodological approach to brand positioning evaluation Michelle BONERA, ALESSANDRO BIGI, ALESSANDRA CAVALLI

How to keep the momentum and support the Italian NHS adoptinginnovation and delivering innovative services 
The impact of Covid-19 emergency on live performing arts: Teatro Coccia in Novara and its supply chain

ClEMENTINA BRUNO, FABRIZIO ERBETTA, GIOVANNI FRAQUELLI

Understanding community enterprise through the humane entrepreneurship lens

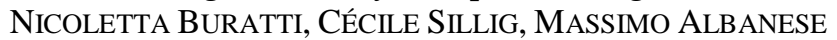

Lo stakeholder engagement tramite l'utilizzo della piattaforma Instagram: un caso studio per l'analisi e le implicazioni del processo di engagement

IRIS BURGIA

Rating di legalità e rating d'impresa a supporto della cultura della legalità.

Un inquadramento concettuale

IRENE BUZZI, ETTORE D'ASCOLI

Ecosistemi di innovazione: il contributo di EIT Health allo sviluppo di partenariati pan-europei dinamici

NUNZIA CAPOBIANCO

Raccolta di fondi nel crowdfunding reward-based: il ruolo delle tipologie di prodotto

FRANCESCO CAPPA, STEFANO FRANCO, EDOARDO FERRUCCI, RICCARDO MAIOLINI

Reti di imprese e innovazione nei servizi turistici. Il caso di Rimini

Giuseppe Cappiello, Valentina Morando, Manuela Presutti, Marco Visentin

The impact of "forced" and "massive" smart-working on the innovative work behavior and creativity of employees. Empirical evidence during the COVID-19 emergency

GRAZIA CARLATTI COSTA, GUIDO BORTOLUZZI

"SalinellaPelle" un progetto di creating shared value per la città di Taranto

DANIELA CAVALLO

Covid-19: crisis management experiences in the private healthcare industry

MARIANNA CAVAZZA, MARIO DEL VECCHIO, LORENZO FENECH, LAURA GIUDICE, ERIKA MALLARINI, LUIGI M. PRETI, VALERIA RAPPINI

Reconcilable differences? On the relation between social and economic goals and the importance of process goals

VALERIA CAVOTTA, ELISA VILLANI,JOHANNA MAIR

Supply chains network during a global crisis: Covid-19 emerging challenges

ALESSANDRO CINTI, ANDREA SABATINI, GIAN LUCA GREGORI

Sustainability, innovation and biological technology in wine production: an empirical analysis NicOla COBELli, MARGHERITA ANGIONI, FABIO MUSSO

An exploration of determinants of tourist experience in the Albergo Diffuso. An Italian case study Cristiana Compagno, Michela C. Mason, Francesco RagGiotTo

Transgenerational succession in long standing family firms: the "Huey, Dewey and Louie" pattern ELISA CONZ, GIOVANNA MAGNANI

Relationship selling and marketing automation during the Covid-19 Pandemic:

A cross-sectional analysis

DANIELA CORSARO, ISABELlA MAGGIONI, MIRKO OLIVIERI

Efficienza e produttività del personale nel settore bancario italiano. Le leve industriali a sostegno dei piani strategici post Coronavirus

Michele Costa, AlBerto PASTORE

CSR disclosure and environmental topics: what's happen in American corporates?

Assuntina COVIELlO, AlESSANDRA DE CHIARA 
Core self-evaluations, dual mind processing, and overconfidence: a laboratory experiment

The humane side of entrepreneurship: an empirical investigation

VAlENTINA CUCINO, CRISTINA MARUllo, ElEONORA ANNUNZIATA, ANDREA PiCCALUGA

Service innovation in the wine sector: evidence from Sicilian firms

Mariapia CUTUGNO, TINDARA ABBATE, FABRIZIO CESARONI

“Privacy concerns: an exploratory analysis through big data”

DAVID D’ACUNTO, SERENA VOLO

The determinants of eco-innovation strategies. An empirical investigation of two European countries IDA D'ATTOMA, SILVIA PACEI

Coopetition strategy as management innovation: evidence from the alliance between

Luna Rossa \& Emirates team New Zealand

GIOVANNi BATTISTA DAGNINO, ANNA MinÀ

The employment of nonfamily managers in family firms: An empirical investigation of normative heterogeneities in top management team (TMT) from a sample of European firms.

ALFREDO D'ANGELO

Which came first: on the evolution of environmental identity and entrepreneurial identity

in environmental entrepreneurship.

CHIARA DE BERNARDI

La risposta emotiva del consumatore alle attività promozionali

FRANCESCA DE CANIO, DAVIDE PELLEGRINI

The challenges of Covid-19 in the tourism industry. The case of the Italian context

Valentina Della Corte, Giovanna Del Gaudio, Giuliana Nevola, EnRico Di Taranto

The revival of corporate magazine in building stakeholder engagement

Alessio Di LEO, LORENZA GERARDi, FABIOLA SFODERA, AlBERTO MATTIACCI

Business models and sustainable firms: a focus on B Corps in Italy

ElEONORA Di MARIA, VALENTINA DEMARCHI, AMBRA GALEAZZO, ElENA BONEL

Initial coin offering: il ruolo dei contenuti linguistici del white paper

GUIDO Di MATTEO, FRANCESCA MASCIARELLI

Il consumer journey nel turismo: elaborazione di un framework integrale sulla base della letteratura VALENTINA DINI, LAMBERTO ZOLLO, CRISTIANO CIAPPEI, RICCARDO RIALTI

Museums' management innovation between crisis and opportunities

ANNAMARIA EsPosito, ANGElA BESANA, M. CRISTINA VANNINI, CHIARA FISICHELlA

Green enablers and disablers in fashion green luxury consumption

MONICA FARAONI, LAMBERTO ZOLLO, RAFFAELE FILIERI

La formazione e l'evoluzione dei team imprenditoriali: un focus sugli spin off accademici Rosangela FeOla, Chiara CRUdele, Roberto PARENTE, MASSIMILIAMO VeSCI.

Innovating and transforming during Covid-19: Insights from Italian firms

GiUlio FERrigno, VALENTINA CUCINO, ANDREA PICCALUGA

Tradition-driven business model, value creation and value capture in high-end hotels

Stefano Franco, Angelo Presenza, Antonio Messeni PeTruZzelli, ENZO PerufFo

In search of new tools for improving transactional processes. A manufacturing case study PIERO GABBERI, ANDREA CHIARINI 
Differenze culturali tra aree geografiche e gestione delle relazioni coopetitive

The innovation of the value capture: insights from the sharing economy

CECILIA GRIECO, GENNARO IASEVOLI

I water safety plans come strumento di gestione preventiva e resiliente: analisi di una esperienza

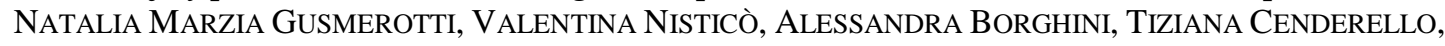
MARCO FREY

Corporate governance, blockholder esteri e performance di impresa: una verifica empirica in Europa ElviRA TIZIANA LA ROCCA, RAFFAELE STAGLIANÒ, AUGUSTO D’AMICO

“Sono super, finanziami!” L'impatto del narcisismo imprenditoriale sulle scelte di finanziamento di business angel e venture capitalist

SIMONA LEONELLI, FRANCESCA MASCIARELLI

Knowledge spillover among Italian cities: the impact of youth entrepreneurship and high-tech firms on cities attractiveness

FILIPPO MARCHESANI, FRANCESCA MASCIARELLI

Resilienza delle città e mobilità degli studenti: come le città rispondono ai disastri naturali FILIPPO MARCHESANI, FRANCESCA MASCIARELLI

The role of digital technologies in International Business and Marketing:

an assessment of the literature

MARCELLO MARIANI, MICHELA MATARAZZO

The SMES digital entrepreneurial ecosystem: a matter of trust

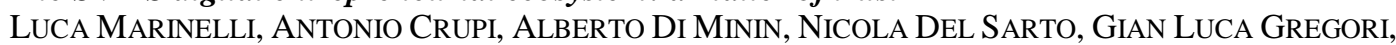
DOMINIQUE LEPORE, FRANCESCA SPIGARELLI

Product authenticity: dimensions from the agri-foodstuffs producers' side

Veronica Marozzo, Alfonso VARgas-Sanchez, Tindara AbBate, Augusto D’Amico

Relational goods between person, acknowledgment and affective commitment: a contribution to the creation of public value

ANNA MARRUCCI, RICCARDO RIALTI, LAMBERTO ZOLLO, CRISTIANO CIAPPEI

Beyond the R\&D Unit. An exploratory study of corporate innovation initiatives in large established organizations

Cristina MARUllo, ISABEl ESTRADA VAQUERo, Alberto Di Minin

Enabling factors of ridesharing: trust is the main driver for potential users

Giovanni MATtia, LUdovicA PRINCIPATO, LAURA Di PIETRO, CARLO AlbERTo PRATESI

Intellectual capital disclosure and third mission in Italian Universities

ROBERTO MAVILIA, ROBERTA PISANI

Strategic approaches to corporate wrongdoing prevention: an explorative analysis of whistleblowing arrangements in Italy

AlESSANDRA MAZZEI, Alfonsa Butera, Silvia RAVAZZANI

Resource-constrained innovation at the BoP: evidences from a digital startup

LAURA MICHELINI, ALESSIA PISONI, GLORIA MARTIGNONI

Opening the box of Universities' Third Mission: theoretical background and empirical investigation Matilde Milanesi, EnRico Marone, VAlentina PAPA, Simone Guercini 
Bridging the gap between sales and marketing: the role of digital content marketing strategy

ELISABETTA MONTI, CHIARA ANCILLAI, FEDERICA PASCUCCI

Taking corporate role in society seriously: the impact of strategic communication during Covid-19 on millennials

GraZia Murtarelli, COLLEONI ElANOR, ROMENTI STEFANIA, OLIVIERI MiRKO

Responsible management: a cutting edge for sustainability in the fashion supply chain

Kunle Francis OgunTEGBe, NADiA Di PAOLA, RoBERTo VonA

Examine organizational routines of US universities for a "better society" under the COVID 19

pandemic

ANTIGONI PAPADIMITRIOU

La gestione del paziente cronico: nuove tecnologie e nuovi modelli organizzativi

RoBerto PARENTE, ANTONIO BOTTI, ANTONELlA MONDA, ERIKA NAPONIELLO

Approccio burocratico versus approccio imprenditoriale: il caso dei Living Lab della rete ENOLL MARIACARMEla PASSARELli, DOMENICO MAZZOTTA, AlFio CARIOLA, GAETANO CUPIDO

Biology and entrepreneurship: how they can meet?

MARIACARMEla PASSARElli, VALENTINA CUCino, ERIKA Cione, Alberto Di Minin, Alfio CARIOLA, ROBERTO CANNATARO

Gli assistenti vocali agli occhi dei millennials: un'indagine esplorativa

Michela PATRIZI, MARIA VERNUCCIO, ALBERTO PASTORE

Art and business. The history of Campari

GIUSEPPE PEDELIENTO, VALERIA PINCHERA, DANIELE DALLI

Diversity \& inclusion (D\&I) in management Academies: state of the art and future challenges

Lara Penco, Arabella Mocciaro Li Destri, Alessandra Perri, Alberto Pastore,

SANDRO CASTALDO

Industry 4.0: challenge or opportunity for social sustainability in firms?

MICHELA PICCAROZZI, BARBARA AQUILANI

Global value chains in the era of 4IR: new paradigm of business models for SMEs

ROBERTA PISANI, ROBERTO MAVILIA

Does the presence of the University affect residents' perceived quality of life?

An empirical investigation

ANGELO RIVIEZZO, MARIA ROSARIA NAPOLITANO, GIANCARLO RAGOZIN

Exploring the antecedents of responsible leadership behaviour at individual and organisational levels FRANCESCO RIZZI, CHIARA PELLEGRINI, ElEONORA ANNUNZIATA, MARCO FREY

Family firms in times of digital innovation: transferring knowledge across generations

EMANUELA RONDI, LEOPOLD VON-SCHLENK BANSDORF, RUTH UBERBACHER, ALFREDO DE MASSIS,

MARCEL HULSBECK

Narcissistic CEOs in family firms and their role in innovation

PAOLA ROVELLI, ALFREDO DE MASSIS, LOUIS GOMEZ-MEJIA

Exploration or exploitation? That's the problem through the lenses of stakeholders

The commercialization of highly technological products in the context of Industry 4.0:

a B2B SMEs perspective

ANDREA SABATINI, SARA BARTOLONI, GIAN LUCA GREGORI

Personal branding: an exploratory study

Rossella SAGLIOCCO, GAETANO BUCCINO 
L'innovazione del business model dell'Università per le attività di formazione

SAVINo SANTOVITO, RAFFAELE SILVESTRI, SERGIO SALOMONE, GAETANO MACARIO

L'impatto del Coronavirus sulla comunicazione aziendale: analisi delle lettere dei CEO agli azionisti Domenico Sardanelli, Agostino Vollero, Alfonso Siano, Francesca ConTe

Data-driven talent management: quali prospettive di sviluppo in Italia?

Domenico SARDANElli, Francesca Conte, Agostino Vollero, Alfonso Siano

Creative crowdsourcing: exploring the relationship between brand seeker and two-sided platform

SARA SCALA, FEDERICA CECCOTTI, AlBERTO PASTORE

Mapping the conceptual structure of patent ecosystems: The case of Singapore

CARMEla Elita Schillaci, Elona MARKU, Maria ChIARA Di GUARDo

Academic Governance insights of University spin-offs: a micro-foundational perspective of life-science ventures

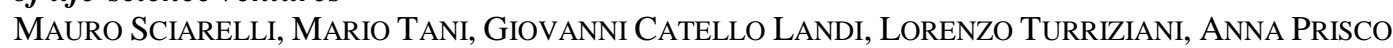

ESG Criteria in the banking industry: a systematic literature review

SEBASTIAN PUSCEDDU, CORRADO GATTI

Transformative value co-creation in healthcare services in the COVID-19 era

RoBERTA SEBASTIANI, ALESSIA ANZIVINO

"Cashback programs in ecommerce retailers: the choice between pure cashback and donation"

ALESSANDRO SIGNORINI

Social spin-offs from established non-profit organizations; factors influencing the behavior

of corporate donors

ALESSANDRO SIGNORINI

Comunicare e promuovere la sostenibilità: il caso dei portali turistici regionali

RICCARDO SPINELLI, MATILDA SCANU

Enhacing triple helix model through university educational offer

GIULIA TAGLIAZUCCHI, GIANLUCA MARCHI

Attitudini ambientali e accettazione pubblica della nanotecnologia. L'influenza del

"new environmental paradigm" e della "green trust" sulla percezione di benefici e rischi

della nanotecnologia

NicCOlò MARIA TODARO, NATALIA MARZIA GUSMEROTTI, TIBERIO DADDI

Effectiveness of training methods for SME managers

OKSANA TOKARCHUK, ROBERTO GABRIELE

Exploring and comparing the impact of reward crowdfunding and equity crowdfunding on company performance

Ciro Troise, Elena CANDElo, Diego Matricano, Mario SorRentino

From online experience to visiting the production plant: management challenges and communication opportunities

KAMEl Ben Youssef, MARTHA FrIEL, GRAZIA MuRTARELli, STEFANIA ROMENTI 


\title{
"SalinellaPelle" un progetto di Creating Shared Value per la città di Taranto
}

\author{
DANIELA CAVALlO*
}

Obiettivi. "SalinellaPelle" è un progetto di rigenerazione urbana e di co-creazione di valore per la città di Taranto, nello specifico per il quartiere Salinella, area periferica e degradata della città, priva di servizi necessari e di spazi urbani comuni attrezzati, ma sulla quale insistono alcuni luoghi deputati allo sport, come stadio, palestre, luoghi in genere attrezzati a questo fine ma che da tempo richiedono un ripensamento ed una rigenerazione. Per questo l'occasione di Taranto Capitale dei XX Giochi del Mediterraneo, che si terranno nella città pugliese nel 2026, è risultata un'occasione ed uno stimolo per sperimentare un modello di partecipazione della popolazione per la governance, ovvero le scelte amministrative, e la pianificazione territoriale del quartiere e della città.

Il progetto nasce con l'obiettivo preciso di porre in atto la partecipazione delle persone, degli abitanti, dal basso per arrivare alla pianificazione territoriale generando co-creazione di valore perché le persone sono il territorio, la città, il quartiere.

Il progetto SalinellaPelle è stato così strutturato per "Integrare" e "Idratare" il quartiere della città di Taranto con l'apporto di azioni di valorizzazione ed iniziative di partecipazione per la progettazione e lo sviluppo dei luoghi dedicati alle attività sportive per i Giochi del Mediterraneo 2026: realizzata una prima azione di indagine conoscitiva e attivato una serie di "associazioni" di valore per gli abitanti: il sale (le origini del nome "Salinella" derivano dalla presenza di due laghi in quella zona (Salina e Salinella) - descritti già nella "Naturalis Historia” di Plinio il Vecchio dai quali era possibile raccogliere un'ottima qualità di sale) svolge un ruolo fondamentale nelle funzioni fisiologiche, in particolare nel mantenimento del volume sanguigno, nel bilanciamento idrico, nell'equilibrio acido-basico e nella conduzione nervosa; l'espulsione del sale dal nostro sistema, soprattutto attraverso il sudore è da controllare soprattutto per chi pratica uno sport e deve stare più attento a non alterare l'equilibrio fisiologico. I luoghi, i territori, le città i quartieri sono corpi ed hanno bisogno dell'apporto di sale e devono essere in grado di espellere quello in eccesso, integrandolo e idratando il corpo stesso; così questo parallelismo ci aiuta a rigenerare il quartiere Salinella che, seppur carente di servizi idonei (sale) per gli abitanti, ha lì concentrati il luoghi dello sport (stadio, Palasport, pista d'atletica, palestre) si appresta a diventare modello di ricezione per i prossimi Giochi del Mediterraneo, necessita dunque di ristabilire un equilibrio fisiologico tra abitanti e territorio, magari attraverso lo sport che ne rappresenta il nuovo sale.

Lo sport per il quartiere di Salinella può diventare "a pelle”, ovvero a intuizione, a sentimento, un elemento identitario e di valore, un miglioramento della qualità della vita, riequilibrando quei valori BES (Benessere equo sostenibile) di cui la città di Taranto è stata pioniera (studi BES e Smart City Camera di Commercio di Taranto). Sale, non in eccesso, non in difetto. Senza sale, niente vita; e un granello di sale ingrandito al microscopio e il logo del progetto. Il quartiere Salinella nasce nella città di Taranto negli anni '60 come "ghetto" in cui vennero confinati alcuni abitanti delle zone dei Tamburi e della Città Vecchia a seguito di alcuni crolli di edifici, solo più avanti si è avuta la rinominazione del quartiere in "Salinella" ricordando il vecchio lago. Ad oggi, i nomi delle strade del quartiere recano il nome di un lago o bacino italiano; oggi si vuole riportare il quartiere "al centro" della città.

\footnotetext{
- Progetto per ANCE TARANTO - Confindustria Taranto

Presidente: Arch. Paolo Campagna

Consulente, ideazione e Referente di progetto: Arch. Daniela Cavallo

Collaboratrice: Eleonora Gualtieri

Referente per Ance: Dott. Pasquale Di Ponzio

Referente Comunicazione per Ance: Dott.ssa Maristella Bagiolini

Architetto, Professore a contratto di Marketing Territoriale - Università di Verona

e-mail: daniela.cavallo@univr.it
}

Il Progetto SalinellaPelle è stato svolto con la collaborazione di Eleonora Gualtieri, laureanda in Marketing e Comunicazione UNIVR, che ha collaborato alla raccolta dati, anche per il presente abstract. 
Fig. 1: Il Logo del Progetto

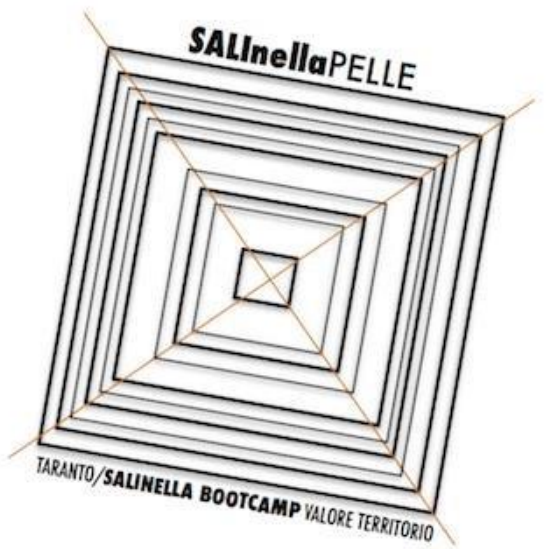

Fonte: elaborazione personale

Gli obiettivi perseguiti durante lo svolgimento del progetto possono essere sintetizzati come segue:

1. creazione della reputazione attraverso la fiducia delle persone nell'iniziativa SalinellaPelle;

2. coinvolgimento e partecipazione attiva delle persone (racconti, condivisione, raccolta dati, ecc.);

3. condivisione del progetto (incontri istituzionali organizzati dai promotori del progetto, ANCE Taranto, Ordine degli Architetti Pianificatori Paesaggisti e Conservatori della Provincia di Taranto, Ordine degli Ingegneri di Taranto, Collegio dei Geometri di Taranto e Osservatorio Permanente Salinella);

4. rielaborazione dei dati e notizie raccolti;

5. verifica;

Il traguardo principale del progetto era quello di predisporre la cittadinanza, e in particolare tutto il quartiere Salinella, ad un atteggiamento di "ascolto" nei confronti della rigenerazione urbana che si vuole porre in atto con una serie di progetti di riqualificazione dei luoghi dello sport e delle infrastrutture all'interno del quartiere stesso. Questo per creare partecipazione e generare la possibilità di co-creare valore attraverso la conoscenza del luogo per arrivare ad una consapevolezza condivisa nello specifico, in generale per costruire una migliore qualità della vita, una società migliore.

La presenza di una laureanda del corso di Marketing e comunicazione d'impresa, indirizzo Marketing territoriale dell'Università di Verona, originaria e residente a Taranto ha facilitato la costruzione di un ponte tra l'Università e il territorio, ponendosi come chiave di volta di un dialogo tra "pari" con i cittadini.

Metodologia. La metodologia all'interno del progetto ha visto in primis l'adozione di strumenti tipici della ricerca qualitativa come questionari online e questionari cartacei per compiere una prima indagine conoscitiva del quartiere Salinella a Taranto, sia dal punto di vista dei residenti nel quartiere che degli abitanti della città in generale, cercando di intercettare le fasce più ampie di età differenziando gli strumenti elo i contenuti. Così il coinvolgimento della cittadinanza è stato ottenuto attraverso un mix di azioni:

- $\quad$ apertura, una settimana prima della somministrazione dei questionari, di una pagina web (social FB) finalizzata a creare diffondere la conoscenza del progetto e incuriosire: Facebook @SalinellaPelle, all'interno di quest'unico canale adottato sono state formulate diverse tipologie di comunicazione (Il questionario online, raccolta fotografica deii momenti con i bambini durante il questionario nelle scuole gli amici, $i$ racconti, le persone, gli atleti, "dicono di noi", video ecc), in questo modo è stato possibile rafforzare l'immagine del progetto e fornire contenuti chiari e facilmente catalogabili; strada facendo il profilo ha contribuito a generare una credibilità dell'iniziativa che ha acquisito una sua reputazione agli occhi della cittadinanza;

- accreditamento del progetto attraverso il sostegno di atleti nazionali che hanno realizzato un video che manifestava il sostegno al progetto e invitava a partecipare ai questionari;

- costruzione della comunicazione attraverso uno storytelling e lo strumento dell'immedesimazione, ovvero si è utilizzato il racconto di Davide, il ragazzino che sconfigge Golia, il gigante, facendo immedesimare l'abitante in Davide e le difficoltà del territorio nel gigante Golia: "Tu sei Davide, c'è Golia da sconfiggere” il pay off;

- $\quad$ partecipazione ai due questionari in cui le domande sono state formulate in base a tre macro-temi, lo sport, la cultura e il mangiar sano, quelli ritenuti utili a comprendere il valore dello sport, la qualità della vita e il grado di conoscenza del territorio;

- $\quad$ racconti sul quartiere, sullo sporta Taranto e sulle persone legate allo sport cittadino;

- $\quad$ una campagna stampa su tv e giornali locali a massima diffusione.

Il progetto per essere continuamente verificabile, "adaptive", è stato strutturato in step, ovvero diverse fasi propedeutiche:

F1. Costruzione della pagina social e della reputazione del progetto

F2. Partecipazione attiva attraverso:

a. questionari 
b. racconti dal basso

F3. Condivisione, ovvero incontri con gli abitanti del quartiere ed i tecnici preposti ai progetti, alle trasformazioni urbane nel quartiere in funzione dei giochi, ma anche della qualità della vita del quartiere stesso:

a. allenamento (sport diversi)

b. laboratorio urbano (progetti di sostenibilità e riciclo)

c. tavoli tecnici di confronto (i progetti di rigenerazione urbana)

F4. Rielaborazione

F5. Verifica

Il metodo sviluppato nel progetto SaninellaPelle è figlio dell'approccio “empatico" del Marketing Territoriale che si sta portando avanti da dieci anni nel Dipartimento di Economia Aziendale dell'Università di Verona, nel Laboratorio annesso di Marketing Territoriale, che consiste nello "allenare" i territori alla valorizzazione, alla cocreazione di valore, alla consapevolezza perché la valorizzazione di un territorio, se vuole essere identitaria e divenire "abito" che quel territorio possa indossare calzandolo a pennello, non può essere progettata "a priori", o meglio i contenuti di uno schema di progetto di marketing territoriale sono il frutto di un'attenta analisi e di confronto con il territorio stesso, in una pratica bottom up che affida alla prima fase, quella di analisi e di conoscenza, una parte importante per definire strategie ed obiettivi raggiungibili. Questo approccio prevede una metodologia "empatica" perché di ascolto del territorio mettendo al centro la persona, l'abitante, la variabile antropologica che di ogni territorio come sistema complesso, è quella più difficile da gestire e pianificare; questo per rendere visibile l'invisibile, o meglio svelare quelle risorse nascoste che ogni territorio possiede, per capire quali siano effettivamente $i$ bisogni e definire una strategia di valorizzazione che sia da una parte qualità della vita per gli abitanti, e dall'altra approccio emozionale e formativo per turisti escursionisti viaggiatori impresa e quanti altri vogliano avvicinarsi a un territorio. Il progetto SalinellaPelle ha tenuto conto di tutto questo, considerando che il Marketing Territoriale "empatico" si muove sempre su due binari: mettersi in ascolto degli abitanti, del territorio, e porre gli abitanti in una modalità di ricezione, di ascolto anch'essi del loro territorio.

Risultati. In questa prima fase il progetto ha ottenuto risultati soddisfacenti in quanto si è ottenuta una buona partecipazione al questionario online (625 persone raggiunte senza acceleratori, ovvero solo con il passa parola senza canali di diffusione a pagamento) e a quello dei bambini nelle scuole (600 bambini), questionari tutti validi. Si è costruita la reputazione del progetto e una parte di fiducia di quanti seguono la pagina web (social FB) che ha superato le 1000 persone; le interazioni con i post sono state più di 22.000, significando che lentamente si è riusciti a catturare prima l'attenzione poi la fiducia da parte degli utenti e dei partecipanti alla pagina web, soprattutto si è conquistata la credibilità, in un territorio assai sospettoso e deluso da progetti vari rimasti spesso "proclami" di tipo amministrativo elo politico. Si sono raccolti dati utili alla riqualificazione urbana e sociale raccolti in un Report consegnato ad Ance Taranto che presenterà progetto e dati in tempi futuri alla cittadinanza ed alla amministrazione locale. Oggi SalinellaPelle può evolvere in un laboratorio attivo dal basso per arrivare ai Giochi del Mediterraneo, di cui la città sarà capitale nel 2026, attraverso la condivisione dei progetti sul territorio, avendo allenato lo stesso ad accogliere, partecipare e condividere le trasformazioni del quartiere, un BootCamp che sia incubatore di un nuovo modello di cittadinanza attiva. I risultati ottenuti spaziano tra diversi ambiti e sono stati riscontrati durante le diverse fasi del progetto stesso. In primis, dalla ricerca qualitativa è emerso il forte carattere contraddittorio presente all'interno del quartiere e, in senso più ampio, in tutta la città di Taranto (sia da parte dei residenti del quartiere Salinella, che di tutti i cittadini). Il carattere contraddittorio sta nel raggiungimento di percentuali simili ed opposte che non riescono a dare un'indicazione di maggioranza per intraprendere una strada di risoluzione, come nell'esempio:

Fig. 2: nostre elaborazioni

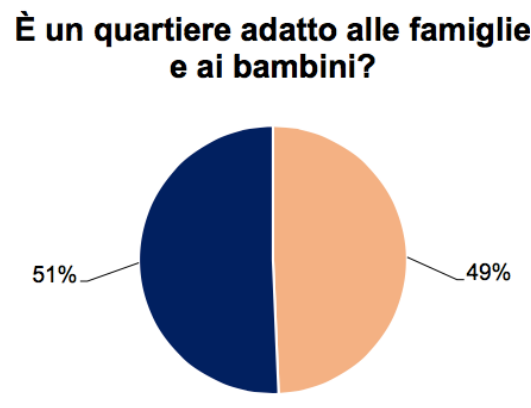

- Sì - No

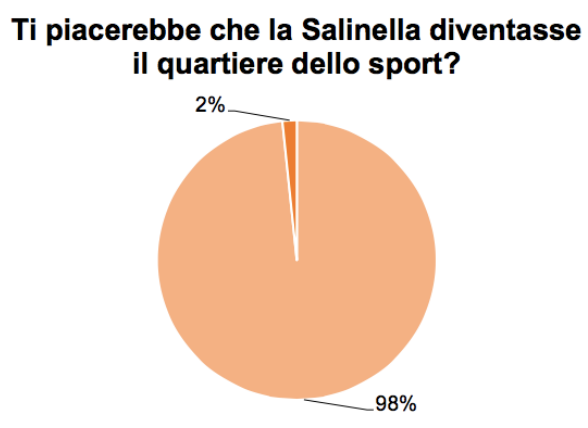

" Sì $=$ No
Ritieni che lo sport sia un elemento identitario della città di Taranto?

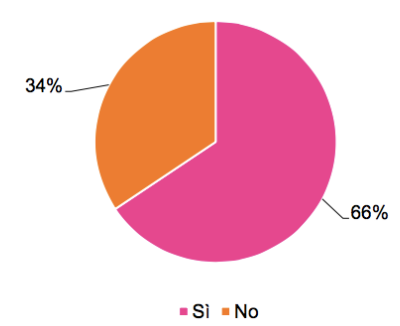

Altri risultati emersi dall'analisi dei dati sono stati il riconoscimento del valore dello sport e delle opportunità ad esso legate per migliorare il quartiere e tutta la città.

Il questionario somministrato ai bambini, in presenza e con l'aiuto dei volontari dell'Associazione OPS (acronimo spiegare) attiva nel quartiere, è stato pensano e strutturato in maniera diversa rispetto a quello on line. Si è pensato 
infatti di intercalare alle domande a risposta multipla la richiesta di disegni e di interagire su mappe per verificare il senso di orientamento e la conoscenza del loro quartiere o della città. Attraverso i questionari cartacei somministrati ai bambini è emerso uno scarso senso di orientamento sul territorio.

Tra gli adulti, invece, attraverso le interazioni con la pagina Facebook, è emersa in maniera significativa quella parte della cittadinanza che desidera raccontare il territorio e di essere ascoltata.

In generale, sia dai questionari online che da quelli cartacei, è emerso che vi è poca conoscenza degli atleti locali (presenti e passati), dato utile in futuro per far leva su una parte della comunicazione sullo sport a Taranto.

Infine, si è potuta riscontrare una difficoltà nel comunicare con gli abitanti del quartiere, poiché non esistono canali istituzionali, né pagine o gruppi informali in grado di racchiudere la cittadinanza, che di per se è mediamente scettica sull'utilità di progetti collettivi. Nonostante questo, il progetto è stato citato all'interno di diversi articoli su giornali locali e attraverso servizi su alcune emittenti televisive del capoluogo ionico.

In sintesi Salinella è un quartiere slegato dalla città, ancora da costruire dal punto di vista urbanistico e identitario, "contraddittorio" perché a seconda di quale parte del quartiere si abita gli abitanti lo percepiscono vivibile o non vivibile, senza mezze misure, un quartiere che ha molte potenzialità e tanto desiderio di "crescere", soprattutto da parte dei giovani.

Per coinvolgere gli abitanti si è realizzato un video di presentazione/suggestione "Salinellapelle", caricato on line sulla pagina youtube: https://www.youtube.com/watch?v=gxNTvt32DIQ consultabile da un pubblico più vasto.

Limiti della ricerca.La ricerca ha presentato alcuni limiti: il coinvolgimento di un campione non pienamente rappresentativo della popolazione, dovuto anche alla difficoltà di comunicare con gli abitanti dei vari quartieri della città. Il progetto è giunto alle prime due fasi (F1. e F2.), in quanto doveva essere solo una prima azione di indagine conoscitiva. Raggiunta la fiducia e la partecipazione degli abitanti sarebbe un peccato chiudere qui l'esperienza, sta ad ANCE ed al Comune di Taranto decidere se proseguire.

Implicazioni pratiche.Una prima implicazione pratica riscontrata è stata l'aver coinvolto dirigenti scolastici, maestri e professori di alcune scuole primarie e secondarie limitrofe al quartiere Salinella e, tramite questo, aver potuto incontrare bambini e adolescenti. Un risultato importante che verrà implementato nel prossimo futuro grazie al progetto SalinellaPelle sarà la creazione del "Salinella Bootcamp": campo scuola di calcio con AIC (Associazione Italiana Calciatori) tenuto durante la stagione estiva nel quartiere Salinella di Taranto.

Una seconda implicazione pratica è stato aver fornito all'Ente pubblico, all'amministrazione del territorio, attraverso ANCE (Associazione Nazionale Costruttori Edili) (committente del progetto) un Report dello stato attuale del quartiere in tema di consapevolezza da parte degli abitanti rispetto al territorio ed alle sue difficoltà, lo stato delle arti, i bisogni prioritari per definire la sostenibilità di ogni progetto di rigenerazione urbana ed il grado di conoscenza del territorio, in particolare il valore dato allo sport come strumento per riqualificare e migliorare la qualità della vita del quartiere Salinella. Le risposte ottenute evidenziano il carattere "contraddittorio"del territorio.

Questa contraddizione emerge sotto diversi aspetti, in primis nell'accoglienza, che deriva dal forte senso di appartenenza al quartiere, contrapposta alla carenza di servizi e allo stato di degrado e abbandono in cui versa il quartiere Salinella e le strutture presenti in esso.

I cittadini riconoscono il valore dello sport e lo vedono come un'opportunità condivisa per migliorare il quartiere e tutta la città, proponendo interventi non solo nel quartiere Salinella, ma in tutte le zone periferiche della città elo che si trovano in condizioni simili di abbandono.

Il progetto SalinellaPelle, oltre a porre una parte degli abitanti in ascolto (e in attesa) ha portato ad avviare una serie partnership tra tutte con l'Associazione Nazionale calciatori il Comune di Taranto e Ance Taranto si realizzerà un vero campo di allenamento per $i$ bambini del quartiere dove sviluppare le tematiche evidenziate dai questionari, aggiungendo anche quella della legalità.

SalinellaPelle può evolvere e diventare un modello di partecipazione urbana attiva, una buona pratica per allenare il territorio alla rigenerazione urbana, per migliorare la qualità della vita degli abitanti del quartiere Salinella, e, per ricaduta, della città di Taranto, rendendo possibile e fattivo l'utilizzo del modello dell'ascolto attivo. Questo tipo di percorso infatti può essere utile al decisore competente per la pianificazione territoriale perché lo mette direttamente in contatto con gli abitanti, costruisce il legame, la relazione, in questo differisce da una semplice raccolta di dati, sui quali poi costruire dall'alto un piano di valorizzazione territoriale per migliorare la qualità della vita della collettività.

Originalità del lavoro. Il progetto "SalinellaPelle" è il primo lavoro di rigenerazione urbana bottom-up a Taranto e, anche, uno tra i primi progetti messi in campo per $i$ XX Giochi del Mediterraneo del 2026 che si terranno nel quartiere Salinella a Taranto. Un'occasione per "allenare" il territorio alla rigenerazione urbana ed alla cocreazione di valore, coinvolgendo gli abitanti del quartiere Salinella attraverso la partecipazione attiva, ovvero "Integrare" e "idratare" il quartiere della città di Taranto con l'apporto di azioni di valorizzazione ed iniziative di partecipazione per la progettazione e lo sviluppo dei luoghi dedicati alle attività sportive per i Giochi del Mediterraneo 2026: un percorso innovativo per avvicinarsi a eventi di grande rilievo internazionale con il coinvolgimento della popolazione. 
Parole chiave: rigenerazione urbana; co-creazione di valore; Taranto; Giochi del Mediterraneo; sport; marketing territoriale; abitanti.

\section{Bibliografia}

BALLANTYNE D., VAREY R.J., (2006), "Creating value-in-use through marketing interaction: the exchange logic of relating, communicating and knowing", SAGE Journals, September; pp. 344-346

BRUNI R., CARRUBBO L., TREGUA M. (2015), "Value co-creation in places: the role and relations between stakeholders and government. Some evidences", Poznam 3rd Place Management and Branding Conference, Jan., pp. 80-109

CARRUBBO L. (2013), La co-creazione di valore nelle destinazioni turistiche, RIREA, Jan.

FORTEZZA F. (2014), Marketing e creazione di valore per il territorio. Evidenze e spunti di riflessione del caso Ferrara, Franco Angeli, Milano.

GUMMESSON E. (2017), "From relationship marketing to total relationship marketing and beyond", Journal of Service Management, Feb., pp. 16-19

MELE C., POLESE F. (2011), "Key Dimensions of Service Systems in Value-Creating Network", in Demirkan H., Spohrer J., Krishna V. (a cura di), The Science of Service Systems, Springer, New York, pp. 37-59

NAMBISAN P., NAMBISAN S. (2013), Engaging Citizens in Co-Creation in Public Services: Lessons Learned and Best Practices, IBM Center for The Business of Government, Jan.

PRAHALAD C.K., RAMASWAMY V. (2004). "Co-creating unique value with customers", Strategy \& Leadership, Vol. 32 n. 3, pp. 4-9

RULLANI E. (2004), L'economia dell'immateriale. Produrre valore con la conoscenza, ed. Carocci, Roma.

TROISI O., CARRUBBO L., MAIONE G., TORRE C. (2016), “The More, The Merrier: Co-Working As Practical Expression Of Value Co-Creation In Sharing Economy”, RESER, 26th annual conference 2016; pp. 1130-1136

\section{Sitografia}

https://www.venetoeconomia.it/2019/06/co-creazione-valore-stakeholders/(ultima consultazione: 15/04/2020)

https://www.forumpa.it/citta-territori/creare-e-misurare-il-valore-pubblico-dei-territori/) (ultima consultazione: 15/04/2020)

http://www.simktg.it/MTF//Content/generica/NUMERO6-ValueCo-Creation_en.pdf(ultima consultazione: 15/04/2020) 



\title{
COVID-19: crisis management experiences in the private healthcare industry
}

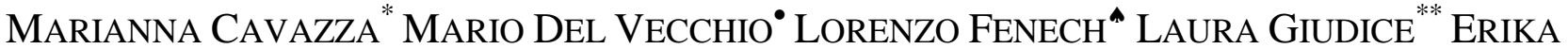 \\ MALLARINI ${ }^{*}$ LUIGI M. PRETI ${ }^{\wedge}$ "VALERIA RAPPINI"
}

\begin{abstract}
Objectives. The healthcare sector has been at the center of the Covid-19 emergency. Health systems, and hospitals especially, were the first required to respond to the virus impacts. In order to take care of patients, guarantee safety and keep running organizations health providers had to revise their organizational and managerial processes. Wards and even whole facilities were transformed into areas dedicated entirely to the care of Covid-19 affected patients. Field hospitals were put in action and personnel were transferred in the most severely hit areas; equipment, medical devices and PPE where in high demand; new ways to keep in touch with patients while respecting physical distancing norms were developed. The extraordinary nature of the events and the peculiar traits of the Sars-Cov2 virus, such has its high contagiousness, have not allowed the prompt development of a shared system's strategy; regulators and organizations, especially in the early days of the emergency, had to improvise on a day to day basis, to handle the crisis. This scenario involved all the players of the healthcare sector, which is typically the result of a combination of public and private resources, as well as private and public providers. Figure 1 provides a well-known framework representation of the Public and Private mix in healthcare systems. In Italy, quadrant number 2 (public financing and production) was under the spot-light, partly due to its relevant weight when it comes to inpatient care. More than three quarters of inpatient services are indeed provided by public hospitals. Yet, Covid-19 has had disruptive effects also on quadrant number 1 and number 3, commonly known as "private healthcare". This what we will call as the "Private Healthcare Industry" and includes a broad variety of players: providers of healthcare services, both accredited with the public health service (either for-profit or not-for-profit in nature) and non-accredited, category associations and player of private health insurance sector. For most of these players it was immediately clear that the needs and dynamics of the public system were an essential reference point: primarily, as the vast majority of demand for private services had vanished in the early days of the Covid-19 crisis due to the new restrictions; secondly, it should be noted that a generalized "retour to the public system" phenomenon has been interesting the whole sectors and is likely to remain a distinctive trait of the medium-term healthcare scenario. The Observatory on Privately financed healthcare consumption $(O C P S)^{l}$, that focuses on the study of privately financed consumption in healthcare (number 3 and number 4 quadrants), has been claiming for a long time that the healthcare sector is characterized by strong interconnections which contribute to make the health system increasingly more hybrid, if considered along the traditional public-private divide. This work therefore aims at investigating, on one side, the effects and the responses put in action by the private healthcare industry during the Covid crisis and, on the other side, what can be considered the changes expected to occur in this field in the medium term. The areas of investigation are the following: (1) the consequences of the Covid emergency in terms of management of internal operations, on relationships with the environment and on the volumes of
\end{abstract}

* Associate Professor of Practice of Government, Health and Not for Profit - SDA Bocconi School of Management - Milano - Italy e-mail: marianna.cavazza@unibocconi.it

- Affiliate Professor of Government, Health and Not for Profit - SDA Bocconi School of Management - Milano - Italy e-mail: mario.delvecchio@unibocconi.it

- Associate Professor of Practice of Government, Health and Not for Profit - SDA Bocconi School of Management - Milano - Italy e-mail: lorenzo.fenech@sdabocconi.it

** Junior Research Fellow in Government, Health and Not-for-Profit - SDA Bocconi School of Management - Milano - Italy e-mail: laura.giudice@unibocconi.it

- Associate Professor of Practice of Government, Health and Not for Profit - SDA Bocconi School of Management - Milano - Italy e-mail: erika.mallarini@sdabocconi.it

^^ Junior Research Fellow in Government, Health and Not-for-Profit - SDA Bocconi School of Management - Milano - Italy e-mail: luigi.preti@unibocconi.it

- Associate Professor of Practice of Government, Health and Not for Profit - SDA Bocconi School of Management - Milano - Italy e-mail: valeria.rappini@unibocconi.it

1 The Observatory on Privately Financed Health Consumption (OCPS) at SDA Bocconi was established in 2012 with the purpose of developing solid and systematic knowledge concerning the portion of health-related consumption that is privately financed. It is part of the network of Observatories within CERGAS, the Centre for Research on Health and Social Care Management, Bocconi University and SDA Bocconi School of Management. 
activity; (2) the introduction of new services and solutions within organizations and at the benefit of users; (3) the perceived impact of the emergency on the sector sustainability.

Fig. 1: Four quadrant of the public-private mix in financing and provision

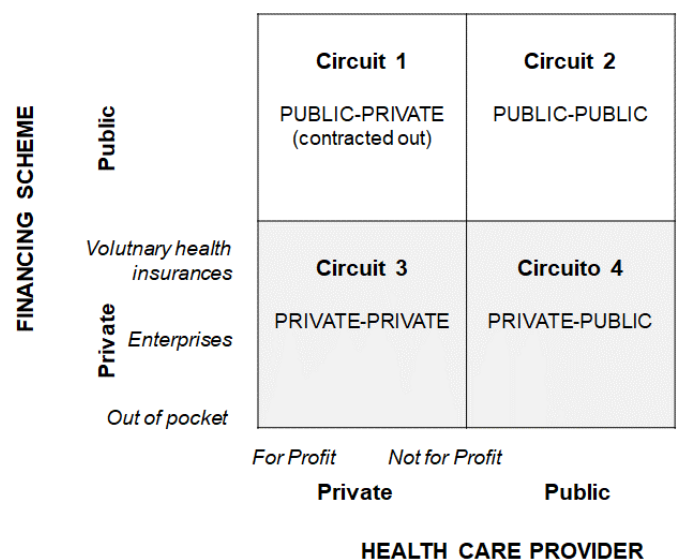

Source: OCPS (2018). Private Health Care Consumption in Italy. The sector at a glance.

Methodology. Given the extraordinary nature of the emergency we are dealing with, a research approach inspired by the Grounded Theory methodology has been privileged (Glaser e Strauss, 1999). The research team has conducted video-interviews with representatives of 22 players, members of the OCPS community (Table 1). The mentioned interviews have followed a semi-structured script which represents a fundamental tool to investigate multidimensional and complex topics. The selected sample allows to take in consideration a significant variety of points of view. Among the interviewees, some providers are active on the outpatient market only, whereas others operate also on the inpatient and LTC markets. In representation of the private health insurance sector, several kinds of third-party payers have taken part to the study, namely some health insurance companies, firms providing group policies, mutual aid societies and third-party administrators (TPAs). From a geographical stand point, 5 interviewees are active only on a local or regional scale, 2 work in multiple regional settings and 14 operate on a national scale. In total, 19 hours, 31 minutes and 58 seconds of interviews have been recorded; such output has then been processed independently by two researchers, in order to minimize the risk of a subjectively biased analysis (Bailey, 1982). On the collected recordings a Content Analysis was then performed (Weber, 1990; Amaturo, 1993; Schreier, 2013) to identify hypotheses of scenarios. During such analysis, all the information conveyed by the respondents has been processed and considered, and to such material researchers have added other considerations. For the sake of methodological rigor, the latter elements have been kept separated from what contributed by interviewees (Bourgeois III e Eisenhardt, 1988).

Tab. 1: Overview of the sample of interviewees

\begin{tabular}{|l|l|c|}
\hline Macro-area & Area & N. \\
\hline \multirow{3}{*}{ Health care providers } & Inpatient providers & 4 \\
\cline { 2 - 3 } & Outpatient providers & 3 \\
\cline { 2 - 3 } & LTC and home care providers & 3 \\
\hline \multirow{2}{*}{ Private health insurance sector } & Third-party payers & 6 \\
\cline { 2 - 3 } & Third-party administrators & 3 \\
\hline Associations & 3 \\
\hline Total & & 22 \\
\hline
\end{tabular}

Source: authors' elaboration

\section{Findings.}

The shocks provoked by the Covid-19 emergency

The factors that have played a significant role on business operations are the following:

- The virus characteristics: the virus Sars-Cov2 has immediately been recognized as highly aggressive and extremely contagious. At the time of writing a vaccine for such a virus is not yet available, and as it might not be so for a considerable amount of time (some say it will take up to two years to an effective vaccine marketed); moreover, also treatment strategies are still under test. Therefore, it is necessary to adapt and develop new organizational and logistic processes that allow to keep patients, users and workers safe, while continuing the search for the most effective treatment procedures. 
- National and regional government interventions: the Italian Government by issuing the Law Decree $n$. 14 on March 9th 2020, has allowed Regions and the autonomous provinces of Trento and Bolzano to suspend or make changes to already booked health services which are deferrable and non-urgent. Regions have therefore revised criteria and conditions allowing the provision of inpatient and outpatient services. The most conservative case is the one of Emilia Romagna that made private providers suspend all healthcare services which were deferrable and could be rescheduled. Lombardy instead has proceeded on suspending all healthcare services, both public and provided via private practice, with the exception of those considered as non-deferrable (such as oncological, dialysis, mental health services and those with priority score equal to $U$ or B). Meanwhile, the Region has excluded from such suspension measures those private providers (both accredited with the public health service and not so) who work only on the outpatient market, specialist private practices, dentist and health workers' clinics. The aim was not to limit too much the provision of services. Such room of maneuver has however remained unexploited as most private players had already worked on redefining activities that were deferrable and could be scheduled, which constituted the bulk of most private providers' activity. The insufficient production capacity exhibited by public healthcare organizations has soon lead to a request made to private providers accredited with the SSN to convert their facilities, to support the treatment of Covid-19 patients.

- $\quad$ Production capacity: the supply of physicians has been shrinking, partly because many of them have been called back into public hospitals to help, especially in the areas more severely hit by the pandemic, and partly due to contagion among medical staff. Even when staff could be supplied, an additional element of complexity was the required training to provide in short time and the scarcity of PPE necessary to allow medical staff to work safely.

- $\quad$ The demand for healthcare services: the fear of contagion spreading among the population since the early days coupled with the social distancing measures caused an explosion of bookings cancellations and no-shows, especially for outpatient procedures that tend to be perceived as more deferrable.

The mentioned institutional and market discontinuities have provoked a dramatic reduction in the sector's volumes of activity, as shown in Figure 3.

Fig. 2: Timeline of the shocks provoked by the Covid-19 outbreak on health care services provision

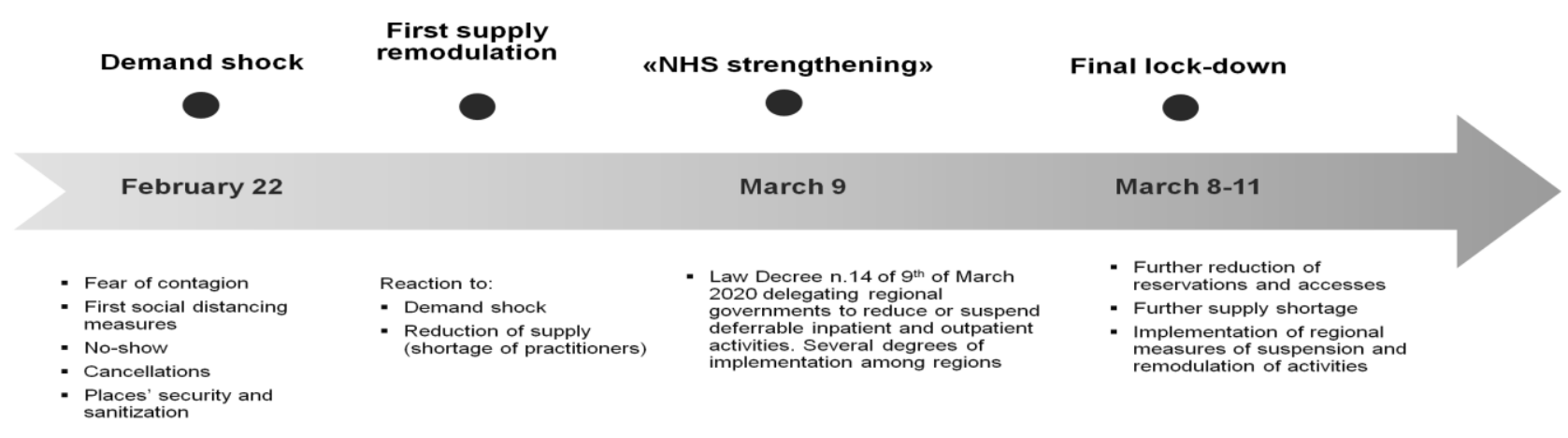

Source: authors' elaboration

Fig. 3: Overview of the impact provoked by the COVID emergency on volumes of the healthcare sectors activities, by financing modality

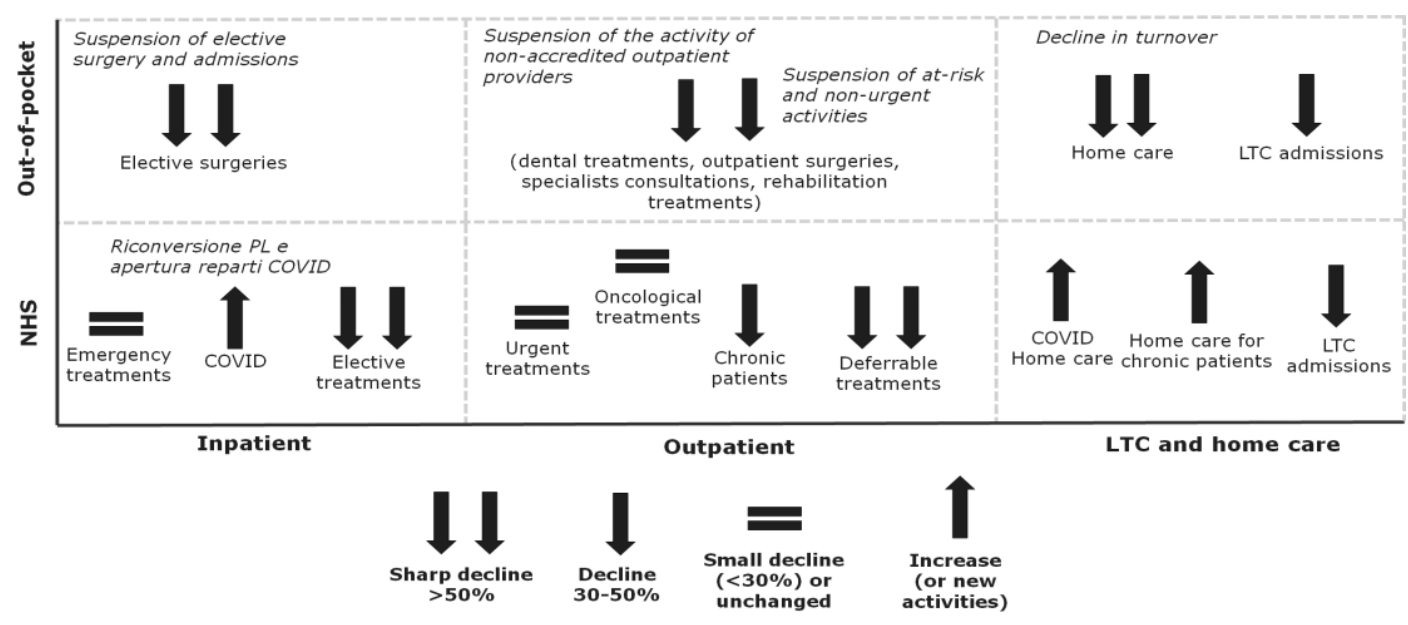

Source: authors' elaboration

The most severe impact has been registered in the outpatient care area, both on the accredited side and on the 
purely private one. That is probably due to the fact that in this area are concentrated the vast majority of procedures and services that can be rescheduled (labelled with priority scores "P" and "D") (Del Vecchio, Mallarini, e Rappini, 2015; Del Vecchio, Fenech, Preti, e Rappini, 2019). Also the volume of consultations for patients affected by chronic conditions has been decreasing even though to a lesser extent, not as a result of regulatory guidelines but mostly to avoid the exposure to the virus. Only procedures labelled as urgent (" $U$ ”), those to be delivered within 10 days ("B") or the ones linked to cancer care have not been subject to variations in volumes. Less severe has been the impact on impatient activities accredited with the public health service and considered urgent, especially those related to cancer care, chronic care and long term care assistance; instead volumes of elective inpatient procedures, both accredited with the SSN and privately purchased, have significantly reduced, to increase the availability of beds for patients affected by Covid-19. The mentioned volumes reductions are likely to materialize between $70 \%$ and $90 \%$ for what concerns outpatient care, and above 50\% when referring to inpatient care services (with a significant revenue drop experienced on the purely private market). The organizations working on LTC have experienced mixed effects deriving from the COVID-19 emergency. The complexities for discharging patients from nursing homes and the suspension of turnovers imposed by some regions clashed with the growth in the need of care due to the increased difficulties of families to rely on formal and informal caregivers. In those cases, that have been subject to a reduction in activity volumes, even though less severe with respect to the drops occurred in the inpatient and outpatient fields, the economic sustainability of the sector (requiring a $90 \%$ bed occupancy rate) is threatened. The private market of home care has remained stable, whereas volumes of accredited home care services have increase in the attempt to free beds in hospitals by assisting non-COVID 19 patients at home.

The reduction in the volumes of providers' activities has clearly impacted the market for private health insurance: all the player in this field have indeed registered a parallel decrease in the number of requests for reimbursement and of accident claims.

Products and solutions proposed by health services providers

Given the extraordinary nature characterizing the events and the generalized uncertainty feeling, the response put in action by the sector's players could not be based on a comprehensive vision, but indeed it was prompt. The primary interventions were focused on guaranteeing the most safety for both patients and staff, and on keeping the operations active. The administrative staff was mostly allowed to work from home; as far as the organizations' premises safety is concerned, the main difficulties were represented by the generalized scarcity of PPE and by the necessary procedures to handle the exemption of staff at risk of exposure to Covid-19. The requisitions of PPE at the Italian frontier, the obstacles faced by those trying to reach autonomously supplier from abroad, the uncertainty surrounding the guidelines and procedures to handle these new needs concerning HR management, the transferal of personnel from and to other organizations and specialties have really made a quick reorganization a complex task. The employers' associations have played a relevant role in the attempt to provide their associates with information, coordination efforts and support in handling PPE supply and other emergency related issues. All organizations have issued new norms on people accessing their buildings and adopted new sanitization procedures as their standard. The adopted changes required also a significant investment also in terms of staff training, carried out in context with low time availability due to higher workloads. In order to adapt to the various changes, organizational flexibility and promptness were crucial. To minimize decision-making time, the organizational processes were revised, some businesses dismantled their functional silos, introduced the so called "war rooms" and formalized daily meetings to strategically coordinate and scale up the organization's reaction capability. In response to the emergency, health services providers and the players of the health insurance sector have developed new products or enhanced and adapted existing ones, partly to attract new clients and partly to preserve the already acquired ones and increase their loyalty. Figure 4 and Figure 5 provide a representation of the various solutions, placed within a Ansoff matrix, which allows to distinguish among: (i) market penetration (preexisting products for the current customer targets), (ii) product development (new products for the current customer targets); (iii) market development (pre-existing products for new targets) and (iv) diversification (new products for new customer targets) (Ansoff, 1957). The main support to the emergency management has come by providers of inpatient health services. In some regions especially, such as Piedmont, Emilia-Romagna, Lombardy, Apulia and Sicily some private hospitals (even non accredited with the SSN) were entirely transformed into Covid-hospitals (which could be considered as a new product intended for a new patient target, in the diversification area). In most facilities, the lack of intensive care units, necessary for the treatment of complex cases (the Ministry of Health, 2019) has not prevented these organizations from providing support, either by dedicating their capacity to the treatment of non-complex Covid cases (new product for a new patient target, diversification area) or by focusing on treating non-Covid patients, who got transferred from other hospitals (pre-existing product for new patient target, product development area), in order to reduce pressure on those organizations working on the front line of the emergency. Therefore, temporary agreements were signed with public institutions, for the provision of the mentioned services. As far as diagnosis is concerned, as of today the contribution of the private healthcare sector is very limited and fragmented and has mostly dealt with the athome collection of samples to test, even though some private players did offer their production capacity to help the SSN increase the volumes of diagnostic tests (new product for a new customer target, diversification area). One of the positive sides unanimously attributed to the emergency was the catalyzing effect it has had on technological innovation, a phenomenon that has invested also some instruments already available in the healthcare domain, whose potential was usually overlooked and used to be characterized by a scarce market penetration (Keesara, Jonas e Schulman, 2020; Boscolo, Fenech, Rappini e Rotolo, 2019). Tele-medicine services such as tele-consultations (meaning episodic specialist consultations with pre-existing or new patients not necessarily receiving treatment at the organization, a 
service made available or enhanced in this period), tele-therapies (therapeutic pathways on pre-existing patients), telemonitoring (new tools to conduct regular check on pre-existing patients or new ones, suffering from COVID but not hospitalized), messaging -consultations (dedicated chat rooms to conduct real time conversation with specialists about mild health issue, a new service for pre-existing patients target) and remote counselling on $x$-rays outputs (market development). These were some of the tele-medicine services put in action by most providers in the sector. Multispecialist clinics and hospitals which had previously invested in such field were able to limit the revenue drop, by compensating part of the lost activity with higher volumes of tele-medicine services (consumed by both existing customers and new ones, who could access the services even from other geographical areas). Additionally, further demand for such services has also been coming from firms, insurance companies, health funds and service providers, now more willing to purchase packages including tele-consultations services within their coverage, to the benefit of their staff or enrollees (diversification area). In some medical fields, such as gynecology, dermatology and especially psychology, tele-consultations have proved to be great substitutes to the conventional delivery of the service, which appears promising for the future of these subsectors. To reduce the risk of contagion as much as possible, at home care services were strengthened and increased (for non-Covid patients this type of service belongs to the market penetration area, whereas for Covid-affected patients it sits into the diversification area). According to that, some providers offered their staff to support public institution working on home-care, while other ventured into home-delivery of drugs and medications (both for profit and not for profit organizations did so) and of food products to vulnerable people (mostly not for profit organizations did so). The employment of home-delivery has skyrocketed during this health crisis and it is really likely to remain very popular also in the future. To the mentioned solutions, other temporary ones put in place by the not-for-profit ecosystem to help the emergency response, should be added: to mention a few examples, field hospitals, high safety bio-containment transportation services, dedicated phone-lines to provide assistance to fragile segments of the population. The matrix shows that most of the products and services concentrate within the diversification area. Among these, it is worth distinguishing three categories: (1) temporary and emergency-related solutions, i.e. all those services intended for Covid-19 patients; (2) new products or services that integrate current business and that might be developed in the post-emergency phase such as medicines home delivery and telemedicine packages for enterprises. Only products that integrate business belong to the market development area. To the product development area belong solutions that are temporary intended for Covid patients. Finally, within the market penetration areas solutions are mainly thought to support the business financial sustainability and reduce the consequences of the economic downturn. These replace traditional services provided in the pre-Covid phase, but they are now delivered remotely such as home care, video-therapies and video-consultations. The latter straddle with the market development segment given that some business activated them ex-novo. Video-consultations belong to all the four quadrants: they can be either intended for current or new customers and either be a new services or a service already tested in the past.

Fig. 4: Products and solutions proposed by health services providers

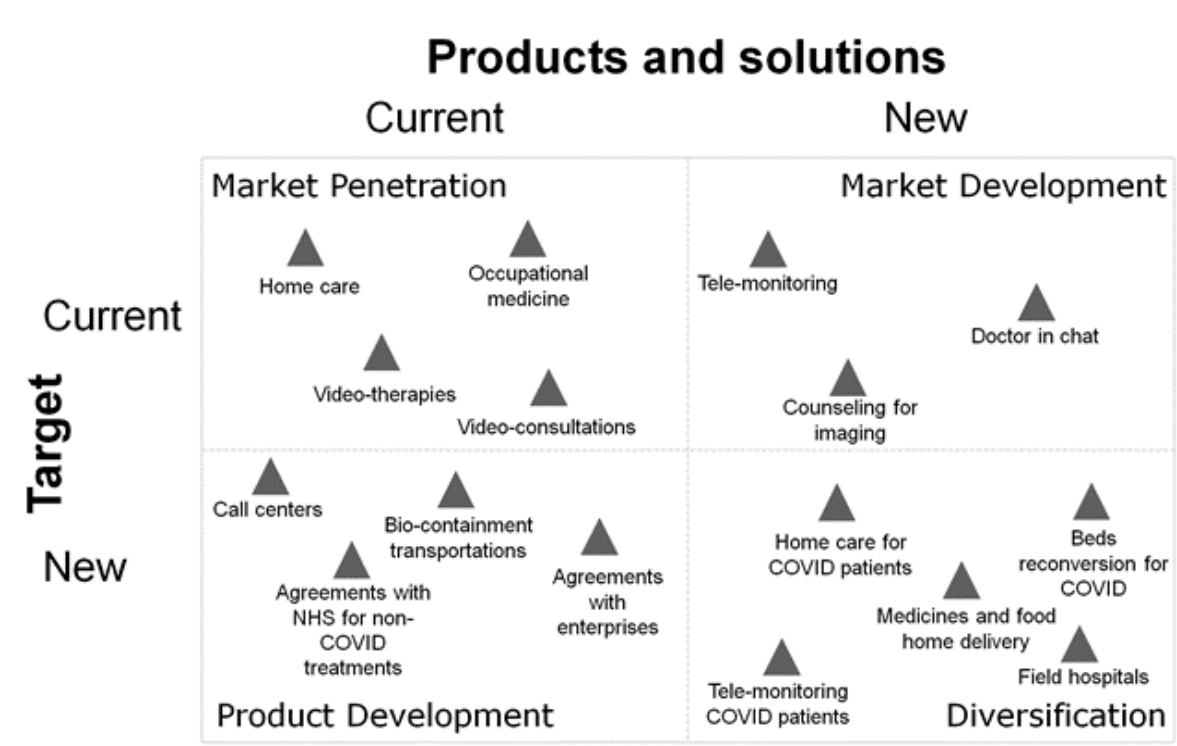

Source: authors' elaboration

Products and solutions of the players of private health insurance sector

Players of private health insurance sector adopted a proactive approach in promoting new solutions both for current customers and new targets (Figure 5). From the beginning of the outbreak, health funds and mutual aid societies have extended their current coverage to Covid expenses either without fees or with negligible additional payments. These extensions were often in contrast with statutory rules that excluded expenses due to epidemics from the coverage (market development). Some insurance companies set up new packages or insurance policies to provide 
expenses reimbursements to people affected by Covid (diversification). The target of these initiatives goes beyond traditional customers and focuses on the extraordinary demand for corporate welfare from businesses. Regardless of the purposes, all the solutions reproduce a similar design. Covid coverages are intended for infected people with a positive test and provide for a daily allowance for home quarantine and one-off compensation for hospitalizations and ICU (intensive care unit) hospitalizations. Some players extended the coverage to post-hospitalization expenses (rehabilitation). Most of the actors have enabled Covid-emergency numbers for customers as well as psychological support services and home delivery services for medicines (market development). They also introduced other peripheral services such as video-consultations, home care, and digital reservation of specialist consultations (diversification).

Fig. 5: Private health insurance sector: products and solutions

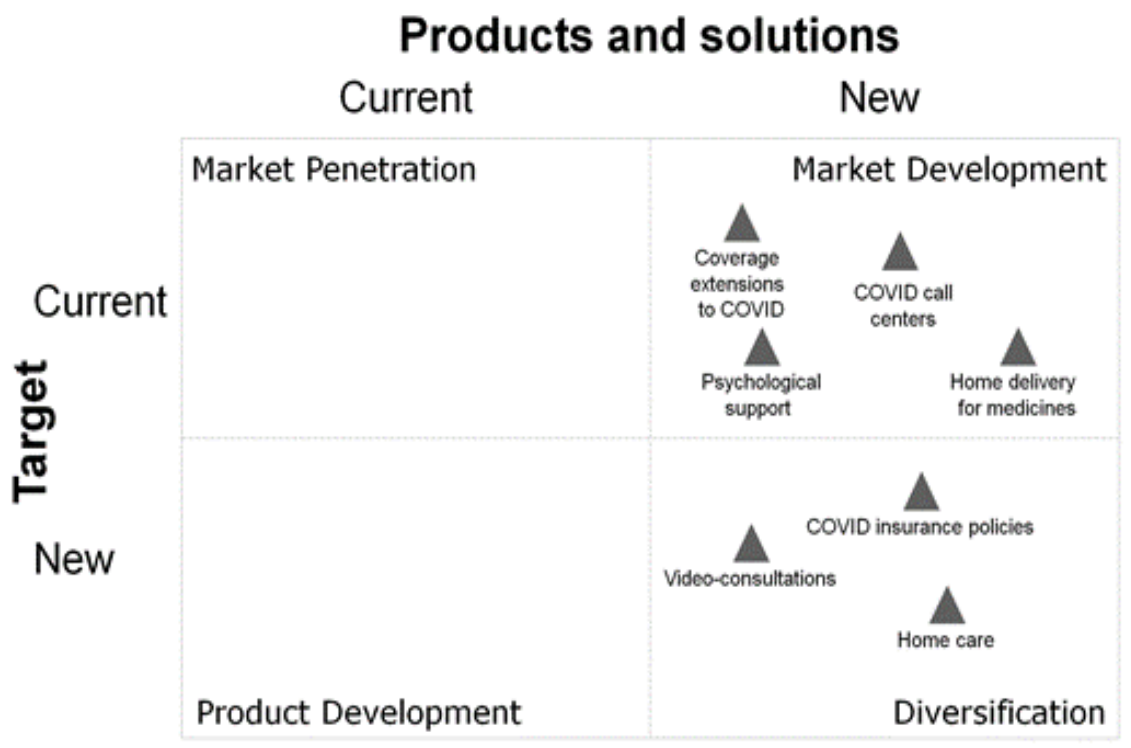

Source: authors' elaboration

The side effects of the emergency

Economic and financial sustainability are going to represent the most relevant concerns for the health care providers in the short-run. For the providers accredited with the NHS, the suspension of the deferrable institutional activities and the reconversion of ordinary hospital beds to COVID beds raise concerns about the earmarked public budget for the current year and the remuneration of COVID activities. The uncertainty on payments from local health authorities adds up the suspension of privately financed activities, which represent a significant source of income and cash for private health care providers, in particular for outpatient providers. To date, regional governments and employers' associations have signed agreements in some regions such as Campania, Emilia-Romagna, and Sicily. There is a substantial risk that the suspension of institutional (public) and privately financed activities is going to put a strain on many small-size providers and produce a more concentrated market than the current scenario. For the private health insurance players, major concerns derive from the impact that the outbreak might have on the economy as a whole, to the extent that small- and medium-sized enterprises will face financial hardship, making more difficult to pay for welfare contributions to (voluntary) health insurances and funds for their employees. Another relevant criticality is the limited supply capacity for the resumption of outpatient care activities, which are highly supply-driven. Supply capacity will also depend on the actions taken by public health care providers to reabsorb the postponed activities and by their approach toward the private practice of their own medical employees.

Research limits. A significant part of the research has been conducted during the most severe phase of the Covid19 emergency. The exceptionality of the event along with the short time passed between the beginning of the outbreak and the interviews might have influenced the considerations of interviewees and made it very difficult to speculate about the medium- and long-term consequences. Moreover, even though the interviewees provide a good representation of the private healthcare industry, they are not completely representative of the entire private healthcare sector in terms of health care segments and geographical locations.

\section{Practical implications.}

Providers: towards new positioning

Even assuming a massive public intervention for economic recovery will take place, we are going to face a long period of economic downturn that is going to affect households' capacity and willingness to pay (IMF, 2020) and to make more uncertain earmarked budgets for accredited activities. It is straightforward that household income is among the main determinants of the demand for private health services (Del Vecchio, et al., 2019). As a consequence, we expect a high number of providers to adopt a low-price positioning to better meet household demand and the increased 
barriers to access public health care services (e.g. longer waiting lists). Further, we expect technological positioning to be crucial in the next future. The emergency opened new scenarios for digital development in health care and accelerated some processes that were spreading very slowly. Technological positioning will be decisive during the transition phase, especially in response to level of social distancing that is going to be maintained in national and local governments measures. A technological posture will be even more crucial in the post-emergency period if the outbreak will have succeeded in changing the behaviors and attitudes of users also in health-related activities.

The industry structure

Players operating in privately financed healthcare are very heterogeneous in terms of positioning in the supply chain (from third-party payers to health care providers), level of specialization, and dimension. When considering health care providers, which mainly work in both publicly and privately financed healthcare, the industry is highly fragmented. Recent estimates (OCPS, 2020) report more than 22,000 providers operating in the market. An expected and dramatic fall in household income, and then in privately financed health consumption, might lead to an acceleration of such a concentration. Indeed, during the last years, the industry was subject to attention from international investors foreseeing the opportunity to invest abundant liquidity in companies characterized by a limited dimension and operational efficiency. The emergent scenario could introduce new incentives for development through business models marked by operational efficiency and a larger dimension. Moreover, a higher degree of dependency from public budgets is likely to be observed in the future, generating uncertainty on the sector's overarching dynamics.

The renewed need for health protection

The emergency has placed health protection at the center of the public and private debate. Therefore, an increased demand for corporate welfare to promote and protect the health status of employees arose in those small-, medium-sized, and large enterprises that activated or extended additional coverage for COVID expenses, in particular for those which were not subject to business suspension because of their relevance in the supply chain.

Public-private co-operation

During the emergency, some problems emerged in the capacity of regional health services to steer the healthcare industry among all its quadrant (Del Vecchio, 2013). Some regional systems have frequently proven to be weak in using the production capacity and the potential that private health care providers, either singularly or collectively, could offer. The case of diagnostic test is emblematic: a full and timely involvement of private authorized and accredited laboratories would have allowed many regions to significantly increase their testing capacity and to comply with national and international guidelines to effectively address the epidemics. Beyond the considerations about the structure of regional health services (mix of public and private provision) and the mechanisms regulating the interaction between public actors and private providers (the financing mix), the themes of trust and habits in relationships among public and private players remain, in particular during an emergency. A system's integration and capacity to co-ordinate the responses depend also on informal relationships that cannot afford to wait longer times of rational analysis and formal decisions. It is more a matter of social capital that has its spillovers on the healthcare sector as a whole.

Originality of the study. Given the exceptionality of the event, this study provides an interesting overview of how private healthcare players have been responding to the most severe global health crisis of the last century, in a more comprehensive attempt to understand the sector's emerging strategy when it comes to crisis management and its likely future prospects.

Key words: crisis management, private healthcare, Covid-19

\section{References}

AMATURO E. (1993), Messaggio simbolo comunicazione. Introduzione all'analisi del contenuto, La Nuova Italia Scientifica, Roma.

ANSOFF H.I. (1957), “Strategies for diversification”, Harvard business review, vol. 35, n. 5, pp. 113-124.

BAILEY K. (1982), Methods of social research, The Free Press, New York.

BOSCOLO P.R., FENECH L., RAPPINI V., ROTOLO A. (2019), "Tecnologia e innovazione nei modelli di servizio in sanità", in Cergas-SDA Bocconi, Rapporto OASI 2019, pp. 529-575, Egea, Milano.

BOURGEOIS III L.J., EISENHARDT K.M. (1988), "Strategic decision processes in high velocity environments: Four cases in the microcomputer industry", Management science, vol. 34, n. (7), pp. 816-835.

DEL VECCHIO M. (2013), Settore, sistema, azienda: logiche di governance in sanità, Egea, Milano.

DEL VECCHIO M., FENECH L., PRETI L., RAPPINI V. (2019), "I consumi privati in sanità", in Cergas-SDA Bocconi, Rapporto OASI 2019, pp. 221-274, Egea, Milano.

DEL VECCHIO M., MALLARINI E., RAPPINI V. (2015), Rapporto OCPS 2015: Osservatorio sui consumi privati in sanità, Egea, Milano.

GLASER B.G., STRAUSS A.L. (1999), Discovery of grounded theory: Strategies for qualitative research, Routledge, New York.

IMF (2020), World Economic Outlook, April 2020: Chapter 1, International Monetary Fund, Whashington D.C..

KEESARA S., JONAS A., SCHULMAN K. (2020), “Covid-19 and health care's digital revolution”, New England 
Journal of Medicine.

MINISTERO DELLA SALUTE (2019), Posti letto per stabilimento ospedaliero e disciplina, tratto da www.dati.salute.gov.it: http://www.dati.salute.gov.it/dati/dettaglioDataset.jsp?menu=dati\&idPag=96.

OCPS (2018), Private Health Consumption in Italy. The sector at a glance, Egea, Milano.

OCPS (2020), Materiali di lavoro del Workshop OCPS del 10 febbraio 2020, SDA Bocconi, Milano.

SCHREIER M. (2013), "Qualitative content analysis", in U. Flick, The SAGE handbook of qualitative data analysis, pp. 170-183, Sage.

WEBER R.P. (1990), Basic Content Analysis, Sage, Newbury Park.

YIN R.K. (2015), Qualitative research from start to finish, The Guildford Press, New York. 


\title{
Reconcilable differences? On the relation between social and economic goals and the importance of process goals
}

\author{
VALERIA CAVOTTA* ELISA VILlANI JOHANNA MAIR ${ }^{\star}$
}

\begin{abstract}
Objectives. Organizational goals can be defined as aspirations, desired organizational outcomes distinct from measurable targets (Kotlar et al., 2018), and the realized outcome along some measurable indicators is called performance (Greve, 2008). Organizational goals are important in organizations as they can be used to guide action, set employee motivations and assess organizational performance (Ethiraj and Levinthal, 2009; Kotlar et al., 2018). In general, organizations pursue a variety of goals, such as improving productivity, reducing costs, as well as social or family goals (Bateman et al., 2002; Gaba and Greve, 2019; Hirschi et al., 2019; Kotlar and De Massis, 2013; Mazzelli et al., 2018). An important question stemming from goal multiplicity is the relation between them. Although goals can be independent, competing or reinforcing, the small extant literature on goal multiplicity has focused on goal conflict (Hirschi et al., 2019). Goals are understood to be in conflict when the pursuit of one jeopardizes the pursuit of another at any given point of time. As such, literature has investigated how organizations can mitigate goals conflicts, for instance through goals prioritization and sequential attention allocation (Ethiraj and Levinthal, 2009; Gaba and Greve, 2019; Greve, 2008). However, multiple goals can not only be in conflict but might also be interdependent or even in synergy. These latter types of relationship in performance goals have been much less investigated. Moreover, extant literature on goal multiplicity has focused on outcome goals such as profitability, rather than more ongoing process goals such as learning from experience, which might play an essential role in the achievement of multiple outcome goals. Process goals and the relation between them and outcome goals has in fact received scant attention. Process goals such as "listening to costumers", "learning from experience", or "communicating with employees" are continuous, ongoing, and tactical ways of operating and doing business (Bateman et al., 2002: 1138). As such, process goals are not only essential to the achievement of outcome goals but, not differently from outcome goals, they can also take large material and attentional resources.

This study aims to fill this gap by investigating the following question: what is the role of process goals to achieve outcome goals and ultimately performance? In asking this question, we set our investigation in the context of social entrepreneurship whereby organizations pursue a variety of economic and social goals that are typically thought of as highly competing (Battilana, 2018).
\end{abstract}

Methodology. The WISE (working integration social enterprise) Giotto was funded in 1986 in Padua (Italy) by a group of fresh graduates who wanted to start an entrepreneurial venture after the happy years spent together at university. They created a cooperative that offered services for the cleaning and maintenance of public parks. In the beginning, the cooperative did not have a social vocation. It started endorsing a social vocation in 1991 when the cooperative won a public tender for the maintenance of the park in the jail of Padua and got in touch with the disadvantaged segment of prisoners.

Over the years, the WISE expanded its services encompassing, among the others, digital services, a call center, a bakery, garbage collection, and the maintenance of green spaces. Most of the job opportunities provided to its beneficiaries came from public tenders (85\%). For this reason, the WISE has recently set an ad hoc office to scan and evaluate available job opportunities in the market.

Over the last four years, commissions largely stopped getting renewed automatically (even in case of good performance). Thus, the WISE must constantly look for new opportunities in the market and work hard to win the bid. All in all, the WISE works to provide its beneficiaries with job that give dignity and places great emphasis on the importance to offer its clients high-quality services. This orientation to the quality got strengthened upon acquiring several ISO certifications.

So far, we conducted eight interviews with six people working for Giotto: the President, the Vice-President, the Director, the manager in charge of supervising the work in jail, and two psychologists working for the Social Office.

\footnotetext{
Assistant Professor of Strategy and Entrepreneurship - Free University of Bozen-Bolzano - Italy

e-mail: valeria.cavotta@unibz.it

- Senior Assistant Professor of Entrepreneurship and Innovation - University of Bologna - Italy e-mail: e.villani@unibo.it

- Full Professor of Organization, Strategy and Leadership at the Hertie School - Berlin - Germany e-mail: Mair@hertie-school.org
} 
They were identified as key actors in this first stage of the study to whom we have generically asked about the WISE'S goals in order to identify which were the most important goals pursued. Interviews to them lasted from forty-five minutes to more than two hours and were recorded and transcribed. We are soon going to interview other key actors, such as the team leaders who supervise the work of the inmates daily. We also interviewed five inmates. Interviews to them could not be recorded due to ordinary restrictions in jail where researchers can only bring paper and pencil within the jail, but we took copious notes.

Finally, we have started collecting archival data, such as brochures, media representations of the WISE, and samples of the Social Diary which is a tool the psychologists use to keep track of inmates' improvements in an important outcome goal: the autonomy in the professional, the relational and the personal sphere.

Data were analyzed following an inductive method aimed at theory building (Glaser and Strauss, 1967). We first engaged in a first-order analysis (Van Maaner, 1979) through open coding of the interviews by retaining informants' words. Initial codes amounted to more than 160 codes. Next, we reduced this number by nesting similar codes and proceeded to derive themes through axial-coding (Locke, 2001). At this stage we elicited 10 goals pursued by the WISE. Being cognizant of different types of goals as per the literature on organizational goals, we then distinguished outcome from process goals and started noticing the relations among them, and the major role taken by the process goal "monitoring" in the pursuit of important outcome goals.

Findings. The performances of social ventures are typically two, a social and an economic mission. The former is the raison d'être of the organization, while the latter is a means to an end that allows the social venture to be sustainable over time (Battilana and Lee, 2014).

Giotto' social performance entails the accomplishment of three outcome goals: a stable provision of job opportunities for its beneficiaries, improvement of beneficiary autonomies in the personal, relational and professional sphere (from now on, the 3As), and an appreciation of the intrinsic value of work. In pursuing social performance, the WISE follows a satisficing criterion:

"we learned to accept the partiality of the results. We do not have to set the goal that all the paths initiated with each person go well at $100 \%$. Some of the path will be longer, other shorter, some with some results other with other results" (\#VP2 interview)

The satisfying criterion is due to the nature of social problems that typically require a long-time horizon, and to the fact that social problems are typically affected or exacerbated by a host factors outside the control of the WISE, such as the finite duration of public commissions on which the job is based, and the difficult context of a totalitarian regime such as that of the jail, that can severely affect the work carried by the WISE with the beneficiaries. For instance, inmates return to cells after the working time, where a completely different worldview exists where animosity and sometimes violence occur. These negative experiences affect inmates badly and come in the way with the work carried by the social enterprise.

We found that the three outcome goals relevant for achieving social performance - stable provision of job opportunities, improvement of beneficiary autonomies in the $3 \mathrm{As}$, and forging an appreciation of the intrinsic value of work - are mutually reinforcing. As anticipated earlier regarding the need to accept the partiality of results, a stable provision of job opportunities impacts the 3As goal not only because job is the means through which the WISE can work on the 3As but also because the interruption or the end of a job opportunity tend to have negative effects on the person. In turn, improvements in the 3As positively affect the stability of job provision via the achievement of highquality service to the client.

As far as the process goals sustaining the outcome goals in the social sphere, we found two major ones: monitoring and reporting. Monitoring occurs on a daily basis and allows for reporting over three moments: monthly upon the consignment of the pay slip when the team leader discusses the performance of the beneficiary in light of the objectives set, every six months, and over extraordinary circumstances when the daily monitoring of the team leader signals urgent issues that need discussion within the WISE and a call for action. Reporting occurs between the team leader and the beneficiary at the presence of a psychologist who intervenes in case of difficult conversations and takes stock of further needed interventions.

The two process goals of monitoring and reporting play an essential role in the achievement of the outcome goals in the social sphere. On the one hand, monitoring allows to control the performance of the beneficiary, which triggers attention on current performance gaps relevant to fulfill the economic mission. On the other hand, reporting allows for space and time of confrontation between WISE's members and the beneficiaries, which impacts the 3As, and thus a goal relevant to achieve social performance.

Regarding economic performance, Giotto's economic performance entails the accomplishment of two independent goals: one outcome goal - providing high quality service to the client - and one process goal - scanning and applying only to commissions that do not imply losses for the WISE. The economic performance follows an optimizer criterion to the aspirations level:

"To us the minimum goal is to take a new job that is financially self-sustaining, meaning that the WISE does not incur in losses. So, our profit is one euro plus a new job. This way we have already achieved two important performance factors. We aim for both to always be there." (\#GD interview)

While the aspiration level of the "high quality to the client" goal is set by the client, which specifies, for instance, the number of calls and the number of positive feedback sought in the call center service, the achievement of this goal is more controllable by the WISE than it is the achievements of the social goals. Here again, we found that the two 
economic goals are sustained by several process goals. For instance, it is essential to seek and evaluate only financially sustainable jobs that do not imply losses for the WISE. It is worth noting the emphasis placed by the WISE on the willingness to be in control of any operation. Losses are not to be avoided at any cost but must be incurred on purpose:

"It is precisely the approach of a careful and serious evaluation of any job opportunity... [...]. The important thing is to never make losses without knowing it, because it means that you have lost control ... Instead, you can decide to incur in losses stemming from the original mission and say: "this year I consciously decide, in this sector, to bear a loss because this allows me to give stability to the activity and to the people who are inside that activity". (\#PW interview)

The goal of providing high-quality service to the client is sustained by one outcome goal - fit between job and beneficiary's ability and several process goals that stem from monitoring.

"Given the objective limits of our beneficiaries, the first balance is made through the correct placement of the correct person. You can't keep correcting a person at work, you have to find the right person for that job. The second force is then in the happening of the job, the monitoring, that tells us whether the choice made is adequate or not, that allows to provide help, correction, until to the allocation of the person to another job. But the strength is this continuous monitoring” (\#GD interview).

Research limits. At the current stage of paper development, the limitations stem from the fact that the data collection has just started. A significant higher number of interviews shall be collected to get a more comprehensive understanding of the processes under investigation and to reach data saturation so that no additional information is found.

Practical implications. In addition to a theoretical contribution to the literatures on goal multiplicity and social entrepreneurship, this study has practical implications for practitioners too. As stated at the beginning, goals are the means through which performance is evaluated. In social entrepreneurship, the evaluation of social performance is not devoid of controversies. Objective metrics capturing the whole value created by social enterprises do not exist. Moreover, a long time-horizon might be needed before the value created can be assessed. These difficulties, among others, are problematic for social entrepreneurs themselves but also for funders who have to decide how to best allocate their resources. A focus on process goals and on their performance, instead, can be more objectively evaluated. This focus can serve as the basis for evaluating social performance more systematically and less controversially.

Originality of the study. With this study we envision to contribute to the literature on goal multiplicity in general and on goal multiplicity in social entrepreneurship.

First, the small extant literature on goal multiplicity has so far focused on conflictual relationships between outcome goals (Gaba and Greve, 2019). The findings of this study portray relationships between goals as riddled with loops and less conflictual. The three outcome goals of high-quality to client, stable job provision and autonomy in the three spheres reinforce one another. A person's improvement in the three autonomies influences positively the quality of the service given to the client, which in turn affects the possibility to provide a stable employment to the beneficiaries who will experience a decline in their autonomy in case of a job interruption.

Moreover, in the presence of multiple goals, extant literature has found and theorized mostly on two strategies: prioritization and sequential attention allocation between goals that differ on levels of priority (Gaba and Greve, 2019; Stevens et al., 2015). Changes in how organizations attend to goals usually occur in the presence of goals-performance discrepancies (Labianca et al., 2009). That is, when performance falls below aspirations, organizations respond through actions that can support the achievement of the aspiration (Kotlar et al., 2014). In attending to the role of process goals, this study makes an important contribution to the literature on goal multiplicity. In particular, the process goal monitoring is crucial for achieving both the economic and the social performance. The aspiration to have everything under control through monitoring, is almost an end in itself for the WISE in this study. Setting a monitoring goal allows to direct attention to performance discrepancies in real-time, thus increasing chances to notice and timely act upon discrepancies via the process goal adjusting. Adjusting is relevant for accomplishing the economic performance, for instance by reallocating the person to another task or by shifting her time work.

Given the limited attention to process goals, we argue that this preliminary study advances our limited understanding on the role of process goals in achieving performance and solicit more research on this topic.

Second, we contribute to the literature on goal multiplicity in social entrepreneurship. Social enterprises are interesting sites where to study goals multiplicity, not because they pursuit multiple goals as this is a feature of any organizations but because social and economic goals are perceived to be highly different (Battilana, 2018). Studies labelling social enterprises as hybrid organizations have treated them mainly as site to understand how this multiplicity affects their ability to deal with external demands (Pache and Santos, 2013), governance (Smith and Besharov, 2019; Mair et al., 2015) or recruitment strategies (Battilana and Dorado, 2010). Fewer have also addressed dual goals and performance and discussed the importance of having differentiated structures for the pursuit of economic and social performance along spaces of negotiation to discuss on needed trade-offs (Battilana et al., 2015).

This preliminary study on goal multiplicity, using social entrepreneurship as a context, suggests that social and economic goals are different but not so irreconcilable, and that the pursuit of the economic and the social performance in the WISE might follow different criteria: satisfying for the social performance and optimizer for the economic 
performance. Highly relevant for achieving both performances is the process goal monitoring. This is in line with the shift Ebrahim and Rangan (2014) have been observing: social enterprises are "shifting from a focus on evaluating impact after implementing their interventions, to also using measurement during program design and implementation in order to get real-time feedback for improving their work" such as "monitoring and learning systems that can better enable mid-course correction" (2014: 135).

As such, setting high the monitoring goal allows the organization to undertake mid-course corrections which are essential for achieving both social and economic performance. In so doing, the process goal monitoring could constitute one of the performance indicators that help impact investors, preoccupied with the organization's ability to achieve the two performances, to better allocate their resources. Moreover, setting high the process goal monitoring might help prevent mission drift, as also recently pointed out by Smith and Besharov (2019).

All in all, in this preliminary study, we argue that it is timing for organizational scholars to investigate more and in depth the role of process goals in the achievement of economic and social performance.

Key words: social enterprises; organizational goals; outcome goals, process goals.

\section{References}

BATEMAN T.S., O'NEILL H., KENWORTHY-U'REN A. (2002), “A hierarchical taxonomy of top managers' goals”, Journal of Applied Psychology, vol. 6, n. 87, pp. 1134-1148

BATTILANA J. (2018), "Cracking the Organizational Challenge of Pursuing Joint Social and Financial Goals: Social Enterprise as a Laboratory to Understand Hybrid Organizing”, M@n@gement, vol. 21, n. 4, pp. 1278-1305.

BATTILANA J., LEE M. (2014), Advancing Research on Hybrid Organizing-Insights from the Study of Social Enterprises. Academy of Management Annals, vol. 8, n. 1, pp. 397-441.

BATTILANA J., SENGUL M., PACHE A.C., MODEL J. (2015), "Harnessing Productive Tensions in Hybrid Organizations: The Case of Work Integration Social Enterprises”, Academy of Management Journal, vol. 58, n. 6, pp. 1658-1685

CYERT R.M., MARCH J.G. (1963), A behavioral theory of the firm, Englewood Cliffs, NJ: PrenticeHall.

EBRAHIM A. RANGAN V. (2014), "What Impact? A Framework for Measuring the Scale and Scope of Social Performance", California Management Review, vol. 56, n. 3, pp. 118-141.

ETHIRAJ S.K., LEVINTHAL D. (2009), "Hoping for A to Z while rewarding only A: Complex organizations and multiple goals", Organization Science, vol. 20, n. 1, pp. 4-21.

GABA V. GREVE H.R. (2019), "Safe or Profitable? The Pursuit of Conflicting Goals", Organization Science, vol. 30, n.4, pp. 647-687.

GREVE H.R. (2008), "A behavioral theory of firm growth: Sequential attention to size and performance goals", Academy of Management Journal, vol. 51, n. 3, pp. 476-94.

GREVE H.R., TEH D. (2018), "Goal selection internally and externally: A behavioral theory of institutionalization”, International Journal of Management Reviews, vol. 20, n. 1, pp. 19-38.

HIRSCHI A., SHOCKLEY K.M., ZACHER H. (2019), “Achieving work-family balance: An action regulation model”, Academy of Management Review, vol. 44, n.1, pp. 150-171.

KOTLAR J., DE MASSIS A. (2013), "Goal setting in family firms: Goal diversity, social interactions, and collective commitment to family-centered goals", Entrepreneurship Theory and Practice, vol. 37, n. 6, pp. 1263-88.

KOTLAR J., DE MASSIS A., WRIGHT M., FRATTINI F. (2018), "Organizational goals: Antecedents, formation processes, and implications for firm behavior and performance", International Journal of Management Reviews, vol. 20 n. 1, pp. S3-S18.

LABIANCA G., FAIRBANK J.F., ANDREVSKI G., PARZEN M. (2009), "Striving toward the future: Aspirationperformance discrepancies and planned organizational change”, Strategic Organization, vol. 7, n. 4, pp. 433-466.

MAIR J., MAYER J., LUTZ E. (2015), "Navigating Institutional Plurality: Organizational Governance in Hybrid Organizations", Organization Studies, vol. 36, n. 6, pp. 713-739.

MAZZELLI A., NASON R.S., DE MASSIS A., KOTLAR J. (2018), "Causality rules: Performance feedback on hierarchically related goals and capital investment variability”, Journal of Management Studies, vol. 56, n. 8, pp. 1630-1654.

PACHE A.C., SANTOS F. (2013), "Inside the Hybrid Organization: Selective Coupling as a Response to Competing Institutional Logics", Academy of Management Journal, vol. 56, n. 4, pp. 972-1001.

SMITH W.S., BESHAROV M. (2019), "Bowing before dual gods: How structured flexibility sustains organizational hybridity", Administrative Science Quarterly, vol. 64, n. 1, pp. 1-44.

VAN MAANEN J. (1979), "Reclaiming qualitative methods for organizational research: A preface", Administrative Science Quarterly, vol. 24, n. 4, pp. 520-527. 


\title{
Supply chains network during a global crisis: Covid-19 emerging challenges
}

\author{
ALESSANDRO CinTI ${ }^{*}$ ANDREA SABATINI ${ }^{*}$ GIAN LUCA GREGORI ${ }^{\star}$
}

Objectives. The COVID-19 outbreak emerged in China in November 2019 and spread rapidly to almost all over the globe. It presents several emerging challenges for the global economy. It is not the first time that a pandemic has been tackled, however, it is the first time that policymakers take impactful restrictive measures on the firms following a pandemic. The study posits that the supply chains are particularly exposed to the emerging challenges from restrictive measures and day-by-day changing laws in order to fight the spread of the virus.

Currently, it is almost impossible to outline an accurate picture of the overall situation, not even through analyzing real-time data, integrated with the most important researches on the supply chain and crisis management. Even the whole scientific community is still in turmoil on these issues, trying to produce answers and hypotheses in order to support the entire population to find a potential exit - or coexistence - strategy with the outbreak.

Of course, the COVID-19 pandemic is negatively impacting the entire world economic system; it has a particular multifaceted effect on the majority part of supply chains. Since 2012, the World Economic Forum (2012), had identified a list of possible causes that would have could carried out significant changes on the Supply Chains. Among the possible causes they cited a pandemic, however it was unlikely to foresee a scenario such as todays.

So far, it is known that COVID-19 rapidly exceeded the economic effects of previous post-war scenarios and pandemics. Actually, most of the first forecasts provided by the experts showed that this pandemic is characterized by unexpected features, large incidence of unpredictable and uncontrollable elements (McKibbin and Roshen, 2020). While analyzing the typologies of crises, Baubion-OECD (2013) has pointed out that a pandemic would have the worst impact on the economy because:

- $\quad$ it affects the entire globe without differences;

- it is temporally indefinite;

- $\quad$ the economic shock is undetermined in duration and intensity:

- $\quad$ it is an event that never occurred during the "modern history", from the post-war onwards.

Thus, the pandemic represents a major challenge for both policymakers and businesses. Within supply chains, the most critical effects will potentially occur on SMEs, embedded in that supply chain affected by the current crisis. Actually, these are often the most vulnerable actor of the business landscape. These actors have low power to affect the policymaker choices and an endemic struggle with the liquidity management in the short term.

The high impact on global economic is due to the fact that the most affected countries by COVID-19 coincide with the most industrialized in the world (Baldwin and Di Mauro, 2020a). These are US, China, Japan, Germany, Britain, France, and Italy, among the first countries in the Johns Hopkins COVID-19 ranking (2020).

Indeed, to describe the ongoing scenario a useful metaphor from car competitions as to the entry of the "safety car". At that moment all the positions are "frozen", but the firms more ready and focused on the restart can take advantage by transforming a potential threat into an opportunity. In fact, every crisis should represent also the moment to seize new opportunities and work to configure new business models.

If during "peace time" the approach is focused towards management of "business as usual" issues, in times of extreme uncertainty it might be mandatory to adopt a new approach to decisions and management, therefore all the organizations shall be ready for a "real time" management (McKinsey, 2020a).

Drawing on Supply Chain Network theories (SCN), (Harland 1999, Huemer, 2002, Gadde et al., 2002), in order to describe how firms and supply chains reacted to the pandemic, the study adopts versatility, adaptability and flexibility concepts to describe firms ability to handle unexpected events (Huemer, 2006, Adekola and Clelland, 2020, McKinsey, 2020a). Hence, the article aims to shed light on how the Supply Chain Network approach supports or constrains firms during major crisis:

Ph.D. Candidate of Business Management - Università Politecnica delle Marche - Ancona -Italy e-mail: a.cinti@pm.univpm.it

- Post-Doctoral Researcher of Business Management - Università Politecnica delle Marche - Ancona - Italy e-mail: a.sabatini@staff.univpm.it

A Full Professor of Business Management - Università Politecnica delle Marche - Ancona - Italy e-mail: g.gregori@staff.univpm.it 
RQ: How SCN approach might support firms to react to the emerging challenges brought after COVID-19 outbreak?

The study is focused on the effects on the global supply chains because their modern network configurations made those exposed to potential risks of disruptions. A globalized supply chain is more vulnerable to disruptions because of the ripple effect (also known as risk propagation) - the phenomenon that a sudden disruption at a few nodes in a SCN can spread to neighboring nodes, and eventually adversely impact other firms ((Dolgui et al., 2018; Scheibe and Blackhurst, 2017; Li et al., 2020), and consequentially on the broader social structure. In fact, it should be remembered that, according to the Confindustria Study Center (2020), more than a third of all employees in the country depend on manufacturing industries.

Methodology. Since we are conducting this ongoing research, the phenomenon is still ongoing, the suitable method is qualitative research, through "multiple case studies" (Yin, 2014). In the past, qualitative research has been proven particularly useful in explore complex research contexts (Finlay et al., 2013). Moreover, qualitative research seems to be the most utilized on crisis research (e.g. Buchanan and Denyer, 2013; Linnenluecke, 2017) as case studies have been successfully applied to investigate several crises as well as the emergence of issues following a crisis (Williams and Shepherd, 2016).

Even though the possibility to rely on-field research has been precluded because of the lockdown, interviews are planned in order to collect primary data by inviting 20 key actors operating in B2B context, involved in international supply networks.

Moreover, because of the sudden changes of business landscape, it was decided to analyze not only primary data but also secondary sources, such as managerial studies and reports, which allowed the researchers to make use of updated and available field-evidences.

The research provided also a review on the background literature (Huff, 2008, Cronin et al., 2008), which allowed us to identify and develop the theoretical framework (Coughlan et al., 2007) of network supply chain and risk. The literature was gathered through snowball sampling, then categorized and analyzed. This type of review is useful to summarize a huge volume of information on a specific field and to provide results in a clear and explicit way (Davoudi at al. 2016). The comparison of the results of the review with primary data and secondary sources has finally allowed us to formulate new constructs and interesting theoretical contribution to underpin emerging managerial suggestions.

Hence, the study aims to provide support to firms by suggesting new perspectives for managing supply chain emerging issues and future opportunities.

Findings. Supply Chain Management (SCM) is defined as the integrated management of information and resources flows that range from the supply of raw materials to the delivery of finished product to the customers (Marcone, 2019).

In order to manage supply chain, the original focus of Porter's Value Chain refers to the organizational process of the company in transforming raw materials or semi-finished products into products. Drawing on the Porter's model, production processes optimization and in-bound and out-bound logistics are key resources for value creation (Huemer, 2006).

Harland (1999) suggests integrating the SCM theory with the Supply Network, considering the firm as a link with a network of partners - upstream and downstream - of the supply chain. Here, the inter-organizational relationships between the actors, upstream and downstream of the firm's supply chain, generate dyadic interactions (Omta et al., 2001).

An important contribution to the Supply Network was developed from the IMP group's Industrial Network Approach (Industrial Marketing and Purchasing), which claims that SCM's perspective contributes substantially to understanding the efficiency of material flows, but does not consider that relationships are not independent and isolate, but embedded and intertwined (Gadde et al 2002). The concept of Supply Network clarifies how to develop business relationships with suppliers and combine these relationships in efficient supply chains (Huemer, 2002). From the Industrial Network approach, the SC is seen as an interconnected network of activities, resources and actors. The development and management of these relationships are a "complicated exercise" for all firms, regardless of their size or the industrial sectors in which they operate (Gregori et al., 2017; Håkansson and Ford, 2002; Gadde et al., 2012; La Rocca et al., 2013). Furthermore, the heterogeneity of the actors involved within the supply network means that they can perceive the network, its boundaries and the nature of the relationships in different ways. The indeterminate nature of networks is one of the intrinsic characteristics: the network and the relationships within the actors are developed towards heterogeneous goals. Therefore, no firm can be identified as the focal firm of the structure. The dynamism is conditioned by the continuous interactions and it enacts a process of mutual adaptation among firms. The awareness of the network context and horizon as well as the types of interdependencies, and its coordination and relative positioning, become firm's key processes in order to develop business relationships. However, the framework does not clarify what processes firms, within complex networks, should deploy in the presence of an emergency or how they can manage the risk of a major emergency such as that of a pandemic or how it can reconfigure itself, transform or destroy itself in these situation.

In fact, the supply chain network studies are mainly focused on "peace time", offering a conceptualization of supply chain structures, interdependencies among the actors, positioning and coordination (Huemer, 2002). These 
studies are not well suited to describe the "crisis time" risks such as those of the Covid-19 outbreak. The study will provide new insight to this literature during "crisis time".

However, while interactions with other firms facilitates access to resources (Pfeffer and Salancik, 1978), any interdependence increases the risks in turbulent conditions in which every company is more vulnerable (Sheffi and Rice $J r$, 2005). The supply chain risks are of different nature and can be classified into operational and disruption risks (Ivanov, 2020, Tang, 2006, Tomlin, 2006, Craighead et al., 2007, Ivanov, 2018, Choi et al., 2019, Xu et al., 2020). Ivanov (2020) points out two main risk categories for supply chains in the presence of the pandemic:

- $\quad$ Operational risk: relating to the performance of day-to-day operations and activities that is compromised and that therefore deadlines and agreements previously taken cannot be respected.

- Disruption risk: it is a profound impact on the entire global supply chain structure that compromises the success of the entire flow.

A specific case of SC disruption risks is represented by the occurrence of natural catastrophic events, such as epidemics. The risks related to these events are characterized by three elements: 1. long-term persistence of the event and unpredictability about its progress, 2. simultaneous interruption of the SC (chain effect) and spread of the population infection (e.g. pandemic propagation), 3. simultaneous interruptions of supply, demand and logistics infrastructure, (Ivanov, 2020). This triad of elements can be fully seen in the current system crisis caused by the COVID-19 pandemic.

In the specific situation of the emergency of Covid-19 - at the time when the authors are working on the research the following events occurred that influenced and made most of the business management processes unpredictable:

- $\quad$ the choices of the policymaker (Cerved, 2020) on:

- Duration of the lockdown

- Incentives and aid to businesses

In particular, the duration and persistence of the lockdown will be also a direct effect of the country's economic damage. This will be also influenced by how the governments will be able to react and manage the current pandemic crisis by safeguarding the economic continuity of the country's ecosystem while managing to save lives.

- $\quad$ the unpredictability of the economic shock (analysed from Confindustria Study Center, 2020), it has two main areas of influence:

- Demand: there has been a stop to the household consumption forced to stay at home, indefinitely interruption, to date to be determined, for the entire tourism sector, interruption or drastic reduction of import / export;

- Supply: directly due to the closure of commercial activities to the customers, indirectly due to interruptions in supplies and discontinuity of production at a global level.

- $\quad$ crisis management in other countries connected to the global supply chain (Baldwin and Di Mauro 2020b).

Therefore, to ensure continuity or manage the interruptions "imposed" by the policymaker, the study identifies the challenges that firms have to deal with in order to survive the emergency.

The study suggests that adopting a supply chain network perspective in pandemic times might lead to several advantages. These advantages can be referred to an increased adaptability, versatility and flexibility within the network thanks to a higher control of the supply chain structure and awareness of the interdependencies among the actors. These, in turn, support the actors in improving mutual adaptation and manage repositioning mechanisms within the network. Thus, having an SCN approach would allow the firms to increase their awareness of the other actors embedded in the supply network, thus allowing them to manage flexibility, adaptability and versatility in the case of a crisis.

The development of these practices constitutes a non-exhaustive response to the two main types of crisis that the supply chain might face: the operational crisis management for firms that are operating within supply chains that the policymaker decided to be "essential"; and the total disruption for those supply chains which the policymakers decided to block.

Research limits. The limitations of this ongoing study are connected to the continuous changing scenario and to the potential impact of the policymaker's further decisions on lockdown to which the firms are subordinated. Furthermore, the limited data leads to the possibility of being able to develop further studies trajectories drawing on both qualitative methodology - thus longitudinal studies - and quantitative empirical studies - thus for assessing the response of a large and heterogeneous number of actors - for a more complete study of the dynamics that characterized supply chain management during the crisis. Certainly, it is also interesting to have a differentiated point of view between "essential" firms that have maintained continuity (for example, fundamental companies such as agri-food) and companies that have instead seen their activity blocked by government decisions (for example clothing, wood, furniture and furnishings sector, etc.).

Practical implications. The unexpected and complex consequences brought by Covid-19 outbreak - and further policymaker decisions - has forced firms and supply chains to adapt in order to continue their activities. The study observes different settings of firms: there are entire supply chains whose are forced to stop, some of those with high risk of running out of money; for the supply chains which continued to do business, there are several which needed to reorganize internal and external processes and other which has to rethink their sales organization; finally, there are some firms which has to rethink their whole strategy, identifying new buyers and new sales channels.

Thus, the practical implications related to the emerging challenges brought from Covid-19 outbreak means that 
firms have to manage the following challenges within the Supply Network:

- Maintaining relationships with customers: all the firms are called to establish a direct channel with consumers and buyers in order to ensure business continuity. Choices in this field might lead to some further issues to manage, such as:

a) Sales intermediates and wholesaler: they might become useless and lose their position in the network.

b) New opportunities for the manufacturing company: they can develop a direct sales channel with their buyers.

c) The sales reps are no longer allowed to travel from customer to customers, but they have to manage customer relationships through digital tools and platforms. All business relationships were translated into digital channels. Here, the level of digitization of the firm at the time of the outbreak of the pandemic plays a crucial role to manage the crisis (Caiozzo and Guenzi, 2020).

- Policymakers' decisions: Since supply chains are now globally interweaved, the risks of interruption due to the different decisions of each countries' policymaker might cause the emerging need to rethink supply choices in terms of supplier and buyers, distribution and sales channels and logistics.

- Demand flattening: due to the forced block of consumption consequent to typical consumers behaviors in times of crisis, often termed as "wait and see" approach. Moreover, because almost all the population around the world is under lockdown into their homes, for these, it is almost impossible to go shopping unless they use e-commerce, where this is still functioning.

- Demand volatility: the external shock forces firms to manage the production and activities with an "accordion effect":

a) In crisis' times there are some goods whose demand is skyrocketing - the case of flour, yeast, DIY and home gym products is the best example. This shift asks companies to reorganize their configuration and their supply management and therefore the need to communicate quickly and effectively also with the supplier base (McKinsey 2020a);

b) However, there will be products that will be almost impossible to sell (products that require interaction, installation at the home or the buyer's premises, which take advantage of closed distribution channels due to regulations, etc.) and which therefore will have to be rescheduled in the procurement and production (McKinsey 2020a).

- $\quad$ Resource management: the pandemic is a great challenge for all the firms according to resource management. In terms of supply chain network, the emerging challenges can be addressed to the following issues:

a) People first: firms have to guarantee people safety and safeguarding by creating environments in compliance with hygiene standards (McKinsey 2020a).

b) Insurance: protect staff who go to workplaces with the necessary insurance coverages.

c) Training and coordination: the issuing of new laws requires to coordinate the entire workforce in short terms. The creation of interdisciplinary teams could be the turning point to define the best strategy to face the crisis and coordinate activities to manage crisis processes (Porsche Consulting 2020).

d) Re-organize: decide which people are to be kept working at the physical location and which ones can be shifted to smart-working mode, or - in the worst case - put into forced stop (Lay-off or paid leave or suspension of occasional work relationships or collaboration). To enhance smart working, firms have to facilitate that for all those functions that do not require specific presence in a physical location. The firms should provide all the technical and ICT devices to allow people work from their homes.

e) Technology: To ease smart working firms are called to provide digital tools and devices. Thus, not only $V P N$-server access and corporate e-mail plus laptop and smartphone; but it will be necessary to have already set all the project management tools in order to check the workflow processes (platforms such as Trello, Slack or Jira) and to ensure information sharing (Skype, MS Teams, Zoom, Telegram, Google G Suite for Business). Information sharing within the organization and between organizations will play a crucial role in managing and overcoming this crisis (Harari 2020).

- $\quad$ Cost management: the firms might face rising costs related to the pandemic and for being compliant with health care regulations. These costs will be of two major categories:

a) Direct costs: sanitization of environments, PSD (Personal safety devices), ICT devices (smartphones, laptops, printers, etc.) for workers in smart working.

b) Indirect costs: running a business with restrictions means, in the best scenario, a lower productivity and lower level of sales, with a less efficient use of commercial and production spaces in order to ensure social distance between people and consequent compliance with the regulations issued by the policymaker.

- $\quad$ Strategy in real time: Firms and entire supply chains have the need to review even the whole business strategy. Firm are required to adopt a real time management approach to cope with the unpredictability of the events. Thus, it is possible to identify three different horizons to reimagine business strategy (McKinsey 2020b):

a) Short/very short-term: manage cash for ensure business safety and adapt quickly to new emerging opportunities;

b) Mid-term: manage to ramp-up the business to achieve a "new normal" operations, here the coordination with the supply chain is crucial to define new interactions processes;

c) Long-term: begin to a "normal" approach and re-align "real time" operations to the firm's strategic vision. 
In these cases, financial and structural stress could be potential risks and failure scenarios. It could be appropriate to create a new system of indicators to monitor the evolution of events (McKinsey 2020b).

Originality of the study. The study analyzes the implications of the current Covid-19 Italian pandemic crisis and the immediate emergent challenges in supply chains management. The uniqueness of the study in addressing a new and still ongoing phenomenon makes the considerations outline in the article in continuous change, presumably there will be several changes with the continuous evolution of the pandemic. As a matter of fact, the research is carried out "inside the eye of a hurricane", since at the time when the document is developed the lockdown has not yet been removed, it has not yet gone to "Fase 2" (the total lockdown in Italy is named "Fase 1", the beginning of the reopening is named "Fase 2"). and therefore, there is still apprehension and full uncertainty about the timing and methods that the government plans to deploy in order to encourage the restart of industrial and commercial activities.

The results of the study include a series of insights that contribute to the theory of supply chains network and in managing the effects of the pandemic. The study attempts to reach a conceptualization of the management challenges responses that can be deployed during a profound crisis such as that triggered by the current Covid-19 outbreak. These insights might become the principles to begin the study of the ex-post effects of this event into supply chains network. Furthermore, it could be useful to begin the understanding on how to manage the re-start of the business landscape and consequently analyze the response of firms to the whole phenomenon.

Furthermore, the research aims to contribute also to managerial literature, offering practical elements to manage supply chain crises, thus a set of operational implications that firms could follow to secure the continuity of their supply chain and therefore to face and live with potential future crises (which of course we hope will not occur).

Key words: Supply Chain; Covid-19; Epidemic outbreak; Risk management; Pandemic plan; Resilience

\section{References}

ADEKOLA J., CLELLAND D. (2020), "Two sides of the same coin: business resilience and community resilience", Journal of Contingencies and Crisis Management, vol. 28, n. 1, pp. 50-60.

BALDWIN R., DI MAURO B.W. (2020a), Economics in the Time of COVID-19, CEPR Press, Centre for Economic Policy Research, London.

BALDWIN R., DI MAURO B.W. (2020b), Mitigating the COVID Economic Crisis: Act Fast and Do Whatever It Takes, CEPR Press, Centre for Economic Policy Research, London.

BAUBION C. (2013), “OECD Risk Management: Strategic Crisis Management”, OECD Working Papers on Public Governance, OECD Publishing, Paris, n. 23, Available at https://doi.org/10.1787/19934351

BUCHANAN D.A., DENYER D. (2013), "Researching tomorrow's crisis: methodological innovations and wider implications", International Journal of Management Reviews, vol. 15, n. 2, pp. 205-224.

CAIOZZO P., GUENZI P. (2020), "Vendere ai tempi del Coronavirus", SDA Bocconi CDR, Available at: https://www.sdabocconi.it/upl/entities/attachment/Vendere_al_tempo_del_Coronavirus_Report_def.pdf, (Accessed 2 April 2020).

CERVED INDUSTRY FORECAST (2020), "Gli impatti del COVID-19 sui ricavi delle imprese italiane”, Available at: https://know.cerved.com/wp-content/uploads/2020/03/Cerved-Industry-Forecast_COVID19-.pdf, (Accessed: 27 March 2020).

CHOI T.M., WEN X., SUN X., CHUNG S.H. (2019), "The mean-variance approach for global supply chain risk analysis with air logistics in the blockchain technology era", Transportation Research Part E: Logistics and Transportation Review, vol. 127, pp. 178-191.

CONFINDUSTRIA STUDY CENTER (2020), "L'effetto COVID-19 affonda la produzione industrial in marzo ($16,6 \%)$ e nel primo trimestre (-5,4\%)", Available at: https://www.confindustria.it/home/centro-studi/temi-diricerca/congiuntura-e-previsioni/tutti/dettaglio/indagine-rapida-produzione-industriale-Italia-marzo-2020, (Accessed 20 April 2020).

COUGHLAN M. CRONIN P., RYAN F. (2007), "Step-by-step guide to critiquing research. Part 1: quantitative research", British journal of nursing, vol. 16, n. 11, pp. 658-63.

CRAIGHEAD C.W., BLACKHURST J., RUNGTUSANATHAM M.J., HANDFIELD R.B. (2007), "The severity of supply chain disruptions: design characteristics and mitigation capabilities”, Decision Science, vol. 38, n. 1, pp. $131-156$

CRONIN P., RYAN F., COUGHLAN M. (2008), “Undertaking a literature review: A step-by-step approach”, British journal of nursing, vol. 17, n. 1, pp. 38-43.

DAVOUDI N., DEHGHAN N.N., RAIESIFAR A., POORTAGHI S., AHMADIAN S. (2016), "Issues of Theoretical Sampling: A Narrative Review”, Nursing and Midwifery Studies, vol. 6, n. 2, pp. 1-9.

DAY D.V., GRONN P., SALAS E. (2004), “Leadership capacity in teams”, The Leadership Quarterly, vol. 15, n. 6, pp. 857-880.

FINLAY I., SHERIDAN M., COBURN A., SOLTYSEK R. (2013), "Rapid response research: using creative arts methods to research the lives of disengaged young people", Research in Post-Compulsory Education, vol. 18, n. 1 , pp. 127-142. 
DOLGUI A., IVANOV D., SOKOLOV B. (2018), "Ripple effect in the supply chain: an analysis and recent literature", International Journal of Production Research, vol. 56, n. 1-2, pp. 414-430.

GADDE L.E., HJELMGREN D., SKARP F. (2012), "Interactive resource development in new business relationship", Journal of Business Research, vol. 65, n. 2, pp. 210-217.

GADDE L.E., HÅKANSSON H. JAHRE M. PERSSON G. (2002), "More instead of less: Strategies for use of logistics resources", Journal on Chain and Network Science, vol. 2, n. 2, pp. 81-91.

GREGORI G.L., PERNA A., SABATINI A. (2017), "L'efficacia del Customer Relationship Management nei mercati dei servizi tecnologici: il caso di una media impresa italiana”, Economia e diritto del terziario, vol. 0, n. 2, pp. 205-224.

HÅKANSSON H., FORD D. (2002), “How Should Companies Interact in Business Networks?”, Journal of Business Research, vol. 55, n. 2., pp. 133-139.

HARARI Y.N. (2020), "The world after coronavirus", Financial Times, 20 March 2020, Available at: https://www.ft.com/content/19d90308-6858-11ea-a3c9-1fe6fedcca75, (Accessed 20 March 2020).

HARLAND C. (1999), "Supply Network Strategy and Social capital", in Lenders T. R., Gabbay M.S. (edited by), Corporate Social Capital and Liability, Kluwer Academic Press, Boston.

HUEMER L. (2002), "Value Creation Strategies in Supply Networks: the Case of Logistics Service Providers", paper presented at the 18th Annual IMP Conference, Dijon, France, Sept. 5th-7th, Retrieved March 2, 2020 from https://www.impgroup.org/uploads/papers/531.pdf

HUEMER L. (2006), "Supply management: value creation, coordination and positioning in supply relationships", Long Range Planning, vol. 39, n. 2, pp. 133-153.

HUFF A.S. (2008), Designing research for publication, Sage Publications, Thousand Oaks.

IVANOV D. (2018), Structural Dynamics and Resilience in Supply Chain Risk Management, Springer, New York.

IVANOV D. (2020), "Predicting the impacts of epidemic outbreaks on global supply chains: A simulation-based analysis on the coronavirus outbreak (COVID-19/SARS-CoV-2) case", Transportation Research Part E: Logistics and Transportation Review, vol. 136, n. 101922 , pp. 1-14.

JOHNS HOPKINS UNIVERSITY (JHU), (2020), "COVID-19 Dashboard by the Center for Systems Science and Engineering (CSSE)", Available at https://coronavirus.jhu.edu/map.html (Accessed: 20 April 2020).

LI Y. ZOBEL C. (2020), "Exploring supply chain network resilience in the presence of the ripple effect”, International Journal of Production Economics, vol. 228, n. 107693, pp. 1-13.

LA ROCCA A., FORD D., SNEHOTA I. (2013), "Initial relationship development in new business ventures", in Industrial Marketing Management, vol. 42, n. 7, pp. 1025-1032.

LINNENLUECKE M.K. (2017), "Resilience in business and management research: a review of influential publications and a research agenda", International Journal of Management Reviews, vol. 19, n. 4, pp. 4-30.

MARCONE M.R. (2019), "Un approccio alla logistica: tra integrazione e sostenibilità", in Gregori, G.L. Perna, A. (a cura di), BtoB marketing: Il business marketing tra teoria e managerialità. EGEA, Milano.

MCKIBBIN W.J., ROSHEN F. (2020), “The Global Macroeconomic Impacts of COVID-19: Seven Scenarios”, CAMA Working Paper No. 19/2020, Available at SSRN: https://ssrn.com/abstract=3547729 or http://dx.doi.org/10.2139/ssrn.3547729

MCKINSEY \& COMPANY, (2020a), "Covid-19: Briefing Material. Global Health and crisis response", Available at: https://www.mckinsey.com/ /media/mckinsey/business\%20functions/risk/our\%20insights/covid\%2019\%20impl ications \%20for\%20business/covid\%2019\%20march\%2025/covid-19-facts-and-insights-march-25-v3.ashx, (Accessed 27 March 2020)

MCKINSEY \& COMPANY, (2020b), "Covid-19: Briefing Material. Global Health and crisis response", Available at: https://www.mckinsey.com/ /media/mckinsey/business\%20functions/risk/our\%20insights/covid\%2019\%20impl ications\%20for\%20business/covid\%2019\%20march\%2030/covid-19-facts-and-insights-april-3.ashx, (Accessed 3 April 2020)

OMTA S.W.F., TRIENEKENS J.H. BEERS G. (2001), “Chain and network science: A research framework”, Journal on Chain and Network Science, vol. 1, n. 1, pp. 1-6.

PFEFFER J. SALANCIK G. (1978), The External Control of Organizations: A Resource Dependence Perspective, Harper \& Row, New York.

PORSCHE CONSULTING (2020), "How the COVID-19 pandemic is changing the consumer goods landscape", Available at: https://www.porscheconsulting.com/fileadmin/docs/Startseite/News/SRX04217/How\%20the\%20COVID19\%20pandemic\%20is\%20 chaning\%20the\%20consumer\%20goods\%20landscape.pdf, (Accessed 28 March 2020).

PORTER M.E. (1985), Competitive Advantage: Creating and Sustaining Superior Performance, Simon and Schuster, New York.

SHEFFI Y., RICE J.J. (2005), “A Supply Chain View of the Resilient Enterprise”, MIT Sloan Management Review, vol. 47, n. 1 , pp. $40-48$

SCHEIBE K.P., BLACKHURST J. (2017), "Supply chain disruption propagation: a systemic risk and normal accident theory perspective.", International Journal of Production Research, vol. 56, n. 1-2, pp. 43-59.

TANG C.S. (2006), "Perspectives in supply chain risk management", International Journal of Production Economics, vol. 103 , n. 2 , pp. 451-488. 
TOMLIN B. (2006), "On the value of mitigation and contingency strategies for managing supply chain disruption risks", Management Science, vol. 52, n. 5, pp. 639-657.

WILLIAMS T.A., SHEPHERD D.A. (2016), "Building resilience or providing sustenance: different paths of emergent ventures in the aftermath of the Haiti earthquake", The Academy of Management Journal, vol. 59, n. 6, pp. 20692102.

WORLD ECONOMIC FORUM, (2012), "New Models for Addressing Supply Chain and Transport Risk", Available at: http://www3.weforum.org/docs/WEF_SCT_RRN_NewModelsAddressingSupplyChainTransportRisk_IndustryA genda_2012.pdf, (Accessed: 27 March 2020).

XU S., ZHANG X., FENG L., YANG W. (2020), "Disruption risks in supply chain management: a literature review based on bibliometric analysis", International Journal of Production Research, vol. 58, n. 10, pp. 1-19.

YIN R.K. (2014), Case Study Research Design and Methods (5th ed.), Sage, Thousand Oaks.

\section{Websites}

https://www.confindustria.it

https://www.ft.com

https://www.impgroup.org

https://www.mckinsey.com

https://www.porsche-consulting.com

https://www.sdabocconi.it

http://www3.weforum.org 



\title{
Sustainability, innovation and biological technology in wine production: an empirical analysis
}

\author{
Nicola COBELli* MARGHERITA ANGIONI FABIO MUSSO
}

Objective and Background The agri-food industry is strongly connected to environmental issues of sustainability; the very concept of quality agri-food goes hand in hand with the development of crops and production methods that protect the territory, and which increasingly reduce the use of substances harmful to humans and the environment (Casini et al, 2010; Cantino et al., 2018). This type of reasoning can be applied to the wine sector which has traditionally shown great attention to the environmental aspect, recognizing in this element a factor of wine quality (Gilinsky et al., 2015). As pointed out in the First Report on the Sustainability of Wine (http://www.vinosostenibile.org), awareness of the technical and commercial importance of the link between characteristics of the place of production and characteristics and identity of the wine led already in the 19th century to the development of the concept of territory and subsequently, with increasing sensitivity to social and environmental issues, many companies, also with a view to corporate social responsibility, have adopted innovations in corporate processes aimed at greater respect for the environment (Szolnoki, 2013; Siepmann, 2018).

The wine world has reacted to the challenge of sustainable development through the development of collective initiatives (Castellini et al., 2014) for the implementation of sustainability programs (Roualt et al., 2016) for the analysis and evaluation of the production processes in the companies involved, with a view to continuous improvement, sharing of best practices for internal and external communication of performance achieved in terms of sustainability (Olaru et al., 2014). In Italy, the world of winegrowing has positevely reacted to the challenge of sustainable development.

In the past twenty years, attention to the issue of environmental sustainability has increased more and more, year after year. The reasons are manifold, both environmental, economic and ethical. According to data published by SINAB (National Information System on Organic Agriculture), since 2010 the area for organic agriculture in Italy has increased by almost 800,000 hectares and 27 thousand farms (SINAB, 2019).

The data as at 31 December 2018 therefore confirm the growth of the organic farming sector while maintaining the positive trend, as organic areas increased by 2.6\% compared to 2017, reaching almost 2 million hectares. Most of the agricultural sectors have recorded an increase in the biological area. Growth for vines and olives is more contained (with only a plus of 1\%) (SINAB, 2019).

As for the regional distribution of biological surfaces, the largest extension was recorded in Sicily with 385,356 hectares, followed by Puglia with 263,653 hectares, Calabria with 200,904 hectares and Emilia-Romagna with 155,331 hectares. Compared to 2017, biological areas in Sicily and Calabria decreased by 10\% and 1\% respectively, while in Puglia and Emilia-Romagna they increased by $4 \%$ and $15 \%$ respectively. The biological surface of these four regions holds $51 \%$ of the entire national biological surface (SINAB, 2019).

At the end of 2018 in Italy it was recorded that 79,046 businesses were included in the certification system for organic agriculture, recording a 4\% increase compared to 2017. It is noted that 58,954 exclusive producers (farms) show a 3\% increase over the previous year (SINAB, 2019).

Of the total area cultivated in Italy, organic grows to affect $15.5 \%$ only of the national UAA (Utilized Agricultural Area), given that in 2017 it grows by one percentage point compared to 2016. From the processing of the surface data, it is clear that on every 100 hectares of UAA are organic: 5.6 hectares in the North-West, 9.3 hectares in the NorthEast, 20.1 hectares in the Center and in the South and 19.2 hectares in the Islands. Organic farms in Italy, on the other hand, represent $6.1 \%$ of total farms. This figure is uniform in all areas of the country. As regards the average size of the farms that make up the Italian organic sector, the average surface area was 28.2 hectares. Larger company areas have been registered in the Center, South and Islands, while North-East and North-West are smaller (SINAB, 2019).

Nevertheless, even though Italy is one of the main wine producers in the world, organic wine production is almost still and is not addressing the growing request for this kind of product. Therefore, it is interesting from s business

\footnotetext{
Assistant Professor of Management - University of Verona - Italy e-mail: nicola.cobelli@univr.it

- Adjunct Professor of International Marketing - The University of Urbino Carlo Bo - Italy e-mail: margherita.angioni@uniurb.it

- Full Professor of Management - University of Urbino Carlo Bo - Italy e-mail: fabio.musso@uniurb.it
} 
management perspective to investigate the factors/latent constructs influencing the choice of adoption/non-adoption of innovative organic wine production technologies by Italian wine producers (Zucconi et al., 2019).

Methodology. Over the past 30 years, the field of interdisciplinary study of innovation adoption has developed rapidly. Different theoretical models were developed and applied. The result of these many years of research is the numerous contributions to the field, which, however, remain highly fragmented. Since the 1960s, researchers in various disciplines have published many studies about the adoption of technologies by individuals (Ogrezeanu, 2015). In Table 1 , the timeline of the main Research Models under discussion in this research are presented.

Tab. 1: The main models studying the choices of adoption/non-adoption of innovation

\begin{tabular}{|c|c|c|}
\hline Year & Research models & Core constructs \\
\hline 1980 & Theory of Reasoned Action (TRA) & Attitude, Subjective Norm \\
\hline $1985 \& 1991$ & Theory of Planned Behaviour (TPB) & Attitude, Subjective Norm, Perceived Behavioural Control \\
\hline $1986 \& 2002$ & Matching Person \& Technology Model (MPT) & Environment, Person, Technology functionality \\
\hline 1989 & Technology Acceptance Model (TAM) & $\begin{array}{l}\text { Perceived Usefulness, Perceived Ease of Use, Subjective } \\
\text { Norm/external variables }\end{array}$ \\
\hline 1992 & Motivational Model (MM) & Extrinsic Motivation, Intrinsic Motivation \\
\hline \multirow{3}{*}{1995} & Innovation Diffusion Theory (IDT) & Five Perceived Attributes \\
\hline & Task-Technology Fit Model (TTF) & Task Requirement, Tool Functionalities \\
\hline & Social Cognitive Theory (SCT) & Self-efficacy, Affect, Anxiety, Outcome Expectations \\
\hline 2000 & Technology Acceptance Model (TAM 2) & Social Influence, Cognitive Instrumental Processes \\
\hline 2003 & $\begin{array}{l}\text { Unified Theory of Acceptance and Use of Technology } \\
\text { (UTAUT) }\end{array}$ & $\begin{array}{l}\text { Performance Expectancy, Effort Expectancy, Social Influence, } \\
\text { Facilitating Conditions, Gender, Age, Experience, Voluntariness of } \\
\text { Use }\end{array}$ \\
\hline 2008 & Technology Acceptance Model (TAM 3) & Pre-and Post-implementation Phases \\
\hline
\end{tabular}

Table 1 Chronologically lists the main Research Models that investigate the choices of adoption/non-adoption of innovation.

Source: Cobelli N., Innovation in Community-Based Private Practices through eHealth: A Business Management Perspective, New York City, Springer, 2020 (forthcoming).

In 2003, Venkatesh et al. formulated the Unified Theory of Acceptance and Use of Technology (UTAUT), as shown in Fig. 1. They theorised that four components have a significant role in usage behaviour and user acceptance: performance expectancy, effort expectancy, social influence and facilitating conditions (Venkatesh et al., 2003). Thus, UTAUT can be considered a unified view of previous works. In particular, it is based on an integration of several previous research Models (Lai 2017). Among all the Models described, UTAUT seems to be in literature on of the most sophisticated and with the highest impact in the study of the owners and managers' reasons behind the choices of adoption/non-adoption of new technologies (Im et al., 2011).

Fig. 1 Unified Theory of Acceptance and Use of Technology (UTAUT)

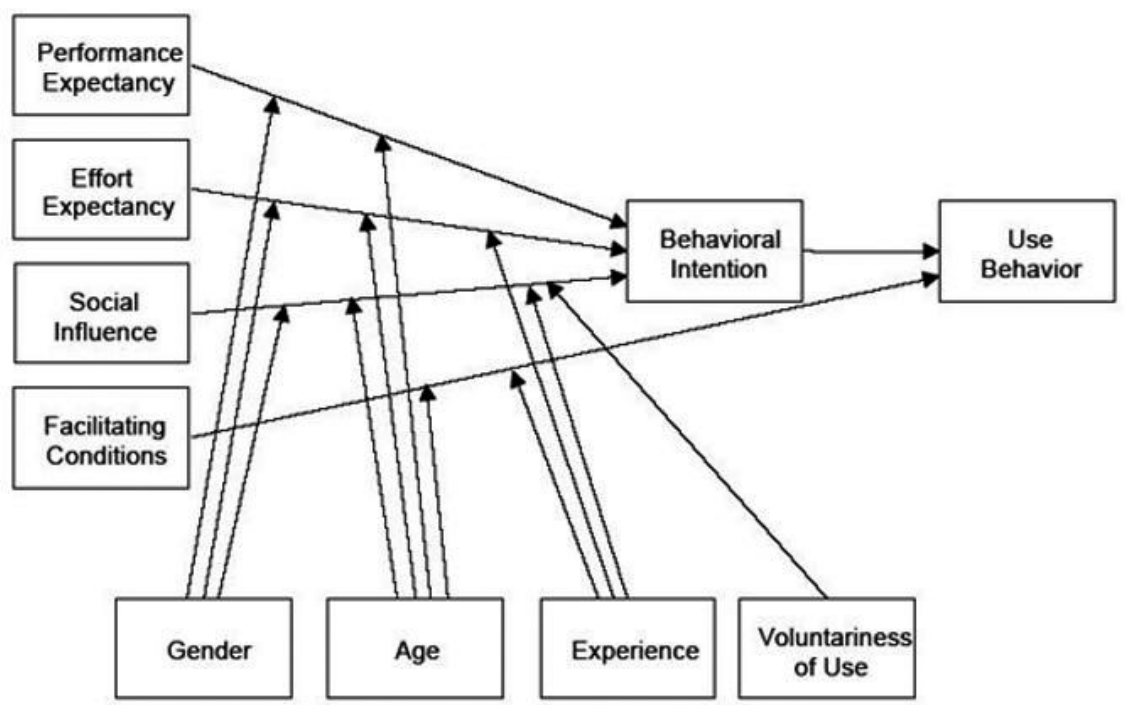

Fig. 1 shows UTAUT, which aims to explain user intentions to use an information system and subsequent usage behaviour.

Source: Venkatesh et al., 2003. 
The literature provides many guidelines with respect to sample size, including having (a) a minimum sample size of 100 or 200 (Boomsma, 1985), (b) five or 10 observations per estimated parameter (Bentler and Chou 1987) or (c) 10 cases per variable (Nunnally and Bernstein 1967; Cobelli, 2020).

For the collection of data to be analysed, a quantitative analysis was carried out using questionnaires based on UTAUT research model. The questionnaire administered to each company consisted of 4 sections with a total of 34 questions. The first part consisted mostly of general questions (14 questions), such as the year the company was founded, the owner's registry, number of employees, etc.

The second part, consisting of 17 questions, focused on marketing and communication strategies and, in particular, on the motivations that pushed producers to pursue a specific production/management path.

The third part aimed to know what the perceptions towards organic wines were and finally on the hypothetical weaknesses and strengths of the production choice undertaken. The fourth and final part, however, included a series of questions directed to the owners' personal data, such as gender, age, role etc..

The sample, taken into consideration for this study, included 891 companies; a response rate of $21 \%$ was recorded, or 181 companies (n. 181), operating throughout the national Italian territory.

Expected Findings. Data analysis is not completed. We are still working on them through the use of $R$ software $(R$ Core Team, 2020). For these reasons, now we can present some expected outcomes and findings, rather than certainly proven findings.

It is a matter of fact that, according to the responses, sustainability in viticulture is defined by two important international organizations: International Organization of Vine and Wine (OIV) and International Federation of Wine and Spirits (FIVS). Both have drawn up sustainability programs called respectively: Guidelines for Sustainable Vitiviniculture (production, processing, and packaging of products) and The Global Wine Sector Sustainability Principles Project.

The OIV defines the sustainable production of wine as follows: "Global approach commensurate with the systems of production and transformation of the grapes, simultaneously associating the economic longevity of the structures and territories, the obtaining of quality products, taking into consideration the needs precision viticulture, risks related to the environment, product safety health and consumers and the enhancement of historical, ecological, cultural and aesthetic heritage" (OIV, 2019, http://www.oiv.int).

In the guidelines, the OIV refers to numerous aspects: the choice of the site, biodiversity, varietal selection, varietal management, soil management, energy use, water and waste management, use of chemicals and finally human resource management. The FIVS, in addition to what is considered by the OIV, also focuses on carbon management, pollution caused by transport and finally the consumption of fossil fuels (Mariani, Vastola, 2015).

As previously stated, the management of human resources must be considered within the concept of sustainability. This makes it clear that the meaning of the word sustainable is not limited only to respect for the environment but is an approach that embraces multiple fields; one of them is human resource management. FairTrade3, Fair Trade is involved in this field. The mark of this international body, placed on food labels, provides the consumer with a guarantee of sustainability in all its forms (Mariani, Vastola, 2015). Globally, according to the 2018 FairTrade Annual Report, in 2018 sales of fair-trade wine increased by 5\% in volume, equivalent to 26 million kilograms of wine grapes.

According to Santini et al. (2013), sustainability is a behavior that can be adopted or not by companies based on the perception of stimuli, both external and internal. This leads to the identification of three important elements: the external stimuli, the organizational characteristics of the company that can lend themselves positively to the sustainable choice and finally the motivations of the company.

The most important external stimuli are institutional, therefore linked to incentives promoted by governments, associations, consumer demand and competitors. As for internal stimuli, these are difficult to determine, as they depend exclusively on the entrepreneur, that is, on his skills, curiosity, creativity, flexibility, the degree of risk appetite: it is very clear that a change of strategy, whatever it is, it is not an easy choice to take.

In the 1990s, a new term, Ecopreneurship, was introduced to define the branch that studies the critical aspects brought to light by entrepreneurs on issues of ecology and the environment, where Gabzdylova et al. (2009), sought to establish what were the main motivations that guide wineries to take the path of sustainability; in particular the role played by the stakeholders in the decision-making process of the companies and the environmental practices adopted relating to the consumption of water, chemical agents and their management. The study has shown that the most important stimuli that lead to the adoption of sustainable practices by wineries concern personal value, preferences and staff satisfaction; followed, in order of importance, by product quality and consumer demand. This means that consumer demand is not always the only motivation capable of influencing a winery's business choices. Our study should give a more insightful view on the constructs behind the decision making of adoption of the innovative technology.

Research limits. As with any research, this work has its limitations. First, convenience sampling was used to maximise the survey response rate; thus, it may be argued that only respondents with an interest in the study made contact with the researchers, creating the possibility of selection bias. Second, the criteria for identifying participants were wide, which may have affected the results emerging from the investigated sample. Finally, the only Italian context has been investigated. However, Italy is one of the main wine producers (Cusmano et al., 2010), there might be factors our study did not take into account and that are present in countries different to Italy. 
Practical implications. An initial examination of the data collected shows that the meaning of the concept of "sustainability" is not yet known in its entirety, as this term is used only in opposition to air pollution and in general to the protection of the environment. Indeed, sustainability encompasses three key points within itself, that is, the environment, as already mentioned, the economy and society. The term environment refers to all practices that are capable of combating polluting sources and climate change (Costanza and Patten, 1995).

Preserving the environment for future generations while ensuring economic and social development at the same time. Indeed, sustainable practices adopted by companies must not only protect the environment, but also protect the health of the consumer and those who work. The company must also ensure that workers' rights, such as safety at work, enhancement and training, are respected and safeguarded; finally, it must produce an income for the people who work there trying to control production costs in the best way. Furthermore, a company can be considered sustainable not only if it metabolizes some sustainable procedures within its production chain but is also capable of being selfsufficient. Finally, to the social and ethical concept of sustainability provides that the company must integrate in the best possible way within the territory that surrounds it, try to create and protect relationships with people who live and work in that same territory (Costanza and Patten, 1995).

The first analysis of the data collected through the questionnaire, however, shows that, although the definition of sustainability is partially known to those who work in this field, the opinion persists that most producers use sustainable methods for a strategic and market end and is therefore not a choice determined by ethical, social and/or environmental reasons. Precisely on this aspect, some respondents wanted to give their own vision of what "organic wine" is. If on one hand some considered it important to point out that organic production is a true lifestyle that bases its foundations on nature, on the other hand, the respondents confirmed that they are looking for a way to increase their revenues.

On the basis of these two polarized positions, it is clear that associations and public decision makers should provide producers with a more precise and complete knowledge of organic productions, taking into consideration revenues and also the relevance of this innovation to preserve the exploitation of natural resources at the expense of future generations, with a view to maximizing profits and differentiating the offer on the market.

Wine production is sustainable, if such sustainability, in relation to organic wine, also concerns other aspects, such as the working conditions of people and the good health of the territory. After all, wine is one of the products of the earth which is strongly linked to the traditions of the territory in which it is grown and the impact of the cultivation itself has important effects in terms of landscape, hospitality and catering. In this, the production of organic wine can bring producers and consumers back to a deeper ethical approach to this product, which, as mentioned, has important connections with all stakeholders.

Originality of the study. At the best of our knowledge, although other studies have been conducted on the sustainability and use of techniques that lead to the production of biodynamic wine, the real and great originality of this study consists in focusing on the psychological factors of entrepreneurs to fully understand, through techniques, including psychometric techniques, the variables on which it is possible to act to fully understand the reasons behind the choices of adoption and non-adoption. This allows to go beyond the mere evaluation of the turnover and the ecological potential made available by organic wine. Organic requires a real change of mentality and approach, which must be independent of merely economic factors.

Key words: innovation, choices of adoption, organic wine, UTAUT

\section{References}

BENTLER P.M., CHOU C.P. (1987), "Practical issues in structural modeling”, Sociological Methods and Research, vol. 16 , n. 1, pp. 78-117.

BOOMSMA A. (1985), "Nonconvergence, Improper Solutions, and Srarting Values in LISREL Maximum Likelihood Estimation", Psychometrika, vol 50, n. 2, pp. 229-242.

CANTINO V., GIACOSA E., CORTESE D. (2018), "A Sustainable Perspective in Wine Production for CommonGood Management. The Case of Fontanafredda Biological Reserve", British Food Journal, vol. 121 n. 2, pp. 259-274.

CASINI L., CAVICCHI A., CORSI A., SANTINI C. (2010), "Hopelessly devoted to sustainability: marketing challenges to face in the wine business" in Proceedings of 119th EAAE Seminar Sustainability in the Food Sector: Rethinking the Relationship between the Agro-Food System and the Natural, Social, Economic and Institutional Environments, Capri, Italy, June 30th - July 2nd, 2010, pp. 1-20.

CASTEllini A., MAURACHER C., PROCIDANO I., SACCHI G. (2014), "Italian Market of Organic Wine: A Survey on Production System Characteristics and Marketing Strategies", Wine Economics and Policy, vol. 3, n. 2, pp. 71-80.

COBELlI N., Innovation in Community-Based Private Practices through eHealth: A Business Management Perspective, Springer, New York City, 2020 (forthcoming).

COSTANZA R., PATTEN B.C. (1995), "Defining and Predicting Sustainability", Ecological Economics, vol. 15, n. 3, pp. 193-196. 
CUSMANO L., MORRISON A., RABELlOTTI R. (2010), "Catching Up Trajectories in the Wine Sector: A Comparative Study of Chile, Italy, and South Africa”. World Development, vol. 38, n. 11, pp. 1588-1602.

GABZDYLOVA B., RAFFENSPERGER J..F, CASTKA P. (2009), "Sustainability in the New Zealand Wine Industry: Drivers, Stakeholders and Practices". Journal of Cleaner Production, vol. 17, n. 11, pp. 992-998.

GILINSKY JR A., NEWTON K. S., ATKIN S. T., SANTINI C., CAVICCHI A., ROMEO CASAS A., HUERTAS R. (2015), "Perceived Efficacy of Sustainability Strategies in the US, Italian, and Spanish Wine Industries", International Journal of Wine Business Research, vol. 27, n. 3, pp. 164-181.

IM I., HONG S., KANG, M.S. (2011), “An International Comparison of Technology Adoption: Testing the UTAUT Model”. Information \& Management, vol. 48, n. 1, pp. 1-8.

LAI P.C. (2017) "The Literature Review of Technology Adoption Models and Theories for the Novelty Technology", Journal of Management Information Systems, vol. 14, n. 1, pp. 21-38.

MARIANI A., VASTOLA A. (2015), "Sustainable winegrowing: current perspectives", International Journal of Wine Research, vol. 7, n. 1, pp. 37-48.

NUNNALLY J.C., BERNSTEIN I.H. (1967), Psychometric theory. McGraw-Hill, New York.

OGREZEANU A (2015), "Models of technology adoption: an integrative approach", Network Intelligence Studies, vol. 3 , n. 5, pp. 55-67.

OLARU O., GALBEAZA M.A., BANACU C.S. (2014), “Assessing the sustainability of the wine industry in terms of investment", Procedia Economics and Finance, vol. 15, n. 14 pp. 552-559.

R CORE TEAM (2020) "R: a language and environment for statistical computing". $R$ Foundation for Statistical Computing, Vienna, Austria.

ROUAULT A., BEAUCHET S., RENAUD-GENTIE C., JOURJON F. (2016), "Life Cycle Assessment of Viticultural Technical Management Routes (TMRs): Comparison Between an Organic and an Integrated Management Route", Journal International des Sciences de la Vigne et du Vin, vol. 50, n. 2, pp. 77-89.

SANTINI C., CAVICCHI A., CASINI L. (2013), "Sustainability in the Wine Industry: Key Questions and Research Trends", Agricultural and Food Economics, vol. 1, n. 9, pp. 1-9.

SIEPMANN L., NICHOLAS K. (2018), "German Winegrowers' Motives and Barriers to Convert to Organic Farming", Sustainability, vol. 10, n. 4215, pp. 1-17.

SINAB (2019) "Bio in cifre (2019), Anticipazioni, progetto del MIPAAFT gestito da ISMEA e CIHEAM - sulla base delle informazioni al 31 dicembre 2018 comunicate dagli Organismi di Controllo, dalle Regioni e dal Sistema Informativo del Biologico (SIB)", ISMEA data on data of Nielsen.

SZOLNOKI G. (2013), "A Cross-National Comparison of Sustainability in the Wine Industry", Journal of Cleaner Production, vol. 53, pp. 243-251.

VENKATESH V., MORRIS M.G., DAVIS G.B., DAVIS F.D. (2003), “User Acceptance of Information Technology: Toward a Unified View", MIS Quarterly, vol. 27, n. 3, pp. 425-478.

VENKATESH V., THONG J.Y.L., XIN X. (2016), "Unified Theory of Acceptance and Use of Technology: A Synthesis and the Road Ahead", Journal of the Association for Information Systems, vol. 17, n. 5, pp. 328-376.

ZUCCONI S., QUAGLIETTI V., GANDINI E. (2019), "Il posizionamento competitivo del BIO Made in Italy sui mercati esteri", Proceedings of $31^{\circ}$ Salone Internazionale del Biologico e del Naturale. 6-9 September 2019, Bologna, Italia, pp. 1-35.

\section{Websites}

http://www.vinosostenibile.org (retrieved on 02.04.2020)

https://www.ifoam.bio/en/organic-landmarks/principles-organic-agriculture (retrieved on 04.04.2020).

http://www.oiv.int/en/technical-standards-and-documents/good-practices-guidelines (retrieved on 07.04.2020) 



\title{
An exploration of determinants of tourist experience in the Albergo Diffuso. An Italian case study
}

\author{
CRistiana COMPAGNO* Michela C. MASON Francesco RagGiotto*
}

Objectives. The Albergo Diffuso (AD) is a typically Italian form of hospitality (Confalonieri, 2011; Paniccia and Leoni, 2017), differing with most of the traditional tourist and holiday accommodation formats like hotels, residences, and $B \& B s$. AD gathers a number of different businesses related to tourist accommodation (e.g., lodging, dining, entertainment), bonded to each other by a certain degree of operational integration (i.e., they are part of the same accommodation structure) and denoted by physical dispersion (Confalonieri 2011). Typically, Albergo Diffuso is located in small rural areas, like small towns and villages, characterized by a significant cultural and/or historical heritage (Presenza et al., 2019). In a few words, the basic concept of the AD is that, "rooms, decorated in a consistently authentic and local style, are scattered throughout different buildings within the town but overseen by one manager" (Williams, 2010).

The AD model of hospitality allows a sustainable usage of place-specific resources into a model of touristic development. The $A D$ considers touristic development as a way to foster the socioeconomic development of the area in which it is located, contributing, on the one hand, to the recovery of isolated rural areas and, on the other, to preserving the local heritage and landscape (Romolini et al., 2017).

Albeit AD has been implemented in several Italian regions (Confalonieri, 2011; Romolini et al. 2017; Presenza et al. 2019), and even abroad (Bloomberg, 2018), it is believed that the AD model was originally conceived in Carnia, a mountain area located within the Italian region of Friuli Venezia Giulia. In its original conceptualization, AD was conceived as system to recover the economic development of the Carnia rural areas, which in the 1970s were experiencing a dramatic process of depopulation. It was a process originated after the end of the Second World War, that worsened after 1976, when a devastating earthquake brought massive destructions throughout the entire region. These negative tendencies were further worsened due to the geographical setting of the Carnia region, isolated from major urban centers.

To contrast such demographic and economic deterioration, in 1979 the young inhabitants of Comeglians a small town in Carnia, supported by some scholars of the Polytechnic of Zurich, developed a model to sustain a redevelopment of the almost inexistent local economy: the $A D$ model. The underlying idea of $A D$ was that "the nearly uninhabited villages could serve as tourist destinations" (Confalonieri, 2011, p. 686). AD was as a project of socioeconomic development through urban restoration. In other words, the original $A D$ model envisioned the recovery of the old, abandoned buildings of the village for touristic purposes as a way to create socioeconomic development (Toson, 2014).

According to the 1979 conceptual framework, tourism was considered as a tool to achieve the very objectives of the model, related to achieving socio-economic recovery and preserve the future existence of the local communities, as well as the preservation of the local heritage (i.e., cultural, human, and natural). After more than forty years from its foundation, the model of the AD has been implemented in several Italian regions and has been also exported in other countries.

Customers' spending in AD is expected to grow progressively, especially after Coronavirus, thanks to its far less mass-market approach closer to the real values of nature, culture, and local food. According to Yuan and Wu (2008), the concept of experience is connected to every purchasing act of consumers (Yuan and Wu, 2008). The concept of experience refers to "the total outcome to the customer from the combination of environment, goods, and services purchased" (Lewis and Chambers, 2000, p. 46).

Literature defines experiential consumption as "those facets of consumer behavior that relate to the multi-sensory, fantasy and emotive aspects of one's experience with products." (Hirschman and Holbrook, 1982, p. 92). In the tourism industry, experiential consumption is crucial, as the intangible experience is the critical element of almost every touristic product and service. (Yuan \& Wu, 2008), which are, by definition, experiential (Williams, 2006), and which

Full Professor of Management - University of Udine - Italy

e-mail: cristiana.compagno@uniud.it

- Associate professor of Marketing - University of Udine - Italy e-mail: michela.mason@uniud.it

- Research fellow - University of Udine - Italy

e-mail: francesco.raggiotto@uniud.it 
can be defined as "total experience" (Lewis and Chambers, 2000). Crafting unique experiences is vital for the success of tourism organizations (Schmitt, 1999).

Indeed, the $A D$ represents a relevant phenomenon concerning new touristic business models focusing on a local, sustainable development, to the benefit of local communities but able to address the changing needs of tourists, in terms, for instance, of increased customer participation and sustainability (Raggiotto et al., 2020). Such new models embed, for instance, values related to the preservation of local communities, heritage and environment, as well as contrasting the overexploitation of places and resources -that characterizes traditional models of touristic development (Loureiro and Gonzalez, 2008).

In this sense, the AD model appears a particularly relevant model, as "is a sustainable model of tourism because it is based on local resources, on awareness of how important it is to preserve and enhance local identity, and also because it combines tourist activities with the growth of the territory and the conservation of the landscape environment" (Cucari et al., 2019, p. 107). In other words, AD is able to enhance, on the one hand, the socioeconomic development of local communities, and on the other hand to deliver unique experiences to the customers.

We aim at developing a study based on a configurational design to conceptualize the AD customers' experience.

We examine the constructs that specifically qualify the AD tourist experience (i.e., place-based elements; satisfaction; green experience quality and authenticity); then, we identify a model aiming to identify the diverse combinations of the above mentioned constructs, influencing tourists' positive Word-of-Mouth (WOM), considering their simultaneous variations.

Our conceptual model is presented in Figure 1.

Fig. 1: Conceptual model

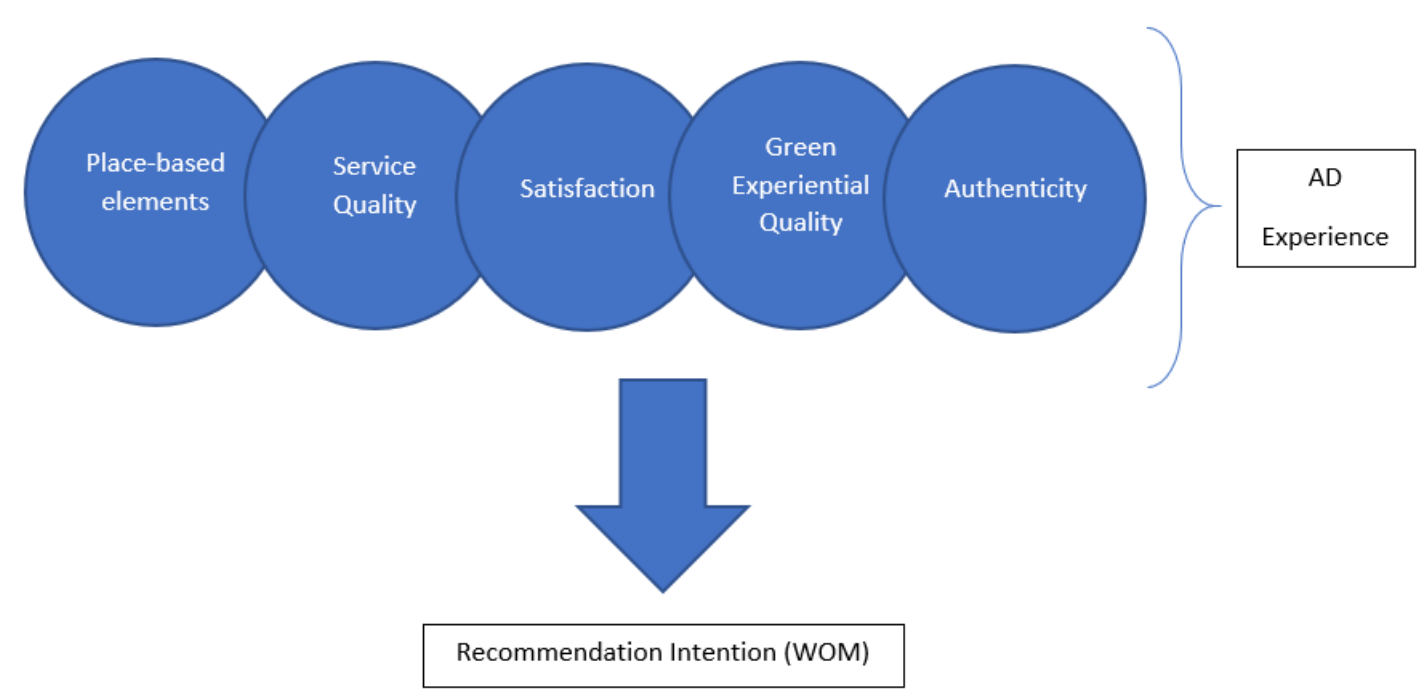

Source: own elaboration

The concept of service quality has received consistent attention in marketing research. Scholars have provided several instruments to assess service quality perceptions, like the SERVQUAL framework (Parasuraman et al., 1988) and the SERVPERF framework (Cronin and Taylor, 1992).

Service quality perception may concern, for instance, technical quality, functional quality, and so forth (Grönroos, 1984), as the ultimate perception of the service is the result of a consumer's view of a bundle of service dimensions, some of which are technical and some of which are functional in nature (Grönroos, 1984, p. 39)

The same concept applies to tourism as well, as touristic products can be seen as bundles of components contributing to the ultimate customer (i.e., tourist experience). Such elements may include, for instance, accommodation, service facilities, leisure opportunities, information sources, and food. In tourism, perceived quality is greatly determined by the process of service delivery (e.g., performance of service personnel) as well as by the service outcomes (e.g., leisure facilities, local accommodation, food, and beverage). Marketing literature has reportedly indicated perceived quality as a key determinant of tourists' post-visit behavior, like, for instance, recommendation intentions and word-of-mouth communication.

In tourism literature, it is recognized that touristic experiences are largely shaped by "place based elements" that refer to what tourists can found in-place: in this sense, the physical space (e.g., natural landscape, local food), the interaction with locals, as well as the availability of services in-place have been identified as key predictors of key outcomes of the touristic experience, like tourists' behavioral intentions.

The physical aspects may encompass, for instance, geographical characteristics of a place, as well as its physical layout and, more broadly, spatial characteristics (Hayllar and Griffin, 2005). These elements are crucial in determining the overall tourist experience, as they can, for instance, motivate tourists, stimulating social interactions, as well as facilitating touristic activities (Cutler and Carmichael, 2010). In the case of the AD model, for instance, the 
architectural peculiarity of the place represents a key differentiating factor of this form of hospitality: tourists can accommodate in ancient buildings, whose structures and spaces have been restored respecting the local tradition and architecture.

In a similar vein, the social environment is another, key determinant of tourism experiences (Selstad, 2007). The social environment encompasses all the possible social and personal interactions tourists can develop while staying at the location (Mossberg, 2007). In this sense, the AD model is designed in such a way to enhance social relationships of tourists with the local community, though, primarily, the interaction with local owners, and through the design of onsite experiences aimed at encouraging encounters between the tourists, the local community and its heritage and culture (Raggiotto et al., 2020).

Arguably, despite such relevant intangible components, touristic products represent, from a marketing perspective, bundles of products and services. in this sense, therefore, a key role in determining the ultimate outcome of the tourist experience is given by the availability, on site, of specific products and services, which may cover a variety of functions (Stamboulis and Skayannis, 2003): for instance, they may provide a key support to the customer experience (e.g., public facilities, logistics, transportation) or reinforce tourists' perceptions during and after the on-site experience: for instance, some studies suggest that the purchase of souvenirs and other symbols of the touristic experience intensify the experience (de Rojas and Camarero, 2008).

Researchers consistently suggest that tourists' evaluations are increasingly shifting towards the sustainability of touristic offerings and of the experiences among which they can choose (Wu and Cheng, 2017). In this sense, environmental sensitivity is a primary driver of tourists' choice: the overall evaluation of touristic experiences is thus influenced by this tourist general orientation, to the point of suggesting that evaluations concerning experiential quality as increasingly focused on the extent to which such experiences are perceived as "green experiential quality" (Wu et al., 2016; Wu and Cheng, 2017). Notably, a major driver distinguishing AD from other forms of hospitality refers, properly, to a model promoting the touristic development to stimulate economic development of local communities in respect respecting the local equilibrium, and promoting a sustainable integration of the touristic experience within local communities (Confalonieri, 2011).

In a similar vein, the concept of authenticity holds a remarkable significance when it comes to consider tourists' experience quality evaluations.

Authenticity concerns the fact that tourists perceive locations, events, and more broadly experiences as genuine (Shen et al., 2014), real (Akhoondnejad, 2016) and adherent to actual history and/or culture (Wang, 1999). Authenticity may encompass multiple facets: in this sense, authenticity can be objective (i.e., concerning how individual see themselves in relation to the external objects (Steiner and Reisinger, 2006), constructive (encompassing socially constructed views of the consumer, the situation and the context (Akhoondnejad, 2016), and existential (focusing on emotions felt during the experience, (Bryce et al., 2014).

Scholars recognize that experience authenticity as a key construct both for theory and practice (Kim and Jamal, 2007); (Scarpi et al., 2019), exerting a key influence in determining key consumer outcomes like revisit intentions (Kolar and Zabkar, 2010), as well as recommending intentions.

Authenticity appears a pervasive determinant of tourists' perceptions: notably, existing conceptualizations have not been able to provide a consistent perspective on the psychological effects of authenticity in touristic settings, with some studies considering it as a direct predictor of satisfaction or revisit intentions (Girish and Chen, 2017); (Ramkissoon et al., 2013), others as an indirect predictor (Kolar and Zabkar, 2010). This heterogeneity in the results of extant research suggests that effects of authenticity on tourists-behavior are likely no to be fixed, and, instead, they are likely to vary according, for instance, to different settings and customer segments.

Finally, satisfaction is key in developing positive word-of-mouth; its effect is stronger as the customer experience exceeds customer expectations. In this sense, if tourists are satisfied of their experience, they may speak positively of a tourist destination to their social circles upon their return (Weaver et al., 2007).

Methodology. The analysis was conducted through an online survey. AD visitors, recruited with the help of owners and local administrators, were invited to answer a Google Modules questionnaire. 300 valid responses were collected.

Place-based elements were adapted from internal factors proposed by Zhonga et al. (2008). Measures for satisfaction were taken from Picón et al. (2014, 3 items); for green experiential quality from Wu and Cheng (2017, 3 items); authenticity was measured with four items, adapted from Akhoondnejad (2016); for word of mouth from $O$ 'Cass and Grace, 2004 (2004, 3 items). Items were measured on a 7-point Likert scale.

Data indicated that respondents were visiting, for the most part, the AD located in the town of Sauris (47\%), Sutrio (47\%), and Comeglians (8\%)

Satisfaction scores 6 or 7 for most respondents (95\%). Regarding Word of Mouth, 97\% of responses present a score of either 6 or 7.

The AD model appears denoted by a high complexity, in that it requires the ability to gather, organize and manage a number of different factors and stakeholder.

It follows that, to identify the key determinants of the touristic experience, the static identification of main effects is unlikely to provide an effective representation of the dynamics occurring between the single variables determining tourists' perceptions. 
In this sense, complexity theory is useful to investigate the relationship among the components of the touristic experience, overcoming the identification of main effects (Russo et al., 2016). Complexity theory focuses on contrarian case analysis, which points out that, given two variables, $X$ and $Y$, even if data may suggest that $X$ positively relates to $Y$, opposite cases may be found in the same dataset: in other words, cases where $X$ and $Y$ are not related at all, or are negatively related (Hsiao et al., 2015).

This suggestion allows for a more insightful perspective of the linkages between dependent and independent variables (Woodside, 2014).

In other words, complexity theory suggests that the same outcome (positive recommendation in this case) may derive from different possible combinations of the same indicators. This suggestion is grounded in the complexity which characterizes the relationships between dependent and independent variables, so that there is the possibility that relationships change basing on different configurations. In this sense, variables may interact without the constraint

of limited, unique situations, with their relationships being not necessarily linear (Woodside, 2014). Hence, complexity theory appears particularly solid tool for assessing the relationship between the dependent and independent variables, by accounting for dynamic and complex relationships.

Thus, to address our research objective, we aim to develop a study applying the a qualitative comparative analysis (QCA) (Chang et al., 2013; Wu et al., 2014); it is a method that uses Boolean algebra rules to identify the possible combinations of the selected attributes, and whether such attributes work as sufficient or necessary conditions for a given outcome (Fiss, 2011).

Preliminary Findings. In summer 2019, we conducted a research aiming at analyzing our specific constructs (i.e., green experiential quality, authenticity, satisfaction, service quality and place-based elements) within the context of the AD experience.

$75 \%$ of responses was satisfied regarding specific place-based elements, and particularly, those concerning local heritage and culture (e.g., food) as well as the natural setting. Oppositely, only $10 \%$ of respondents is satisfied with regards to infrastructural services offered by the place, like for instance public facilities (e.g., roads) as well as logistics.

With respect to Green Experience Quality, 97\% of respondents provide a positive evaluation of Green Service Quality (scoring either 6 or 7), also if compared to other, more traditional forms of tourist accommodation.

Finally, 96\% of the sample perceived authenticity as highly authentic (scoring either 6 or 7), especially with regards to the interaction with local people, culture, and activities.

Using the IBM SPSS program (v25) we performed a confirmatory factor analysis (CFA) on the data we collected. Table 1 reports the results of the CFA. Convergent validity of the constructs is supported, with composite reliability $(C R)$ and the average variance extracted (AVE) scoring higher than the recommended thresholds $(0.5$ and 0.7 respectively) (Fornell and Larcker, 1981).

Tab. 1: Title

\begin{tabular}{|l|l|l|l|l|}
\hline & Factor Loadings & AVE & CR & Chronbach's Alfa \\
\hline Satisfaction (SAT) & & & & .96 \\
\hline SAT01 & .86 & .90 & .74 & \\
\hline SAT02 & .85 & & & \\
\hline SAT03 & .87 & & & \\
\hline Green experiential quality (GEQ) & & & & .85 \\
\hline GEQ01 & .63 & .51 & .73 & \\
\hline GEQ02 & .63 & & & \\
\hline GEQ03 & .79 & & & \\
\hline Authenticity (AUT) & & & & .84 \\
\hline AUT01 & .85 & .52 & .81 & \\
\hline AUT02 & .71 & & & \\
\hline AUT03 & .61 & & & \\
\hline AUT04 & .68 & & & \\
\hline Word of Mouth (WOM) & & & & .70 \\
\hline WOM01 & .65 & .51 & .71 & \\
\hline WOM02 & .70 & & & \\
\hline WOM03 & .51 & & & \\
\hline
\end{tabular}

Source: our elaboration

Originality of the study. To understand the complexity of touristic experiences, it appears increasingly necessary to test an integrated model of explanatory constructs. 
Thus, after a preliminary analysis in which we identified the constructs (i.e., green experiential quality, authenticity, satisfaction, service quality and place-based elements) of the AD customers' experience and we confirmed their structure through CFA, the study will investigate these aforementioned constructs in accounting for tourists' recommending intentions, by employing a configuration design based on qualitative comparative analysis (QCA).

This will contribute to a better understanding of the future intention of the tourists after their AD experience.

Key words: Albergo diffuso; tourism; tourist experience

\section{References}

AKHOONDNEJAD A. (2016), "Tourist loyalty to a local cultural event: The case of Turkmen handicrafts festival", Tourism Management, vol. 52, n. March, pp. 468-477.

BLOOMBERG. (2018), "Is Your Town Nearing Extinction? Try Turning It Into a Resort", available at: https://www.bloomberg.com/news/features/2018-09-20/from-italy-to-japan-alberghi-diffusi-are-saving-dyingvillages (accessed 10 May 2020).

BRYCE D., CURRAN R., O'GORMAN K. TAHERI B. (2014), "Visitors' engagement and authenticity: Japanese heritage consumption", Tourism Management, vol. 46, n. 46, pp. 571-581.

CHANG C.W., TSENG T.H., G. WOODSIDE A. (2013), "Configural algorithms of patient satisfaction, participation in diagnostics, and treatment decisions 'influences on hospital loyalty", Journal of Services Marketing, vol. 27, n. 2, pp. 91-103.

CONFALONIERI M. (2011), “A typical Italian phenomenon: The "albergo diffuso"”, Tourism Management, vol. 32, n. 3 , pp. 685-687.

CRONIN J.J., TAYLOR S.A. (1992), "Measuring Service Quality: A Reexamination and Extension”, Journal of Marketing, vol. 56, n. 3, p. 55 .

CUCARI N., WANKOWICZ E., ESPOSITO DE FALCO S. (2019), "Rural tourism and Albergo Diffuso: A case study for sustainable land-use planning", Land Use Policy, Elsevier, vol. 82, pp. 105-119.

CUTLER S.Q., CARMICHAEL B.A. (2010), "Chapter 1. The Dimensions of the Tourist Experience", in Morgan, M., Lugosi, P., Ritchie, J.R.B. (Eds.), The Tourism and Leisure Experience, vol. 44, Multilingual Matters, Bristol, Blue Ridge Summit, pp. 3-26.

FISS P.C. (2011), "Building Better Causal Theories: A Fuzzy Set Approach to Typologies in Organization Research", Academy of Management Journal, Academy of Management Briarcliff Manor, NY, vol. 54, n. 2, pp. 393-420.

FORNELL C., LARCKER D.F. (1981), "Evaluating Structural Equation Models with Unobservable Variables and Measurement Error", Journal of Marketing Research, vol. 18, n. 1, pp. 39-50.

GIRISH V.G., CHEN C.F. (2017), “Authenticity, experience, and loyalty in the festival context: Evidence from the San Fermin festival, Spain", Current Issues in Tourism, Taylor \& Francis, pp. 1-6.

GRÖNROOS C. (1984), “A Service Quality Model and its Marketing Implications”, European Journal of Marketing, vol. 18 , n. 4 , pp. $36-44$.

HAYLLAR B., GRIFFIN T. (2005), “The precinct experience: a phenomenological approach”, Tourism Management, Elsevier, vol. 26, n. 4, pp. 517-528.

HIRSCHMAN E.C., HOLBROOK M.B. (1982), "Hedonic Consumption: Emerging Concepts, Methods and Propositions", Journal of Marketing, vol. 46, n. 3, p. 92.

HSIAO J.P.H., JAW C., HUAN T.C. WOODSIDE A.G. (2015), “Applying complexity theory to solve hospitality contrarian case conundrums", International Journal of Contemporary Hospitality Management, vol. 27, n. 4, pp. 608-647.

KIM H., JAMAL T. (2007), “Touristic quest for existential authenticity”, Annals of Tourism Research, vol. 34, n. 1, pp. $181-201$

KOLAR T., ZABKAR V. (2010), “A consumer-based model of authenticity: An oxymoron or the foundation of cultural heritage marketing?", Tourism Management, vol. 31, n. 5, pp. 652-664.

LEWIS R.C., CHAMBERS R.E. (2000), Marketing Leadership in Hospitality, Wiley.

LOUREIRO S.M.C., GONZALEZ F.J.M. (2008), "The importance of quality, satisfaction, trust, and image in relation to rural tourist loyalty", Journal of Travel and Tourism Marketing, vol. 25, n. 2, pp. 117-136.

MOSSBERG L. (2007), "A Marketing Approach to the Tourist Experience", Scandinavian Journal of Hospitality and Tourism, vol. 7, n. 1, pp. 59-74.

O'CASS A., GRACE D. (2004), "Exploring consumer experiences with a service brand", Journal of Product \& Brand Management, vol. 13, n. 4, pp. 257-268.

PANICCIA P.M.A., LEONI L. (2017), "Co-evolution in tourism: the case of Albergo Diffuso", Current Issues in Tourism, vol. 0, n. 0, pp. 1-28.

PICÓN A., CASTRO I., ROLDÁN J.L. (2014), "The relationship between satisfaction and loyalty: A mediator analysis", Journal of Business Research, vol. 67, n. 5, pp. 746-751.

PRESENZA A., MESSENI PETRUZZELLI A., SHEEHAN L. (2019), "Innovation trough tradition in hospitality. The Italian case of Albergo Diffuso”, Tourism Management, vol. 72, n. November 2018, pp. 192-201. 
RAGGiOTTO F., COMPAGNO C., MASON M.C. (2020), "Place-Based Business Models of Value Creation in Tourism: Case of the Albergo Diffuso", in Dixit, S.K. (Ed.), The Routledge Handbook of Tourism Experience Management and Marketing, Routledge, London, available at:https://doi.org/10.4324/9780429203916.

RAMKISSOON H., SMITH L.D.G., WEILER B. (2013), "Testing the dimensionality of place attachment and its relationships with place satisfaction and pro- environmental behaviours: a structural equation modelling approach", Tourism Management, vol. 36, June, pp. 552-566.

DE ROJAS C., CAMARERO C. (2008), "Visitors' experience, mood and satisfaction in a heritage context: Evidence from an interpretation center", Tourism Management, vol. 29, n. 3, pp. 525-537.

ROMOLINI A., FISSI S., GORI E. (2017), "Integrating territory regeneration, culture and sustainable tourism. The Italian albergo diffuso model of hospitality", Tourism Management Perspectives, vol. 22, April, pp. 67-72.

RUSSO I., CONFENTE I., GLIGOR D.M., AUTRY C.W. (2016), "To be or not to be (loyal): Is there a recipe for customer loyalty in the B2B context?", Journal of Business Research, vol. 69, n. 2, pp. 888-896.

SCARPI D., MASON M., RAGGIOTTO F. (2019), "To Rome with love: A moderated mediation model in Roman heritage consumption", Tourism Management, vol. 71, n. September 2017, pp. 389-401.

SCHMITT B.H. (1999), "Experiential marketing”, How To Get Customers To Sense, Feel, Think, Act, and Relate To Your Company and Brands, pp. XIX, 280.

SELSTAD L. (2007), "The Social Anthropology of the Tourist Experience. Exploring the "Middle Role", Scandinavian Journal of Hospitality and Tourism, vol. 7, n. 1, pp. 19-33.

SHEN S., GUO J., WU Y. (2014), "Investigating the Structural Relationships among Authenticity, Loyalty, Involvement, and Attitude toward World Cultural Heritage Sites: An Empirical Study of Nanjing Xiaoling Tomb, China", Asia Pacific Journal of Tourism Research, vol. 19, n. 1, pp. 103-121.

STAMBOULIS Y., SKAYANNIS P. (2003), "Innovation strategies and technology for experience-based tourism", Tourism Management, vol. 24, n. 1, pp. 35-43.

STEINER C.J., REISINGER Y. (2006), “Understanding existential authenticity”, Annals of Tourism Research, vol. 33, n. 2, pp. 299-318.

TOSON C. (2014), Il Racconto Dell'Albergo Diffuso: 1978-2014, CreateSpace Independent Publishing Platform.

WANG N. (1999), "Rethinking authenticity in tourism experience", Annals of Tourism Research, vol. 26, n. 2, pp. 349370.

WEAVER P.A., WEBER K., MCCLEARY K.W. (2007), "Destination Evaluation: The Role of Previous Travel Experience and Trip Characteristics", Journal of Travel Research, vol. 45, n. 3, pp. 333-344.

WILliAMS G. (2010), "Saving Towns by Filling Rooms in Italy", The New York Times, available at: https://www.nytimes.com/2010/05/23/travel/23journeys.html.

WOODSIDE A.G. (2014), "Embrace•perform•model: Complexity theory, contrarian case analysis, and multiple realities", Journal of Business Research, vol. 67, n. 12, pp. 2495-2503.

WU H.C., AI C.H., CHENG C.C. (2016), "Synthesizing the effects of green experiential quality, green equity, green image and green experiential satisfaction on green switching intention”, International Journal of Contemporary Hospitality Management, vol. 28, n. 9, pp. 2080-2107.

WU H.C., CHENG C.C. (2017), "What drives green advocacy? A case study of leisure farms in Taiwan", Journal of Hospitality and Tourism Management, vol. 33, pp. 103-112.

WU P.L., YEH S.S., HUAN T.C., WOODSIDE A.G. (2014), “Applying complexity theory to deepen service dominant logic: Configural analysis of customer experience-and-outcome assessments of professional services for personal transformations", Journal of Business Research, vol. 67, n. 8, pp. 1647-1670.

YUAN Y.H.E., WU C.K. (2008), "Relationships Among Experiential Marketing, Experiential Value, and Customer Satisfaction”, Journal of Hospitality and Tourism Research, vol. 32, n. 3, pp. 387-410.

ZHONG L., DENG J., XIANG B. (2008). "Tourism development and the tourism area life-cycle model: A case study of Zhangjiajie National Forest Park, China", Tourism Management, vol. 29, n. 5, pp. 841-856 


\title{
Transgenerational succession in long standing family firms: the "Huey, Dewey and Louie" pattern
}

\author{
ELISA CONZ ${ }^{*}$ GIOVANNA MAGNANI*
}

\begin{abstract}
The aim of this "work in progress" is to analyse the transgenerational succession of a century old family firm from an entrepreneurial perspective, through an inductive single case study of the luxury textile company Reda 1865. We explore transgenerational entrepreneurship in what we call the "Huey, Dewey and Louie" succession pattern of the Botto Poala family: from incumbents - the uncles - to successors - the cousins. In doing so, we uncover a succession pattern characterised by an "uncle-nephew" mentoring relationship - instead of the traditional parent-child one and contribute to the family business literature on succession and transgenerational entrepreneurship by showing how this pattern ensures conflict management and nurtures transgenerational entrepreneurship enabling continuity and growth of the firm over time.
\end{abstract}

Objectives. Huey, Dewey and Louie are three characters of the Disney's Duck universe. They are three twins, that belong to the McDuck family, as they are sons of Della Duck, a minor character in the series, nephews of Donald Duck and grandnephews of Scrooge McDuck. In the original comic Huey, Dewey and Louie end up living with Donald Duck, their uncle and legal guardian. Uncle Donald raises Huey, Dewey and Louie as if they were his sons, creating strong uncle - nephew family ties.

Furthermore, the mentoring relationship between the nephews and Uncle Donald evolves with time: when they are adopted, the three are undisciplined and unruly, while during the novel their behaviour improves for better and the relationship with the uncle transforms into an opportunity of personal growth.

Like Huey, Dewey and Louie, Ercole, the chief executive officer, Francesco, the chief operating officer, Fabrizio, the purchasing manager, and Guglielmo, the export manager, are four cousins of the Botto Poala's family, that is currently owning and managing Reda 1865 - a century old Italian family firm, operating in the textile industry. The cousins -the fourth generation of the family - as in the Disney's comics, have been trained by their uncles - and not by their parents as in traditional parent-child mentoring relationships in family businesses (Eddleston and Kidwell, 2012) - to manage the firm, since they were adolescents. Moreover, Reda is a peculiar and interesting case explaining as nontraditional mentoring relationship, i.e. the uncle-nephew, as alternative - yet successful - succession pattern.

As we describe through our case study, the family's succession strategy chosen and developed by its third generation is peculiar. The penultimate generation of owners - cousins' parents - was made of seven brothers: three of them decided to get out of the business, while the remaining four, managed the family business succession by selecting only one successor each who had to belong to the next generation. This means that each parent chose only one son as his/her heir and liquidated the other brothers with company shares.

By addressing the research question: how does an uncle-nephew relationships (UNR) enable transgenerational succession in family firms?, this study provides empirical evidence on transgenerational succession in family firms, adding to the little knowledge about how intra-family business ownership and management succession take place and how incumbent and successors interact (Long and Chrisman, 2014). We will also contribute to uncovering the complexity of social relationships in family firms as highlighted by influential scholars in the field (Chrisman et al., 2003; Eddleston and Kidwell, 2012; Grote, 2003; Zellweger et al.,, 2019), thanks to the investigation of a peculiar succession pattern characterised by an uncle-nephew relationship.

The extended abstract is structured as follows: we first introduce extant research on parental relationships, succession and transgenerational entrepreneurship in family business studies; than we illustrate the methodology we will use to investigate the nephew-uncle succession pattern in Reda Last, we present expected findings.

Theoretical Framework

Parental relationships in family businesses

Parental relationships are key to the family business literature (Miller et al., 2003). Scholars have investigated the facets of parent-child relationships (Eddleston and Kidwell, 2012) through the lenses of the two most influential

\footnotetext{
Assistant Professor of Marketing - University of Pavia - Italy

e-mail: elisa.conz@unipv.it

- Assistant Professor of Business Management - University of Pavia - Italy

e-mail: giovanna.magnani@unipv.it
} 
theories in family firms' studies i.e. agency theory and stewardship theory (Verbeke and Kano, 2012). Both theories are central to understanding succession in family firms. Whereas agency theory assumes opportunistic behaviours by children in the firm (e.g. Eddleston and Kellermanns, 2007; Zahra, 2008), stewardship theory emphasises proorganizational and cooperative involvement in the firm (Schulze et al., 2001). Research has been advanced to understand family firm succession by looking at successors being either stewards or deviants i.e. by focusing at their behaviours as either committed to pro-firm or anti-firm (Eddleston and Kidwell, 2012), thus emphasising that parental relationships as highly critical factor in the succession and, then, performance of the firm over time.

Within the Family Business literature, parental relationships have been investigated as one of most critical factors of a family firm's continuity: in fact, family businesses are inherently characterised by relational conflict (Harvey and Evans, 1994). Therefore, managing conflict is important to the success of the family firm (Eddleston and Kellermanns, 2007), because relationship conflict can determine poor performance in family firms (Beckhard and Gibb Dyer, 1983; Danes et al.,, 1999). However, not all family firms fail to manage conflict: some family firms that are successfully transitioning from one generation to the other can prompt the continuity of the firm (Ibrahim et al., 2009). Stewardship theory suggests that mutually trusting relationships increase pro-organizational behaviours and firm performance (Corbetta and Salvato, 2004; Davis et al.,, 1997). In particular, it has been argued that altruism, participative strategy process and control concentration are key resources to manage conflict and contribute to firm continuity and performance (Eddleston and Kellermanns, 2007). Our case is representative of a family business that has been able to positively manage conflict and successfully achieve transgenerational succession.

\section{Succession and transgenerational entrepreneurship}

Succession is one on the most debated topic in family business literature, but as argued by Long and Chrisman (2014) it still lacks of theoretical coherence, in particular they underline the need of explaining the "how" of family business succession and to apply a multi-level perspective to explore succession "as a process". The underlying assumption in the processual view is that succession might be considered as a long term process rather than a single event, characterized by four stages: a) owner management, b) training/development, c) cross-generational partnership and d) transfer power (Handler, 1994).

Family businesses transgenerational succession are usually characterised by a relationship "parent-son" that involves training the son so that (s)he can successfully hand down the business' (Eddleston and Kidwell, 2012).

Exploring succession from an entrepreneurial perspective, we can define succession as a transgenerational entrepreneurial process in which "new owners, from within or outside the owner family, enter the business as owners and add new capital and resources that have consequences for firm processes and outcomes such as innovation, entrepreneurial orientation and growth" ((Nordqvist et al., 2013: 1090). This definition is consistent with the concept of transgenerational entrepreneurship, defined by Habbershon and Pistrui (2002:1) as "the process through which a family uses and develops entrepreneurial mindsets and family influenced resources and capabilities to create new stream of entrepreneurial, financial and social value across generations".

There is now agreement that family businesses are entrepreneurial (Habbershon and Pistrui, 2002; D. Miller and Le Breton-Miller, 2005; Nordqvist and Melin, 2010; Sieger et al.,, 2011). Nonetheless, how families nurture entrepreneurship across generations remains a major theoretical gap (Baù, Hellerstedt et al.,, 2013; Jaskiewicz et al., 2015; Nordqvist et al., 2013). Despite succession is one on the most debated topic in family business literature, it still lacks theoretical coherence (Long and Chrisman; 2014). In fact, succession research describes processes and family attributes that characterize successful transfer of ownership and control (e.g. Breton-Miller et al., 2004; Handler, 1994), but does not explain how succession can be performed to ensure that successors have the motivation and ability to act entrepreneurially (Jaskiewicz et al., 2015).

By acting entrepreneurially - i.e., being among the first to introduce new products and services, enter new markets, or adopt innovative new technologies or production processes some family firms do, however, engage in transgenerational entrepreneurship wherein they act entrepreneurially and do so across multiple family generations (ibid). However, only one theory to date (ibid) explains how these families nurture transgenerational entrepreneurship.

We contend the generalisability of results, providing a case in which the activity of strategic succession is put in practice in a completely different way. The Reda case is an intriguing and successful example of transgenerational entrepreneurship in which the older generation permitted siblings buyouts and did not integrate potential in-laws into the family.

Furthermore, a few researches have investigated other types of relations such as involving cousins, nephews, uncles. The empirical study which is presented hereafter contributes to the study of uncle-nephew relationship as a successful succession pattern nurturing transgenerational entrepreneurship.

Methodology. We propose an inductive inquiry to investigate the research issue (Glaser, 2004), carried out through a qualitative in depth single case study (Yin, 2014). Consistent with previous research on the factors enabling the nurturing of transgenerational entrepreneurship (Jaskiewicz et al., 2015) we chose a micro-level inductive and interpretive approach. This approach best suits our need to investigate member behaviours across different generations.

\section{Selection of the company object of study}

Reda 1865 represents a single significant case that offers "rich and deep understanding of the subject...and has distinct, stand-out importance" (Patton, 2014: 266), which for this study lies first in the uniqueness of mode followed for the selection of the heir and, secondly, in the knowledge transfer process in the relationship nephew-uncle. 
The cousins represent the 4th generation of the Botto Poala family, a long-standing textile company, 100\% family owned and based in Biella, in the north-west of Italy. Reda 1865 is internationally-oriented firm, exporting to various markets such as the United States, European, Asian and Middle Eastern, supplying fabric luxury brands in the fashion industry as Giorgio Armani, Gucci, Tom Ford and Hugo Boss with an annual turnover of almost \$140 million in 2017 (Source: Orbis Van Djik, 2019). The cousins, started in their boyhood when they were 14 old to work during summer holidays, each year changing division and trained by one uncle and not by their father. This peculiar succession methodology was chosen by the "uncles" to avoid the emotional involvement in the relationship father-son. For instance, Ercole was trained by his uncle in the financial area. In 2005 - when the cousins were all in their 35-40 - each parent choose one son and the four cousins took over the management and the ownership of the business. The dominant coalitions retired maintaining only a shareholder position and, as Ercole said: "for one year we never saw them in the plant" (Exitu, 2017).

Reda's unicum is the type of succession adopted to guarantee business survival and profitability, as well as the goals driving the succession. Specifically, the case offers an insightful perspective on transgenerational succession as a process where incumbent-successor relationships diverge from the traditional father-son model, influenced by a long term bond that might negatively affect the transaction and the family harmony (Cabrera-Suárez, 2005). Indeed, the uncle-nephew relationship provides an example of rational knowledge transfer in the incumbent-successor relation, since its choice helps avoiding the ambivalence generated by the father-son mentoring relationship (ibid).

In addition, the "Huey, Dewey and Louie" succession pattern represents a case of opportunity creation that overcomes the dominant intrafirm succession approach to explain longevity - mostly focused on familiar, social, managerial, cultural factors preventing family succession (De Massis et al., 2008; D. Miller and Le Breton-Miller, 2005; D. Miller et al., 2003).

The case explain transgenerational entrepreneurship in the succession in family firms (Nordqvist et al., 2013), where management and ownership transition represent the medium to pursue new business opportunities. Indeed, the entrance of the cousins fostered change, entrepreneurial development and growth of the family business $(+44 \%$ in the time range 2008-2017), differentiating the business model - i.e. creating a luxury sport and urban outdoor collection, Rewoolution - or investing in start-ups and new ventures (i.e. textile e-commerce Lanieri).

In Reda's succession pattern, to avoid conflicts in the mentoring relationship parent-son and to guarantee a successful succession, the training program was planned by assigning each nephew to his uncle. As Ercole reported in a recent interview: "... as Donald Duck has been raised by his uncle Scrooge McDuck, each of us has been trained by one uncle"; and on the succession process he asserted: "We decided to change the rules even if it was not a painless process, but we did it for the company, to let the succession worked out" (Data Stampa, 2018).

\section{Data collection}

We collected data triangulating (Janesick, 1994) two main sources of information: semi-structured interviews and written and electronic documentation. We conducted 10 in-depth interviews - two interviews for each cousins, two with the wife of one uncle - with highly knowledgeable informants (Eisenhardt and Graebner, 2007). Uncles are all alive but in their late 80s or early 90s, so we considered to not interviewing them to avoid the risk of "biased information" in their retrospective reconstruction of the events.

First author's personal relationship with members of the Botto Poala family has been crucial to gather access to informants and in obtaining reliable data. We plan to collect more primary data through multiple semi-structured interviews with the four cousins as well as their relatives. Interviews we already performed lasted on average 60-90 minutes. The interview protocol was almost standardized across informants. Interviews were co-conducted by the two researchers and, on average, last from one to two hours. We guided the interviews by structuring them in two steps. We began by asking the informants to illustrate the history of the firm. A second set of questions was designed to track the succession dynamics and how the mentoring relationship uncle-nephew took place. In order to reduce retrospective bias we asked informants to stick to specific behaviors and facts (Bingham and Eisenhardt, 2011; C. C. Miller, Cardinal, and Glick, 1997). We at the same time managed the possible social desirability bias by maintaining a neutral tone when reacting to respondents' narratives.

All interviews have been recorded on a digital device and then transcribed and compared to researchers' handwritten field notes. Within 24 hours after the interviews we mailed the transcripts to our informants and asked them to amend any inconsistency, and to complete missing data. Both researchers transcribed the interviews and confronted each other's transcripts. Furthermore, in order to increase the trustworthiness of our data we used a qualitative data management and coding software. Interviews, their transcripts, and the very first conceptual analysis have been undertaken in the native language of the respondents. Interviews transcripts have then been analyzed, schematized and conceptualized in English language. This method enables the avoidance of any translation bias. Apart from structured interviews, we collected documental data through company reports, press releases, books and papers containing companies' analyses.

\section{Data analysis}

In line with a grounded theory approach to data analysis, we follow the so-called "Gioia method" (cf. Corley and Gioia, 2004; Gioia et al., 2013) to both analyze the data and present our findings. This method aims to provide closeness to so-called "first order" participant perspectives, and yet to add the authors' "second-order", interpretations of these perspectives distilled into a set of inter-related overarching categories or themes that resonate with both participants and readers, and yet communicate new insight" (Langley and Abdallah, 2011: 2013). We first proceed by developing the open coding (i.e. the 1st level analysis, or "conceptual coding") where we let emerging 
codes that are skin linked to the informant (Corbin and Strauss, 1990). Both researchers independently coded the interviews transcripts and afterwards met to compare each other's codes. A set of codes was agreed based on a discussion undertaken by the two researchers and the third independent one who was asked to provide a neutral advice. Then, looking at similarities and differences among the open codes - we aggregate the 1st level themes into more abstract 2 nd order themes (i.e. "axial coding”) (cf. Gioia et al., 2010). In line with the grounded theory approach, 2nd order themes are developed through the constant comparison between emerging patterns, relationships, and extant theory (Shepherd and Sutcliffe, 2011) "going back and forth" between cases evidence, emerging patterns, and existing theory. Last, we collapsed 2nd order themes into "overarching aggregate dimensions" (Gioia et al., 2010) to facilitate the presentation of our emergent model.

Findings. We expect that our empirical findings will add to recent studies in the field (Jaskiewicz et al., 2015) about transgenerational succession and entrepreneurship a model that explains the "Huey, Dewey and Louie" succession pattern through i) the practice of resilience - i.e. the capacity to self-renew the business over time despite changes, ii) the creation of new business opportunities that is enhanced by the "perceived freedom" of the cousins that feel free to operate and innovate the business, not perceiving parental control on them iii) the calibration of rationality and emotions in managing business and family interests, during and after the succession, to preserve the family and business harmony and ensuring management of conflicts. These three activities - that characterize a successful transgenerational succession pattern - enable the entrepreneurial continuity of the business.

Proposition 1: The uncle-nephew relationship (UNR) contributes to avoid deviance behaviours in the family firm, through avoiding any favouritism in the selection of managerial responsibilities among family members.

Proposition 2a: The UNR enables the continuity of the firm.

Proposition 2b: The UNR enables product innovation within the firm.

Proposition 3. The UNR contributes to the resilience of the firm, by enhancing the development of incumbents' capabilities to manage and adapt to change.

Originality of the study. Our findings will add to family business literature on transgenerational succession explaining how the uncle-nephew succession pattern allows the family to effectively transfer the business from one generation to another, via establishing objective criteria for the selection and the training of its successor/s (De Massis et al., 2008). This non-traditional succession pattern contributes to the enduring growth of the firm, while at the same time ensuring the management of conflicts and rivalry typical of family businesses (Grote, 2003). Thanks to an inductive single case study following best practices in grounded research (Gioia, Corley, and Hamilton, 2013), we will explain how this alternative succession type also enhances the continuity of the family business, as it enables the adaptation to external chancing circumstances. Moreover, the case contributes to expand extant knowledge on transgenerational entrepreneurship (Jaskiewicz et al., 2015), contextualising the behaviour of entrepreneurial family families during succession processes. Summarising, through exploring last transgenerational succession dynamics of the Botto Poala family, the present study aims to contribute to research in FB literature i) exploring the "Huey, Dewey and Louie" succession type as an entrepreneurial process to successfully manage intra-family succession; ii) analysing the incumbent-successor relation in the form of uncle-nephew; iii) providing empirical evidence on transgenerational entrepreneurship in family firms.

Key words: succession; transgenerational entrepreneurship; opportunities; mentoring, family relationships

\section{References}

BAÙ M., HELLERSTEDT K., NORDQVIST M., WENNBERG K. (2013), "Succession in family firms", in Sorenson R.L., Yu A., Brigham K.H., Lumpkin G.T. (eds.) The landscape of family business", Edward Elgar Publishing. pp. 167-197.

BECKHARD R., GIBB DYER W. (1983), "Managing continuity in the family-owned business", Organizational Dynamics, vol. 12, n. 1, pp. 5-12.

BINGHAM C.B., EISENHARDT K.M. (2011), "Rational heuristics: the 'simple rules' that strategists learn from process experience”, Strategic Management Journal, vol. 32, n. 13, pp. 1437-1464.

BRETON-MILLER I.L., MILLER D., STEIER L.P. (2004), "Toward an Integrative Model of Effective FOB Succession", Entrepreneurship Theory and Practice, vol. 28, n. 4, pp. 305-328.

CABRERA-SUÁREZ K. (2005), "Leadership transfer and the successor's development in the family firm", The Leadership Quarterly, vol. 16, n. 1, pp. 71-96.

CHRISMAN J.J., CHUA J.H., STEIER L.P. (2003), An introduction to theories of family business, Citeseer.

CORBETTA G., SALVATO C. (2004), "Self-serving or self-actualizing? models of man and agency costs in different types of family firms: a commentary on 'comparing the agency costs of family and non-family firms: conceptual issues and exploratory evidence”, Entrepreneurship Theory and Practice, vol. 28, n. 4, pp. 355-362.

CORBIN J.M., STRAUSS A. (1990), "Grounded theory research: Procedures, canons, and evaluative criteria", Qualitative Sociology, vol. 13, n. 1, pp. 3-21. 
CORLEY K.G., GIOIA D.A. (2004), "Identity ambiguity and change in the wake of a corporate spin-off", Administrative Science Quarterly, vol. 49, n. 2, pp. 173-208.

DANES S.M., ZUIKER V., KEAN R., ARBUTHNOT J. (1999), "Predictors of family business tensions and goal achievement", Family Business Review, vol. 12, n. 3, pp. 241-252.

DATA STAMPA. (2018, May 7), "Per noi il modello è Walt Disney: solo zii'. La svolta di Reda campione del tessile"; Retrieved from http://www.daily-press.it/ConfartigianatoFvg/PDF/2018/2018-05-07/2018050738978302.pdf

DAVIS J.H., SCHOORMAN F.D., DONALDSON L. (1997), "Davis, Schoorman, and Sonaldson reply: the distinctiveness of agency theory and stewardship theory", The Academy of Management Review, vol. 22, n. 3, pp. 611-613.

DE MASSIS A., CHUA J.H., CHRISMAN J.J. (2008), "Factors preventing intra-family succession", Family Business Review, vol. 21, n. 2, pp. 183-199.

EDDLESTON K.A., KELLERMANNS F.W. (2007), "Destructive and productive family relationships: A stewardship theory perspective", Journal of Business Venturing, vol. 22, n. 4, pp. 545-565.

EDDLESTON K.A., KIDWELL R.E. (2012), "Parent-child relationships: planting the seeds of deviant behavior in the family firm", Entrepreneurship Theory and Practice, vol. 36, n. 2, pp. 369-386.

EISENHARDT K.M., GRAEBNER M.E. (2007), "Theory building from cases: Opportunities and challenges", Academy of Management Journal, vol. 50, n. 1, pp. 25-32.

EXITU E. (2017, July 13), "Ero un bimbominkia, eppure mio padre e mio zio hanno creduto in me", Retrieved from https://www.ilfoglio.it/economia/2017/07/13/news/ero-un-bimbominkia-eppure-mio-padre-e-mio-zio-hannocreduto-in-me-144354/

GIOIA D.A., CORLEY K.G., HAMILTON A.L. (2013), "Seeking qualitative rigor in inductive research notes on the Gioia methodology", Organizational Research Methods, vol. 16, n. 1, pp. 15-31.

GIOIA D.A., PRICE K.N., HAMILTON A.L., THOMAS J.B. (2010), "Forging an identity: an insider-outsider study of processes involved in the formation of organizational identity", Administrative Science Quarterly, vol. 55, n. 1, pp. 1-46.

GLASER B.G. (2004), “Naturalist inquiry” and grounded theory”, Forum Qualitative Sozialforschung / Forum: Qualitative Social Research, vol. 5, n. 1.

GROTE J. (2003), "Conflicting generations: A new theory of family business rivalry", Family Business Review, vol. 16, n. 2, pp. 113-124.

HABBERSHON T.G., PISTRUI J. (2002), "Enterprising Families Domain: Family-Influenced Ownership Groups in Pursuit of Transgenerational Wealth", Family Business Review, vol. 15, n. 3, pp. 223-237.

HANDLER W.C. (1994), "Succession in Family Business: A Review of the Research", Family Business Review, vol. 7, n. 2, pp. 133-157.

HARVEY M., EVANS R.E. (1994), "Family Business and Multiple Levels of Conflict”, Family Business Review, vol. 7, n. 4, pp. 331-348.

IBRAHIM A.B., MCGUIRE J., SOUFANI K. (2009), “An empirical investigation of factors contributing to longevity of small family firms", Global Economy \& Finance Journal, vol. 2, n. 2, pp. 1-21.

JANESICK V.J. (1994), "The dance of qualitative research design: Metaphor, methodolatry, and meaning", in Handbook of qualitative research (pp. 209-219). Thousand Oaks, CA, US: Sage Publications, Inc.

JASKIEWICZ P., COMBS J.G., RAU S.B. (2015), "Entrepreneurial legacy: Toward a theory of how some family firms nurture transgenerational entrepreneurship", Journal of Business Venturing, vol. 30, n. 1, pp. 29-49.

LANGLEY A., ABDALLAH C. (2011), "Templates and Turns in Qualitative Studies of Strategy and Management", in Bergh D.D., Ketchen D.J. (Eds.), Research Methodology in Strategy and Management (Vol. 6, pp. 201-235).

LONG R.G., CHRISMAN J.J. (2014), "Management Succession in Family Business". In The SAGE Handbook of Family Business (pp. 249-268).

MILLER C.C., CARDINAL L.B., GLICK W.H. (1997), "Retrospective Reports In Organizational Research: A Reexamination Of Recent Evidence", Academy of Management Journal, vol. 40, n. 1, pp. 189-204.

MILLER D., LE BRETON-MILLER I. (2005), Managing for the long run: Lessons in competitive advantage from great family businesses, Harvard Business School Press, Boston.

MILLER D., STEIER L., LE BRETON-MILLER I. (2003), "Lost in time: intergenerational succession, change, and failure in family business", Journal of Business Venturing, vol. 18, n. 4, pp. 513-531.

NORDQVIST M., MELIN L. (2010), "Entrepreneurial families and family firms", Entrepreneurship \& Regional Development, vol. 22, n. 3-4, pp. 211-239.

NORDQVIST M., WENNBERG K., BAU’ M., HELLERSTEDT K. (2013), “An entrepreneurial process perspective on succession in family firms. Small Business Economics”, vol. 40, n. 4, pp. 1087-1122.

PATTON M.Q. (2014), Qualitative Research \& Evaluation Methods, Palgrave.

SCHULZE W.S., LUBATKIN M.H., DINO R.N., BUCHHOLTZ A.K. (2001), "Agency Relationships in Family Firms: Theory and Evidence", Organization Science, vol. 12, n. 2, pp. 99-116.

SHEPHERD D.A., SUTCLIFFE K.M. (2011), "Inductive top-down theorizing: A source of new theories of organization”, Academy of Management Review, vol. 36, n. 2, pp. 361-380.

SIEGER P., BERNHARD F., FREY U. (2011), "Affective commitment and job satisfaction among non-family employees: Investigating the roles of justice perceptions and psychological ownership", Journal of Family Business Strategy, vol. 2, n. 2, pp. 78-89. 
VERBEKE A., KANO L. (2012), “An internalization theory rationale for MNE regional strategy. Multinational Business Review”, vol. 20, n. 2, pp. 135-152.

YIN R.K. (2014), Case Study Research: Design and Methods (5th ed.), Sage, Los Angeles.

ZAHRA S.A. (2008), "The virtuous cycle of discovery and creation of entrepreneurial opportunities", Strategic Entrepreneurship Journal, vol. 2, n. 3, pp. 243-257.

ZELLWEGER T.M., CHRISMAN J.J., CHUA J.H., STEIER L.P. (2019), "Social Structures, Social Relationships, and Family Firms", Entrepreneurship Theory and Practice, vol. 43, n. 2, pp. 207-223. 


\title{
Relationship selling and marketing automation during the Covid-19 pandemic: a cross-sectional analysis
}

\author{
DANIELA CORSARO ${ }^{*}$ ISABELLA MAGGIONI ${ }^{\bullet}$ MIRKO OLIVIERI $^{* *}$
}

The Covid-19 pandemic impacted dramatically the global economy with repercussions on the marketing activities of companies operating in all industries. Digital technologies play a crucial role during the lockdown period as they facilitate the communication between buyers and sellers. By exploring the role of digital technologies in supporting marketing activities, this study (1) provides insights into the current marketing automation and sales technologies implemented by companies, (2) assesses the level of integration between physical and virtual touchpoints and crossfunctional collaboration among marketing, sales and customer service, and (3) identifies the motivations driving the adoption of marketing automation solutions, evaluating their benefits and challenges. Through survey of 200 professionals operating primarily in marketing, sales, and communication, the study highlights the central role of social media in developing and maintaining a relationships selling approach during the lockdown period. Furthermore, this research reveals the benefits of the marketing automation as a means to align marketing and sales functions and to integrate all touchpoints following an omni-channel strategy. This paper presents practical implication for professionals who are involved in marketing and communication activities in the digital environment.

Objectives. The Covid-19 pandemic has brought the global economy to facing an unprecedented crisis that has negatively impacted most industries and pushed several companies to rethink the way they develop and maintain their relationships with their stakeholders. Quickly spreading across the globe, the virus generated a world pandemic with repercussions still difficult to estimate. In Italy, as in the rest of the world, the impact of this pandemic has affected all sectors of the society, especially the economic one generating an unprecedent stock reaction (Baker et al. 2020). Nowadays, it is difficult to establish the severity of the impact that the Covid-19 pandemic is having on marketing, as the economy is today starting to recover after several weeks of lockdown. During the lockdown period, digital communications and online platforms have been key to maintain and develop business and personal relationships. In this context, communications, and information technology (IT) and social media represent key channels to invest in, as they are transforming the ways in which individuals and companies search for information and interact with one another (Kietzmann et al. 2011). In the last decades, a radical change entails the growing influence of digital technologies in customer purchasing decisions (Lingqvist et al. 2015). Hence, in this study we focus on the digital technologies role in marketing activities during the Covid-19 pandemic. Our research (1) provides insights into the current marketing automation and sales technologies implemented by companies, (2) assesses the level of integration between physical and virtual touchpoints and cross-functional collaboration among marketing, sales and customer service, and (3) identifies the motivations driving the adoption of marketing automation solutions, evaluating their benefits and challenges.

This paper is structured as follows. Section 2 reviews the literature on marketing automation. Section 3 presents the research question and the method of this study. Results are discussed in Section 4 and Section 5 presents the research limits. The paper ends with Section 6 and Section 7, containing practical implications and conclusions (i.e. originality of the study).

According to Vargo and Lusch (2004), marketing should be at the center of the company's strategic positioning, where functional processes are built based on marketing strategies in order to generate a competitive advantage for the company. The evolution of the buyer-seller relationship translates into a greater importance of marketing activities, such as the provision of relevant information to the buyer and the interaction with prospects and customers through digital channels. Indeed, the use of digital technologies is changing companies' business models, providing new revenue and value-producing opportunities (Gensler et al. 2013). In the meantime, the sales function has gradually evolved to adapt to increasingly sophisticated and informed customers. This has led sales activities to transform from simple order fulfillments to focus more on the management of the relationships. This phenomenon is evident with an

\footnotetext{
Associate Professor of Management - IULM University - Milano - Italy e-mail: daniela.corsaro@iulm.it

- Assistant Professor of Management - ESCP Business School - Paris - France e-mail: imaggioni@escp.eu

** Ph.D. Candidate of Management - IULM University - Milano - Italy e-mail: mirko.olivieri4@ studenti.iulm.it
} 
increasing number of key account managers (Storbacka et al. 2009). Such transformation has generated a series of challenges for companies, which increasingly face great difficulties in aligning the marketing and sales functions (Wiersema 2013), despite the fact that both functions focus on customer relationships. This misalignment often leads to a decreased performance of sales, reflected by wasted leads that are not adequately followed up and fully leveraged. Hosford (2012) confirms the advantages of the alignment of the two departments, revealing that $80 \%$ of participating companies with a highly effective lead generation process, have a strong proximity between the marketing and sales areas. This highlights the relevance of the alignment of marketing and sales, particularly in the acquisition of new customers.

To achieve these objectives, marketers had begun investing in a variety of technology solutions which consequently led to a rapidly expansion of the marketing technologies market (Biegel 2009). Particularly, marketing automation is one of the most promising areas of marketing technology (Redding 2015). Burka and Kelly (2018) define marketing automation as technologies focusing on the definition, planning, segmentation and tracking of marketing campaigns, allowing the marketing and sales functions to cultivate leads with highly personalized content aimed at attracting and retaining customers. According to Mero et al. (2019), there are two perspectives regarding the marketing automation definition. First, marketing automation is considered a tool used to automate marketing operations, as it is a computerized technology to support companies in the achievement of their business objectives performing specific tasks (Buttle and Maklan 2015; Heimbach et al. 2015). Second, other scholars treat marketing automation as a strategic initiative with the potential to revolutionize organizational structures, processes and culture of conducting marketing activities (Järvinen and Taiminen 2016).

Buttle and Stan (2015) outline a set of values that marketing automation is able to provide to companies: (1) greater marketing efficiency thanks to higher cost control, (2) greater productivity resulting from the numerous campaigns which are implemented through multiple channels simultaneously, (3) more effective marketing through a closed cycle, (4) greater responsibility for marketing expenses thanks to better data and analysis, (5) greater responsiveness with instant response to opportunities and involvement in real-time marketing, (6) advanced marketing intelligence with integrated reporting and analysis features, (7) better customer experience through personalized and relevant communications offered at the best times, (8) greater customer engagement through emotional identification and the customers behavior when they experience personalized messages. These values are widely reported and extensively explored in the literature. Specifically, Järvinen and Taiminen (2016) demonstrate that the application of marketing automation generates high-quality sales leads through behavioral targeting and content personalization. Indeed, companies could acquire deeper insight into the customer data in customer relationship management systems (CRM) which allows the integration of marketing and sales systems (Kotler et al. 2006; Wiersema 2013). Sin et al. (2005) define CRM technology as the IT technology implemented for specific purpose of customer relationship management. This technology allows companies "to formulate more appropriate marketing strategies and to execute specific marketing actions more efficiently and quickly by offering superior first-line support and the access of integrated access customer data" (Chang et al. 2010, p. 850).

Hence, in the traditional CRM, companies possess information on their customers, which they use to manage relationships with them (Verhoef et al. 2010). However, the rise of social media is challenging this traditional CRM framework (Malthouse et al. 2013), as in these social networking platforms the customer is no longer limited to a passive role in his or her relationship with businesses expressing opinions to large audiences (Schulze et al. 2012). The relationship between sellers and buyers has in fact undergone the impact of social media, which produce positive results for sales organizations if sellers use them to facilitate their marketing campaigns (Andzulis et al. 2012). According to Agnihotri et al. (2016), in addition to the seller's responsiveness, social media positively increase customer satisfaction and this encourages companies to adopt social networking platforms in sales actions.

Methodology. This study aims to investigate the role of digital technologies (i.e. the marketing automation) during the Covid-19 pandemic. Particularly, we focus on benefits and costs of marketing and sales automation technologies implemented by companies. Our research objectives refer to the control of digital channels, the adoption of technologies by companies, the diffusion and applications of marketing automation systems, CRM applications, the state of marketing policies and the marketing plan future investments in digital and automation tools. Hence, this paper seeks to answer the following research question:

RQ: How is marketing and sales automation evolving during the Covid-19 pandemic? What is the role of marketing automation in the integration between physical and virtual touchpoints? What are the motivations driving the adoption of marketing automation solutions in the companies?

To achieve our research objective, a cross-sectional survey was administered online to professionals operating primarily in marketing, sales, and communication, or holding senior leadership positions in Italian companies. Respondents were sourced through an online panel provider and were invited to complete the survey during the Covid19 lockdown period (March 2020).

The questionnaire comprised of a series of questions covering the current level of adoption of digital channels with a specific focus on social media usage, the level of integration among sales, marketing and customer service, and the degree of channel integration in their selling and marketing activities. The second section of the questionnaire focused on the application of marketing automation solutions, asking about trends during the pandemic, benefits, challenges and future implementation and development of such technology. Items were measured on a 7-point Likert scale. Participants were also asked to provide some firmographic and demographic information. A sample of 200 
responses was collected whose profile is presented in Table 1. Data were analyzed through univariate and bivariate descriptive statistics to identify key trends and applications of marketing automation solutions during the Covid-19 pandemic.

Tab. 1: Sample Profile

\begin{tabular}{|c|c|c|}
\hline \multicolumn{3}{|l|}{ Firmographics } \\
\hline \multirow[t]{8}{*}{ Industry } & Services & $28 \%$ \\
\hline & Manufacturing & $15 \%$ \\
\hline & Retail & $13 \%$ \\
\hline & Insurance services & $10 \%$ \\
\hline & Consultancy & $7 \%$ \\
\hline & Construction & $6 \%$ \\
\hline & Telecommunications & $5 \%$ \\
\hline & Other & $16 \%$ \\
\hline \multirow[t]{3}{*}{ Type of business } & Mainly $B 2 B$ & $38 \%$ \\
\hline & Mainly B2C & $24 \%$ \\
\hline & Both $B 2 B$ and $B 2 C$ & $38 \%$ \\
\hline \multirow[t]{4}{*}{ Number of employees } & Less than 10 & $34 \%$ \\
\hline & $10-50$ & $11 \%$ \\
\hline & $51-250$ & $14 \%$ \\
\hline & $250+$ & $41 \%$ \\
\hline \multirow{4}{*}{$\begin{array}{l}\text { Annual revenues (in } \\
\text { Euros) }\end{array}$} & Less than $2 M$ & $39 \%$ \\
\hline & $2-10 \mathrm{M}$ & $15 \%$ \\
\hline & $10-50 \mathrm{M}$ & $12 \%$ \\
\hline & More than $50 \mathrm{M}$ & $34 \%$ \\
\hline \multicolumn{3}{|l|}{ Demographics } \\
\hline \multirow[t]{2}{*}{ Gender } & Male & $59 \%$ \\
\hline & Female & $41 \%$ \\
\hline \multirow[t]{4}{*}{ Age } & $25-34$ & $27 \%$ \\
\hline & $35-44$ & $38 \%$ \\
\hline & $45-54$ & $25 \%$ \\
\hline & $55-64$ & $10 \%$ \\
\hline \multirow[t]{12}{*}{ Job position } & Owner/Entrepreneur & $21 \%$ \\
\hline & Brand Manager/Marketing Manager & $10 \%$ \\
\hline & Managing Director & $9 \%$ \\
\hline & Marketing Director & $9 \%$ \\
\hline & Digital Marketing Manager/Specialist & $7 \%$ \\
\hline & Sales Manager & $7 \%$ \\
\hline & CRM Manager & $4 \%$ \\
\hline & E-commerce manager & $4 \%$ \\
\hline & Sales director & $4 \%$ \\
\hline & $\mathrm{CDO} / \mathrm{CMO} / \mathrm{Head}$ of Digital & $4 \%$ \\
\hline & Communication manager & $3 \%$ \\
\hline & Other & $18 \%$ \\
\hline \multirow{5}{*}{$\begin{array}{l}\text { Years in the job } \\
\text { position }\end{array}$} & Less than 1 year & $9 \%$ \\
\hline & $1-3$ years & $17 \%$ \\
\hline & $3-5$ years & $25 \%$ \\
\hline & $5-7$ years & $14 \%$ \\
\hline & More than 7 years & $37 \%$ \\
\hline
\end{tabular}

Source: our analysis

Findings. This study, by confirming previous studies (Zeng et al. 2020) which reveal the central role of the social media in the countries most affected by the virus (Facebook saw a 50\% increase), with voice and video calls doubling on Messenger and WhatsApp, highlights an increasing usage of social media in companies during the pandemic. Specifically, in the majority of companies, the use of social media is encouraged and has resulted in an improvement in customer relations. Social media are mainly adopted for sales purposes, i.e. to identify new business opportunities and to identify decision makers. Indeed, companies develop a culture of integration between marketing and sales (Andzulis et al. 2012), and the social media marketing strategy should be fundamental in integrating channels for marketing and sales purposes. Today, customers look for answers when and where they are needed, and the real-time communication in digital touchpoints such as social media has become a fundamental element to be included in the phases of the customer journey. The buyer asks for answers when the need or problem arises, and the touchpoints must therefore be activated in the right context. As a matter of fact, from our research it emerges that emails remain a static channel for marketing campaigns, while social media are becoming increasingly important due to their flexibility and speed, which respond to the request for real-time communication. Moreover, social media gain importance for another reason: $59 \%$ 
of customers buy independently and without the support of a seller. Therefore, social media are used for instant messaging communication with companies. Hence, immediate forms of communication are preferred by customers such as instant messaging systems or voice messages more and more to interact with their customers.

Therefore, the touchpoints available to the buyer have increased and for this reason the integration has become crucial in the marketing and sales strategies of the companies. Firms increasingly adopt integrated sales policies between online and offline channels and maintain an integrated customer database. Indeed, the majority of companies claim to use different channels for sales: from an operational point of view, this translates into integration of the order fulfillment system, and integrated inventory between channels. In addition, 54\% of respondents say they have an incentive system developed from an omnichannel perspective. Confirming previous studies (Wiersema 2013), we found the integration between marketing and sales translates into alignment in terms of objectives (64\%) and with respect to customer needs (62\%), as a mutual support between the two functions through the sharing of performances and the shared definition of priorities. This is even more evident in an omnichannel strategy.

Marketing automation has a positive impact on different aspects of the business of companies. However, our research revealed that the diffusion of marketing automation is still moderate: $44 \%$ of interviewed companies declare to use marketing automation systems and $17 \%$ of those who said they use a marketing automation system did not indicate which system it was or did not remember the name of the software. Although these technologies are still being disseminated, this study confirms the benefits for marketing automation-oriented firms. The motivations behind the adoption of marketing automation concern the increase of the general efficiency of the business through a reduction of the action times (48\%), the personalization of the communications conveyed to the customers in a data-driven perspective (47\%), the improvement of the customer experience through customer journey mapping (45\%) and the more effective reporting via shared dashboards (43\%). Indeed, personalized promotions and campaign delivery is one of the main marketing automation activities, as these technologies are mainly used to: personalize promotions and customer interactions, convey campaigns to prospects and generate leads. Instead, the main areas of improvement of marketing automation include the need to cover a greater number of channels, integration with other tools including CRM and greater ease of use.

As regards the benefits of marketing automation, we found the possibility of establishing better relationships with customers and increasing turnover. However, currently marketing automation is mainly focused on activities aimed at the acquisition and conversion and therefore only on the first stages of the funnel, while in the future the companies declare they want to invest more in activities aimed at developing the relationship and referring to the post-purchase. The benefits of marketing automation also change depending on the dimension of the company: for medium-profit companies, the increase in efficiency, the acceleration of the sales cycle and the increase in leads represent the main benefits; for large companies, the main driver is the increase in leads generated through marketing activities; and for small businesses the turnover increase. However, this study confirms some difficulties in implementing these technologies by companies. Particularly, we refer to integration problems with existing systems at company level, the limited budget, the market dynamics, the lack of skills or dedicated resources within the marketing teams and the complexity of the platforms. Indeed, from an integration point of view, the majority of the CRM systems of the companies surveyed appear to be integrated internally, while only 48\% state that their CRM is able to integrate internal data with external data, particularly the social networks data.

Research limits. This research has limitations. This study was conducted during the pandemic and therefore cannot offer a complete view of the adoption of digital technologies in the post-Covid-19 period. Companies are still in a phase of rethinking their strategies where digital has certainly already proven to play a crucial role, however the legacy of the global lockdown on marketing activities will only be visible in future research.

Practical implications. As regards the managerial implications, this paper offers suggestions to professionals involved in marketing and communication activities, with particular focus on the digital environment. Indeed, the study highlights consumers' needs to be reached by personalized communications on digital platforms such as social media. This implies for companies a shift from traditional touchpoints such as emails, which are now considered a static communication channel, to instant messaging chats which provide voice messages and video calls. This research highlights a general increase in digital investment, particularly for customization and optimization of digital technologies such as marketing automation, which represents a solution capable of developing omnichannel strategies that reach the consumer with personalized communications at the right time on the right channel. The social distancing due to the Covid-19 pandemic has given a strong push to the development of increasingly digital-oriented relationships, and marketing and communication strategies of the companies cannot take into account these new market's evolutions.

Originality of the study. This study provides original highlights regarding the marketing automation adoption during the Covid-19 pandemic. By confirming previous studies (Buttle and Stan 2015), this paper highlights the marketing automation benefits with a particular focus on the opportunities for companies during the lockdown period, when the relationships with customers are more difficult to maintain because of the social distancing. Indeed, before the Covid-19 pandemic, marketing automation was used by companies as a computerized technology to support companies in the achievement of their business objectives performing specific tasks (Heimbach et al. 2015). Today, our research reveals that in an uncertainty economic phase, digital technologies such as marketing automation represent an alternative to human contact. As a matter of fact, the interviewed companies declare that while so far these 
technologies were mainly adopted in the early stages of the funnel with the aim of acquiring and converting, in the future marketing automation will play a key role in post-purchase and particularly to strengthen customer relationships. Indeed, during the lockdown period, channels for maintaining relationships with consumers have also evolved. Nowadays, buyers' expectations have increased thanks to the rapid development of new technologies (Arli et al. 2018), and customers look for answers when and where they are needed: the real-time communication in digital touchpoints such as social media has become a key element to be included in the customer journey. Therefore, the instant messaging channels such as social media for marketing and sales purposes are the areas in which companies will intervene more. In other words, the relationship approach becomes even more central in the post Covid-19 market. The result is the need for an improvement of the customer experience, through the personalization that is also achieved by responding in real-time to customers. Marketing automation gives companies the opportunity to develop an omnichannel strategy that also includes social media, instant messaging channels and all digital touchpoints.

Key words: Covid-19; digital technologies; marketing automation; relationship selling

\section{References}

AGNIHOTRI R., DINGUS R., HU M.Y., KRUSH M.T. (2016), "Social media: Influencing customer satisfaction in B2B sales", Industrial Marketing Management, vol. 53, pp. 172-180.

ANDZULIS J.M., PANAGOPOULOS N.G., RAPP A. (2012), “A review of social media and implications for the sales process", Journal of Personal Selling \& Sales Management, vol. 32, n. 3, pp. 305-316.

ARLI D., BAUER C., PALMATIER R.W. (2018), "Relational selling: Past, present and future", Industrial Marketing Management, vol. 69, pp. 169-184.

BAKER S.R., BLOOM N., DAVIS S.J., KOST K., SAMMON M., VIRATYOSIN T. (2020), "The unprecedented stock market reaction to COVID-19", White Paper, pp. 1-14.

BIEGEL B. (2009), "The current view and outlook for the future of marketing automation", Journal of Direct, Data and Digital Marketing Practice, vol. 10, n. 3, pp. 201-213.

BURKA K., KELLY B. (2018), “Martech intelligence report: B2B marketing automation platforms: A marketer's guide", 6th edition, Third Door Media. martechtoday.com/new-b2b-marketing-automation-platforms- marketersguide-updated-2018-212578

BUTTLE F., STAN M. (2015), Customer relationship management: concepts and technologies, 3rd ed., Routledge, New York.

CHANG W., PARK J.E., CHAIY S. (2010), "How does CRM technology transform into organizational performance? A mediating role of marketing capability", Journal of Business Research, vol. 63, n. 8, pp. 849-855.

GENSLER S., VOLCKNER F., LIU-THOMPKINS Y., WEIRTZ (2013), "Managing brands in the social media environment", Journal of Interactive Marketing, vol. 27, n. 4, pp. 242-256.

HEIMBACH I., KOSTYRA D.S., HINZ O. (2015), "Marketing automation", Business \& Information Systems Engineering, vol. 57, n. 2, pp. 129-133.

HOSFORD C. (2012), “Automated marketing helps Jefferson National hone direct content”, BtoB, vol. 97 , n. 4.

JÄRVINEN J. (2016), The use of digital analytics for measuring and optimizing digital marketing performance, Academic dissertation, Jyväskylä Studies in Business and Economics, Jyväskylä.

JÄRVINEN J., TAIMINEN H. (2016), "Harnessing marketing automation for B2B content marketing”, Industrial Marketing Management, vol. 54, pp. 164-175.

KIETZMANN J.H., HERMKENS K., MCCARTHY I.P., SILVESTRE B.S. (2011), "Social media? Get serious! Understanding the functional building blocks of social media", Business Horizons, vol. 54, n. 3, pp. 241-251.

KOTLER P., RACKHAM N., KRISHNASWAMY S. (2006), "Ending the war between sales and marketing", Harvard Business Review, vol. 84, n. 7/8, pp. 68-78.

LINGQVIST O., PLOTKIN C., STANLEY J. (2015). "Do you really understand how your business customers buy?", Research article, McKinsey, $\quad$ February 2015. mckinsey.com/Insights/Marketing_Sales/Do_you_really_understand_how_your_business_custo mers_buy?cid=mckgrowth-eml-alt-mkq-mck-oth-1502

MALTHOUSE E.C., HAENLEIN M., SKIERA B., WEGE E., ZHANG M. (2013), "Managing customer relationships in the social media era: Introducing the social CRM house", Journal of Interactive Marketing, vol. 27, n. 4, pp. 270-280.

MERO J., TARKIAINEN A., TOBON J. (2019), "Effectual and causal reasoning in the adoption of marketing automation”, Industrial Marketing Management, vol. 86, pp. 212-222.

REDDING S. (2015), "Can marketing automation be the glue that helps align sales and marketing?", Journal of Direct, Data and Digital Marketing Practice, vol. 16, n. 4, pp. 260-265.

SCHULZE C., BERND S., THORSTEN W. (2012), "Linking Customer and Financial Metrics to Shareholder Value: The Leverage Effect in Customer-Based Valuation", Journal of Marketing, vol. 76, n. 2, pp. 17-32.

SIN L.Y.M., TSE A.C.B., YIM F.H.K. (2005), "CRM: conceptualization and scale development”, European Journal of Marketing, vol. 39, n. 11/12, pp. 1264-1290. 
STORBACKA K., RYALS L., DAVIES I.A., NENONEN S. (2009), “The changing role of sales: viewing sales as a strategic, cross-functional process", European Journal of Marketing, vol. 43, n. 7/8, pp. 890-906.

VARGO S.L., LUSCH R.F. (2004), "Evolving to a new dominant logic for marketing”, Journal of Marketing, vol. 68, n. 1, pp. 1-17.

VERHOEF P.C., VENKATESAN R., MCALISTER L., MALTHOUSE E.C., KRAFFT M., GANESAN S. (2010), "CRM in data-rich multichannel retailing environments: a review and future research directions", Journal of Interactive Marketing, vol. 24, n. 2, pp. 121-137.

WIERSEMA F. (2013). “The B2B agenda: The current state of B2B marketing and a look ahead", Industrial Marketing Management, vol. 4, n. 42, pp. 470-488.

ZHENG T., FOSCHI L., HAYNIE M., LYSTER L., PITTARD B., DIRKX D., LOW B., FRIEDMAN K., KELLY S. (2020), "The role of social media during the Coronavirus pandemic", PMG, April 2020. pmg.com/blog/the-roleof-social-media-during-the-coronavirus-pandemic/?cn-reloaded=1 


\title{
Efficienza e produttività del personale nel settore bancario italiano. Le leve industriali a sostegno dei piani strategici post Coronavirus
}

\author{
Michele Costa ${ }^{*}$ Alberto Pastore ${ }^{\bullet}$
}

\begin{abstract}
Obiettivi. La crisi sanitaria ed economica causata dal Coronavirus sta mettendo a dura prova il sistema finanziario italiano, causando il congelamento dei mercati del credito e mettendo sotto pressione il settore bancario. La stretta delle condizioni finanziarie comporterà per gli istituti finanziari nel breve periodo una contrazione delle commissioni e proventi da attività di trading e nel medio-lungo periodo un aumento delle perdite su crediti, con impatti negativi sulla redditività. All'interno dell'attuale contesto di crisi, inoltre, le banche italiane si troveranno ad affrontare nei prossimi anni una crescente competizione - sia diretta che indiretta - che renderà indispensabile l'eliminazione delle proprie inefficienze operative per evitare di perdere vantaggio competitivo o di rischiare l'uscita dal mercato. In particolare, i Digital Champions come Google, Apple, Facebook e Amazon (GAFA) hanno aggredito diversi prodotti finanziari, come attività di lending o servizi di pagamento, puntando alle parti più redditizie della catena del valore. Tali organizzazioni sono in grado di offrire servizi personalizzati grazie ad architetture innovative, con un front/back-office potente che ha accesso ad un vasto mercato costituito prevalentemente da giovani, assai distante dal sistema finanziario tradizionale, e funzioni di middle-office non soggette a vigilanza come per le banche.

In tale contesto di crisi e di pressione competitiva, azioni volte a favorire il recupero di efficienza e il progressivo miglioramento della produttività, mediante interventi di contenimento e di razionalizzazione del personale, saranno tra le maggiori sfide che le banche dovranno affrontare nell'evoluzione del sistema finanziario italiano.

La necessità di interventi di razionalizzazione del personale appare evidente dalla quantificazione degli esuberi evidenziata nei piani industriali e di ristrutturazione del settore. Gli esuberi identificati andranno ad aggiungersi alle circa 35 mila uscite registrate dal 2012 ad oggi, dovute principalmente alla diminuzione dell'operatività degli sportelli e dalla digitalizzazione dei servizi bancari. Tali uscite però, non sono da intendersi come licenziamenti. La funzione ricoperta dalle banche all'interno del sistema economico italiano ha sempre reso necessario un forte impegno sociale nella gestione degli esuberi tramite prepensionamenti volontari e pensionamenti, e prevede anche cantieri per il ricambio generazionale e la riqualificazione e riconversione del personale, al fine di evitare la distruzione di posti di lavoro.

Per l'efficienza del personale risulta importante valutare la capacità delle imprese bancarie di allocare le risorse a disposizione in modo ottimale, dato un prefissato livello di produzione e tecnica produttiva, erogando servizi al costo minimo efficiente. Le risorse devono essere, quindi, adeguatamente organizzate e combinate fra le unità produttive in modo tale da massimizzare la produttività e conseguire un equilibrio economico e finanziario nel medio e lungo periodo.

La letteratura ha più volte sottolineato la dipendenza tra questi due concetti: efficienza e produttività. Tra le più note interpretazioni di tale dipendenza si rilevano due contributi, ovvero la produttività come "indice di efficienza" di Schmookler (1952), e la produttività come "cambiamento nell'efficienza produttiva" di Kendrick (1956). Lo stretto legame tra i concetti di efficienza e di produttività permette una migliore lettura del contesto operativo delle banche italiane, attraverso l'affiancamento degli indici di efficienza agli indici di produttività parziale dei fattori, quest'ultimi forniti dal rapporto tra la quantità di output prodotta ed un solo fattore produttivo, quale il personale.

Tra $i$ diversi indicatori di efficienza utilizzati in banca, quello maggiormente diffuso e condiviso dagli addetti ai lavori risulta essere il cost/income ratio, calcolato come rapporto tra costi operativi e margine di intermediazione. Il cost/income ratio, anche a fronte della spinta da parte degli organi di vigilanza verso migliori livelli di efficienza, è riconosciuto oggi come uno degli obiettivi strategici principali degli intermediari finanziari, che ne definiscono il valore obiettivo da raggiungere nei relativi piani industriali. Per migliorare il valore dell'indicatore, evidentemente, $\grave{e}$ possibile intervenire sulle due componenti che costituiscono l'indicatore stesso: sulla cost efficiency mediante la riduzione del nominatore, o sulla revenue efficiency attraverso l'incremento del denominatore. Nell'attuale contesto di crisi economica e finanziaria, le banche non possono che mirare ad interventi di contenimento dei costi piuttosto che di incremento dei ricavi, data la maggiore discrezionalità e il maggior grado di controllo sulle dinamiche organizzative interne rispetto alle variabili di mercato inerenti al versante dei ricavi aziendali.
\end{abstract}

\footnotetext{
Dottorando in Management, Banking and Commodity Sciences - Sapienza Università di Roma - Italy e-mail: michele.costa@uniroma1.it

- Ordinario di Economia e Gestione delle Imprese - Sapienza Università di Roma - Italy e-mail: alberto.pastore@uniroma1.it
} 
L'indagine annuale "Dati cumulativi delle principali banche internazionali" dell'Area Studi di Mediobanca (2019) condotta sulle 24 banche europee più grandi per dimensione dell'attivo, evidenzia che nel triennio 2016-2018 $i$ due principali istituti bancari italiani, Intesa Sanpaolo e UniCredit, hanno migliorato la loro efficienza, ottenendo un significativo decremento del cost/income ratio cumulato (del-5,8\% sul 2016 e del -0,8\% sul 2017) che raggiunge un valore pari al 63,6\%. Tale miglioramento di produttività nel periodo risulta maggiore rispetto al campione europeo, soprattutto in funzione della riduzione del numero dei dipendenti, che è stato del 14\% (circa 28 mila unità) rispetto al $4 \%$ del perimetro europeo (circa 96 mila unità in totale). Nonostante questi risultati, in termini di produttività del lavoro, calcolata come ricavi pro-capite (al netto dei risultati da trading, maggiormente dipendenti da fattori esterni alla banca e per loro natura più volatili), i due principali istituti italiani presentano nel 2018 ricavi aggregati per dipendente pari a 201.000 euro, ancora inferiori rispetto alla media europea di 211.000 euro. (Tabella 1)

Tab. 1: Numero Dipendenti, Cost/Income e Produttività del lavoro nel settore bancario europeo

\begin{tabular}{|c|c|c|c|c|}
\hline Paesi & Campione & Numerc & Dipenden & i (unità) \\
\hline & $\#$ & 2016 & 2017 & 2018 \\
\hline Svizzera & 2 & 107.433 & 107.325 & 110.331 \\
\hline Regno Unito & 5 & 625.717 & 585.526 & 555.044 \\
\hline Danimanrca & 1 & 19.176 & 19.536 & 20.226 \\
\hline Francia & 5 & 664.398 & 668.781 & 676.191 \\
\hline Paesi Bassi & 3 & 122.610 & 116.996 & 114.231 \\
\hline Finlandia & 1 & 30.873 & 31.437 & 29.395 \\
\hline Germania & 3 & 180.750 & 176.301 & 174.275 \\
\hline Spagna & 2 & 328.312 & 328.236 & 331.165 \\
\hline Italia & 2 & 206.255 & 182.480 & 178.260 \\
\hline Intesa Sanpaolo & & 84.670 & 87.352 & 88.891 \\
\hline UniCredit & & 121.585 & 95.128 & 89.369 \\
\hline Europa & 24 & 2.285 .524 & 2.216 .618 & 2.189 .118 \\
\hline
\end{tabular}

\begin{tabular}{|c|c|c|c|c|c|}
\hline \multicolumn{3}{|c|}{ Cost/Income ratio (\%) } & \multicolumn{3}{|c|}{ Produttività del lavoro $(\mathrm{K} €)$} \\
\hline 2016 & 2017 & 2018 & 2016 & 2017 & 2018 \\
\hline $87,2 \%$ & $81,7 \%$ & $77,7 \%$ & 340 & 348 & 344 \\
\hline $69,7 \%$ & $66,4 \%$ & $62,2 \%$ & 166 & 174 & 187 \\
\hline $51,0 \%$ & $50,5 \%$ & $56,4 \%$ & 331 & 312 & 341 \\
\hline $68,4 \%$ & $69,5 \%$ & $68,2 \%$ & 176 & 179 & 185 \\
\hline $62,2 \%$ & $60,9 \%$ & $58,8 \%$ & 309 & 309 & 339 \\
\hline $48,5 \%$ & $53,1 \%$ & $56,7 \%$ & 265 & 258 & 274 \\
\hline $82,6 \%$ & $84,5 \%$ & $87,3 \%$ & 223 & 207 & 212 \\
\hline $55,3 \%$ & $54,7 \%$ & $52,1 \%$ & 197 & 213 & 209 \\
\hline $69,4 \%$ & $64,7 \%$ & $63,6 \%$ & 168 & 191 & 201 \\
\hline $62,4 \%$ & $63,1 \%$ & $62,7 \%$ & 174 & 174 & 180 \\
\hline $74,9 \%$ & $66,1 \%$ & $64,3 \%$ & 163 & 206 & 222 \\
\hline $68,7 \%$ & $67,3 \%$ & $65,4 \%$ & 197 & 203 & 211 \\
\hline
\end{tabular}

Fonte: elaborazione propria su dati dell'Arena Studi Mediobanca

Prendendo in esame il periodo 2008-2017, decennio successivo alla crisi finanziaria dei sub-prime, si osserva come la competitività aggregata dei due istituti italiani $(0,30)$, sia frenata dal più vivace incremento del costo del personale per dipendente (+20\%) rispetto all'aumento della produttività (+5,9\%). Seppur l'analisi evidenzi, nello stesso periodo, una competitività del campione italiano in linea con la media europea (0,31), saranno necessarie, da parte degli istituti italiani, ulteriori azioni dirette alla continua ricerca di ottimizzazione del costo del lavoro e aumenti di produttività, per mantenere nel tempo la competitività agli stessi livelli dei competitor europei, maggiormente capaci di puntare sullo sviluppo dei ricavi in paesi con situazioni economiche-finanziarie più stabili. (Tabella 2).

Tab. 2: Produttività del lavoro, Costo del lavoro per dipendente e Competitività nel settore bancario europeo

\begin{tabular}{|c|c|c|c|c|}
\hline Paesi & Campione & $\begin{array}{c}\text { Produttività } \\
\text { del lavoro }\end{array}$ & $\begin{array}{c}\text { Costo del lavoro per } \\
\text { dipendente }\end{array}$ & Competività \\
\hline & $\#$ & Variazione \% su 2008 (a) & Variazione \% su 2008 (b) & $a / b$ \\
\hline Italia & 2 & $+5,9$ & +20.0 & 0,30 \\
\hline Europa & 28 & $+7,4$ & $+24,0$ & 0,31 \\
\hline
\end{tabular}

Fonte: elaborazione propria su dati dell'Arena Studi Mediobanca

In questo contesto risulta fondamentale identificare le strategie e le azioni che i principali istituti bancari italiani potranno mettere in atto per fronteggiare l'attuale situazione economica sfavorevole ed ottenere ulteriori miglioramenti di efficienza e produttività del personale. L'obiettivo di questo working-paper, dunque, è quello di mettere a fuoco quali sono le leve industriali utilizzabili dalle imprese bancarie italiane per favorire l'ottimizzazione dell'impiego del personale, in modo da consentire il raggiungimento degli obiettivi strategici di efficienza e produttività.

Metodologia. Data la carenza di ricerche empiriche previsionali riguardanti l'efficienza e produttività della forza lavoro nel settore finanziario italiano, questo working-paper concettuale si propone di fare un'analisi delle principali azioni industriali adottabili dalle banche per il raggiungimento degli obiettivi strategici di miglioramento dell'efficienza e della produttività prefissati nel medio-lungo periodo.

Il lavoro, attraverso un approccio esplorativo, ha affrontato l'argomento a partire dallo studio della letteratura scientifica e della reportistica e documentazione aziendale e professionale disponibile, ancorché limitata, elaborandola e sistematizzandola al fine di fornire una prima risposta alla domanda di ricerca, ponendo l'attenzione su "perché” $e$ “come” gli eventi cambiano (Mintzberg 1979; Langley 1999). 
Il disegno complessivo della ricerca prevede che il presente working-paper costituisca il punto di partenza per la successiva realizzazione di una indagine empirica, volta all'analisi in profondità di un case study, in grado di dare un riscontro all'impostazione teorica e a fornire ulteriori insight. Al fine di validare empiricamente il framework concettuale ipotizzato, è prevista una triangolazione dei dati primari e secondari relativi al caso studio identificato: documenti pubblici e privati, ed interviste semi-strutturate. Le interviste coinvolgeranno manager rappresentanti delle aree aziendali maggiormente coinvolte nella ricerca di migliori livelli di produttività ed efficienza della forza lavoro, allo scopo di registrare le caratteristiche olistiche dei fenomeni studiati e confermare le ipotesi sinora esposte attraverso riscontri sul campo.

Risultati. Il lavoro condotto ci ha portato ad individuare tre principali leve industriali in capo al management delle imprese bancarie italiane, finalizzate al raggiungimento degli obiettivi strategici di miglioramento dell'efficienza e della produttività della forza lavoro, ancora più necessari di fronte alle sfide poste dall'attuale crisi sanitaria ed economica-finanziaria:

a) La prima leva è lo_Strategic Workforce Planning. Lo Strategic Workforce Planning (SWP) è il "processo di analytics, forecasting and planning che permette di connettere e gestire le attività della forza lavoro in modo da garantire all'organizzazione il perseguimento della propria strategia di business, assicurandosi la persona giusta, nel posto giusto, al momento giusto, al giusto costo" (Young, 2009). Lo Strategic Workforce Planning permette di analizzare gli scenari di cambiamento e di determinare le linee di intervento sulla base dell'analisi della domanda $e$ dell'offerta di personale rispetto alle esigenze, definendo la workforce attesa capace di attuare la strategia di business. L'ottimizzazione dei costi è tra i principali vantaggi derivanti dalla piena realizzazione dallo strategic workforce planning. La pianificazione di lungo periodo della forza lavoro consente di fornire una visione sui segmenti critici della popolazione lavorativa e sui relativi gap. Il processo deve partire dalla mappatura del patrimonio delle competenze presenti all'interno dell'organizzazione per andare a identificare il gap di abilità e talenti rispetto alle esigenze aziendali dettate dalla necessità di colmare rapidamente le lacune e criticità di business derivanti dall'attuale congiuntura economica sfavorevole, dai trend di settore e dall'attuazione delle strategie aziendali. Questi gap fondamentalmente sono dettati da due fattori strutturali tra loro interconnessi: da una parte la velocità e profondità del cambiamento tecnologico e organizzativo e dall'altra l'invecchiamento della popolazione lavorativa. Il problema va dunque affrontato anche in una logica di Age Management, andando a definire le più opportune politiche di gestione delle risorse umane in funzione dell'età, rivolte prevalentemente alla valorizzazione del contributo dei lavoratori più maturi.

Ma il fattore che maggiormente influenzerà le strategie di business delle banche, determinando anche delle profonde trasformazioni strutturali nel settore, è costituito dalle nuove tecnologie applicate ai processi di produzione. Secondo il rapporto "Banche Italiane su un piano inclinato" di Oliver Wyman (2019), oltre il 45\% della forza lavoro attualmente impegnata nei prossimi anni dovrà acquisire know-how e creare nuove competenze per poter operare nel nuovo ambiente digitale. I ruoli impattati riguardano tutta la filiera produttiva bancaria, dalle filali al middle e back-office, mentre aumenterà la richiesta di professionalità legate alle nuove tecnologie, alla gestione del cambiamento e al trattamento e analisi dei dati. Il cambiamento tecnologico richiesto alle istituzioni bancarie richiederà azioni straordinarie di upskilling per affrontare al meglio la trasformazione digitale, favorendo l'apprendimento di nuove competenze o tecnologie per il mantenimento del ruolo attuale, o aggiungendo nuove competenze per progredire nella carriera. Secondo lo studio "Upskilling your workforce for the age of the machine" (Capgemini 2018), l'automazione è un potente fattore di incremento della produttività, ma solo un appropriato programma di upskilling della forza lavoro può permettere il raggiungimento del suo pieno potenziale. La spesa per la riqualificazione del personale rappresenta, un investimento significativo da affrontare da parte delle imprese bancarie. Tuttavia, come evidenziato dalla ricerca "Towards a Reskilling Revolution" della Word Economic Forum in collaborazione con la Boston Consulting Group (2018), essa verrebbe compensata dai benefici derivanti dalla riduzione dei costi di licenziamento dell'attuale forza lavoro e di assunzione di nuovo personale nonché dalla maggiore produttività dei dipendenti riqualificati rispetto alla più ridotta produttività dei nuovi assunti, (Tabella 3)

Tab. 3: Produttività dipendenti riqualificati vs personale neoassunto

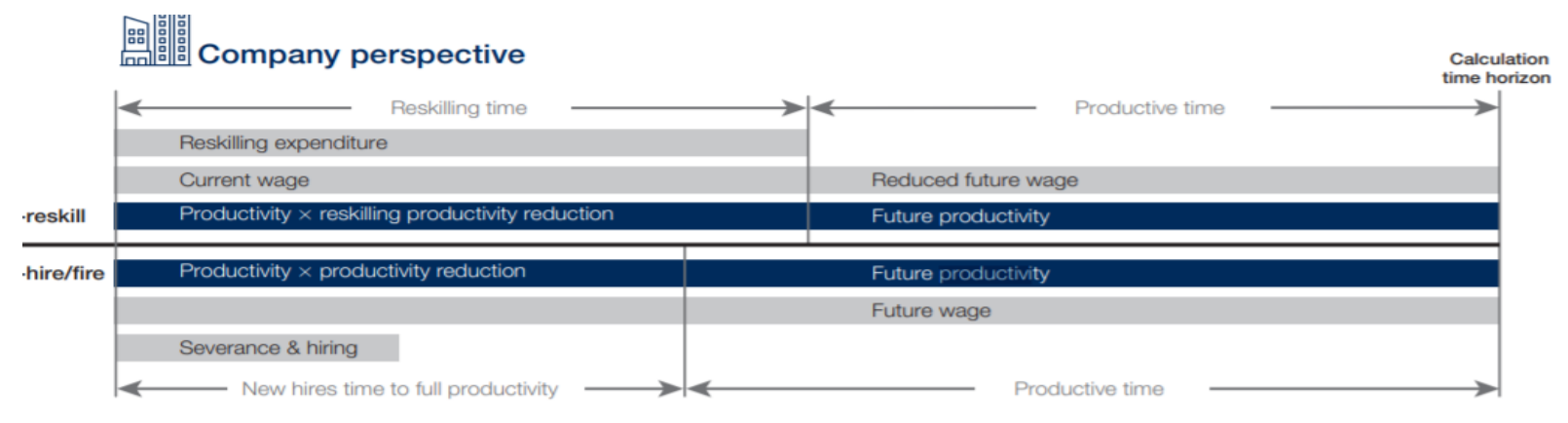

Fonte: Word Economic Forum 
Nella gestione dell'attuale crisi sanitaria ed economica-finanziaria da Coronavirus, la riqualificazione del personale assume ancora più importanza. Gli istituti creditizi stanno garantendo $i$ servizi bancari necessari nonostante la carenza di personale dovuta alla riduzione del numero di filiali sul territorio e la ricollocazione dei dipendenti in congedo per garantire il rispetto delle distanze minime e le norme di sicurezza all'interno degli spazi lavorativi. Le banche hanno la necessità di colmare rapidamente le lacune e criticità di business cogliendo l'opportunità di far apprendere al personale nuove competenze e software, come programmi di videoconferenze, webinar o sistemi di messaggistica, per supportare al meglio l'operatività in altre aree aziendali in sofferenza.

b) Ottimizzazione dei processi paperless: I processi operativi per l'erogazione dei servizi bancari determinano in larga misura i costi dell'organizzazione. Nella loro configurazione e nel loro svolgimento si riscontrano ampie varianze e sprechi e il loro ridisegno, sovente basato su nuove soluzioni tecnologiche, può portare a significativi incrementi di efficienza. È necessario, allo scopo di migliorare l'efficienza e la produttività della forza lavoro, ottimizzare l'utilizzo delle risorse tramite l'eliminazione degli sprechi del settore: sovrapproduzione, trasporto, movimento, attese, scorte, processi inutilmente costosi e difetti.

Gli istituti di credito dovranno esprimere un consistente impegno nel miglioramento dei processi aziendali. Sarà necessario analizzare $i$ processi e i servizi esistenti in base a somiglianze, ridondanze e interdipendenze, e realizzare un ridisegno per rimuovere le inefficienze, ridurre la variabilità, diminuire $i$ tempi, contenere $i$ costi e incrementare la produttività e il livello di servizio.

L'attuale crisi sanitaria ed economica-finanziaria causata dal Coronavirus ha evidenziato l'elevata competitività dei Digital Champions e delle imprese provenienti dal mondo Fintech, e ha accentuato la necessità di ridurre ulteriormente, se non eliminare, il contatto fisico tra la banca e la clientela finale. L'alto costo derivante dalla chiusura temporanea delle filiali, le spese di sanificazione degli ambienti e la carenza di personale disponibile, spinge inesorabilmente le banche verso superiori livelli di digitalizzazione, con l'home banking e lo smart working. La presente situazione richiede nuove strategie di posizionamento e nuovi modelli di business in grado di portare tutta la catena di produzione e di vendita di un prodotto sui canali digitali, attraverso l'implementazione di tecnologie paperless capaci di ridisegnare gli attuali sistemi di acquisizione, gestione, archiviazione e distribuzione, ancora oggi basati prevalentemente sull'utilizzo della carta. Oltre all'impatto positivo sul fatturato, la soluzione della dematerializzazione offre l'opportunità di snellire sia i costi delle reti esterne (agenti, rivenditori e dealer), mediante l'apertura di canali diretti e remoti verso la clientela, sia i costi operativi derivanti dall'abbattimento delle risorse materiali impiegate nel processo produttivo e dall'ottimizzazione della forza lavoro dedicata nella gestione e archiviazione di documenti, stimata pari a circa il 7\% del totale dei dipendenti.

La reingegnerizzazione delle attività dovrà essere effettuata sia per i processi orizzontali (Accounting, Compliance, HR, ecc.) sia per quelli banking-specific, liberando il personale verso progetti considerati più rilevanti e verso attività e funzioni a maggiore valore aggiunto.

UniCredit, apripista sul tema paperless nel settore bancario italiano, ha previsto nel piano industriale 2020-2023 per la trasformazione e massimizzazione della produttività, l'adozione di nuove modalità di lavoro per ottimizzare costantemente i processi, migliorare l'esperienza del cliente e ottenere maggiore efficienza. In Italia per il cliente retail i servizi saranno totalmente paperless da metà del 2020, in Germania e Austria nel 2021, con una riduzione dei costi del $12 \%$. Nella successiva fase della ricerca, sarà interessante verificare quanto della spesa per l'elaborazione dei documenti, oggi pari al 7-14\% del totale dei costi, potrà ridursi nei prossimi anni, evidenziando le aree aziendali e $i$ servizi bancari maggiormente idonei a divenire paperless.

c) Automazione: L'industria finanziaria, e il settore bancario nello specifico, si contraddistingue rispetto al comparto manufatturiero per l'elevata intensità informativa del suo prodotto, essenzialmente immateriale, e conseguentemente per la strategicità che l'Information Technology ha sul processo-prodotto bancario. In tale contesto di crisi economica-finanziaria e di compressione dei margini, l'uso intenso e diffuso di tecnologie rappresenta la leva principale a disposizione del management, attraverso l'efficientamento dei costi operativi e l'aumento della produttività, per mantenere la posizione acquisita nel tempo, e in taluni casi incrementare il vantaggio competitivo nei confronti dei rivali. Una conferma dell'indissolubile relazione tra il settore bancario e tecnologia è fornito dall'incremento degli investimenti ICT negli ultimi anni e dalla necessità di destinare ingenti investimenti nei prossimi piani industriali. Nonostante le condizioni di mercato sfavorevoli, si dovrà fare il possibile affinché il livello di investimenti si mantenga costantemente elevato, verificando che $i$ benefici attesi derivanti dall'applicazione della tecnologia in termini di produttività e di efficienza siano superiori non solo ai costi diretti d'acquisto, ma anche $i$ costi di manutenzione, formazione del personale e gestione della stessa tecnologia.

I campi di applicazione delle tecnologie sono diversi: da soluzioni di machine learning per il credit scoring e lo studio comportamentale della clientela, all'intelligenza artificiale a supporto del customer care, all'automazione dei processi ripetitivi a bassa variabilità. La Robotic Process Automation (RPA), in particolare, sta suscitando grande interesse ed aspettative all'interno del settore finanziario. Essa permette di interagire con le applicazioni in essere emulando task manuali, routinarie e ripetitive di una risorsa umana, consentendo di allocare il personale ad attività innovative a maggior valore aggiunto. I vantaggi sono notevoli: l'automazione permette di ottimizzare $i$ costi operativi e il ritorno sugli investimenti, incrementare la produttività lavorando in modo continuativo 24/7, ridurre i tempi di lavorazione, diminuire i margini di errore umani, migliorare la soddisfazione dei clienti con servizi di maggiore qualità. La necessità di rispondere tempestivamente alle criticità di business connesse all'attuale contesto di crisi sta già determinando una forte accelerazione nell'adozione di strumenti di 
automazione, che rappresentano per il management bancario un asset fondamentale per ridurre la pressione sulle strutture operative e competere negli scenari futuri.

Potenzialmente, il successo dell'RPA risiederà nel vincere la sfida rappresentata dal costo minore del software robot rispetto alla manodopera offshore, da cui scaturisce l'attuale vantaggio economico derivante dall'arbitraggio del lavoro. Negli ultimi 20 anni la chiave strategica degli operatori finanziari è stata l'attività di offshore dei processi di middle e back-office nei Paesi con un minor costo del lavoro, quali Est Europa, Asia e America Latina. Oggi, la diminuzione dei differenziali tra il costo del lavoro onshore e offshore, le difficoltà legate al turnover del personale, le instabilità politiche e le correnti sovraniste mettono in forte discussione tale modello. Il basso costo d'esercizio e mantenimento dei robot, di circa 1/3 del costo di una risorsa offshore e 1/9 di una risorsa onshore, cambieranno radicalmente le strategie di internazionalizzazione e localizzazione e dei processi di innovazione. Secondo il rapporto "Rise of the Robots" di KPMG (2019), nei prossimi 15 anni una quota compresa tra il $45 \%$ e il $75 \%$ dei posti lavorativi delocalizzati verranno eseguiti dai robot. Il progresso tecnologico, dunque, avrà un ruolo importante nella composizione del back-middle office del settore bancario, abilitando strategie di reshoring, ossia di rientro nel paese di origine delle attività in precedenza delocalizzate all'estero, in seguito alle quali torneranno ad essere svolte presso l'headquarter le principali attività a valore aggiunto, come quelle legate alla gestione e all'utilizzo dell'informazione.

Limiti della ricerca. Evidentemente la ricerca si trova nella sua fase embrionale. Il piano di ricerca prevede una fase esplorativa field attraverso l'analisi di un case study, volto a fornire un riscontro empirico e una comprensione più approfondita della materia.

Implicazioni pratiche. Lo studio offre una sintetica sistematizzazione delle azioni industriali attuabili per il miglioramento della produttività e dell'efficienza della forza lavoro degli istituti bancari.

Originalità del lavoro. La ricerca vuole dare un riscontro concreto alle strategie di miglioramento dell'efficienza e della produttività della forza lavoro nel settore bancario, fornendo una visione d'insieme delle leve industriali adottabili per il raggiungimento di tali obiettivi all'interno delle strategie di crescita organica.

Parole chiave: Banche; Efficienza; Produttività; SWP, Paperless; RPA

\section{Bibliografia}

ANTONY J., ESCAMILlA J.L., CAINE P. (2003), "Lean Sigma [production and supply chain management]", Manufacturing Engineer, vol. 82, n. 2, pp. 40-42.

ANTONY J., GIJO E.V., CHILDE S.J. (2012), "Case study in Six Sigma methodology: manufacturing quality improvement and guidance for managers", Journal of Production Planning and Control, vol. 23, n. 8, pp.624640.

ANTONY J., FOUTRIS F., BANUELAS R., THOMAS A. (2004), “Using Six Sigma”, Journal of Manufacturing Engineer, vol. 83, n. 1, pp.10-12.

CAPGEMINI (2018), "Upskilling your workforce for the age of the machine: Why a workforce upskilling strategy is key to unleashing automation's productivity potential".

CASU B., GIRARDONE C. MOLYNEUX P. (2004), "Productivity change in European banking: a comparison of parametric and non-parametric approach", Journal of Banking \& Finance, vol. 28, n. 10, pp. 2521-2540.

CHAKRABORTY A., ANTONY J. (2019), "Lean Six Sigma in financial services industry: a systematic review and agenda for future research", Journal of Total Quality Management \& Business Excellence, vol. 30, n. 3, pp. 447465.

COSTA M., PASTORE A. (2019), "How the Automation Impacts on the Reshoring Strategy in the Financial and Business Services", Conference Proceedings Sinergie-SIMA 2019, pp. 477-481.

DE KONING H., DOES R.J.M.M. (2008), "Lean Six Sigma in Financial Services”, International Journal of Six Sigma and Competitive Advantage, vol. 4, n.1, pp.1-17.

DELOITTE (2017), The Digital Workforce is here. Understanding and Exploring Robotic Process Automation (RPA).

DYER J., GODFREY P., JENSEN R., BRYCE D., PASTORE A. (2018), Strategic management. Principi e applicazioni, ISEDI.

DYER W.G., WILKINS A.L. (1991), "Better Stories, Not Better Constructs, To Generate Better Theory: A Rejoinder to Eisenhardt", Academy of Management Review, vol. 16, n. 3, pp. 613-619.

FARRELL M.J. (1957), "The measurement of productive efficiency”, Journal of Royal Statistical Society, vol. 120 , n. 3, pp. 253-28.

FOERSTL K., KIRCHOFF J.F., BALS L. (2016), "Reshoring and insourcing: drivers and future research directions", International Journal of Physical Distribution \& Logistics Management, vol. 46, n. 5, pp. 492-515.

FRATOCCHI L., ANCARANI A., BARBIERI P., DI MAURO C., NASSIMBENI G., SARTOR M., ZANONI A. (2015), Manufacturing Back-Reshoring as a Nonlinear Internationalization Process, The Future of Global Organizing, pp. 365-403. 
FRATOCCHI L., ANCARANI A., BARBIERI P., DI MAURO C., NASSIMBENI G., SARTOR M., ZANONI A. (2016), "Motivations of manufacturing reshoring: an interpretative framework", International Journal of Physical Distribution \& Logistics Management, vol. 46, n. 2, pp. 98-127.

FURTERER S., ELSHENNAWY A.K. (2005), "Implementation of TQM and Lean Six Sigma tools in local government: A framework and a case study", Total Quality Management and Business Excellence Journal, vol. 16, n. 10, pp. 1179-1191.

GROSSKOPF S. (1986), "The Role of the Reference Technology in Measuring Productive Efficiency", The Economic Journal, vol. 96, n. 382, pp. 499-513.

HARTMAN T.E., STORBECK J.E., BYRNES P. (2001), “Allocative efficiency in branch banking”, European Journal of Operational Research, vol. 134, n. 2, pp. 232-242.

HENSLEY R., DOBIE K. (2005), “Assessing readiness for six sigma in a service setting”, Journal of Service Theory and Practice, vol. 15, n. 1, pp. 82-101.

KEARNEY A.T (2017), Global Services Locations Index, The Widening Impact of Automation.

KENDRICK J.W. (1956), "Productivity Trends: Capital and Labor", National Bureau of Economic Research, vol. 53, pp. 3-23.

KINKEL S. (2012), “Trends in production relocation and backshoring activities”, International Journal of Operations \& Production Management, vol. 32, n. 6, pp. 696-720.

KPMG (2019), Rise of the Robots.

KUMAR S., WOLFE A. D., WOLFE K. A. (2008), "Using Six Sigma DMAIC to improve credit initiation process in a financial services operation”, International Journal of Productivity and Performance Management, vol. 57, n. 8, pp. 659-676.

LANGLEY A. (1999), "Strategies for Theorizing from Process Data”, Academy of Management Review, vol. 24, n. 4, pp. 691-710.

MEDIOBANCA (2019), Dati cumulativi delle principali banche internazionali.

MINTZBERG H. (1979), “An Emerging Strategy of "Direct” Research”, Administrative Science Quarterly, vol. 24, n. 4, pp. 580-589.

PWC (2016), Robotic Process Automation in Shared Services How RPA applies to Finance, HR and Procurement.

SCHMOOKLER J. (1952), "The Changing Efficiency of the American Economy, 1869-1938", The Review of Economics and Statistics, vol. 34, n. 3, pp. 214-231.

SHAPIRO C., STIGLITZ J.E. (1984), "Equilibrium Unemployment as a Worker Discipline Device", The American Economic Review, vol. 4, n. 3, pp. 433-444

SHARMA D., SHARMA A.K, MUKESH K. BARUA M.J. (2013). "Efficiency and productivity of banking sector: A critical analysis of literature and design of conceptual model," Qualitative Research in Financial Markets, Emerald Group Publishing, vol. 5, n. 2, pp. 195-224.

SOLOW R.M. (1979), “Another possible source of wage stickiness", Journal of Macroeconomics, vol. 1, n. 1, pp. 7982.

TATE W.L., ELLRAM L.M., SCHOENHERR T., PETERSEN K.J. (2014), “Global competitive conditions driving the manufacturing location decision”, Business Horizons, vol. 57, n. 3, pp. 381-390.

THE HACKETT GROUP (2007), Hachett Enterprice Strategy Series. One of the biggest decisions you will make next 5-10 years - How to Balance Business Process Globalization and Transformation.

TORCELLAN C., VIANI G. (2019), “Banche Italiane su un piano inclinato”, Oliver Wyman report. pp. 1-12.

VIJAYA SUNDER M. (2016), "Rejects reduction in a retail bank using Lean SixSigma", Journal of Production Planning \& Control, vol. 27, n. 14, pp. 1131-1142.

WORD ECONOMIC FORUM (2018), "Towards a Reskilling Revolution A Future of Jobs for All"

YOUNG M. (2009), Implementing Strategic Workforce Planning, The Conference Board, Research Working Group Report 1444. 


\title{
CSR disclosure and environmental topics: what's happen in American corporates?
}

\author{
Assuntina Coviello* Alessandra De Chiara*
}

\begin{abstract}
Objectives. This work in progress focuses on corporate social responsibility (CSR) disclosure practices of American multinational corporations $(M N C)$. In light of the new politics of Trump, the paper focuses on the behaviour of the corporations to communicate their commitment to the environment analysing 40 CSR reports of the main American multinational corporations.

Is CSR disclosure positively associated with social context, especially government policy on sustainable development? And what is the role of government policy on companies engaged in green strategies commitment. These questions are investigated by the research in this paper.

The literature on corporate social responsibility (CSR) and on disclosure states that implementing CSR depends also on the social context within which CSR occurs (Athanasopoulou et al. 2015). Companies' responsible behavior is affected by several institutional factors (public and private regulations, the presence of institutionalized norms on corporate accounting, cultural systems, and the degree of openness to firm's stakeholders) (Coluccia et al. 2018).

The environmental policy in the United States (US) and the corporate social responsibility disclosure (CSRD) practices of American multinational corporations $(M N C)$ is the relation investigated in this work in progress.

The environmental policy in the United States aims to conserve natural resources and maintain the quality of air, water and land to protect public health and the natural environment. Policymakers harmonize environmental protection with economic growth, property rights, public health and energy production and use. Environmental policy has also expanded in recent years to include global warming and man-made climate change theory. The issue of environmental protection is addressed by the American Agency for the Protection of the Environment (EPA), founded on December $2^{\text {nd }}, 1970$, born as a result of a high concern for environmental pollution and to consolidate a series of federal activities research, monitoring, standard setting and supervisory activities. Since its inception, the EPA has been working towards a cleaner and healthier environment for the American people. For the first time on January $2^{\text {nd }}$, 2011, the EPA began regulating greenhouse gases $(G H G)$ from mobile and stationary sources of air pollution under the Clean Air Act (CAA).
\end{abstract}

In the aftermath of his election, Donald Trump presented what he calls the America First Energy Plan. His administration says that: «America has been held back by heavy energy sector regulations».

America currently has 264 billion barrels of oil reserves, the largest oil reserve in any nation. The United States also has a large amount of coal reserves, accounting for $26 \%$ of the world total, more than any other nation.

The White House estimates that by removing the Obama climate action plan, wages will rise by more than $\$ 30$ billion by 2024. Trump wants America to achieve energy independence from OPEC and from all nations that are hostile to the interests of the United States, to ensure national security and ensure it from possible supply disruptions and price fluctuations from the global oil market.

However, fossil fuels have run out, and entities such as the Pentagon claims that climate change also poses a threat to national security. During the first 100 days of the presidency, Donald Trump signed executive orders that direct the EPA to consider the formal revocation of the Clean Power Plan, a federal rule aimed, in 2015, to reduce carbon dioxide and similar emissions from power plants. electric.

On June $1^{\text {st }}$, 2017, President Donald Trump announced that the United States would withdraw from the Paris climate deal. According to which, the signatory countries are committed to reducing carbon dioxide emissions and the like in an attempt to limit man-made climate change. Trump argued that the deal was unfair to the United States, as it would cut jobs and have little effect on global temperatures.

Trump's new environmental policy has therefore caused major concerns by over 360 companies especially American, including Starbucks, General Mills, Kellogg, Levi Strauss, L'Oréal USA, alongside European giants such as Schneider Electric and Unilever, the which have launched an appeal to President Donald Trump asking to join the Paris Climate Agreement: "We ask to support investments in favour of a low-carbon economy in the United States and abroad, to ensure greater clarity for financial decision-makers and strengthen investor confidence all over the world-

Research fellowship- Department of Human and Social Sciences - University of Naples L'Orientale - Napoli - Italy e-mail:covielloas@libero.it

- Full Professor of Management - University of Naples L'Orientale - Napoli - Italy e-mail: adechiara@unior.it 
the letter reads - we want the American economy to be energy efficient and based on low-emission energy. Innovative and convenient solutions that can allow us to create jobs and strengthen American competitiveness. We are committed to doing our part to achieve the Paris goal of a world economy that limits heating well below 2 degrees Celsius».

The environmental policy of the administration of Donald Trump represents a shift from the political priorities and objectives of the mandate of his predecessor Barack Obama. Trump, during his campaign, has often described environmental regulations as an obstacle to business. Stating, in March 2016, that he wanted to eliminate the US Environmental Protection Agency (EPA) and to revoke many regulations and a moratorium on the leasing of federal coal reserves.

In light of the new politics of Trump, this work focuses on corporate social responsibility disclosure practices of American multinational corporations $(M N C)$. The paper focuses on the behaviour of the corporations to communicate their commitment to the environment analysing 40 CSR reports of the main American multinational corporations, during two consecutive years, respectively 2016 and 2017.

The research questions of the paper are aimed at identifying the presence of a positive relationship between companies engaged in green strategies commitment and CSR reports, analysing the degree of diffusion of the environmental issue in the CSR reports by US companies and analysing whether the environmental communication is changed in the run-up to the years preceding Trump's candidacy and subsequent to his election, connecting it to the green strategies of the multinationals themselves.

CSR disclosure (CSRD) can be defined as «the process of communicating the social and environmental effects of organizations' economic actions to particular interest groups within society and to society at large» (Gray et al. 1987, p. 9). In recent years, the concept of CSRD has developed enormously (Adhikariparajul et al. 2019; Alshbili and Elamer 2019; Tilt 2018; Coluccia et al. 2018).

Communication is considered an important aspect in sustainability strategies, both in the literature and in the sustainability guidelines, proposed by the various institutional bodies. The first considered CSR an important element of the competition (Cerana 2004) as it is not only aimed at improving the image, the corporate reputation (Hoeffler and Keller 2002) and at achieving social legitimacy (Morsing 2006), but may be aimed at influencing the consumer purchasing process. Even in the guidelines drawn up by various international bodies, CSR communication is considered important. Europe stressed that those who communicate their social responsibility strategy transmit a positive example to other companies. In the latest communication on the European CSR strategy, with reference to the dissemination of social and environmental information, it was stressed that communication «can facilitate engagement with stakeholders and identify concrete sustainability risks. It also constitutes an important element for accountability and can contribute to increasing public confidence in companies» (EU, 2011 p.13).

Many are the studies regarding the upgrading of general guidelines, principles and standards in refence to CSR to support firms, trying to establish them, that are very important to inform about the social and environmental disclosure (OECD 2011). The firms should report CSR information about the objective, aims, intentions and progress. It is important in order to incentive the firms and improve their actions and performances.

One of the most common problem regarding the divulgation of the CSRD regards the destination of the reports, because some authors concentrate their interest on various aspects of social and environmental disclosure causing conflicting findings (Aerts et al., 2006; Du et al., 2010; Morhardt, 2010; Schaltegger and Burritt 2010).

Some researchers believe that the reporting practices are like a public relation in order to defense or mitigate the risks of the firms (Deegan 2002; Beck et al. 2010; Bondy et al. 2012; Chauvey et al. 2015); but there being changing this perspective in fact CSR disclosure is becoming part of the firms' strategies in order to create added value (PérezLopez et al. 2013; Russo Spena et al. 2018).

If the firms implementing a proactive approach to CSR disclosure have results not only in terms of ethical and reputation, but also in term of business (McElhaney 2009; Porter and Kramer 2006; Xueming and Bhattachary 2006), reducing operating risks and input costs, implementing long term orientation of management and potentially innovation, increasing market opportunities (Dhaliwal et al. 2011; Eccles et al. 2011; Guenster et al. 2011; Barnett and Salomon 2012; O" berseder et al. 2013). Nevertheless, some authors recently started to doubt on the real value of reporting (Arena et al. 2014). Others focused on the quality of information disclosed in CSR reports, considering communication with stakeholders as a part of assumed social responsibility (Szczepankiewicz and Mućko, 2016), and finding that CSR reporting practices did not improve the quality of disclosure (Michelon et al. 2015). Some authors observed that often companies tend to disclose CSR information by diluting the relevant CSR information with unnecessary information to build their desired images (Anugerah et al. 2018).

Several studies have attempted to investigate the effect of general contextual factors on CRS disclosure, but findings are not univocal. Factors that may influence CSR disclosure practices fall broadly into internal and external and are commonly classified in (Tilt 2016): 1. corporate characteristics (such as size, industry group, financial/economic performance and share trading volume, price and risk), 2. general contextual factors (such as country of origin, time, specific events, media pressure, stakeholders and social, political, cultural and economic context, 3. internal contextual factors, including different aspects of corporate governance.

Some studies focus on the meaning of social context, underling that three theoretical approach can be used: institutional theory that has become the predominant perspective in organization studies and has used to explain the external context of CSR; the cognitive/sensemaking perspective is been selected because of the important role of individual decision makers in CSR; cultural approach that describes culture as a key component of a multidimensional approach and it is the most widely integrated social context approach in CSR studies (Athanasopoulou et al. 2015). 
A review of the literature, in the paper of Alshbili et al. 2019, shows that the level of CSRD practices is different between developed and developing countries, because developed countries have employed practical actions and procedures to push firms to reveal their CSR information. The differences between developed and developing countries suggest that CSRD practice is largely affected by the institutional context in which firms operate (Alshbili et al. 2019). Other studies, explaining the meaning of institutional factors - such as public and private regulations, the presence of institutionalized norms on corporate accounting, cultural systems, and the degree of openness to firm's stakeholdersunderline that the theoretical debate announces that CSRD are higher in countries with weaker institutions' mechanisms. Companies, by adopting CSR initiatives, fill institutional voids and CSR seems to act as a substitute for institutional forces and that it is stronger in liberal market economies (Coluccia et al. 2018). In this line, several studies underline that the practices of CSRD are more popular in western part of Europe then in Central and Eastern European (CEE) countries and empirical studies are filling this gap (Hąbek 2017, Fijatkowska et al. 2018; Ehsan et al. 2018).

The meaning of social and institutional context is particularly relevant: different political, social, cultural and economic environments impact on reporting of CSR activities (Tilt 2016). On these topics some studies underline the important impact of the institutional environment (at the institutional, group, and firm level) on CSR reporting practices, analysing different levels of corporate governance mechanisms as determinant factors of the CSR reporting practices (Miras-Rodríguez et al. 2019).

Several studies have examined the role of government in CSR activities, analysing the political function, the political dependence and political monitoring (Marquis and Qian 2013), or examining both political function and economic function together (Wang et al. 2016). This study shows that: "political regulation through issuing regulatory disclosure does improve CSR reporting quality as people anticipated, but governmental economic control on listed firms cancels out the positive link between regulation and CSR reporting quality, in particular for government controlled larger firms, which gives insights into the reasons why recent studies of social disclosure regulation suggest that government interventions do not seem to resolve the problems that are generally attributed to voluntary disclosures» (Ibidem, p. 69).

Methodology. The aim of the empirical research is to verify how American MNC moved in the two years, 20162017, in relation to the new American environmental policy. Based on a longitudinal study of CSR reports of firms operating in different sectors, the paper offers a detailed study on how disclosure practices are changing and which principles and approaches influence and drive the development of such disclosures.

The usage of the indicator of the disclosure to evaluate the commitment toward responsible behaviour is valorised by the literature which emphasize not only the CSR initiatives but also the deeper knowledge regarding them, inside and outside the corporations (Brønn and Vironi 2001).

The research was conducted on a sample of 40 American MNCs (Tab.1), belonging to different industries, and it has investigated, through a qualitative analysis, the sustainability reports relating to the years 2016 and 2017 for each company.

The analysis method used in the research is the Content Analysis (Guthrie and Abeysekera, 2006). This type of analysis made it possible to quantify and identify the presence of contents, through the systematic reading of company reports. Obtaining descriptive data, such as word frequencies.

This method is in line with studies which use content analysis of selected CSR reports to describe and assess patterns and structure of information disclosed in them (Szczepankiewicz, Mucko, 2016).

The software used for reading and research is Nvivo, a software that offers a wide range of tools (Silver and Lewins 2014). The analysis concerned the identification of words deemed fundamental to analyse the environmental issue of the companies examined from point of view of qualitative.

It was identified a sample of 86 words, related to the environment, to which it was possible to associate four elements, representative of the environmental theme: 'air', 'water', 'earth' and 'fire'. For each element was assigned the 86 words (topics) deemed most significant, from the point of frequency, as well as for the information provided.

Subsequently, the elements and the topics were also analysed in relation to the category of actor to which they refer, distinguished in the same companies and/or their supply chains.

Lastly, an analysis of the topics was carried out in relation to the strategic relevance for the companies, highlighting, in the proximity analysis (range of 10 words), the use of the words relating to the topics in conjunction with other words such as 'strategic', 'objective', 'goal', 'aim' and 'target', as they testify to the relevance of the commitment to environmental sustainability by the companies investigated.

The evaluation on green communication was carried out for the purpose of comparing from a temporal point of view, the year 2016 and 2017. 
Tab. 1: The MNCs analysed

\begin{tabular}{|c|c|c|}
\hline & MNCs & SECTOR \\
\hline 1 & S. C. JOHNSON \& SON INC & Consumer goods \\
\hline 2 & BAXTER INTERNATIONAL & Pharmaceuticals \\
\hline 3 & TIFFANY \& CO. & Jewelery and Silverware \\
\hline 4 & COCA-COLA & Beverage \\
\hline 5 & APPLE INC & Elettronic and hardware \\
\hline 6 & CISCO SYSTEMS INC & Computer technology \\
\hline 7 & DELL & $\begin{array}{l}\text { Computer hardware, } \\
\text { Computer software }\end{array}$ \\
\hline 8 & THE WALT DISNEY COMPANY & Media and Entertainment \\
\hline 9 & GENERAL MOTORS & Automotive \\
\hline 10 & CHEVRON & Energy \\
\hline 11 & HEWLETT-PACKARD & Computer technology \\
\hline 12 & $I B M$ & Technology \\
\hline 13 & INTEL CORPORATION & Semiconductors \\
\hline 14 & THE KELLOGG COMPANY & Food processing \\
\hline 15 & STARBUCKS CORPORATION & Coffee shop \\
\hline 16 & CONOCOPHILLIPS INC & Oil and gas \\
\hline 17 & AGILENT TECHNOLOGIES INC & Life sciences tool \& services \\
\hline 18 & NEWMONT MINING CORP & Metals \& Mining \\
\hline 19 & ABBOTT LABORATORIES & Health Care Equipment \& Supplies \\
\hline 20 & UNITEDHEALTH GROUP INC & Health Care Providers \& Supplies \\
\hline 21 & MASTERCARD INC & Software \& Services \\
\hline 22 & SALESFORCE.COM INC & Software \& Services \\
\hline 23 & SCHLUMBERGER LTD & Energy \\
\hline 24 & $M E R C K \& C O I N C$ & Pharmaceuticals, Biotechnology \& Life Sciences \\
\hline 25 & PEPSICO INC & Food, Beverage \& Tobacco \\
\hline 26 & ALTRIA GROUP INC & Food, Beverage \& Tobacco \\
\hline 27 & MORGAN STANLEY & Diversified Financials \\
\hline 28 & HUMANA INC & Health Care Equipment \& Services \\
\hline 29 & WASTE MANAGEMENT INC & Commercial Services \& Supplies \\
\hline 30 & BIOGEN INC & Biotechnology \\
\hline 31 & OWENS CORNING & Building Products \\
\hline 32 & ANTHEM INC & Health Care Equipment \& Services \\
\hline 33 & SEMPRA ENERGY & Utilities \\
\hline 34 & GENERAL MILLS INC & Food, Beverage \& Tobacco \\
\hline 35 & PROCTER \& GAMBLE & Consumer goods \\
\hline 36 & NIKE INC & Apparel, Accessories and Sports equipment \\
\hline 37 & MICROSOFT CORPORATION & $\begin{array}{l}\text { Computer software, } \\
\text { Computer hardware, } \\
\text { Consumer electronics, } \\
\text { Social networking service, } \\
\text { Cloud computing, } \\
\text { Video games, } \\
\text { Internet and } \\
\text { Corporate venture capital }\end{array}$ \\
\hline 38 & ANHEUSER-BUSCH INBEV & Drink, brewing \\
\hline 39 & YUM! BRANDS, INC. & Restaurants \\
\hline 40 & $E B A Y I N C$. & Electronic auction \\
\hline
\end{tabular}

Source: Authors' elaboration

Findings. The first step regards the identification of the main environmental topics, through simple frequencies analysis, we found 86 words related to the environment which have been associated to four elements: 'air', 'earth', 'water' and 'fire'. Concerning the period, 2016-2017, the table 2 shows the number of the frequency for each element.

Tab. 2: Simple frequency of the environmental elements (2016-2017 years)

Source: Authors' elaboration

\begin{tabular}{|l|l|l|}
\hline & $\mathbf{2 0 1 6}$ & $\mathbf{2 0 1 7}$ \\
\hline AIR & 6792 & 5888 \\
\hline WATER & 2927 & 2603 \\
\hline EARTH & 2834 & 1993 \\
\hline FIRE & 5775 & 5110 \\
\hline
\end{tabular}


The table shows that the US corporations pay particular attention to the element 'air', being the frequencies higher than the others, for both the years 2016 and 2017. But for the year 2017 there is a reduction of attention to this element. Data also carried out that emissions and gas are the topics on which the firms are focused, showing a great interest on the phenomenon of the air pollution.

Within the 'earth' category for 2017 there was a reduction in frequencies, which could suggest a decrease in attention compared to issues such as packaging and recycling. Also, for the 'fire' category, there was a decrease in frequencies for the year 2017, so even in this case we could hypothesize a reduction in the company's sensitivity towards energy and renewable sources.

The cross frequencies analyses describe the context in the usage of the environmental elements respect to the actors to which they refer. In particular, the words 'business', 'corporate', 'company', 'supply chain' and 'supplier', were considered and classified into two categories: firm (the first three words that can be considered as synonyms); supplier (for the last two words) (Tab.3).

Through this cross-analysis, a logical connection has been created between the category of actors and the environmental elements.

Tab. 3: Cross frequencies environmental elements-actors (2016 - 2017 years)

\begin{tabular}{|l|l|l|l|l|}
\cline { 2 - 5 } \multicolumn{1}{c|}{} & \multicolumn{2}{c|}{ FIRM } & \multicolumn{2}{c|}{ SUPPLIER } \\
\cline { 2 - 5 } \multicolumn{1}{c|}{} & $\mathbf{2 0 1 6}$ & $\mathbf{2 0 1 7}$ & $\mathbf{2 0 1 6}$ & $\mathbf{2 0 1 7}$ \\
\hline AIR & 822 & 747 & 550 & 365 \\
\hline WATER & 207 & 224 & 136 & 100 \\
\hline EARTH & 602 & 501 & 292 & 229 \\
\hline FIRE & 672 & 590 & 244 & 189 \\
\hline
\end{tabular}

Source: Authors' elaboration

From this table it emerges that the element 'air', in 2016, is considered important both in relation to companies and their suppliers. In particular, attention has been paid to Gas and CO2 emissions, and therefore to their reduction. In fact, companies often implement internal guidelines, aimed at selecting suppliers, which is important for building and guiding a sustainable supply chain. The companies also push their suppliers to make transitions that lead to a reduction in environmental impacts. The same situation seems to repeat itself in 2017.

The third step is the cross frequencies analyses useful to describe the context in the usage of the environmental topics respect to their strategic importance for the corporates. The analysis moves on a sample of 15 words (Tab.4) selected in order to carry out the strategic importance that the company associates to the topics.

Tab. 4: Environmental topics

\begin{tabular}{|l|l|}
\hline & \multicolumn{1}{|c|}{ WORDS } \\
\hline 1 & CARBON \\
\hline 2 & CARBON FOOTPRINT \\
\hline 3 & CLIMATE \\
\hline 4 & CO2 \\
\hline 5 & ELECTRICITY \\
\hline 6 & EMISSIONS \\
\hline 7 & ENERGY \\
\hline 8 & FOOTPRINT \\
\hline 9 & GAS \\
\hline 10 & GHG \\
\hline 11 & MATERIAL \\
\hline 12 & PACKAGING \\
\hline 13 & RECYCLING \\
\hline 14 & RENEWABLE \\
\hline 15 & WATER \\
\hline
\end{tabular}

Source: Authors' elaboration

This cross analysis creates a logical connection between the topics and companies' strategic importance, though an analysis of the proximity words (with a range of 10 words). The proximity to the topics of terms was evaluated as 'strategic', 'objective', 'goal', 'aim' and 'target', as they testify the relevance of the commitment to environmental sustainability by the firms investigated (Tab.5). 
Tab. 5: Cross frequencies, environmental topics - strategic issue (2016- 2017)

\begin{tabular}{|l|c|c|c|c|c|c|c|c|}
\cline { 2 - 9 } \multicolumn{1}{c|}{} & \multicolumn{2}{c|}{$\begin{array}{c}\text { STRATEGIC } \\
\text { OBJECTIVE }\end{array}$} & \multicolumn{2}{c|}{ GOAL } & \multicolumn{2}{c|}{ AIM } & \multicolumn{2}{c|}{ TARGET } \\
\cline { 2 - 9 } & $\mathbf{2 0 1 6}$ & $\mathbf{2 0 1 7}$ & $\mathbf{2 0 1 6}$ & $\mathbf{2 0 1 7}$ & $\mathbf{2 0 1 6}$ & $\mathbf{2 0 1 7}$ & $\mathbf{2 0 1 6}$ & $\mathbf{2 0 1 7}$ \\
\hline AIR & 26 & 29 & 371 & 295 & 13 & 32 & 114 & 151 \\
\hline WATER & 15 & 17 & 89 & 97 & 15 & 18 & 32 & 23 \\
\hline EARTH & 16 & 20 & 102 & 62 & 11 & 18 & 33 & 18 \\
\hline FIRE & 28 & 38 & 69 & 192 & 20 & 32 & 73 & 62 \\
\hline
\end{tabular}

Source: Authors' elaboration

From the analyses emerges that the corporations show more interest in the element of water, in term of strategic objectives, goal and aim, in 2017. On the other side, regarding the element of air, the emissions have the higher frequencies in relation to the word 'target', but a reduction in terms of word 'objective'; a reduction in interest, for Gas and GHG, in terms of scope and a small increase as regards the corporate target; a significant increase in the term carbon footprint, $\mathrm{CO} 2$ and climate associated with a corporate target, so for the first (Gas and GHG) there is a reduction in the use of the term as an objective for the climate there is an increase of frequencies in term of corporate objective.

As regard the energy sources, the analysis highlights, for the carbon element, that there is an increase in terms of target and strategic objective; while for energy there is a reduction in corporate sensitivity in relation to an objective and target consideration; while the attention in terms of objective for the energy element and renewable, is reduced.

In closing, it seems that corporations do not pay particular attention to packaging and recycling as a target and objective for the company; as for the word 'material' there is a low interest in CSR reports.

The first results of the analysis show a reduction of the contents in the CSR reports and in opposition a major focus on the strategic objectives of the companies, regarding environmental topics.

Research limits. In the first step, the research regards the identification of the main environmental topics, through simple frequencies analysis, the cross frequencies analyses in order to describe the context in the usage of the environmental elements, respect to the actors to which they refer, and to create a logical connection between the topics and companies'strategic importance, though an analysis of the proximity words. Other insights are needed.

Practical implications. It seems that the politics of Trump has produced a kind of skimming on the companies' ability to communicate their engagement in the environmental sustainability. In the other words, the companies which make of sustainability their strategical target, a driver of competitivity, continue to communicate the actions taken and investments made to reduce the environmental impact of their processes and products; on the other hand those who consider CSR disclosure as a tool to improve the image of the company, due to the low interest in environmental issues promoted by US policy, have reduced the communications aimed to explain the environmental sustainability of the company. For these companies, the first results seem to show a positive relation between the social context, related to environmental government policy, and CSR disclosure, related to contents regarding environmental issues.

For those companies which make of sustainability their strategical target, the findings of the research seem to be in line with the literature that identifies in CSR disclosure a part of an integrated strategy for firms to create added value (Pérez-Lopez et al. 2013). In other words, the important discriminating factor is the strategy pursued by companies.

Originality of the study. The work contributes to deepen the debate on the relationship between CSR disclosure and social context, specially government policy on sustainable development, and on the role of government policy on companies engaged in green strategies commitment.

The research focuses on the analysis of these relationships in relation to the recent and questionable American environmental policy and in this aspect it represents an element of originality.

Key words: CSR, disclosure, environment, government policy, USA

\section{References}

AERTS W., CORMIER D., MAGNAN M. (2006), "Intra-industry imitation in corporate environmental reporting: An international perspective”, Journal of Accounting and Public Policy, vol. 25, n. 3, pp. 299-331.

ALSHBILI I., ELAMER A. (2019), "The influence of institutional context on corporate social responsibility disclosure: a case of a developing country", Journal of Sustainable Finance \& Investment, Forthcoming (Accepted $30^{\text {th }}$ September, 2019), doi: 10.1080/20430795.2019.1677440 
ANUGERAH E.G., SARASWATI E., ANDAYANI W. (2018), "Quality Of Disclosure And Corporate Social Responsibility Reporting Practices In Indonesia”, Journal Akuntansi, vol. XXII, n. 03, pp. 337-353.

ARENA C., BOZZOLAN S., MICHELON G. (2014), "Environmental reporting: Transparency to stakeholders or stakeholders' manipulation? An analysis of disclosure tone and the role of board of director", Corporate Social Responsibility and Environmental Management, vol. 22, n. 6, pp. 346-361.

ATHANASOPOULOU A., SELSKY J. (2015), "The Social Context of Corporate Social Responsibility”, Business \& Society, vol. 54, n. 3, pp. 322-364.

BARNETT M.L., SALOMON R. M. (2012), "Does it pay to be really good? Addressing the shape of the relationship between social and financial performance", Strategic Management Journal, vol. 33, n. 11, pp. 1304-1320.

BECK A.C., CAMPBELL D., SHRIVES P.J. (2010), "Content analysis in environmental reporting rehearsal of the method in a British-German context", British Accounting Review, vol. 42, n. 3, pp. 207-222.

BONDY K., MOON J., MATTEN D. (2012), “An institution of corporate social responsibility (CSR) in multi-national corporations (MNCs): Form and implications”, Journal of Business Ethics, vol. 111, n. 2, pp. 281-299.

BRØNN P.S., VRIONI A.B. (2001), "Corporate social responsibility and cause related marketing: an overview", International Journal of Advertising, vol. 20, n. 2, pp. 207-222.

CHAUVEY J., GIORDANO-SPRING S., CHO C.H., PATTEN D.M. (2015), “The normativity and legitimacy of CSR disclosure: Evidence from France”, Journal of Business Ethics, vol. 130, n. 4, pp. 789-803.

COLUCCIA D., FONTANA S., SOLIMENE S. (2018), "Does Institutional Context Affect CSR Disclosure? A Study on Eurostoxx 50", Sustainability, n. 10, 2823, doi:10.3390/su10082823.

DEEGAN C. (2002), "The legitimizing effect of social and environmental disclosures: A theoretical foundation", Accounting, Auditing and Accountability Journal, vol. 15, n. 3, pp. 282-311.

DHALIWAL D. S., LI O. Z., TSANG A., YANG Y. G. (2011), "Voluntary nonfinancial disclosure and the cost of equity capital: The initiation of corporate social responsibility reporting", The Accounting Review, vol. 86, n. 1, pp. 59-100.

DU S., BHATTACHARYA C.B., SEN S. (2010), "Maximizing business returns to corporate social responsibility (CSR): The role of CSR communication", International Journal of Management Reviews, vol. 12, n. 1, pp. 8-19.

ECCLES R.G., KRZUS M.P., SERAFEIM G. (2011), "Market interest in non-financial information”, Journal of Applied Corporate Finance, vol. 23, n. 4, pp. 113-127.

EHSAN S., NAZIR M.S., NURUNNABI M., RAZA KHAN Q., TAHIR S., AHMED I. (2018), “A Multimethod Approach to Assess and Measure Corporate Social Responsibility Disclosure and Practices in a Developing Economy", Sustainability, n. 10, 2955, doi:10.3390/su10082955.

FIJAŁKOWSKA J., ZYZNARSKA-DWORCZAK B., GARSZTKA P. (2018), "Corporate Social-Environmental Performance versus Financial Performance of Banks in Central and Eastern European Countries”, Sustainability, n. 10, 772, doi:10.3390/su10030772.

GAMERSCHLAG R., MÖLLER K., VERBEETEN F. (2011), "Determinants of voluntary CSR disclosure: empirical evidence from Germany”, Review of Managerial Science, vol. 5, n. 2, pp. 233-262.

GRAY R., OWEN D., MAUNDERS K. (1987), Corporate social reporting: Accounting and accountability, PrenticeHall, London.

GUENSTER N., BAUER R., DERWALL J., KOEDIJK K. (2011), “The economic value of corporate eco-efficiency”, European Financial Management, vol. 17, n. 4, pp. 679-704.

GUTHRIE J., ABEYSEKERA I. (2006), “Content analysis of social, environmental reporting: What is new?”, Journal of Human Resource Costing \& Accounting, vol. 10, n. 2, pp. 114-126.

HĄBEK P. (2017), "CSR Reporting Practices in Visegrad Group Countries and the Quality of Disclosure", Sustainability, vol. 9, n. 12, 2322, doi.org/10.3390/su9122322.

MARQUIS C., QIAN C. (2013), “Corporate social responsibility reporting in China: Symbol or Substance?” Organization Science, vol. 25, n. 1, pp. 127-148.

MCELHANEY K. (2009), “A strategic approach to corporate social responsibility”, Leader to Leader, vol. 52, n. 1, pp. 30-36.

MICHELON G., PILONATO S., RICCERI F. (2015), “CSR Reporting Practices and the Quality of Disclosure: An Empirical Analysis”, Critical Perspectives on Accounting, vol. 33, pp. 59-78.

MIRAS-RODRÍGUEZ M.M., MARTÍNEZ-MARTÍNEZ D., ESCOBAR-PÉREZ B. (2019), "Which Corporate Governance Mechanisms Drive CSR Disclosure Practices in Emerging Countries”, Sustainability, n. 11, p. 61, doi:10.3390/su11010061.

MORHARDT J.E. (2010), "Corporate social responsibility and sustainability reporting on the internet", Business Strategy and the Environment, vol. 19, n. 7, pp. 436-452.

O”BERSEDER M., SCHLEGELMILCH B.B., MURPHY P.E. (2013), "CSR practices and consumer perceptions”, Journal of Business Research, vol. 66, n. 10, pp. 1839-1851.

OECD (2011), OECD guidelines for multinational enterprises, OECD, Paris.

PÉREZ-LOPEZ D., MORENO-ROMERO A., BARKEMEYER R. (2013), "Exploring the relationship between sustainability reporting and sustainability management practices", Business Strategy and the Environment, vol. 24, n. 8, pp. 720-734.

PORTER M.E., KRAMER M.R. (2006), "The link between competitive advantage and corporate social responsibility”, Harvard Business Review, vol. 84, n. 12, pp. 78-92. 
RUSSO-SPENA T., TREGUA M., DE CHIARA A. (2018), "Trends and Drivers in CSR Disclosure: A Focus on Reporting Practices in the Automotive Industry", Journal of Business Ethics, vol. 151, n. 2, pp. 563-578.

SCHALTEGGER S., BURRITT R.L. (2010), "Sustainability accounting for companies: Catchphrase or decision support for business leaders?”, Journal of World Business, vol. 45, n. 4, pp. 375-384.

SCHRECK P. (2013), Disclosure (CSR Reporting), in IDOWU S.O., CAPALDI N., ZU L., GUPTA A.D. (EDS), Encyclopedia of Corporate Social Responsibility, Springer, Berlin

SILVER C., LEWINS A. (2014), Using software in qualitative research: A step-by-step guide (2nd ed.), Sage, London.

SZCZEPANKIEWICZ E.I., MUĆKO P. (2016), "CSR Reporting Practices of Polish Energy and Mining Companies", Sustainability, vol. 8, n. 2, 126, DOI: 10.3390/su8020126

TILT C.A. (2016), "Corporate social responsibility research: the importance of context", International Journal of Corporate Social Responsibility, vol. 1, n. 2, pp. 2-9.

WANG J., TIAN G., FAN W., LUO D. (2016), "The Effect of Mandatory Regulation on Corporate Social Responsibility Reporting Quality: Evidence from China”, Journal of Applied Business Research (JABR), vol. 33 , n. 1, pp. 67-86.

XUEMING L., BHATTACHARY C.B. (2006), "Corporate social responsibility, customer satisfaction, and market value", Journal of Marketing, vol. 70, n. 4, pp. 1-18. 


\title{
Core self-evaluations, dual mind processing, and overconfidence: a laboratory experiment
}

\author{
MATTEO CRISTOFARO* LUNA LEONI ${ }^{\bullet}$
}

\begin{abstract}
Objectives. In order to survive in the current competitive environment, organizations - both private and public are constantly looking for reaching organizational effectiveness and efficiency; however, the achievement of these results depends on how effective and efficient the organization organizational agents are (Inuwa, 2016) and how much good are in making decisions. According to the established literature, organizational agents' ability to make successful decision making processes mainly (but not exclusively) relays, on the one hand, on the organizational environment (Wu and Lee, 2016) and, on the other hand, on individual characteristics such as emotions (Cristofaro, 2019; 2020) and personal traits (Cristofaro, 2016, 2017a; Busic-Sontic et al., 2017). Among personal traits, the "core evaluations" (CE) (Judge and Bono, 2001), namely the evaluations that individuals make about others, the world, and themselves (in this last case, we talk about core-self evaluations - CSE), is the one that has been receiving increasing attention from behavioral strategy scholars (Powell et al., 2011) due its ability to predict job performance (Judge and Bono, 2001). According to Judge et al. (1998), CE is made up of four components (also called "dispositions"): i) Self-Esteem: the in general esteem a individual has with respect to himself/herself; ii) Generalized Self-Efficacy: the self-estimation of being successful; iii) Locus of Control: the conviction in controlling life's variables; and, iv) Emotional Stability: the capacity to maintain a low neuroticism level. These four dispositions are altogether inter-related and have been broadly illustrated as influencing decision making processes (Hollenbeck et al., 1988; Judge et al., 1998; Silvester et al., 2002).

Thus, the CEs' construction calls for a deep examination and understanding of the "human factor" within the organizational environment (Judge et al., 2009). In this vein, previous studies on the topic have already demonstrated how individuals who rate CEs high also show high scores in work interest (Erez and Judge, 2001), career accomplishment, objective achievement, and wage and job-related status (Judge and Hurst, 2008).

Specifically referring to the evaluations that individuals make about themselves - i.e., core-self evaluations - CSE henceforth), according to the previous literature, individuals with a high degree of CSE are generally better at coping with stress and learning from training, more conscientious, and good at leading and inspiring their teams, maintain a positive outlook, manage multiple roles and responsibilities, and even at reach higher salary (Hollenbeck et al., 1988; Silvester et al., 2002; Judge and Hurst, 2007; Cristofaro, 2017b).

Therefore, management scholars contend that CSE ought to be accepted as a powerful, confirmed concept to investigate the executive self-concept. In this last vein, Hiller and Hambrick (2005) state that managers with high values of CSE are beyond any doubt of their capacities, and they consider profoundly that the application of their abilities will bring positive results for their organization. Thus, CSE seems to be connected to the results achieved by the individuals (or groups of individuals, i.e., teams) and - consequently - to the decisions taken by the same in carrying out the various activities within the working environment.

According to the above, this paper aims to answer the following research question: "How Core-Self Evaluations influence team decision making processes?". In particular, the investigation of the relationship between CSE and decision making process is carried out by considering, as unit of analysis, a team. Moreover, in order to properly carry on the investigation, the paper is based on and tests the following two hypotheses:
\end{abstract}

\section{H1: Teams with high CSE are inclined to intuitive thinking.}

H2: Teams with high CSE are inclined to overconfidence bias.

Concerning the first hypothesis, previous studies on the topic suggest that exist a link between CSE and intuitive thinking. In particular, the study of Jordan et al. (2007) demonstrate how individuals who chronically consider their instinct as predominant are more inclined to self-esteem (one of the four fundamentals components of CSE). Moreover, the study of Claxton et al. (2015) show how a significant level of CSE (i.e., hyper-CSE or hubris - Hiller and Hambrick, 2005) is usually connected with intuition.

Post-Doc Research Fellow in Management - University of Rome Tor Vergata - Italy e-mail:matteo.cristofaro@uniroma2.it

- Assistant Professor in Management - University of Rome Tor Vergata - Italy e-mail: luna.leoni@uniroma2.it 
Lastly, concerning the second hypothesis, according to Baumeister et al. (1993), Kramer et al. (1993) and Zacharakis and Shepherd (2001), individuals with a high self-esteem make excessively positive self-evaluation. Thus, hyper CSE (or hubris) can lead people to fall into the so-called "overconfidence trap" (Bazerman and Moore, 2013; Gudmundsson and Lechner, 2013; Cain et al., 2015), with dramatic consequences on the efficiency of their decision making process (Abatecola et al., 2018; Abatecola and Cristofaro, 2019).

Methodology. As to test the two developed hypotheses and answer the research paper aim, a simulation game (i.e., business game) has been used. This method has already been recognized by several scholars (e.g., Lainema and Makkonen, 2003; Faria et al., 2009; Kim et al., 2013; Henriksen and Børgesen, 2016; Korchinskaya et al., 2020) as useful to investigate the accuracy of managerial decisions and their application through an analysis of the performances made by the participants of their experiments. In this study, 120 graduate students were involved in the experiment by taking part to the simulation game. The experiment took part when participants were asked to run the fifth and final module of the simulation game in which they had all the managerial functions under control with the aim of grasping to the most elevated conceivable execution for the firm. The day of the experiment the leading researcher explained the interest in studying the relationship between their personality traits, some behavioural decision variables and their connections with their performance in simulation game. Before running the fifth module of the simulation game, each participant was firstly invited to answer the 12-item CSE Scale (CSES) (Judge et al., 2003) and seven-item Cognitive Reflection Test (CRT) as to measure their CSE degree and tendency to adopt an intuitive or reflective thinking. Then, they were asked to perform the fifth and last module of the simulation game; this occurred in three hours. During this time period, participants were not aware of their performance (tracked by the leading researcher). At the end of the performance, each individual within groups were asked to estimate the reached final net worth of their firm and to write it down on a paper. Variables at the centre of the two developed hypotheses to be tested were measured as follows:

- $\quad$ Core Self-Evaluations. The CSE score of each group was calculated according to the average of the CSE score of its members. The CSE score at the individual level was derived by asking participants to fill the 12-item CSES (Judge et al., 2003) that provides an explicit and integrative estimation of a person's core self-perception. Respondents were asked to rank their predisposition on the 12 items according to a five-point Likert scale ranging from 1 (strongly disagree) to 5 (strongly agree) (Joo et al., 2012). It is worth notice that values assigned to reverse grades' questions were subtracted; from that, the maximum and minimum values that can be reached by completing the CSES are, respectively, 24 and -24, with a neutral point at 0. Thanks to the STATA function called 'egen', it was possible to derive three main clusters according to the average CSE value of groups: i) low CSE groups (whose averages range from -24 to -9); ii) average CSE groups (whose averages range from -8 to 8); and, iii) high CSE groups (whose averages range from 9 to 24). Accordingly, the initial 30 groups were relocated in these three clusters, counting 10 groups each.

- Reflective and intuitive thinking. To assess the cognitive predisposition of respondents between reflective and intuitive thinking, it was adopted the seven-item CRT by Toplak et al. (2014). The test is presumed to estimate a person's tendency to engage in intuitive or reflective thinking (Patel et al., 2019). Each correct answer was counted as 1, while incorrect answer as 0; so, the maximum and minimum values that can be reached by completing the CRT are, respectively, 7 and 0. After having calculated the sum of correct and incorrect answers for each individual, this value was summed with the ones of the other members of the group and a final average was derived.

- Overconfidence. Moore and Healy (2007) defined that overconfidence has been usually measured in terms of "overestimation" and this is the declination of overconfidence that has been used and operationalized for this study. In particular, participants were not made aware during the simulation game of their current net worth; at the end of their performance, it has been demanded at each individual within groups to make an estimation of their final reached net worth. After having collected the estimation of the net worth for each individual, this value was summed with the ones of the other members of the group and a final average of the estimation of the net worth was derived. As to calculate the overestimation of each group - in line with the one adopted by Hoppe and Kusterer (2011) - the final average of the estimation of the net worth of the group was compared with the actual net worth and a subtraction was operated as to find how much was the overestimation of their results.

Finally, as to test the two developed hypotheses, two one-way Analysis of Variance (ANOVA) have been implemented. This is the most suitable statistical technique that can be used in order to compare means of two or more samples. A Tukey post hoc test was conducted after each one-way ANOVA as to determine differences among groups.

Findings. As to verify whether teams with high CSE are inclined to intuitive thinking (H1), a one-way ANOVA was firstly implemented considering the different CSE clusters (low, average, high) and their groups' results on the CRT test. 
Tab. 1: ANOVA Table - CSE on intuitive-reflective thinking

\begin{tabular}{|c|c|c|c|c|c|}
\hline & Sum of squares & df & Mean Square & F & Sig. \\
\hline Between Groups & 120.467 & 2 & 60.233 & 80.510 & .000 \\
\hline Within Groups & 20.200 & 27 & .748 & & \\
\hline Total & 140.667 & 29 & & & \\
\hline
\end{tabular}

Source: Authors elaboration on the dataset.

Tab. 2: Post-hoc test-CSE on intuitive-reflective thinking

\begin{tabular}{|c|l|c|c|c|c|c|}
\hline \multirow{2}{*}{$(\mathbf{I}) \mathbf{C S E}$} & \multirow{2}{*}{$(\mathbf{J})$ CSE } & \multirow{2}{*}{ Mean Difference (I-J) } & \multirow{2}{*}{ Std. Erorr } & \multirow{2}{*}{ Sig. } & \multicolumn{2}{|c|}{ 95\% Confidence Interval } \\
\cline { 3 - 7 } & & $-4.30000^{*}$ & .38682 & 0.000 & -44.181 & -41.819 \\
\hline LowCSE & AverageCSE & -.10000 & .38682 & 0.964 & -0.2181 & 0.0181 \\
\hline & HighCSE & $4.30000^{*}$ & .38682 & 0.000 & 41.819 & 44.181 \\
\hline AverageCSE & LowCSE & $4.20000^{*}$ & .38682 & 0.000 & 40.819 & 43.181 \\
\hline & HighCSE & .10000 & .38682 & 0.964 & -0.0181 & 0.2181 \\
\hline HighCSE & LowCSE & $-4.20000^{*}$ & .38682 & 0.000 & -43.181 & -40.819 \\
\hline \multicolumn{2}{|l|}{} \\
\hline
\end{tabular}

Source: Authors elaboration on the dataset.

As shown in Table 1, there was a statistically significant difference between groups as determined by one-way ANOVA $(F(2,27)=80.510, p=0.000)$. A Tukey post hoc test, shown in Table 2, revealed that high CSE groups were more inclined to average CSE groups to intuitive thinking (-4.2 right answers compared to them; $p=0.00)$ but they were equally inclined to intuitive thinking respect to low CSE groups $(p=0.964)(p=0.989)$.

In order to verify whether teams with high CSE are inclined to be victim of the overconfidence bias (H2), a oneway ANOVA was implemented considering the different CSE clusters (low, average, high) and their average teams' estimation of performance.

Tab. 3: ANOVA Table - CSE on overconfidence

\begin{tabular}{|c|c|c|c|c|c|}
\hline & Sum of squares & df & Mean Square & F & Sig. \\
\hline Between Groups & $4.560 \mathrm{E}+9$ & 2 & $2.280 \mathrm{E}+9$ & 295.962 & 0.000 \\
\hline Within Groups & 208000000 & 27 & 7703703.70 & & \\
\hline Total & $4.768 \mathrm{E}+9$ & 29 & & & \\
\hline
\end{tabular}

Source: Authors elaboration on the dataset.

Tab. 4: Post-hoc test-CSE on overconfidence

\begin{tabular}{|c|c|c|c|c|c|c|}
\hline \multirow{2}{*}{ (I) CSE } & \multirow{2}{*}{ (J) CSE } & \multirow{2}{*}{ Mean Difference (I-J) } & \multirow{2}{*}{ Std. Erorr } & \multirow{2}{*}{ Sig. } & \multicolumn{2}{|c|}{ 95\% Confidence Interval } \\
\hline & & & & & Lower Bound & Upper Bound \\
\hline \multirow[t]{2}{*}{ LowCSE } & AverageCSE & $-18000.00 *$ & 1241.26 & \multirow{6}{*}{$\begin{array}{l}0.000 \\
0.000 \\
0.000 \\
0.000 \\
0.000 \\
0.000\end{array}$} & -18379.008 & -17620.992 \\
\hline & HighCSE & $-30000.00 *$ & 1241.26 & & -30379.008 & -29620.992 \\
\hline \multirow[t]{2}{*}{ AverageCSE } & LowCSE & $-18000.00 *$ & 1241.26 & & 17620.992 & 18379.0077 \\
\hline & HighCSE & $-12000.00 *$ & 1241.26 & & -12379.008 & -11620.9923 \\
\hline \multirow[t]{2}{*}{ HighCSE } & LowCSE & $-30000.00 *$ & 1241.26 & & 29620.9923 & 30379.0077 \\
\hline & AverageCSE & $-12000.00 *$ & 1241.26 & & 11620.9923 & 12379.0077 \\
\hline
\end{tabular}

Source: Authors elaboration on the dataset.

As shown in Table 3, there was a statistically significant difference between groups as determined by one-way ANOVA $(F(2,27)=295.962, p=0.000)$. A Tukey post hoc test, shown in Table 4, revealed that high CSE groups were more inclined to average CSE groups $(+12,000 \$$ of net worth overestimation compared to them; $p=0.00)$ and low CSE groups (+30,000\$ of net worth overestimation compared to them; $p=0.00)$ to be victim of overconfidence bias. So, high CSE groups were the ones the overestimated their performance more than other CSE groups, while low CSE groups were the ones that least overestimated their performance compared to other CSE groups.

Thus, according to the results obtained through the different one-way ANOVA and Tukey post hoc tests performed, we can conclude that: 
- $\quad$ Our first hypothesis - H1: Teams with high CSE are inclined to intuitive thinking - is only partially verified because both teams with high and low CSE are equally inclined to intuitive thinking; whilst

- $\quad$ Our second hypothesis - H2: Teams with high CSE are inclined to overconfidence bias - is verified because teams with a high CSE are more inclined to both average CSE teams and low CSE teams to fall into the overconfidence trap.

Research limits. To verify hypothesis at the basis of this work, it was collected a population sample composed of 120 students attending the first year of a Bachelor of Science in Business Administration and Economics. Their status, i.e., students, represents a first research limit because most of the students who participated in the simulation game have small or no work experience. A second and connected limit is determined by the fact that the experiment was conducted during the lectures of the General Management course. Therefore, participants applied their strategies in an environment that was comfortable for them without external pressure, maybe biasing their behaviour or (at least) their risk orientation when making decisions, with obvious consequences on the potential performance that would have been attained with another 'purer behavior'. A third and no less important limitation of this research arises from the fact that some variables have not been controlled - such as, for example, risk orientation - although they obviously affect, in real life, the behaviour and attitude of managers in managing situations and acting upon them. Finally, a fourth and last research limit results from the structure of the platform provided to the students. Indeed, like all simulation games, there are limitations about the representation of all the variables playing within real world choices. In sum, despite the fact that respondents' decisions have been implemented (and tracked by the researchers) within a very well simulated environment (i.e., the simulation game) - better than paper-based cases -, sampling managers in real life situations would be necessary for extending the generalizability of these results.

Practical implications. Stemming from the fact that teams composed of people that have high level of CSE lead to intuitive thinking and overconfident judgments, some important practical implications can be derived for practitioners. Firstly, being CSE hardly reducible - because it is an individual personal trait - practitioners can only work to reduce its value to an average one by composing ad hoc teams. Thus, it is fundamental that human resource managers track the CSE level of each individual within organizations. In this way, they also have to possibility to properly suggest - to department or unit heads - the "best teams' composition" to achieve better decisional and organizational performance. On the contrary, whether an organization needs to quickly answer to internal or external pressures - such as identifying a commercial strategy to counteract a sudden and huge price cut of a competitor - composing teams with individuals having high CSE levels can be beneficial for the production of intuitive (and quick) responses.

Originality of the study. The originality of this work is threefold. Firstly, we are not aware of any study that has investigated the influence exercised on decision making processes by CSE in relation to reflective/intuitive thinking and to overconfidence. Secondly, studies that investigated CSE with regard of some decision making variables (not the ones within the scope of this word) did that at the "individual level" - although most of the tasks in an organization are performed at team level and decisions are rarely made individually. Thirdly and lastly - despite the limitations previously exposed - this paper gives evidence of what really happens within organizations without resorting to case studies but through the direct participation of individuals who act and make decisions.

Keywords: Behavioral Strategy; Decision making; Core-Self Evaluations; Dual Mind Processing; Overconfidence.

\section{References}

ABATECOLA G., CAPUTO A., CRISTOFARO M. (2018), "Reviewing cognitive distortions in managerial decision making. Towards an integrative co-evolutionary framework", Journal of Management Development, vol. 37, n. 5, pp. $409-424$.

ABATECOLA G., CRISTOFARO M. (2019), "Ingredients of sustainable CEO behavior: Theory and practice", Sustainability, vol. 11, n. 7, pp. 1950.

BAUMEISTER R.F., HEATHERTON T.F., TICE D.M. (1993), "When ego threats lead to self-regulation failure: Negative consequences of high self-esteem”, Journal of Personality and Social Psychology, vol. 64, n. 1, pp. 141156.

BAZERMAN M.H., MOORE D.A. (2013), Judgment in Managerial Decision Making. Wiley, New York.

BUSIC-SONTIC A., CZAP N.V., FUERST F. (2017), "The role of personality traits in green decision-making", Journal of Economic Psychology, vol. 62, pp. 313-328.

CAIN D.M., MOORE D.A. HARAN U. (2015), "Making sense of overconfidence in market entry", Strategic Management Journal, vol. 36, n. 1, pp. 1-18.

CLAXTON G., OWEN D., SADLER-SMITH E. (2015), "Hubris in leadership: A peril of unbridled intuition?", Leadership, vol. 11, n. 1, pp. 57-78.

CRISTOFARO M. (2016), "Cognitive styles in dynamic decision making: a laboratory experiment", International Journal of Management and Decision Making, vol. 15, n.1, pp. 53-82. 
CRISTOFARO M. (2017a), "Reducing biases of decision-making processes in complex organizations", Management Research Review, vol. 40, n. 3, pp. 270-291.

CRISTOFARO M. (2017b), “Candidates' attractiveness in selection decisions: a laboratory experiment”, Baltic Journal of Management, vol. 12, n. 4, pp. 390-407.

CRISTOFARO M. (2019), "The role of affect in management decisions: A systematic review", European Management Journal, vol. 37, n. 1, pp. 6-17.

CRISTOFARO M. (2020), "I feel and think, therefore I am: An Affect-Cognitive Theory of management decisions", European Management Journal, vol. 38 n. 2, pp. 344-355.

EREZ A., JUDGE T.A. (2001), "Relationship of core self-evaluations to goal setting, motivation, and performance", Journal of Applied Psychology, vol. 86, n. 6, pp. 1270-1279.

FARIA A.J., HUTCHINSON D., WELLINGTON W.J., GOLD S. (2009), "Developments in business gaming: A review of the past 40 years", Simulation \& gaming, vol. 40, pp. 464-487.

GUDMUNDSSON S.V., LECHNER C. (2013), "Cognitive biases, organization, and entrepreneurial firm survival”, European Management Journal, vol. 31, n. 3, pp. 278-294.

HENRIKSEN T.D., BØRGESEN K. (2016), “Can good leadership be learned through business games?”, Human Resource Development International, vol. 19, pp. 388-405.

HILLER N.J., HAMBRICK D.C. (2005), "Conceptualizing executive hubris: the role of (hyper-) core self-evaluations in strategic decision-making”, Strategic Management Journal, vol. 26, n. 4, pp. 297-319.

HOLLENBECK J.R., WHITENER E.M., PAULI K.E. (1988), “An empirical note on the interaction of personality and aptitude in personnel selection", Journal of Management, vol. 14, n. 3, pp. 441-451.

HOPPE E. I., KUSTERER D.J. (2011), "Behavioral biases and cognitive reflection”, Economics Letters, vol. 110, n.2, pp. $97-100$.

INUWA M. (2016), “Job satisfaction and employee performance: An empirical approach”, The Millennium University Journal, vol. 1, n. 1, pp. 90-103.

JOO B.B.K., JUN YOON H., JEUNG C.W. (2012), "The effects of core self-evaluations and transformational leadership on organizational commitment”, Leadership \& Organization Development Journal, vol. 33, pp. 564582.

JORDAN C.H., WHITFIELD M., ZEIGLER-HILL V. (2007), "Intuition and the correspondence between implicit and explicit self-esteem", Journal of Personality and Social Psychology, vol. 93, n. 6, pp. 1067-1079.

JUDGE T.A., EREZ A., BONO J.E., THORESEN C.J. (2003), "The core self-evaluations scale: Development of a measure", Personnel psychology, vol. 56, n.2, pp. 303-331.

JUDGE T.A., HURST C. (2007), "Capitalizing on one's advantages: Role of core self-evaluations", Journal of applied Psychology, vol. 92, n. 5, p. 1212.

JUDGE T.A., BONO J.E. (2001), "Relationship of core self-evaluations traits: self-esteem, generalized self-efficacy, locus of control, and emotional stability with job satisfaction and job performance: A meta-analysis", The Journal of Applied Psychology, vol. 86, n. 1, pp. 80-92.

JUDGE, T.A., HURST, C. (2008), "How the rich (and happy) get richer (and happier): Relationship of core selfevaluations to trajectories in attaining work success", Journal of Applied Psychology, vol. 93, n. 4, pp. 849-863.

JUDGE, T.A., HURST, C., SIMON, L.S. (2009), "Does it pay to be smart, attractive, or confident (or all three)? Relationships among general mental ability, physical attractiveness, core self-evaluations, and income", The Journal of Applied Psychology, vol. 94, n. 3, pp. 742-755.

JUDGE T.A., LOCKE E.A., DURHAM C.C. (1998), "The dispositional causes of job satisfaction: A core evaluations approach", Journal of Applied Psychology, vol. 83, pp. 17-34.

KIM H., MACDONALD R.H., ANDERSEN D.F. (2013), "Simulation and managerial decision making: a double-loop learning framework", Public Administration Review, vol. 73, pp. 291-300.

KORCHINSKAYA O., IVANOVA I., SHCHUKINA N., MENDZIV M. (2020, January), "Business Games as a Teaching Strategy for Delivering a Practice-Oriented Course in Mathematics at Agricultural University". In International Scientific Conference The Fifth Technological Order: Prospects for the Development and Modernization of the Russian Agro-Industrial Sector (TFTS 2019) (pp. 355-361). Atlantis Press.

KRAMER R.M., NEWTON E., POMMERENKE P.L. (1993), "Self-enhancement biases and negotiator judgment: Effects of self-esteem and mood", Organizational Behavior and Human Decision Processes, vol. 56, n. 1, pp. 110-133.

LAINEMA T., MAKKONEN P. (2003), “Applying constructivist approach to educational business games: Case REALGAME”, Simulation \& gaming, vol. 34, pp. 131-149.

MOORE D.A., HEALY P.J. (2008), “The trouble with overconfidence”, Psychological review, vol. 115, n. 2 , p. 502.

PATEL N., BAKER S.G., SCHERER L.D. (2019), "Evaluating the cognitive reflection test as a measure of intuition/reflection, numeracy, and insight problem solving, and the implications for understanding real-world judgments and beliefs", Journal of Experimental Psychology: General, vol. 148, n.12, pp. 2129-2153.

POWELL T.C., LOVALLO D., FOX C.R. (2011), "Behavioral strategy”, Strategic Management Journal, vol. 32 n, 13 , pp. 1369-1386. 
SILVESTER J., ANDERSON-GOUGH F.M., ANDERSON N.R., MOHAMED A.R. (2002), "Locus of control, attributions and impression management in the selection interview", Journal of Occupational and Organizational Psychology, vol. 75, n. 1, pp. 59-76.

TOPLAK M.E., WEST R.F., STANOVICH K.E. (2014), “Assessing miserly information processing: An expansion of the Cognitive Reflection Test”, Thinking \& Reasoning, vol. 20, n. 2, pp. 147-168.

WU W.L., LEE Y.C. (2016), "Do employees share knowledge when encountering abusive supervision?", Journal of Managerial Psychology, vol. 31, n. 1, pp. 154-168.

ZACHARAKIS A.L., SHEPHERD D.A. (2001), "The nature of information and overconfidence on venture capitalists' decision making", Journal of Business Venturing, vol. 16, n. 4, pp. 311-332. 


\title{
The "humane side" of entrepreneurship. An empirical investigation of startup with a social mission in Italy
}

\author{
VAlentina CuCino * CRistina Marullo* \\ ELEONORA ANNUNZIATA`ANDREA PICCALUGA**
}

Objectives. Entrepreneurial behavior brings a purely selfish orientation and very often motivated by profit. However, in recent years, overcoming the traditional view of capitalism has changed entrepreneurial behavior.

Firms have started to act by integrating the sustainable use of natural resources, better use of the capital produced and further investments in human capital (Melè, 2003; Spitzeck, 2011). Therefore, new entrepreneurial concepts such as social entrepreneurship, sustainable entrepreneurship and more recently humanitarian entrepreneurship have spread (Parente et al., 2018). This new orientation towards a new way of defining entrepreneurship has been defined by some authors as Humane Entrepreneurship (Kim et al., 2017; 2018).

Human entrepreneurship is defined as "a virtuous and sustainable integration of entrepreneurship, leadership and human resource management, in which successful implementation leads to a beneficial increase in the creation of quality and wealth jobs, perpetuated in a continuous cycle "(Kim et al., 2018). However, the orientation to this new entrepreneurial behavior encompasses two well-known concepts in the entrepreneurship literature: social entrepreneurship and sustainable entrepreneurship. Social enterprise and sustainable enterprise are two expressions of Humane Entrepreneurship because they both pay attention to their external relationships and impacts on society. However, by themselves they are not sufficient to express the concept of "humane enterprise".

Current entrepreneurial theories emphasize primarily the "creation" of value and not the "distribution" of value for employees, stakeholders and companies (Kim et al., 2018). Adding the "human-centered" discussion to entrepreneurship requires advancing these traditional concepts and theories in order to understand how human capital affects economies in the 21st century. Today, entrepreneurship must be inclusive and sustainable, focusing on both the production of traditional profits and the needs of individuals and overall society (Kim et al., 2018).

Several authors have studied and developed the theoretical model (Parente et al., 2018; Kim et al., 2018). However, to date there are still few empirical studies that investigate the characteristics of human entrepreneurship (Bae et al., 2018; Kim et al., 2016). For this study, the authors selected Italian SMEs registered in the Italian Startup Companies Register, an official database in which companies operating in sectors with high social impact are identified (Decree No. 155/2006 Innovative startups with a social vocation - SIaVS). These companies were selected by the authors because their mission stated a clear orientation to the "social purpose".

Although firms with a social mission are only a small subset of human-oriented firms, these firms deal with issues relevant to society such as human poverty, social inequality and environmental and social challenges. The creation of social value requires a different entrepreneurial orientation, which pays attention to the stakeholders and their needs. However, there is an empirical knowledge gap with respect to the weight and role that the characteristics of humane entrepreneurship assume within companies and their relationship with the performance in terms of value distribution carried out by companies with a social mission.

This study aims to provide a first empirical evidence on this phenomenon. Based on an investigation - a sample of Italian startups with a social mission, we investigate the role of different aspects that characterize human entrepreneurship. In particular, our research question aims to investigate: "Does human entrepreneurship influence the value distribution of startups with a social mission?"

The theoretical model of Humane Entrepreneurship is composed of multiple structures that interact continuously (Kim et al., 2018; Parente et al., 2018). This model consists of three main dimensions that have been considered in our study. The first dimension is leadership, understood as the role of the leader in the management of the company (Kim et

\footnotetext{
Post-Doc Research fellow of Management - Scuola Superiore Sant'Anna - Pisa - Italy

e-mail: valentina.cucino@santannapisa.it

- Researcher of Management - Scuola Superiore Sant'Anna - Pisa - Italy

e-mail: cristina.marullo@santannapisa.it

- Researcher of Management - Scuola Superiore Sant'Anna - Pisa - Italy e-mail: eleonora.annunziata@santannapisa.it

** Full Professor of Management - Scuola Superiore Sant'Anna - Pisa - Italy e-mail: alberto.piccaluga@ santannapisa.it
} 
al., 2018). According to Alvarez and Barney (2007) and Gonzalez et al. (2017) we adapt the concept of leadership to the identification of the opportunity that led to the establishment of the company. In this case we will talk about identifying the business opportunity. The second dimension of the model is entrepreneurial orientation. Following Kim et al., 2018 and Covin and Slevin (1988; 1991) we adopt the "Entrepreneurial orientation" EO, measured by the propensity of the top managers to (1) take risks related to businesses; (2) foster change and innovation to create competitive advantage; and (3) proactivity in competing aggressively with other firms.

Finally, the last part of the model is represented by humane entrepreneurial orientation. Through empathy, mutual trust, respect and support you can understand the needs not only of customers (Brown 2008; 1998) but also of employees (Judge and Piccolo 2004; Jude and Bretz, 1992). In addition to empathy, there are three other common elements that emphasize the "humane" management of people within an organization. These elements are (1) equity in terms of "the measure in which a society treats people fairly and the same way" (Agòcs and Burr 1996), (2) empowerment in terms of the "delegation of power and responsibility from higher levels of the organizational hierarchy to lower levels, especially in regard to an employee's ability to make decisions "(Spreitzer, 2012) and (3) enablement in terms of "the extent to which a company provides the environment where each individual employee is able to develop skills and knowledge, consisting of both skill and infrastructure" (Kim et al., 2018). A "Humane Oriented" firm motivates employees by sharing their emotions and information, but not only. A "humanity-oriented" firm acts fairly and provides the creation of an environment in which each individual employee is able to develop skills and knowledge. When these elements are present together, there is Human Orientation.

Finally, current theories of entrepreneurship mainly emphasize the "creation" of value and not the "distribution" of value for employees, stakeholders and society (Kim et al., 2018). However, the concept of "distribution" of value is fundamental for achieving overall well-being.

The present study focuses on the "distribution" of value of only one of these three subjects. In particular, the analysis aims to provide indications regarding the "distribution" of value for stakeholders such as firms, organizational performance in terms of network and ecosystem development (Crittenden et al., 2011; Parente et al., 2018). Therefore, adapting Darnall et al., 2010's identification of categories of external stakeholders, we identify the company's "distribution" value in terms of the number and intensity of relationships with stakeholders in companies with a social mission.

The paper proceeds as follows. Section 2 discusses the methodology used to answer our research question. Section 3 explains the preliminary findings of the study. However, research is still work in progress. Section 4 illustrates the limitations of research and future research. Section 5 illustrates the practical implications. The last section analyzes the original elements of the study.

Methodology. To evaluate our hypotheses, we relied on survey data collected from Italian startup firms. Based on the concepts developed by Kim et al., (2018) and Darnall et al., (2010) the authors designed and adapted the questionnaire to the Italian context. A test with a small sample of companies was carried out to verify the possible weaknesses and misunderstandings of the questions. The administration of questionnaire started in October 2019 and is still in progress.

Respondents were identified from the Italian Business Register of innovative startups, an official database in which firms operating in sectors with high social impact are identified (Decree 155/2006 Startup Innovative a vocazione Sociale - SIaVS). Over a population of 227 firms (identified on October 21, 2019) we obtained a response rate of $21 \%$. To explore the possibility of non-response bias, we compared respondents (48) and non-respondents (179) in terms of size and industry composition. We did not find statistically significant differences.

Tab. 1: summarizes the main information (i.e., size, age, and industry composition) about the respondents

\begin{tabular}{|c|c|c|c|c|}
\hline INDUSTRY & $\mathrm{n}$ & $\mathrm{n}(\%)$ & Age (mean) & Size (mean) \\
\hline Manufacturing & 8 & $17 \%$ & 3,3 & 4,5 \\
\hline Services & 24 & $50 \%$ & 3,9 & 5 \\
\hline Public Administration, Education, Health, Social Services & 16 & $33 \%$ & 2,5 & 7,1 \\
\hline Total & 48 & $100 \%$ & 3,6 & 6,1 \\
\hline
\end{tabular}

Source: authors elaboration

Our hypotheses are based on the link between the three dimensions of the conceptual model of Humane Entrepreneurial Orientation (H-EO) proposed by Parente et al. (2018), namely Sustainability Orientation (SO), Entrepreneurial Orientation (EO), Humane Resources Orientation (HRO), and different outcomes related to network and ecosystem development (Crittenden et al., 2011; Parente et al., 2018). Further, we were interested in focusing on the different components of HRO, as it represents the main strategic posture characterizing firms whose strategic activities are centered on human resources involvement (Empathy, Equity, Empowerment, Enablement) (Kim et al., 2018).

We operationalized our dependent variables (network and ecosystem development) drawing on the concept of proactive involvement of external stakeholders. As sustainability practices of H-EO are strictly related to stakeholder relationships, we considered the breadth of involvement of external stakeholders as a proxy of firms' organizational performance in terms of network and ecosystem development (Crittenden et al., 2011; Parente et al., 2018). More in 
detail, we considered two different stakeholders groups: i) value chain stakeholders, including private consumers and users, commercial buyers, and suppliers, other firms operating in social sectors, and ii) societal stakeholders, including environmental groups, civic organizations, community organizations (protection of minority rights, protection of patients' rights, protection of human rights), labor unions, industry and trade associations (Darnall et al., 2010). Respondents were asked to consider the degree of involvement of each type of stakeholder in their daily business and operations using a 5 point Likert scale ranging from " 1 "= no involvement to "5"= high involvement. Each response was coded as a binary variable, "1" meaning that the firm involves the stakeholder and " 0 " otherwise. For each category of stakeholders and for the total number of stakeholders we calculated the BREADTH of involvement as the number of types of stakeholders the firm is involved with (Laursen and Salter, 2006).

As for the independent variables, based on prior studies on humane entrepreneurship proposing an operationalization of the different model components (Kim et al., 2018) detailed information on a list of seven items associated with the different dimensions of the model was collected. The respondents were asked to evaluate their agreement on a set of statements representing the components of the EO (innovation, risk-taking, proactivity) and HRO (empathy, equity, empowerment, enablement) based on a 5 point Likert scale ranging from $1=$ disagree to $5=$ completely agree. EO was operationalized as a latent construct through a 1-parameter logistic Item Response Theory (IRT 1pl) model. Based on the set of observed measures (survey responses on the three components of the construct: innovation, risk-taking, proactivity) we estimated a measure of EO as a firm-level continuous variable representing the respondents' perceived degree of EO.

As we were interested in investigating in-depth the link between HRO and organizational performance we operationalized the four components of the HRO construct separately as the weighted average score of responses at the firm-level (empathy, equity, empowerment, enablement).

Opportunity identification (as a proxy of managerial culture) was included in the model as a dummy variable, " 1 " meaning that the firm was founded based on a social opportunity and " 0 " meaning that the firm was founded based on a business opportunity (Alvarez and Barney 2007; Gonzalez et al.2017).

We further controlled for a set of firm-level variables that might play a role in this relationship: age, size, the experience of the respondent (number of years working in the firm). Industry dummies were also included in the model.

Our analytical approach was based on an Ordinary Least Squares (OLS) regression model, allowing us to evaluate the relationship between the single independent variables (representing the components of the Humane Entrepreneurship model) and the outcome variables. We estimated two distinct models, describing the relationship between the independent variables and: breadth of involvement of value chain stakeholders (Model 1) breadth of involvement of societal stakeholders (Model 2). A third model (full model) was estimated for all the categories of stakeholders.

A more advanced analytical approach including interactions between different dimensions and based on a larger sample size will be estimated at the end of the data collection process. In the following section we will, therefore, introduce our preliminary empirical findings.

Findings. Our findings (Table 2) reveal a positive and significant link between firms' EO and HRO and organizational performance in terms of network and ecosystem development. Interestingly, the different components underlying the H-EO theoretical model differently influence the breadth of relationships with external stakeholders, as they have different impacts on different stakeholders' groups: value chain stakeholders (Model 1) and societal stakeholders (Model 2).

While both the EO and HRO dimensions play a role in firms' capacity to purposively involve an external network of supply chain stakeholders (Model 1), a strong HRO is crucial to a higher involvement of societal stakeholders. As Model 2 shows, social opportunity recognition and a strong HRO positively and significantly influence the breadth of involvement of societal stakeholders. Within the components of HRO, empathy and enablement have a positive and significant impact on the outcome variable, while equity and empowerment show a negative and significant coefficient.

Tab. 2: Model estimation

\begin{tabular}{|c|c|c|c|c|c|c|c|}
\hline & \multicolumn{2}{|c|}{ Model 1} & \multicolumn{2}{|c|}{ Model 1} & \multicolumn{2}{|c|}{ Model 3} \\
\hline & & \multicolumn{2}{|c|}{ Value chain stakeholders } & \multicolumn{2}{|c|}{ Societal stakeholders } & \multicolumn{2}{|c|}{ Full model } \\
\hline & & Coef. & p-value & Coef. & p-value & Coef. & p-value \\
\hline \multicolumn{8}{|c|}{ HR ORIENTATION } \\
\hline & Empathy & 0.404 & 0.017 & 1.759 & 0.007 & 1.256 & 0.017 \\
\hline & Equity & -0.025 & 0.865 & -0.727 & 0.025 & -0.576 & 0.217 \\
\hline & Empowerment & -0.153 & 0.255 & -1.162 & 0.025 & -0.845 & 0.047 \\
\hline & Enablement & 0.046 & 0.764 & 1.566 & 0.01 & 1.298 & 0.010 \\
\hline \multicolumn{2}{|c|}{ ENT ORIENTATION } & 0.278 & 0.021 & 0.717 & 0.107 & 0.385 & 0.290 \\
\hline \multicolumn{2}{|c|}{ OPP RECOGNITION (baseline $=$ social) } & 1.081 & 0.048 & 6.069 & 0.004 & 4.051 & 0.019 \\
\hline \multicolumn{2}{|c|}{ AGE } & 0.159 & 0.197 & 0.878 & 0.062 & 0.605 & 0.110 \\
\hline \multicolumn{2}{|l|}{ SIZE } & 0.083 & 0.511 & -0.042 & 0.929 & -0.149 & 0.706 \\
\hline \multicolumn{2}{|l|}{ EXPERIENCE } & -0.157 & 0.283 & 0.030 & 0.956 & 0.161 & 0.722 \\
\hline \multicolumn{2}{|c|}{ INDUSTRY DUMMIES } & Yes & & Yes & & Yes & \\
\hline \multicolumn{2}{|l|}{ _cons } & 2.950 & 0.005 & 1.287 & 0.509 & -0.036 & 0.982 \\
\hline
\end{tabular}




\begin{tabular}{|l|r|r|r|r|r|}
\hline $\mathrm{n}$ & 48 & & 48 & & \\
\hline $\mathrm{r}-\mathrm{sq}$ & 0.4329 & & 0.4832 & & \\
\hline $\mathrm{F}$ & 2.82 & & 3.46 & & \\
\hline $\mathrm{p}>\mathrm{F}$ & 0.0104 & & & & \\
\hline
\end{tabular}

Source: authors elaboration

These considerations hold for the full model (Model 3), including all the categories of external stakeholders. While EO itself is not a necessary condition for a higher capacity of involvement of external stakeholders' involvement, managerial culture and HRO are key. What is more novel and interesting in our results is that, within HRO, different ways to strategically involve human resources will have a different impact on firms' network and ecosystem development capacity.

Research limits. The present study has some limitations. First, research is still work in progress. In particular, the survey (started in October 2019) is open and the data presented in this paper are a first version of the study. As a result, the data may not accurately explain the population. However, it is necessary to note that to date $21 \%$ of companies have responded to the survey. At the end of the data collection process, a more advanced analytical approach will be estimated which includes interactions between different dimensions and based on a larger sample size. Therefore, we present our preliminary empirical results.

Second, our study considers only Italian SMEs. However, the authors consider a limited sample of firms. The decision to focus on these kinds of firms is guided by two reasons. On the one hand, SMEs are the ones that mostly represent the Italian industrial landscape. On the other hand, the government has created a specific register for Italian small and medium-sized companies that have a social mission. Within the "social mission" not only social enterprises are considered, but the concept is extended to all those small and medium-sized companies that respond to a problem in society. For this reason the authors believe that the identification of the sample can empirically represent the concept of Humane Entrepreneurship (Kim et al., 2018).

Third, the responses could be influenced by the recent Covid-19 pandemia. However, it may be interesting to analyze this data in anticipation of future research that analyzes the role of "humane" firms in response to the Covid19 pandemia.

Practical implications. Our study contributes to entrepreneurship literature in three different ways. First, it shows empirical evidence of the application of humane entrepreneurship. One of the most important conclusions in our document is the practical integration of humane orientation into enterprises with a social mission. Our study shows how human resource orientation significantly influences the firm's external orientation in terms of relations with stakeholders.

Second, it shows empirical evidence showing a positive and significant link between the EO and HRO of firms and organizational performance in terms of network and ecosystem development. However, the different components underlying the HEO theoretical model have a different influence on the extent of relations with external stakeholders, as they have different impacts on the different groups of stakeholders: stakeholders of the value chain (Model 1) and parts interested parties of the company (Model 2). As Model 2 shows, recognition of social opportunities and a strong HRO positively and significantly influence the breadth of stakeholder involvement in society.

Third, the results show a different role of the individual components of the HRO. In fact, empathy and habilitation have a positive and significant impact on the outcome variable, while equity and empowerment show a negative and significant coefficient.

Originality of the study. Humane entrepreneurship is a relatively new theory, but we raise substantial questions about its positive and sustainable business practices. Considering the lack of studies that apply and investigate the concept of Humane Entrepreneurship, the present study aims to be one of the first examples of empirical application of the concept of humane entrepreneurship in Italy.

The Italian context is indicated for this analysis for two reasons. First, it is made up of the majority of small and medium-sized innovative companies that have historically been more responsive than large companies. Second, within the landscape of small and medium-sized companies there is a definition of companies with a social mission (Syrjä et al., 2019). These companies are collected in a Italian Business Register of innovative startups (Decree 155/2006 Startup Innovative a vocazione Sociale - SIaVS) and controlled by the government year by year. The inclusion to the register depends on the compliance with the requirements of innovation, investment in research and development and the hiring of highly specialized human resources (with a PhD or degree). Therefore, the population used for this study reflects how closely it corresponds to the concept of human entrepreneurship.

Key words: humane entrepreneurship; humane entrepreneurial orientation; start-up; stakeholders; well-creation.

\section{References}

AGOCS C., BURR C. (1996), "Employment Equity, Affirmative Action and Managing Diversity: Assessing the Differences", International Journal of Manpower, vol. 17, n. 4/5, pp. 30-45. 
ALVAREZ S., BARNEY J.B. (2007), “The entrepreneurial theory of the firm”, Journal of Management Studies,, vol. 44, n. 7, pp. 1057-1063

BAE Z.T., GANG M.S., KIM K.C., PARK J.H. (2018), "Humane entrepreneurship: Theoretical foundations and conceptual development", The Journal of Small Business Innovation, vol. 20, n. 4, pp. 11-21

BROWN T. (2008), “Design Thinking”, Harvard Business Review June,, vol. 86, n. 6, pp. 84-92.

BROWN S.L., EISNEHARDT K.M. (1998), Competing on the Edge: Strategy as Structured Chaos, Harvard Business School Press. Boston, MA.

COVIN J.G., SLEVIN D.P. (1989), "Strategic Management of Small Firms in Hostile and Benign Environments", Strategic Management Journal, vol. 10, n. 1, pp. 75-87.

COVIN J.G., SLEVIN D.P. (1991), “A Conceptual Model of Entrepreneurship as Firm Behavior”, Entrepreneurship Theory and Practice, vol. 16, n. 1, pp. 7-25.

CRITTENDEN W.L., CRITTENDEN W.F., FERRELL L.K., FERREL O.C., PINNEY C.C. (2011), "Market-Oriented Sustainability: A Conceptual Framework and Propositions", Journal of the Academy of Marketing Science, vol.39, n. 1, pp. 71-85.

DARNALL N., HENRIQUES I., SADORSKY P. (2010), “Adopting Proactive Environmental Strategy: The Influence of Stakeholders and Firm Size”, Journal of Management Studies, vol. 47, n. 6, pp. 1072-1094

GONZALEZ M.F., HUSTED B.W., AIGNER D.J. (2017), "Opportunity discovery and creation in social entrepreneurship: An exploratory study in Mexico", Journal of Business Research,, vol. 81, n. 1, pp. 212-220.

KIM K.C. (2016), "Global survey: Humane entrepreneurship", In 2016 Entrepreneurship and SME World Conference, Seoul, South Korea.

KIM Y.J., KIM K.C., SONG C.S., KANG M.S. (2017), The impact of humane entrepreneurship on business ecosystem and economic development. In ICSB World Conference Proceedings (pp. 1-8), International Council for Small Business (ICSB),

LAURSEN K., SALTER A. (2006), “Open for innovation: the role of openness in explaining innovation performance among UK manufacturing firms”, Strategic management journal,, vol. 27, n. 2, pp. 131-150

MELE D. (2003), "The Challenge of Humanistic Management", Journal of Business Ethics, vol. 44, n. 1, pp. 77-88.

PARENTE R., EL TARABISHY A., VESCI M., BOTTI A. (2018), "The epistemology of humane entrepreneurship: Theory and proposal for future research agenda", Journal of Small Business Management, n. 56(sup1), pp. 3052.

SPITZECK H. (2011), “An Integrated Model of Humanistic Management”, Journal of Business Ethics, vol. 99, n. 1, pp. 51-62.

SPREITZER G., PORATH C. (2012), “Creating sustainable performance”, Harvard Business Review, vol. 90, n. 1, pp. 92-9

SYRJA P., PUUMALAINEN K., SJÖGRÉN H., SOININEN J., DURST S. (2019), "Entrepreneurial orientation in firms with a social mission-a mixed-methods approach", Cogent Business \& Management, vol. 6, n. 1, pp. 1602016.

JUDGE T.A., BRETZ R.D. (1992), "The Effects of Work Values on Job Choice Decisions", Journal of Applied Psychology, , vol. 77, n. 3, pp. 261-271.

JUDGE T A., PICCOLO R.F. (2004), "Transformational and Transactional Leadership: A Meta-Analytic Test of Their Relative Validity”, Journal of Applied Psychology, vol. 89, n. 5, pp. 755-768. 
Valentina CuCino - Cristina Marullo - Eleonora AnnunZiata - Andrea Piccaluga 


\title{
Service innovation in the wine sector: evidence from Sicilian firms
}

\author{
MARIAPIA CUTUGNO* TindARA ABBATE ${ }^{*}$ FABRIZIO CESARONI $^{\bullet}$
}

Objectives. The main objective of this work is to investigate the role assumed by universities in supporting small and medium-sized manufacturing enterprises in the development of innovative processes oriented to services.

In the last decade, the transition to an experience economy has made the innovation of services omnipresent and essential for creating economic growth and well-being (Ordanini and Parasuraman, 2010), Therefore, the gradual transition from the product to the service becomes a priority for many.

Studies on the innovation paths (Bifulco 2004; Silvestrelli 2004) show how production processes are progressively dematerializing. In this context, the interaction between production and services has rapidly increased (Bryson and Daniels 2010; Falk and Peng 2013; Francois and Woerz 2008),

In developed economies, the service sector now dominates their gross domestic products and its share continues to grow (Gasiorowski 2015), Recent data suggest that, globally, over a third of manufacturing companies offer services, with a percentage rising to almost $60 \%$ in western economies (Neely, 2008), Therefore, both services and service innovation represent the central drivers of the widest economic and innovation growth (Gallouj, 2002; Miles, 1993; OECD, 2005),

In dynamic environments where technology and the market must change rapidly, managing service means not only the ability to design the new service concept, but also continuously redesigning and adapting new and existing services to face frequent exogenous changes and emerging opportunities (Carlborg et al. 2014),

SMEs, like large companies, are also called to make this shift from the production of products only to the provision of services, if they intend to achieve positions of competitive advantage. In the beginning, this concept is defined in the literature with the acronym of "servitization". From the literature it is clear that this phenomenon is a process of organizational change in continuous evolution (Baines et al. 2017); therefore, manufacturing SMEs, to maintain their market share, try to change their orientation, the traditional production processes, for the implementation of this innovative managerial practice.

Vandemerwe and Rada defined servitization as "the largest offering of the most complete market packages or" packages "of customer-focused combinations of goods, services, support, self-service and knowledge to add value to key product offerings. "Here, they considered that "the services are provided and not produced and are essentially intangible” (pag 318),

In general, servitization is associated with the progressive transformation of socio-economic systems towards a quantitative and qualitative increase in the importance of service supply activities compared to manufacturing and / or commercial activities (Skòrska, 2011),

In this context, Baines et al. (2009) characterize servitization as "the innovation of an organization's capabilities and processes to better create mutual value through a transition from selling products to selling services and product systems" (pag. 550),

Along this line, manufacturing companies need to merge the sale of products with that of services; in fact, these realities are increasingly moving towards the commercialization of systems of products and services, which in the literature are known as Product Service Systems (PSS), However, PSS was presented as the most comprehensive market package offer or customer-focused combination package of goods, services, support, self-service and knowledge in order to add value to key product offerings. In this view, services are provided and not produced and are essentially intangible. This means allowing the customer to satisfy their needs and to realize value in the development of an integrated solution (Tukker 2006),

The ability to offer a PSS package exposes the organization to very important challenges in their entity, which generally require a change of collective skills and evolution of the whole context in which the company operates. In fact, this new approach is a process of organizational change at all company levels, because we are approaching a completely new and exploratory way of selling and producing (Wallin, Parida and Isaksson, 2015)

What has been said so far, can be illustrated through Figure 1, to make the clear exploration of the phenomenon.

\footnotetext{
PhD Student in Economics, Management and Statistics - University of Messina - Italy

e-mail: mcutugno@unime.it

- Associate Professor of Marketing - University of Messina - Italy.

e-mail: abbatet@unime.it

- Professor of Strategic Management - University of Messina - Italy

e-mail: fcesaroni@unime.it
} 
Fig. 1: Transition from a Product to a Product-Service-System

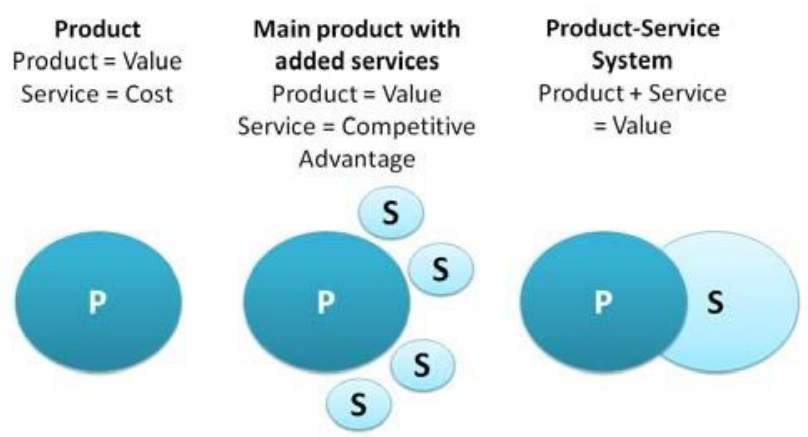

Source: R. Oliva and R. Kallenberg 2003

According to this PSS scheme, the value for a common manufacturer is provided by the product itself, while each service implemented in an accessory way involves additional costs. In order to obtain a competitive advantage (for example, for uniqueness) and to distinguish and stand out from the competition, some well-chosen and product-related services are implemented to enrich the total offer. Finally, products and services come together in a product-service system that provides its unique value only in their combination (Baines, Lightfood, Steve, Neely, Greenough, Peppard 2007; Goedkoop 1999),

By conducting the PSS strategy, both in large and small to medium-sized enterprises, there are several options for its implementation: the most common categorization available in the literature divides the PSS into three types (Tischner, Verkuijl 2002; Baines et al. 2007; Tukker 2004): product-oriented services (POS), use-oriented services (UOS) and results-oriented services (ROS), These types differ substantially from the relationship between manufacturer and customer.

- $\quad$ Product-oriented services (POS): involves selling a product in the traditional way, in which the customer retains ownership of the product, although it includes some associated services. For example: after-sales service to guarantee functionality and durability of the product. In this case, the company is motivated to introduce a PSS to minimize usage costs during the product life cycle;

- User Oriented Services (UOS): the product is owned by the manufacturer, who sells the use or functions of a product. In this case, the company is motivated to create a PSS to maximize the use of the product, satisfy the demand, extend the life of the product and reuse the materials;

- $\quad$ Results-oriented services (ROS): this involves the sale of a result or a competence rather than a product.

Subsequently Neely in 2008, due to the complexity and extension of the PSS phenomenon, expanded these types, adding an integration-oriented approach and a service-oriented approach.

- Integration-oriented PSS: which provides services through vertical integration, a very common practice in the manufacturing sector. Typical applications of integration-oriented PSS are retail and distribution services;

- $\quad$ Product-oriented PSS: offers a service directly related to the product considered, which ultimately also translates into a transfer of ownership between the interested parties (Kumar and Markeset 2007),

Ultimately, it can be said that in order to pursue the PSS approach changes are required in the business model, in resources and skills at all company levels, as the company's offer must be entirely redesigned, since it is an approach of the all new.

For SMEs it could be a very important obstacle, in fact, they may not have these resources especially if they operate in low-tech sectors or in mature sectors, characterized by a low rate of introduction of innovations (Yoon, Kim and Rhee, 2012),

To overcome these problems, SMEs need to cooperate with external partners to obtain those resources necessary for the implementation of a new production approach, such as PSS. Among the various partners, which can go from customers, suppliers, competitors, there is a category that deserves all our attention which is the university, which can be classified as a huge cauldron containing all the knowledges and resources that the company, at this crucial moment, may need.

In recent years, universities and research centers have focused their attention on improving and strengthening their relations with industry, with the ultimate goal of promoting regional and national economic development and innovation systems (Etzkowitz \& Leydesdorff, 2000; Giuliani \& Arza, 2009; Cesaroni and Piccalunga, 2016), Therefore, the ability of companies to acquire, use and integrate external sources of knowledge has been recognized as one of the most relevant competitive factors, in particular for companies that are interested in adopting a servitization process, more precisely a Product Service System process. (Baines et al. 2007),

Methodology. This study uses a qualitative methodology based on multiple case studies approach (Yin, 2014), Case studies are a useful way to look around the specific phenomenon utilizing data of different sources (Yin, 2009), The case here selected are: Tasca d'Almerita; Calabretta Winery; and Colomba Bianca.

Tasca d'Almerita winery operates in Sicily. It started its activity in 1830 and over the years has distinguished itself 
for the implementation of innovative practices along the entire production chain and not only in this sector.

Calabretta Winery operates in the hinterland of Etna. This firm has very ancient origins (there is talk of at least 3 generations), but it was modernized by the current owner in 1997, and has affirmed its leadership in the wines of the Streets of Etna, thanks to its tenacity and stubbornness in the change of the traditional conceptions of wine production.

Colomba Bianca winery is a cooperative that was born in 1970, and has seen an exponential increase in the participation of the members in the last 10 years, today it counts 2480 . The winery operates in the western part of Sicily, where it has distinguished itself for its prudence in introducing the services in its own company structure, convincing even the smallest wine producer to take this winning path.

Our choice fells on these wineries because they were among the first in Sicily to see an opportunity for growth and enrichment of knowledge in the university-business relationship. Precisely for this reason, in recent years, these firms have established lasting relationships with Italian and European universities. The data were derived both from primary data (semi-structured interviews) and from secondary data (document analysis, internal reports and documents, files and other printed materials), The interviews were conducted in March 2020, lasting approximately from one to three hours, following the traditional methodological prescriptions on data collection through personal interviews (Lee, 1999), The results of this analysis are reported in the next section.

Findings. The results show that even low-tech enterprises, which are purely manufacturing, are increasingly seeking to intensify their interactions with universities to internalize innovative practices that can make wine production and marketing easier and more attractive in a constantly evolving market.

In addition, efforts are being made to overcome the obstacles to internal and external communication that occur when the company decides to develop a new process completely distant from the traditional production process. Many times, the introduction of internal changes is countered by psychological and attitudinal limits of internal employees and collaborators. In this specific context, internal viticulturists should face a change in mentality, a very difficult action due to their attachment to traditional grape growing practices.

Going deeper into the question, the three companies proudly externalized the introduction into the cellar of services that enhance the purchase of the mere bottle of wine: from the accommodation and restaurant service (Tasca d'Almerita and Colomba Bianca), to personally experience the viticulture and the whole fermentation process with experts (Calabretta), experiment with new types of grapes that were previously unknown in this area (Calabretta), and many other services. From interactions with the main exponents of the firms interviewed, we perceived the difficulties that the owners encountered along the way, for wanting to use internally practices that are very far from the cultivation of wine. For example, the obstacles to overcome were represented by the oenologists and wine growers, characterized by mental barriers built over the years and attachment to their winemaking traditions. Additionally, a further obstacle was that of being afraid to approach a completely new world, of which the implementation dynamics are unknown. For example, a guided tour of the cellar, the "jealousy" in externalizing one's "secrets" of fermentation, rather than the method of cultivation of a certain grape unknown in the territory.

Thanks to the will of the owners, the introduction of these innovations become an additional motivation for all the components of the company: from skeptics and opponents, employees have become the creators of new organizational practices in the field of services and cultivation.

All this has led firms to make themselves known outside their territory, nationally and internationally, not only for the beautiful and delicious bottle of wine, but also for the promotion of their territory, by encouraging the discovery of flavors and places unknown today.

To understand a completely new approach prompted them to look towards science involvement and collaboration: the advantage of acquiring further knowledge, to be integrated from those already owned, to better explore this transformation.

Going into more detail, the companies investigated here have externalized the need to undertake collaborations with universities, but with different intensity and attention. The Tasca d'Almerita company has embarked on a path of collaboration with the university both as regards the development of services and for the mere production and vinification of grapes: the sphere of services has embraced the need to promote the conversion of the entire company towards sustainability with the SoStain project; instead in the productive sector it has opened the doors of its lands and cellars to the students, assisted by their professors, to study and implement new cultivation and fermentation practices.

Instead, Calabretta and Colomba Bianca have shown themselves to be very open to learning new practices for implementing services, but the interviews show the attention to exploiting academic knowledge to improve their wine production process. In the Calabretta case, there has been an approach to local universities with the intent to start internships in the company for recent graduates or students, as they allow both subjects to have benefits in the practical field and especially in the development of knowledge and increasingly effective skills to be applied at all stages of the production process, leaving the world of services a bit.

Finally, as regards Colomba Bianca, its interest in collaborating with universities is very strong; in fact, it has developed projects both in the production and in the services sector: it has interacted with a local research institute to experiment with innovative winemaking practices (micro-winemaking within the "Resilience" project); as part of the services, however, it has developed, in collaboration with meteorological departments, weather sheds for the benefit of both the company itself and the community in which it operates, making publicly available data for the phytosanitary protection of the land.

The implementation and continuous development of all these innovative practices, born from the precious 
collaboration between universities and the productive world, are testimony and incentive for the creation of new university-business agreements, in order to create a common lexicon with shared meanings and interests. (Carlile, 2004; Le Dain and Merminod, 2014),

Research limits. This study has several limits. It uses an exploratory analysis based on multiple case studies from only one region, therefore, the findings cannot be generalized to the whole population of winemakers. To extend the validity and generalizability of the findings, other cases from different regions should be examined, and a quantitative analysis should be developed.

Practical implications. From the results illustrated above, practical implications can be extrapolated which are very useful to managers operating in the low-tech sectors. The opening of the innovation processes of these companies, however, by improving relations with external sources, can allow them to obtain knowledge $n$ that previously could be seen as pure utopia.

It is the demonstration how highly standardized sectors stigmatized by traditional practices, such as the wine sector, can insert entirely new actions within their organizational structure, and have more than positive returns, both in economic and managerial terms.

Originality of the study. The present study, which is included in a larger research project, aims to highlight the key concepts examined in the literature focused on the relationships between university and firm in the context of the introduction of systems service-product. Thanks to the in-depth study of the companies taken into analysis, we have merged these topics, which are normally treated separately, to explain more clearly the process that occurs in winegrowing SMEs that intend to open their horizons, moving from the production and exclusive sale of products (bottles of wine) to the development of additional services (tastings, accommodation, conferences, etc.) in the context of the system of services-products.

Key words: Services; low-tech SMEs; university; wine sector.

\section{References}

BAINES T., LIGHTFOOT H., BENEDETTINI O., KAY J. (2009), “The servitization of manufacturing: A review of literature and reflection on future challenges", Journal of Manufacturing Technology Management, vol. 20, n. 5, pp. 547-567.

BAINES T., ZIAEE BIGDELI A., BUSTINZA O.F., SHI V. G., BALDWIN J., RIDGWAY K. (2017), "Servitization: revisiting the state-of-the-art and research priorities", International Journal of Operations and Production Management, vol. 37, n. 2, pp. 256-278.

BIFULCO F. (2004), "I percorsi di innovazione nelle imprese industriali: un approccio olistico", Sinergie, n. 64-65, 135-154.

BRYSON J.R., DANIELS P.W. (2010), 'Service worlds: the 'services duality' and the rise of the 'manuservice' economy”, The handbook of service science Springer, pp. 79-106.

BYUNGUN Y., SOJUNG K., JONGTAE R. (2012), "An evaluation method for designing a new Product-Service System”, Expert Systems with Applications, vol. 39, n. 3, pp. 3100-3108.

CARLBORG P., KINDSTRÖM D., KOWALKOWSKI C. (2014), "The evolution of service innovation research: A critical review and synthesis", The Service Industries Journal, vol. 34, n. 5, pp 373-398.

CARLILE P.R. (2004), "Transferring, Translating, and Transforming: An Integrative Framework for Managing Knowledge Across Boundaries”, Organ. Sci. vol. 5, n. 15, pp. 555-568.

CESARONI F., PICCALUGA A. (2016), "The activities of university knowledge transfer offices: towards the third mission in Italy", The Journal of Technology Transfer, vol. 41, n. 4, pp. 753-777.

CHESBROUGH H., CROWTHER A.K. (2006), "Beyond high-tech: early adopters of open innovation in other industries", R\&D Management, vol. 36, n. 3, pp. 229-326.

ETZKOWITZ H., LEYDESDORFF L. (2000), “The dynamics of innovation: From National Systems and 'Mode 2' to a Triple Helix of university-industry-government relations", Research Policy, vol. 29, n. 2, pp. 109-123.

FALK M., PENG F. (2013), “The increasing service intensity of European manufacturing”, Service Industries Journal, vol. 33, n.15/16, pp. 1686-1706.

FRANCOIS J., WOERZ J. (2008), "Producer services, manufacturing linkages, and trade", Journal of Industry, Competition and Trade, vol. 8, n. 3, pp. 199-229.

GALLOUJ F. (2002), "Innovation in services and the attendance old and new myths", Journal of Socio-Economics, vol. 31, n. 2, pp. 137-154.

GASIOROWSKI D.E. (2015), “The big business of small companies", http://www.iso.org/iso/ news.htm?refid=Ref1937.

GIULIANI E., ARZA V. (2009), "What drives the formation of 'valuable' university-industry linkages?: Insights from the wine industry", Research Policy, vol. 38, n. 6, pp. 906-921.

GOEDHUYS M., JANZ N., MOHNEN P. (2013), "Innovation paths and the innovation performance of low-technology 
firms-An empirical analysis of German industry”, Industrial and Corporate Change, vol. 23, n. 1, pp. 1-23.

LAURSEN K., SALTER A. (2006), "Open for innovation: the role of openness in explaining innovation performance among UK manufacturing firms", Strategic Management Journal, vol. 2, n. 27, pp. 131-150.

LEE T.W. (1999), Using qualitative methods in organizational research, Sage, Thousand Oaks, CA.

LE DAIN M.A., MERMINOD V.V. (2014), “A knowledge sharing framework for black, grey and white box supplier configurations in new product development", Technovation, vol. 34, n. 11, pp. 688-701.

GOEDKOOP M., HALEN C., TE RIELE H., ROMMENS P. (1999), "Product Service- Systems, ecological and economic Basics", Report for Dutch Ministries of Environment (VROM) and Economic Affairs (EZ).

MANZINI E., VEZZOLI C. (2002), "Product-service systems and sustainability", United Nations Environment Program (UNEP), Division of Technology Industry and Economics (DTIE), Production and Consumption Branch.

MILES I. (1993), "Services in the new industrial economy”, Futures, vol. 25, n. 6, pp. 653-672.

KRYVINSKA N., KACZOR S., STRAUSS C., GREGUŚ M. (2014), "Servitization - its Raise through Information and Communication Technologies”, 5th International Conference on Exploring Services Science (IESS 1.4), pp. 5-7, Lecture Notes in Business Information Processing (LNBIP 169), pp. 72-81.

NATALICCHIO A., ARDITO L., MESSENI PETRUZZELLI A., DEL GIUDICE M. (2019), “The origins of external knowledge inflows and the impact of university technologies", $R \& D$ Management, vol. 49, n. 4, pp. 639-651.

NEELY A. (2008), "Exploring the financial consequences of the servitization of manufacturing", Oper. Manag. Res., vol. 2, n. 1, 103-118.

ORDANINI A., PARASURAMAN A. (2010), "Service innovation viewed through a service-dominant logic lens: a conceptual framework and empirical analysis", Journal of Service Research, vol. 14, n. 1, pp. 3-23.

KUMAR R., MARKESET T. (2007), "Development of performance-based Service Strategies for the Oil and Gas Industry - A Case Study", Journal of Business \& Industrial Marketing, vol. 22, n. 4, pp. 272-280.

OLIVA R., KALLENBERG R. (2003), "Managing the Transition from Products to Services", International Journal of Service Industry Management, vol. 14, n. 2, pp. 160-172.

SILVESTRELLI S. (2004), "L'innovazione nei settori industriali: implicazioni di mercato e nuove logiche concorrenziali", Sinergie, n. 64-65, pp. 25-64.

STEFAN LACHIEWICZ, MAREK MATEJUN, PAWEŁ PIETRAS, MACIEJ SZCZEPAŃCZYK (2018), "Servitization as a Concept for Managing the Development of Small and Medium-sized Enterprises", Sciendo Management, vol. 22, n. 2, pp. 80-94.

BAINES T., LIGHTFOOD H., STEVE E., NEELY A., GREENOUGH R., PEPPARD J. (2007), "State-of-the-art in Product Service-Systems", Proceedings of the Institution of Mechanical Engineers. Part B. Journal of engineering manufacture, vol. 221, n. 10, pp. 1543- 1552.

TUKKER A. (2004), “Eight Types of Product-Service System: Eight Ways To Sustainability?”, Business Strategy And The Environment, vol. 13, n. 4, pp. 246-260.

TUKKER A., TISCHNER U. (2006), "New business for Old Europe: Product-service development, competitiveness and sustainability", Routledge.

VANDERMERWE S., RADA J. (1988), "Servitization of business: adding value by adding services", European Management Journal, vol. 6, n. 4, pp. 314-324.

YIN R.K. (2009), Case Study Research: Design and Methods, Essential guide to qualitative methods in organizational research. Applied Social Research Methods Series.

YIN R. K. (2014), Case study research: Design and methods (applied social research methods), Thousand Oaks, CA: Sage publications.

WALLIN J., PARIDA V., ISAKSSON O. (2015), "Understanding product-service system innovation capabilities development for manufacturing companies", Journal of Manufacturing Technology Management, vol. 26, n. 5, pp. 763-787.

\section{Websites}

http://www.societamanagement.it

http://www.sinergiejournal.it 



\title{
Privacy concerns: an exploratory analysis through big data
}

\author{
DAVID D’ACUNTO * SERENA Volo •
}

Objectives. The role of big data is widely acknowledged in tourism and hospitality literature with most authors pointing out the relevance of adequately collecting, analyzing and processing online user-generated content to investigate various aspects of consumer behavior and explore tourism and hospitality performances (Li et al., 2018; Mariani et al., 2018; Volo, 2018). In the realm of big data, online travel reviews (OTR) have received extensive attention for their ability to serve as source of input data for companies to understand of their customers and destinations to explore the image portrayed by tourists (Volo, 2019; Marine-Roig, 2019). The usefulness of big data has led scholars to explore a variety of topics both in tourism and hospitality literature, indeed using the analysis of OTR recent contributions investigate among the others: customers' motivation to contribute to OTR (Yoo, \& Gretzel, 2008); the persuasive effect of online travel reviews (Sparks, Perkins \& Buckley, 2013); OTR value and connection to hotel performance (Xie, Zhang, \& Zhang, 2014); the influence of trust and its antecedents on online reviews (Filieri, Alguezaui, \& McLeay, 2015); the differences in image as portrayed by destination agents and as perceived by tourists (Liu, Teichert, Rossi, Li, \& Hu, 2017; Paül i Agustí, 2018; Marine-Roig \& Mariné Gallisà, 2018); hotel customer characteristics and their perception of satisfaction (Gao, Li, Liu, \& Fang, 2018).

The aim of this extended abstract is to explore the relevance of consumers' offline privacy discourse through big data analytics. Exploiting the advantages of text mining techniques applied to big datasets, the present study contributes to the ongoing debate on consumer offline privacy concerns in the hospitality domain by mean of an exploratory analysis of the extent to which the privacy discourse appears in user-generated content of hotel guests.

Methodology. The privacy dictionary developed by Vasalou et al. (2011), and with the sub-dimensions reported in the study by Gill et al., (2011), was used for the purpose of this study. The privacy dictionary offers the opportunity to track the overall privacy perceptions over time as well as to detect the extent of elements referring to each subdimension of privacy namely: negative privacy, norms requisites, outcome state, private secret, intimacy, law, restriction and open visible.

Hotel reviews from TripAdvisor.com were collected and used for the purpose of this study. This online travel review platform has proved to be the most suitable and popular data source to study tourists' evaluations and preferences (Xie et al., 2014; Filieri et al., 2015; Mkono \& Tribe 2017; Ma et al., 2018; Marine-Roig, 2019). Hotel reviews of guests travelling to five main European cities were investigated, namely: Rome, Paris, Amsterdam, Barcelona and Istanbul. These cities were selected with the aim of capturing different cultural traits of NorthEuropean, Mediterranean, and Middle Eastern countries across Europe allowing to differentiate possible privacy issues related to different cultures. Furthermore, the selection of cities considers the volume and revenues generated by international overnight incoming visitors as ranked by the GDCI (2015), since this metric offers a reliable benchmark in the hospitality industry (D'Acunto et al., 2020).

Data was collected considering the information on hotels characteristics, (e.g. independent hotels, hotel-chains), the reviewer details (e.g. nickname, age class, gender, trip purpose) and reviews' text and ratings. For the purpose of this study, only hotel reviews originally written in American English were retrieved, this allowed for a straightforward use of the privacy dictionary adopted to run the analysis. The final dataset used consists of 68.936 reviews covering slightly more than ten years' time span: 2006-2016. Table 1 provides the characteristics of the dataset.

\footnotetext{
Postdoctoral research assistant in Marketing - Free University of Bozen-Bolzano - Italy e-mail: ddacunto@unibz.it

- Associate Professor of Marketing - Free University of Bozen-Bolzano - Italy e-mail: serena.volo@unibz.it
} 
Tab. 1: Dataset characteristics

\begin{tabular}{|c|c|c|c|}
\hline & & $\mathrm{n}$ & $\%$ \\
\hline \multirow{6}{*}{ Reviewer age } & -24 & 1007 & 1.5 \\
\hline & $25-34$ & 13621 & 19.8 \\
\hline & $35-39$ & 22541 & 32.7 \\
\hline & $50-64$ & 23536 & 34.1 \\
\hline & $65+$ & 8231 & 11.9 \\
\hline & Total & 68936 & 100.0 \\
\hline \multirow{3}{*}{ Reviewer gender } & Man & 33330 & 48.3 \\
\hline & Woman & 35606 & 51.7 \\
\hline & Total & 68936 & 100.0 \\
\hline \multirow{6}{*}{ Trip purpose } & As a couple & 35579 & 51.6 \\
\hline & On business & 5704 & 8.3 \\
\hline & Solo & 5561 & 8.1 \\
\hline & With family & 13550 & 19.7 \\
\hline & With friends & 8542 & 12.4 \\
\hline & Total & 68936 & 100.0 \\
\hline \multirow{6}{*}{ City of stay } & Amsterdam & 8374 & 12.1 \\
\hline & Barcelona & 11046 & 16.0 \\
\hline & Istanbul & 7733 & 11.2 \\
\hline & Paris & 23736 & 34.4 \\
\hline & Rome & 18047 & 26.2 \\
\hline & Total & 68936 & 6.4 \\
\hline \multirow{6}{*}{ Review rating } & 1 & 1332 & 1.9 \\
\hline & 2 & 2382 & 3.5 \\
\hline & 3 & 7735 & 11.2 \\
\hline & 4 & 23519 & 34.1 \\
\hline & 5 & 33968 & 49.3 \\
\hline & Total & 68936 & 100.0 \\
\hline
\end{tabular}

Source: Authors' elaboration

The reviews' distribution per rating class shows the typical positively biased distribution which is observable in most review platforms (e.g. Fradkin et al., 2018; Guo et al., 2017; Zervas et al., 2017), with extreme positive reviews covering more than $49 \%$ of the overall dataset.

In this paper, automated content analysis was deemed to be the most appropriate type of analysis to explore hotel reviews' text by adopting the privacy dictionary in its validated original structure thus preserved its reliability. The adoption of automated content analysis is rapidly growing in different domains of research such as consumer behaviour (e.g. Humphreys \& Wang, 2018), marketing (e.g. Cruz et al., 2017; Hewett et al., 2016) and psychology (e.g. Bazarova et al., 2013; Boyd \& Pennebaker, 2017). The privacy dictionary has been specifically developed for content analysis purposes by means of the software LIWC (Pennebaker et al., 2007), which was also used in this study. LIWC is a text mining software allowing researchers to detect terms belonging to predefined psychologically and cognitively coherent categories (Pennebaker et al., 2003). The software converts text in numbers and gives as output the relative frequency of words belonging to the specific dictionary category out of the total word count in the given text.

While within the marketing and consumer research literature, several scholars already adopted LIWC as a text mining tool to mine online reviews' text (e.g. Ludwig et al., 2013; van Laer et al., 2019; Villarroel et al., 2017), its incorporation to the tourism and hospitality domain is still at its infancy, with few studies carried out only in the last years. Ulqinaku \& Sarial-Abi (2020) used LIWC to content analyse user-generated data (i.e. tweets) to explore people's responses to tourism destination after terrorist attacks. Liu et al. (2019) employed LIWC to mine the sentiment embedded in online reviews of outbound Chinese tourists travelling to Australian destinations. D'Acunto et al. (2020) used LIWC in their study on guests' perception on hotels' CSR commitment. Thus, in this context, the current research also offers a methodological contribution by adding evidence of appropriate use of automated content analysis.

Findings. Privacy elements embedded in reviews' text offer a descriptive overview of the extent hotel guests travelling in Europe concern about their privacy during the stay. By looking at figure 1, privacy elements discussed in reviews' text do not show a linear trend over time. The analysis shows how people travelling to Europe experienced the highest level of privacy concerns in 2009. As a possible interpretation, the 2008 financial crisis may have had some influences on consumers' awareness of privacy risks. Figure 1 shows the trend over time. 
Fig. 1. Overall privacy elements in online reviews: trend over time

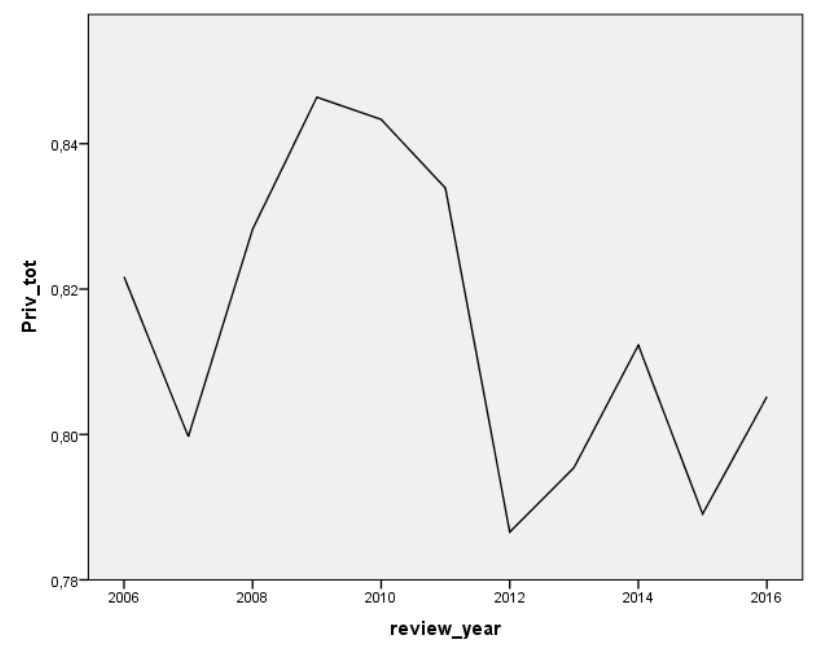

Source: Authors' elaboration

When examining the trend of each privacy dimension over time (figure 2), the results show how hotel guests travelling to Europe mainly discuss privacy elements referring to i) Restriction and ii) Outcome State categories. This finding offers a first comprehensive overview of which privacy dimensions are mostly discussed in their online feedbacks.

Fig. 2: Single privacy dimensions' elements in online reviews: trend over time

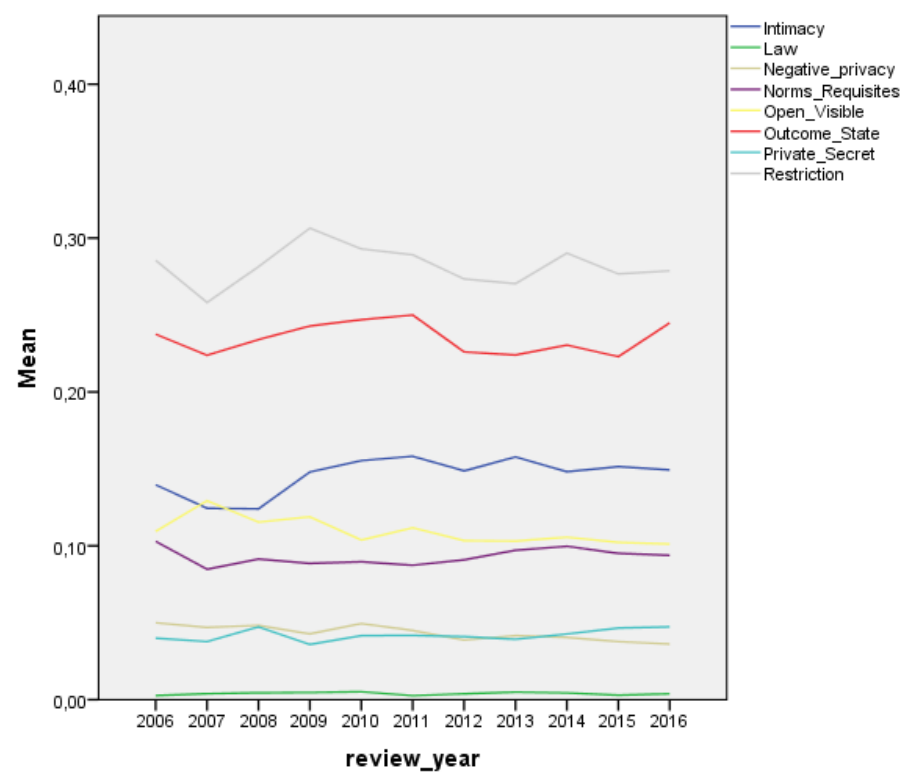

Source: Authors' elaboration

The results related to the levels of privacy elements per city of stay show some interesting findings. Hotel guests tend to mention more often privacy elements when travelling to Paris (0.832), while Istanbul (0.734) is the destination with the lowest level of privacy elements, indicating how different levels of privacy concerns are associated to different destinations $(F=16.265 ; p<.001)$.

Furthermore, the highest level of concern for privacy is experienced by tourist travelling either with friends (0.940) or with family (0.895), while people travelling in couple (0.746) and on business (0.743) result to be the less interested in such issues $(F=122.039 ; p<.001)$.

When looking at reviewers' features, hotel customers show the highest level of privacy concerns in the 65+age class (0.912). Also, the distribution of privacy elements per reviewer age classes recalls a positive relation between the two variables (i.e. privacy elements and reviewer's age), except for -24 class. The insight is that the older the guests, the greater the privacy concerns reported in their reviews $(F=99.536 ; p<.001)$. In terms of gender, women tend to report higher levels of privacy concerns (0.829) compared to men (0.788), (F=32.950; $p<.001)$. Table 2 reports the above-mentioned findings and ANOVA test results: 
Tab. 2: Overall privacy elements per destination and reviewer's characteristics

\begin{tabular}{|c|c|c|c|c|}
\hline & & Privacy total & Std. Dev & Anova \\
\hline \multirow{6}{*}{ Reviewer age } & -24 & 0.772 & 0.956 & $F=99.536$ \\
\hline & $25-34$ & 0.695 & 0.832 & $\mathrm{p}<0.001$ \\
\hline & $35-39$ & 0.784 & 0.917 & \\
\hline & $50-64$ & 0.865 & 0.999 & \\
\hline & $65+$ & 0.912 & 1.017 & \\
\hline & Total & 0.809 & 0.946 & \\
\hline \multirow{3}{*}{ Reviewer gender } & Woman & 0.829 & 0.939 & $\mathrm{~F}=32.950$ \\
\hline & Man & 0.788 & 0.952 & $\mathrm{p}<0.001$ \\
\hline & Total & 0.809 & 0.946 & \\
\hline \multirow{6}{*}{ Trip purpose } & As a couple & 0.746 & 0.890 & $\mathrm{~F}=122.039$ \\
\hline & On business & 0.743 & 0.923 & $\mathrm{p}<0.001$ \\
\hline & Solo & 0.871 & 0.973 & \\
\hline & With family & 0.895 & 1.005 & \\
\hline & With friends & 0.940 & 1.037 & \\
\hline & Total & 0.809 & 0.946 & \\
\hline \multirow{6}{*}{ City of stay } & Amsterdam & 0.797 & 0.943 & $\mathrm{~F}=16.265$ \\
\hline & Barcelona & 0.818 & 0.966 & $\mathrm{p}<0.001$ \\
\hline & Istanbul & 0.734 & 0.876 & \\
\hline & Paris & 0.832 & 0.959 & \\
\hline & Rome & 0.811 & 0.944 & \\
\hline & Total & 0.809 & 0.946 & \\
\hline
\end{tabular}

Source: Authors' elaboration

Research limits. This study is not without limitations. Firstly, giving the exploratory nature of the study the dataset is based only on one language and tourists speaking other languages might experience differently the issues related to privacy. Secondly, the dataset is based only on TripAdvisor reviews and despite this is the most used platform for online reviews a comparison with other online review platforms would be beneficial. Thirdly, data-mining analysis while advantageous to explore large dataset does not allow for a deep understanding of the discourse.

Future investigations would benefit from addressing the above-mentioned limitations, thus exploring other platforms, other cultures and analyzing the narratives of privacy with qualitative methods.

The approach to this study mainly aimed to provide a perspective on a topic that is still largely unexplored. The study, exploratory in nature, offers a descriptive viewpoint of consumers' offline privacy concerns in online reviews. Therefore, this study did not test for causal relationships, for instance testing the effects of privacy elements in online reviews on consumer behaviors, as well as on firms' responses. Future steps of the research will consider these elements to better understand the relationship between privacy and overall guest experience.

Practical implications. This contribution offers insights to the hospitality industry by providing a snapshot of the privacy issues that are mostly debated in online travel reviews by guests. The results show interesting aspects related to the eight dimensions of privacy alerting hotel owners and managers of aspects that were so far neglected by the literature.

This study offers important contributions to the hotel managerial practice. It provides insights to hotel managers on the extent of privacy concerns experienced by their guests during the stay. Hotel firms should be aware of the overall privacy perception that consumers feel when staying at their hotels, due to the strong relationship between privacy risks and consumer behaviors and orientation toward a brand (Morosan \& DeFranco, 2015) and trust (Ponte et al., 2015). It also provides information on which privacy dimensions are more discussed by customers (i.e. Restriction and Outcome State), thus allowing owners and managers to improve in those directions.

The present study also offers implication for digital marketers working in the hospitality industry. Online sharing of privacy concerns may negatively influence other platform members as well as potential customers, thus it is important for reputation managers to rapidly answer to such reviews in order to prevent negative eWOM effects.

Finally, the study suggests to firms operating in the hospitality domain not only to focus on the online dimension of privacy, rather to adopt voluntary disclosed consumer data -such as online reviews- to assess the actual comprehensive perception of offline privacy during the whole service delivery process.

Originality of the study. Despite the growing literature that explores various aspects of tourism and hospitality behavior using big data, a gap is identified with respect to the issues of privacy. Indeed, in the current OTR literature the role of trust and privacy is often addressed with respect to online data sharing habits and the consequent consumer's concerns (Morosan \& DeFranco, 2015; Filieri, 2016) and among the trust and privacy dimension studied, 
the most recently addressed in literature are those that relate to the online dimension of these constructs and the effect of data sharing on location-based social media (Kim, Yoon \& Zemke, 2017; Wang et al., 2020).

This extended abstract explores a novel area of privacy concerns. Offline privacy issues as traceable in online travel reviews are investigated using a reliable and validated privacy dictionary (Vasalou et al, 2011). This contribution is -to the authors knowledge-the first one to explore through an automated content analysis a big dataset of online travel reviews with the aim of providing insights about offline privacy. Indeed, the importance of consumers' privacy in the hospitality domain moves beyond the online dimension encompassing offline aspects of tourists' privacy which are often undetected.

Keywords Offline privacy; user-generated content; hotel reviews; automated content analysis; big data analytics.

\section{References}

BAZAROVA N.N., TAFT J.G., CHOI Y.H., COSLEY D. (2013), "Managing impressions and relationships on Facebook: Self-presentational and relational concerns revealed through the analysis of language style", Journal of Language and Social Psychology, vol. 32, n. 2, pp. 121-141.

BOYD R.L., PENNEBAKER J.W. (2017), "Language-based personality: a new approach to personality in a digital world", Current opinion in behavioral sciences, vol. 18, pp. 63-68.

CRUZ R.E., LEONHARDT J.M., PEZZUTI T. (2017), "Second person pronouns enhance consumer involvement and brand attitude", Journal of Interactive Marketing, vol. 39, pp. 104-116.

D'ACUNTO D., TUAN A., DALLI D., VIGLIA G., OKUMUS F. (2020), "Do consumers care about CSR in their online reviews? An empirical analysis”, International Journal of Hospitality Management, vol. 85, 102342.

FILIERI R. (2016), "What makes an online consumer review trustworthy?", Annals of Tourism Research, vol. 58, pp. 46-64.

FILIERI R., ALGUEZAUI S., MCLEAY F. (2015), "Why do travelers trust TripAdvisor? Antecedents of trust towards consumer-generated media and its influence on recommendation adoption and word of mouth", Tourism Management, vol. 51, pp. 174-185.

FRADKIN A., GREWAL E., HOLTZ D. (2018), “The determinants of online review informativeness: Evidence from field experiments on Airbnb", SSRN Electronic Journal, 2939064. DOI: https://doi.org/10.2139/ssrn.2939064.

GAO B., LI X., LIU S., FANG D. (2018), How power distance affects online hotel ratings: The positive moderating roles of hotel chain and reviewers' travel experience. Tourism Management, vol. 65, pp. 176-186.

GILL A.J., VASALOU A., PAPOUTSI C., JOINSON A.N. (2011), "Privacy dictionary: a linguistic taxonomy of privacy for content analysis", in Proceedings of the SIGCHI conference on human factors in computing systems, Association for Computing Machinery, New York, NY, USA, pp. 3227-3236.

GUO Y., BARNES S.J., JIA Q. (2017), "Mining meaning from online ratings and reviews: Tourist satisfaction analysis using latent dirichlet allocation", Tourism Management, vol. 59, pp. 467-483.

HEWETT K., RAND W., RUST R.T., VAN HEERDE H.J. (2016), "Brand buzz in the echoverse", Journal of Marketing, vol. 80, n. 3, pp. 1-24.

HUMPHREYS A., WANG R.J.H. (2018), “Automated text analysis for consumer research”, Journal of Consumer Research, vol. 44, n. 6, pp. 1274-1306.

KIM J.S., YOON S., ZEMKE D.M.V. (2017), "Factors affecting customers' intention to use of location-based services (LBS) in the lodging industry", Journal of Hospitality and Tourism Technology, vol. 8, n. 3, pp. 337-356.

LI J., XU L., TANG L., WANG S., LI L. (2018), "Big data in tourism research: A literature review", Tourism Management, vol. 68, pp. 301-323.

LIU Y., HUANG K., BAO J., CHEN K. (2019), "Listen to the voices from home: An analysis of Chinese tourists' sentiments regarding Australian destinations", Tourism Management, vol. 71, pp. 337-347.

LIU Y., TEICHERT T., ROSSI M., LI H., HU F. (2017), "Big data for big insights: Investigating language-specific drivers of hotel satisfaction with 412,784 user-generated reviews", Tourism Management, vol. 59, pp. 554-563.

LUDWIG S., DE RUYTER K., FRIEDMAN M., BRÜGGEN E.C., WETZELS M., PFANN G. (2013), "More than words: The influence of affective content and linguistic style matches in online reviews on conversion rates", Journal of Marketing, vol. 77, n. 1, pp. 87-103.

MA E., CHENG M., HSIAO A. (2018), "Sentiment analysis-a review and agenda for future research in hospitality contexts", International Journal of Contemporary Hospitality Management, vol. 30, n. 11, pp. 3287-3308.

MARIANI M., BAGGIO R., FUCHS M., HÖEPKEN W. (2018), "Business intelligence and big data in hospitality and tourism: a systematic literature review", International Journal of Contemporary Hospitality Management, vol. 30, n. 12, pp. 3514-3554.

MARINE-ROIG E., MARINÉ GALLISÀ E. (2018), "Imatge de Catalunya percebuda per turistes angloparlants i castellanoparlants" [Image of Catalonia perceived by English-speaking and Spanish -speaking tourists], Documents d'Anàlisi Geogràfica, vol. 64, n. 2, pp. 219-245.

MARINE-ROIG E. (2019), "Destination image analytics through traveller-generated content", Sustainability, vol. 11, n. $12,3392$. 
MKONO M., TRIBE J. (2017), "Beyond reviewing: Uncovering the multiple roles of tourism social media users", Journal of travel research, vol. 56, n. 3, pp. 287-298.

MOROSAN C., DEFRANCO A. (2015), "Disclosing personal information via hotel apps: A privacy calculus perspective", International Journal of Hospitality Management, vol. 47, pp. 120-130.

PAÜL I AGUSTÍ D. (2018), "Characterizing the location of tourist images in cities. Differences in user-generated images (Instagram), official tourist brochures and travel guides", Annals of Tourism Research, vol. 73, pp. $103-$ 115.

PENNEBAKER J.W., BOOTH R.J., FRANCIS M.E. (2007), Linguistic inquiry and word count: LIWC [Computer software], Austin, TX: liwc. net, 135.

PENNEBAKER J.W., MEHL M.R., NIEDERHOFFER K.G. (2003), "Psychological aspects of natural language use: Our words, our selves", Annual Review of Psychology, vol. 54, n. 1, pp. 547-577.

PONTE E.B., CARVAJAL-TRUJILLO E., ESCOBAR-RODRÍGUEZ T. (2015), "Influence of trust and perceived value on the intention to purchase travel online: Integrating the effects of assurance on trust antecedents", Tourism Management, vol. 47, pp. 286-302.

SPARKS B.A., PERKINS H.E., BUCKLEY R. (2013), "Online travel reviews as persuasive communication: The effects of content type, source, and certification logos on consumer behavior", Tourism Management, vol. 39, pp. 1-9.

ULQINAKU A., SARIAL-ABI G. (2020, in press), “Tourism implications of online response to terrorism”, Annals of Tourism Research, 102914. DOI: 10.1016/j.annals.2020.102914.

VAN LAER T., EDSON ESCALAS J., LUDWIG S., VAN DEN HENDE E.A. (2019), "What happens in Vegas stays on TripAdvisor? A theory and technique to understand narrativity in consumer reviews", Journal of Consumer Research, vol. 46, n. 2, pp. 267-285.

VASALOU A., GILL A.J., MAZANDERANI F., PAPOUTSI C., JOINSON A. (2011), "Privacy dictionary: A new resource for the automated content analysis of privacy", Journal of the American Society for Information Science and Technology, vol. 62, n. 11, pp. 2095-2105.

VILLARROEL ORDENES F, LUDWIG S., DE RUYTER K., GREWAL D., WETZELS M. (2017), "Unveiling what is written in the stars: Analyzing explicit, implicit, and discourse patterns of sentiment in social media", Journal of Consumer Research, vol. 43, n. 6, pp. 875-894.

VOLO S. (2018), "Tourism data sources: from official statistics to big data", in Cooper C., Volo S., Gartner W.C., (edited by), The Sage Handbook of Tourism Management, SAGE, London, pp. 193-201.

VOLO S. (2019), "Tourism statistics, indicators and big data: a perspective article", Tourism Review, 75(1), $304-309$.

WANG Y., ASAAD Y., FILIERI R. (2020), "What makes hosts trust Airbnb? Antecedents of hosts' trust toward Airbnb and its impact on continuance intention", Journal of Travel Research, vol. 59, n. 4, pp. 686-703.

XIE K.L., ZHANG Z., ZHANG Z. (2014), „The business value of online consumer reviews and management response to hotel performance", International Journal of Hospitality Management, vol. 43, pp. 1-12.

YOO K.H., GRETZEL U. (2008), "What motivates consumers to write online travel reviews?", Information Technology \& Tourism, vol. 10, n. 4, pp. 283-295.

ZERVAS G., PROSERPIO D., BYERS J.W. (2017), "The rise of the sharing economy: Estimating the impact of Airbnb on the hotel industry", Journal of marketing research, vol. 54, n. 5, pp. 687-705.

\section{Internet websites}

GDCI. (2015), "Mastercard global worldwide insights", available at: https://newsroom.mastercard.com/wpcontent/uploads/2015/07/Mastercard_GDCI_2015_Letter_Final_70814.pdf 


\title{
The determinants of eco-innovation strategies. An empirical investigation of two European countries
}

\author{
IDA D’ATTOMA* SILVIA PACEI
}

Objectives. The present paper is a work in progress focusing on the driving forces behind the adoption of different types of eco-innovation mode in German manufacturing sectors compared to Romania over 2012-2014, through an empirical analysis of the community innovation survey (CIS). To this end, in our empirical study, we considered a measure of eco-innovation performance that counts different types of eco-innovation that enterprises have undertaken. Moreover, we considered a wide and comprehensive set of potential drivers, including "technology push", "regulatory push-pull" and "firm specific factors" clusters of drivers. Due to the count nature of our dependent variable and to the large presence of zeros, we estimate a zero-inflated negative binomial model. Given the early stage of this study, in the present paper preliminary findings on the differences in the determinants of eco-innovation in the two countries will be presented.

Environmental innovation, or eco-innovation, is commonly understood as innovations that are associated with environmental benefits. Differently from traditional innovation, eco-innovation 'emphasizes the firms' mitigation of negative impacts on the natural environment' (Liao and Tsai, 2018). Some papers discussed the existence of a positive relationship between eco-innovation and firm performance and growth, thus motivating the identification and the analysis of trigger factors for eco-innovation. The early study of Russo and Fouts (1997) found that the more enterprises eco-innovate, the greater the positive impacts on their performance. Firms implementing eco-innovation tend to be recognized in a positive sense (Buysse and Verbeke, 2003) by consumers that are nowadays increasingly aware of environmental topics. Not only to obtain or enhance social legitimacy but also to react or pre-empt their rival's environmental moves, corporations are inclined to use eco-innovation strategies to exploit emerging opportunities (Liao and Tsai, 2018).

In this scenario, investigating eco-innovation determinants can be helpful for policy-makers and managers who wish to promote its adoption and diffusion (Ghisetti and Pontoni, 2015). Although there has been a significant increase in eco-innovation knowledge, some conflicting results are still present in the literature (Bitencourt et al., 2020; DíazGarcia et al., 2015). Moreover, over the past decade, many empirical works have analysed the drivers of ecoinnovation for single countries and especially among manufacturing firms because of their higher environmental impact (Jové-Llopis and Segarra-Blasco, 2018) but there is still a lack of country comparisons (Horbach, 2016; Ghisetti et al al. 2015 as exceptions).

In light of this, the main purpose of this study was to analyse the main factors enhancing firms focusing on a different number of eco-innovations in Germany and Romania. Specifically, the following research questions were asked:

RQ1: what types of factors do enhance firms focusing on a different number of eco- innovations?

RQ2: how does the context influence these relations in different countries?

We considered data taken by the Community Innovation Survey (CIS) in 2014. We constructed a count measure of eco-innovativeness and then we analysed its determinants by estimating a zero-inflated negative binomial model (Greene, 2009; Hilbe, 2007).

We decided to compare Germany - that is an eco-innovation leader, to Romania, that is a catching up with ecoinnovation country. According to the European innovation scoreboard, Germany was a strong innovator in 2013, whereas Romania was the less innovative one. Germany is also Romania's most important trading partner and the second largest foreign direct investor in the country. Given the intense interplay between them it is worth analysing eco-innovation determinants they might share, by not forgetting that they do not share the same institutional/regulatory context.

Methodology. The empirical literature on the determinants of eco-innovation has typically considered a binary measure of eco-innovation that keeps track to some extent of the specific eco-innovation strategy adopted. Horbach (2016), for example, estimated several binary probit models, one for each eco-innovation strategy represented by a

Senior Assistant Professor of Economic Statistics - University of Bologna - Italy

e-mail: Ida.dattoma2@unibo.it

- Associate Professor of Economic Statistics - University of Bologna - Italy

e-mail: silvia.pacei@unibo.it

Sinergie-SIMA 2020 Conference

Grand challenges: companies and universities working for a better society

Electronic Conference Proceedings

7-8 September 2020 - University of Pisa-Sant'Anna School of Advanced

ISBN 97888943937-6-7

Studies Pisa (Italy) - Online Conference

DOI 10.7433/SRECP.EA.2020.01 
binary variable. Jové-Llopis \& Segarra-Blasco (2018) used as outcome a binary variable that takes the value 1 if the firm $i$ states that eco-innovation motivation has been of high or medium importance in a specific period.

We believed that empirical research on eco-innovation determinants based on a unidimensional eco-innovation construct were incomplete. The use of a binary variable to measure eco-innovation activity might cause the loss of valuable information regarding the eco-innovative intensity (Triguero et al. 2013). It is noteworthy that firms usually do not focus on only one type of eco-innovation, rather they simultaneously adopt more types of eco-innovations. This is also due to the interrelation between various types of green innovations that might motivate firms that have developed $R \& D$ and managerial capabilities to simultaneously introduce more than one type of green innovation (Castellacci \& Lie, 2017).

Only a few studies have considered a non-binary measure of eco-innovation. Ghisetti et al. (2015) considered the firm's introduction of an eco-innovation (binary) as well as the enlargement of its eco-innovation-portfolio (i.e. the number of eco-innovation typologies). In particular, the authors defined a count variable in order to identify the existence of regularities across the different typologies of eco-innovation. Then, following Ghisetti et al. (2015), Liao and Tsai (2018) used a count variable, as well. Castellacci and Lie (2017) used a Principal Component Analysis to reduce eco-innovation variables into a smaller number of factors then used to identify different clusters of ecoinnovators.

In this study we used the degree of eco-innovativeness as dependent variable in our model, that is a count variable used to keep track of the different types of eco-innovations adopted by the enterprise. Within CIS data, each indicator on its own provides information on a firm's eco-innovative activity. Therefore, we constructed a measure of firm's ecoinnovativeness by counting the various forms of eco-innovation adopted by a firm.

The literature on the determinants of eco-innovation has developed rapidly during the past decade, and prior literature has shown that no definite conclusions can be derived whether determinants differ according to the ecoinnovation type addressed, nor if determinants of eco-innovation affect in the same way the degree of ecoinnovativeness. We built the present work on the specific strand of literature relevant to the empirical analysis of the drivers of eco-innovation. In particular, a relatively recent body of literature has focused on four main clusters of drivers: "technology-push", "market-pull”, "regulatory-push-pull” and "firm specific factors" (Zulbeltzu-Jaka et al. 2018; Horbach et al., 2012).

"Technology-push factors" are factors related to the development of technological and organizational capabilities. Cooperation (Horbach,2008; 2016; Jovè-Llopis \& Segarra-Blasco, 2018), for example, is recognized as one of these technology-push factors. Similarly, information sources have been recognized as central technology-push factors in spurring the adoption of an eco-innovation (Horbach, 2016; Ghisetti et al. 2015). However, the econometric evidence of their effects on different eco-innovations, is mixed and inconclusive (Castellacci and Lie, 2017).

As far as "market-pull factors" are concerned, among other factors, i.e. market turbulence (Hofstra and Huising, 2014), there is a general consensus in the empirical literature on the fact that the expectation of a future demand created by eco-conscious customers is likely to give rise to investments in environmental innovations (Horbach, 2008, 2016; Wagner, 2008; Triguero et al., 2013; Liao and Tsai, 2018), having enterprises realized that green consumers can be a profitable segment (Hojnik, 2017). Eco-conscious consumers' demand is a strong driver of eco-innovativeness especially in those product markets which are close to the final consumers (Doran and Ryan, 2012). However, a market pull effect is more likely in countries with high environmental awareness, such as Germany, and less likely in countries with low environmental awareness and low willingness to pay more for eco-products, including Spain (Jové-Llopis and Segarra-Blasco, 2018) and some eastern European countries.

As far as "regulatory-push-pull factors" are concerned, many studies have stressed that environmental regulation is the most important stimulus that lead firms to eco-innovate (Ghisetti and Rennings,2014; Horbach, 2016; Liao and Tsai, 2018; Jové-Llopis and Segarra-Blasco,2018). Environmental regulation refers to the regulations enacted by governments to protect or improve the environment to promote sustainability (Liao and Tsai, 2018). According to the Porter Hypothesis environmental regulations lead to a win-win situation where simultaneously pollution is reduced and productivity or the product-value for the end-user increased (Porter, 1991; Porter \& van der Linde, 1995).

Finally, as far as "firm-specific factors" are concerned, firm size, industry, whether the firm belongs to a group, foreign market focus (Liao \& Tsai, 2018; Dangelico, 2017; Chiavesio et al., 2015), country dummies (Horbach, 2016) and age, are all considered as important factors of eco-innovation.

The CIS sample used in this study covers 3,250 manufacturing firms with more than 10 employees across different industries for Germany and 4,325 manufacturing firms for Romania.

The CIS defines an eco-innovation as "a new or significantly improved product (good or service), process, organizational method or marketing method that creates environmental benefits compared to alternatives". The definition is not only confined to the technological sphere but it also encompasses organizational and market aspects.

The outcome of our model was the number of eco-innovations adopted by a firm and ranged from 0 (no ecoinnovation strategy were in place) through 10 (all environmental strategies were implemented) 1 . For what concerns

1 The CIS 2014 includes ten types of eco-innovations: material use reduction; energy saving; air, water, noise or soil pollution reduction within enterprise; substitution of polluting and hazardous materials; substitution of fossil energy with renewable energy; waste, water and material recycling; $\mathrm{CO} 2$ emissions reduction; air, water, noise or soil pollution reduction during the consumption by the end user; recycling of a product after use; extending product life through longer - lasting, more durable products. 
explanatory variables, we followed the body of literature that has focused on four main clusters of drivers: technologypush, regulatory-push-pull, market-pull, and firm specific factors (Horbach et al, 2012; Zulbeltzu et al., 2018). As technology-push factors we considered the degree of cooperation defined as the number of innovation cooperation partners type with which the enterprise undertakes an active cooperation, the innovation intensity described by the ratio of the total expenditure on innovation and technological capabilities proxied by qualified employees. As regulatory push-pull factors, we took into account whether the enterprise has received public support for its innovation activity. Then, because CIS data did not allow us to directly consider the role of environmental regulations, as a proxy of environmental regulation we adopted the logarithm of $\mathrm{CO} 2$ air emissions intensities expressed as ratios relating carbon dioxide emissions to value added by manufacturing industries (classified by NACE Rev. 2) in each country considered. As firm-specific factors we considered firm size, industry, whether the firm belongs to a group, the foreign market focus, the exporting behaviour, the employee growth rate and the turnover growth rate. No market-pull factors were available. Moreover, we envisaged the forms of innovation protection as an important trigger factor of eco-innovation. In fact, in light of the double externality problem (Rennings, 2000), even when a firm successfully reaches the market with an ecoinnovation, the profit appropriation could result still difficult especially in case the eco-innovation is accessible to potential imitators (Hojnik, 2017), thus requiring protection.

Due to the beforementioned count nature of our dependent variable $Y$ and the large presence of zeros, we use the zero-inflated Negative Binomial regression model (ZINB) (Greene, 2009; Hilbe, 2007). In fact, in our case, the Negative Binomial model may not accurately assign probability to the outcome $Y=0$. The zero count $Y=0$ occurs because the enterprise would never eco-innovate, regardless of the characteristics that appear in the model. Otherwise, $Y=0$ happens to be the number of eco-innovations adopted in the survey period. But, at some other time, the same enterprise might choose $Y=j>0$.

The ZINB model is a "two-part" count data model, as it considers two data generation processes simultaneously influencing the outcome. For each observation $i$ the first process, represented by $d_{i}$, gives zero counts $\left(Y_{i}=0\right)$ with probability $\pi i$ (when $d_{i}=0$ ), and the second process, with the complementary probability $1-\pi_{i}($ when di=1) provides counts $\left(Y_{i} \geq 0\right)$ according to a negative binomial with mean $\lambda_{i}$. Therefore, the second process may generate zero counts as well.

The model can be represented as follows:

$Y_{i}=0$ with probability $\pi_{i}$

$Y_{i} \sim N B\left(\lambda_{i}\right)$ with probability $1-\pi_{i}$

so that, the probabilities connected to the two possible outcomes are:

$\operatorname{Prob}\left[Y_{i}=0\right]=\pi_{i}+\left(1-\pi_{i}\right) R_{i}(0)$

$\operatorname{Prob}\left[Y_{i}=j>0\right]=\left(1-\pi_{i}\right) R_{i}(j)$

where

$R_{i}(j)=$ the negative binomial probability $=\Gamma\left(\theta+y_{i}\right) /\left[y_{i} ! \Gamma(\theta)\right] u_{i}^{\theta}\left[1-u_{i}\right]^{y_{i}}$

$\theta=1 / \alpha$, where $\alpha$ is the overdispersion parameter

$u_{i}=\theta /\left(\vartheta+\lambda_{i}\right)$

$\lambda_{i}=\exp \left(\boldsymbol{\beta}^{\prime} \boldsymbol{x}_{\boldsymbol{i}}\right)$

with $\boldsymbol{x}_{i}$ as the vector of covariates and $\boldsymbol{\beta}$ the vector of related coefficients.

For probability $\pi_{i}$ we use a logistic probability model:

\section{$\pi_{\boldsymbol{i}} \sim \operatorname{Logistic}\left(\boldsymbol{\delta}^{\prime} \boldsymbol{w}_{\boldsymbol{i}}\right)$}

and we consider the same auxiliary variables used in the NB model $\left(\boldsymbol{w}_{\boldsymbol{i}}=\boldsymbol{x}_{\boldsymbol{i}}\right)$.

The joint density can be written as follows:

$P\left(y_{i}, d_{i} \mid x_{i}\right)=\left(1-d_{i}\right) \pi_{i}+d_{i}\left(1-\pi_{i}\right) R_{i}(y)$

while the conditional mean function is $\left(1-\pi_{i}\right) \lambda_{i}$.

We use the incidence rate ratio (IRR) to evaluate the effect of auxiliary variables on the dependent variable.

Findings. Our response variable is a count variable and represents the number of eco-innovations adopted by a firm. The Cronbach's Alpha coefficient is computed to estimate the reliability of this type of construct by determining its internal consistency. The Cronbach's Alpha coefficient of our dependent variable is 0.83 and 0.89 for Germany and Romania, respectively 2 .

With reference to Germany, $11 \%$ of firms in the data reported only one type of eco-innovation, whereas about $70 \%$ reported two or more types, as many as $4.4 \%$ reported all 10 and about $20 \%$ reported zero eco-innovations. The presence of zeros is higher in the Romania case, where about 57\% of manufacturing firms reported zero ecoinnovations, about $5 \%$ only one type, about $36 \%$ reported two or more types and only about $2 \%$ reported all 10 . The

2 These values are much greater than the suggested value of 0.70 given by Nunnally \& Bernstein (1994). 
number of eco-innovations adopted by German and Romanian firms is shown in Figure 1. Table 1 reports results of the estimated zero inflated negative binomial model for Germany and Romania, respectively.

Fig. 1: Number of eco-innovations in Germany and Romania

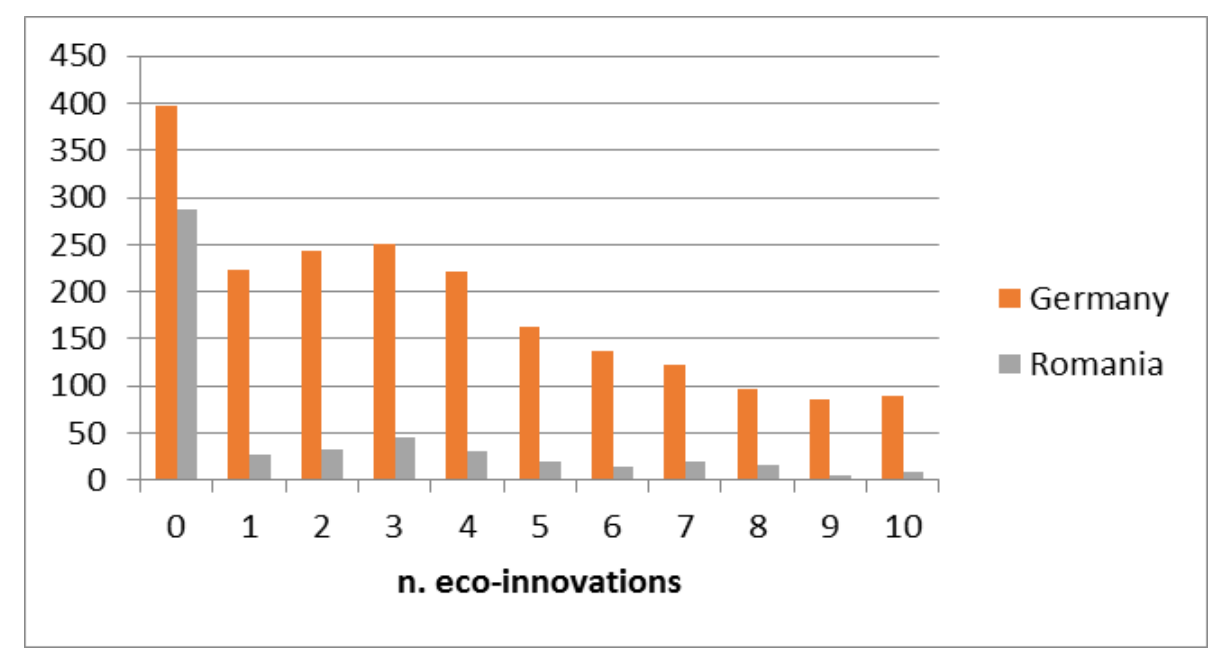

Source: Own elaboration of the CIS 2014 data.

Table 1 reports results of the estimated zero inflated negative binomial model for Germany and Romania, respectively. The Vuong statistic is 7.3 for Germany and 7.51 for Romania. In both cases it favors the zero inflated negative binomial model with respect to the standard negative binomial model.

The following variables were significant at $1 \%$ or $5 \%$ level for the Germany case: degree of cooperation, innovation intensity, environmental regulation, size (medium and large), high-tech sector, medium-tech sector and level of protection.

As the degree of cooperation of enterprises increased of one unit, the number of eco-innovations had a $46.33 \%$ increase $(I R R=1.4633)$ in the number of eco-innovations. This result might be due to the fact that eco-innovations are more complex and demanding than other types of innovation, thus requiring more resources picked up from external partners and sources of knowledge. In line with literature, innovation intensity was found to have a positive effect on eco-innovation. A firm with a one unit change in the internal and external $R \& D$ is expected to have a $51 \%$ increase $(I R R=1.5138)$ in the number of eco-innovations. Environmental regulation was found to be an important stimulus to eco-innovation: a one unit change in the CO2 air emissions intensity increased by $2.5 \%$ (IRR=1.0254) the number of eco-innovations. The number of eco-innovations adopted by a firm increased as size classes increased (the smallest class dummy 1-49 employees was excluded from the model). Enterprises with 250-499 employees had about a $25 \%$ $(I R R=1.2473)$ increase in the number of eco-innovations compared to enterprises who had less than 50 employees. Enterprises with 500 and more employees had about (31\%) increase (IRR $=1.3117)$ in the number of eco-innovations compared to enterprises with less than 50 employees. Furthermore, a one unit change in the level of protection caused a $54 \%$ increase $(I R R=1.5430)$ in the number of eco-innovations. Conversely, enterprises who belong to the high-tech sector had a $23.78 \%$ decrease $(I R R=0.7622)$ in the number of eco-innovations compared to the enterprises in the lowtech sector (reference category). Moreover, enterprises in the medium-tech sector experienced a $9.77 \%$ decrease $(I R R=0.9023)$ in the number of eco-innovations compared to enterprises in the low-tech sector.

For the absolute zero group (inflation equation), the risk of being in the absolute zero was found to be significant related to the environmental regulation, the size, the sector and the level of protection.

As far as Romania is concerned, the determinants relevant for eco-innovation were different from those discussed for Germany, except for the cooperation intensity and innovation intensity. Similarly to Germany, a firm that experienced a one unit change in the cooperation intensity is expected to have an increase of $126.37 \%$ (IRR=2.2637) in the number of eco-innovations. Moreover, an enterprise that experienced a one unit change in the innovation intensity had a $140.24 \%$ increase (IRR=2.4024) in the number of eco-innovations. Differently from Germany, enterprises who belong to the medium-tech sector experienced a $25.33 \%$ increase $(I R R=1.2533)$ in the number of eco-innovations compared to enterprises in the low-tech sector.

In addition, differently from Germany, the following firm's characteristics were significant at $1 \%$ or $5 \%$ level: qualified employees (squared), export.

On the other hand, the environmental regulation as well as those covariates connected with the need to protect one's own innovations, as the level of protection, did not affect the Romanian firms' level of eco-innovation.

For the absolute zero group (inflation equation), the risk of being in the absolute zero was found to be significant related to the public support to innovation, the environmental regulation, the size and the level of protection. Differently from Germany the risk of being in the absolute zero group decreased of $65.91 \%$ as the enterprises received public support to innovation. 
These results highlighted how the different regulatory contexts and different levels of competitiveness of the market affect the firms' eco-innovation behavior in the two Countries.

Tab. 1: The determinants of eco-innovation in Germany and Romania: parameter estimates in the ZINB model

\begin{tabular}{|c|c|c|c|c|}
\hline \multirow[b]{2}{*}{ Covariate } & \multicolumn{2}{|l|}{ Germania } & \multicolumn{2}{|l|}{ Romania } \\
\hline & $\operatorname{IRR}(S E)$ & $z$ & $\operatorname{IRR}(S E)$ & $z$ \\
\hline \multicolumn{5}{|l|}{ Count equation } \\
\hline Degree of cooperation & $\begin{array}{l}1.4633^{* * *} \\
(.1677)\end{array}$ & 3.32 & $\begin{array}{l}2.2637^{* * *} \\
(.6908)\end{array}$ & 2.68 \\
\hline Innovation intensity & $\begin{array}{l}1.5138^{*} \\
(.3305) \\
\end{array}$ & 1.90 & $\begin{array}{l}2.4024^{*} \\
(1.2027)\end{array}$ & 1.75 \\
\hline Qualified employees & $\begin{array}{l}.9989 \\
(.0030)\end{array}$ & -0.36 & $\begin{array}{l}1.0110 \\
(.0083) \\
\end{array}$ & 1.33 \\
\hline Qualified employees (squared) & $\begin{array}{l}.9999 \\
(.0000) \\
\end{array}$ & -0.04 & $\begin{array}{l}.9998^{*} \\
(.0000) \\
\end{array}$ & -1.82 \\
\hline Public funding & $\begin{array}{l}.9449 \\
(.0468) \\
\end{array}$ & -1.14 & $\begin{array}{l}.7932 \\
(.1156) \\
\end{array}$ & -1.59 \\
\hline Environmental regulation (In) & $\begin{array}{l}1.0254^{*} \\
(.0135) \\
\end{array}$ & 1.91 & $\begin{array}{l}1.0155 \\
(.0294) \\
\end{array}$ & 0.53 \\
\hline Export & $.9933(.0490)$ & -0.13 & $\begin{array}{l}1.4955^{\star \star \star} \\
(.1815)\end{array}$ & 3.31 \\
\hline Group membership & $\begin{array}{l}.9326 \\
(.0683) \\
\end{array}$ & -0.95 & $.8629(.1016)$ & -1.25 \\
\hline Foreign Multinational & $\begin{array}{l}.9794 \\
(.0690)\end{array}$ & -0.29 & $1.3253(.2514)$ & 1.48 \\
\hline 50-249 employees & $\begin{array}{l}1.0640 \\
(.0483) \\
\end{array}$ & 1.37 & $\begin{array}{l}.8186 \\
(.1036) \\
\end{array}$ & -1.58 \\
\hline 250-499 employees & $\begin{array}{l}1.2473^{* * *} \\
(.0901)\end{array}$ & 3.06 & $1.0148(.1517)$ & 0.10 \\
\hline 500 and more employees & $\begin{array}{l}1.3117^{* * *} \\
(.0982)\end{array}$ & 3.62 & $\begin{array}{l}1.1918 \\
(.1915) \\
\end{array}$ & 1.09 \\
\hline High-tech sector & $\begin{array}{l}.7622^{* * *} \\
(.0584) \\
\end{array}$ & -3.54 & $\begin{array}{l}.6488^{*} \\
(.1532) \\
\end{array}$ & -1.83 \\
\hline Medium-tech sector & $\begin{array}{l}.9023^{* *} \\
(.0386)\end{array}$ & -2.40 & $\begin{array}{l}1.2533^{* \star} \\
(.1329)\end{array}$ & 2.13 \\
\hline Employees growth rate & $1.0522(.0565)$ & 0.95 & $.8571(.1002)$ & -1.32 \\
\hline Turnover growth rate & $\begin{array}{l}1.0002 \\
(.0005) \\
\end{array}$ & 0.45 & $\begin{array}{l}.9972 \\
(.0050) \\
\end{array}$ & -0.53 \\
\hline \multirow[t]{2}{*}{ Level of protection } & $\begin{array}{l}1.5430^{* \star *} \\
(.1335)\end{array}$ & 5.01 & $\begin{array}{l}.9617 \\
(.2884) \\
\end{array}$ & -0.13 \\
\hline & \multicolumn{2}{|l|}{ Germania } & \multicolumn{2}{|l|}{ Romania } \\
\hline Covariate & OR (SE) & p-value & $O R(S E)$ & $p$-value \\
\hline \multicolumn{5}{|l|}{ Inflation equation } \\
\hline Degree of cooperation & $\begin{array}{l}0.4416 \\
(.3236) \\
\end{array}$ & 0.2648 & $\begin{array}{l}.3707 \\
(.4287) \\
\end{array}$ & .3909 \\
\hline Innovation intensity & $\begin{array}{l}1.3083 \\
(1.0363)\end{array}$ & 0.7344 & $\begin{array}{l}.9991 \\
(1.3061)\end{array}$ & 0.9995 \\
\hline Qualified employees & $\begin{array}{l}.9900 \\
(.0124) \\
\end{array}$ & 0.4259 & $\begin{array}{l}1.0272 \\
(.0217) \\
\end{array}$ & 0.2045 \\
\hline Qualified employees (squared) & $\begin{array}{l}1.0002 \\
(.0001) \\
\end{array}$ & 0.1864 & $\begin{array}{l}.9996 \\
(.0002) \\
\end{array}$ & 0.1895 \\
\hline Public funding & $\begin{array}{l}.9646 \\
(.2364) \\
\end{array}$ & 0.8832 & $\begin{array}{l}.3409^{*} \\
(.1606) \\
\end{array}$ & 0.0224 \\
\hline Environmental regulation (In) & $\begin{array}{l}.7840^{\star} \\
(.0751)\end{array}$ & 0.0111 & $\begin{array}{l}.8284^{*} \\
(.0644)\end{array}$ & 0.0155 \\
\hline Export & $\begin{array}{l}1.0537 \\
(.2020) \\
\end{array}$ & 0.7848 & $\begin{array}{l}1.0712 \\
(.2899) \\
\end{array}$ & 0.7993 \\
\hline Group membership & $\begin{array}{l}.4497 \\
(.2600)\end{array}$ & 0.1669 & $\begin{array}{l}.7234 \\
(.2478)\end{array}$ & 0.3447 \\
\hline Foreign Multinational & $\begin{array}{l}.4518 \\
(.2653)\end{array}$ & 0.1762 & $\begin{array}{l}1.0679 \\
(.6175)\end{array}$ & 0.9095 \\
\hline 50-249 employees & $\begin{array}{l}.4881^{* * *} \\
(.0982)\end{array}$ & 0.0004 & $\begin{array}{l}.5383^{*} \\
(.1583)\end{array}$ & 0.0353 \\
\hline 250-499 employees & $\begin{array}{l}.3973^{\star} \\
(.1820) \\
\end{array}$ & 0.0439 & $\begin{array}{l}.3483^{* *} \\
(.1351)\end{array}$ & 0.0066 \\
\hline 500 and more employees & $\begin{array}{l}.2838^{*} \\
(.1650)\end{array}$ & 0.0303 & $\begin{array}{l}.3402^{*} \\
(.1483)\end{array}$ & 0.0134 \\
\hline High-tech sector & $\begin{array}{l}1.1855 \\
(.3564)\end{array}$ & 0.5713 & $\begin{array}{l}.7332 \\
(.4426)\end{array}$ & 0.6073 \\
\hline Medium-tech sector & $\begin{array}{l}.6580^{*} \\
(.1292)\end{array}$ & 0.0331 & $\begin{array}{l}.7905 \\
(.2129)\end{array}$ & 0.3829 \\
\hline Employees growth rate & $\begin{array}{l}.8461 \\
(.2330) \\
\end{array}$ & 0.5442 & $\begin{array}{l}1.1254 \\
(.2890) \\
\end{array}$ & 0.6453 \\
\hline Turnover growth rate & $\begin{array}{l}.9989 \\
(.0068)\end{array}$ & .8723 & $\begin{array}{l}.9777 \\
(.0240) \\
\end{array}$ & 0.3592 \\
\hline Level of protection & $\begin{array}{l}.1915^{* *} \\
(.1010)\end{array}$ & .0017 & $\begin{array}{l}.0194^{* *} \\
(.0250)\end{array}$ & 0.0022 \\
\hline
\end{tabular}

Notes: $* * * 1 \%$ significance, $* * 5 \%$ significance and $* 10 \%$ significance

Source: Own elaboration of the CIS 2014 data 
Research limits. This study had several limitations. The cross-sectional nature of our sample did not enable us to draw valid conclusions regarding any association or possible causality, as the anonymized CIS data does not allow to match enterprises across different waves. Further research, with a different set of data, could study the determinants of eco-innovation by adopting a longitudinal perspective. This approach would allow for the extraction of findings on how determinants are robust across multiple time periods. Unfortunately, the data at hand did not include precise information on eco-innovative expenditure that might influence the adoption of different eco-innovations, but it only included the expenditure on innovation in general.

Moreover, the CIS data are self-reported by the enterprises, thus reducing objectivity compared to other kind of data, like those on patents. Finally, it would be valuable to measure eco-innovation performance with additional output measures. This would increase the robustness of findings and offer a more insightful perspective on the determinant of eco-innovation performance.

Practical implications. These preliminary results suggest important implications for the design of smart policy mix supporting eco-innovation. First of all, if we look at the environmental regulations, for example, it assumes importance for Germany but not for Romania. In Romania, eco-innovation should be further promoted and incentivized by policymakers, resorting to new strategies, as high levels of eco-innovation seem at the moment a prerogative of firms more open to the external, such as those which cooperate and export.

With regards to Germany, we found that, smaller firms are less prone to adopt eco-innovations. This could be due to the lack of knowledge and human and material resources that characterized small sized enterprises. Therefore, small enterprises should be incentivized more than larger ones to develop eco-innovation activities, by helping them in acquiring the necessary knowledge and skills.

The intellectual property regime assumes a relevant role in stimulating firms to carry out eco-innovations. From our empirical examination it emerged that the level of protection assumed a relevant role for Germany in both the examined decisions, namely the decision to eco-innovate (inflate equation) and the decision on the number of ecoinnovation strategies to adopt (count equation), but not for Romania. To increase the eco-innovation intensity governments should ensure and continue to ensure a safe intellectual property regime.

Originality of the study. This paper aims to contribute to the previous literature in several ways. First, with a new set of data it proposes a new empirical framework that explains the possible factors that affect the firm's decision to eco-innovate and to adopt a certain number of eco-innovations. Second, few studies have focused on a cross-country analysis. Instead, we considered the cases of Germany and Romania, thereby expanding the geographical scope of econometric research on eco-innovation in Europe, which has to date largely focused only on Germany. Third, differently from the large body of literature that used to consider a binary measure of eco-innovativeness, we considered a multidimensional eco-innovation construct that keeps track of all eco-innovations that enterprises simultaneously adopt.

Key words: eco-innovation, eco-innovation drivers, CIS data, zero-inflated negative binomial-regression.

\section{Disclaimer}

The anonymous data of the Community Innovation Survey 2014 (CIS 2014) used in the analysis of this paper was provided by EUROSTAT. All results and conclusions are given by the authors and represent their opinion and not those of EUROSTAT, the European Commission or any of the national authorities whose data have been used. The responsibility for all conclusions drawn from the data lies entirely with the authors.

\section{References}

BITENCOURT C.C., DE OLIVIERA SANTINI F., ZANANDREA G., LADEIRA W.J., FROHELICH C. (2020), "Empirical generalizations in eco-innovation: A meta-analytic approach", Journal of Cleaner Production, vol. 245, pp. 1-14

BUYSSE K., VERBEKE A. (2003), "Proactive environmental strategies: A stakeholder management perspective”, Strategic Management Journal, vol. 24, n. 5, pp. 453-470

CASTELLACCI F., LIE C. M. (2017), "A taxonomy of green innovators: Empirical evidence from South Korea”, Journal of Cleaner Production, vol. 143, pp. 1036-1047.

CHIAVESIO M., DE MARCHI V., DI MARIA E. (2015), "Environmental innovations and internationalization: Theory and practices", Business Strategy and the Environment, vol. 24, n. 8, pp. 790-801.

DANGELICO R.M. (2017), "What drives green product development and how do different antecedents affect market performance? A study of Italian companies with eco-labels", Business Strategy and the Environment, vol. 26, pp. 1144-1161.

DÌAZ-GARCÌA C., GONZÀLEZ-MORENO A., SÀEZ-MARTÌNEZ F.J. (2015),"Eco-innovation: Insights from a literature review”, Innovation: Management, Policy \& Practice . vol. 17, n. 1, pp. 6-23 
DORAN J., RYAN G. (2012), "Regulation and Firm Perception, Eco-innovation and Firm Performance", European Journal of Innovation Management, vol. 15, n. 4, pp. 421-441.

GHISETTI C., PONTONI F. (2015)," Investigating policy and R\&D effects on environmental innovation: A metaanalysis", Ecological Economics, vol. 118, pp. 57-66.

GHISETTI C., RENNINGS K. (2014), "Environmental innovations and profitability. How does it pay to be green? An empirical analysis on the German innovation survey", Journal of Cleaner Production, vol. 75, pp. 106-117.

GHISETTI C., MARZUCCHI A., MONTRESOR S. (2015), "The open eco-innovation mode. An empirical investigation of eleven European countries", Research Policy, vol. 44, n. 5, pp. 1080-1093.

GREENE W. (2009), "Models for count data with endogenous participation", Empirical Economics vol. 36, pp. 133173.

HILBE J.M. (2007), Negative Binomial Regression, Cambridge University Press, Cambridge.

HOFSTRA N., HUISINGH D. (2014), "Eco-innovations characterized: a taxonomic classification of relationships between humans and nature", Journal of Cleaner Production, vol. 66, pp. 459-468.

HOJNIK J. (2017), In Pursuit of Eco-innovation: drivers and consequences of eco-innovation at firm level. Primorska: University of Primorska Press.

HORBACH J. (2008), "Determinants of environmental innovation- New evidence from German panel data source", Research Policy, vol. 37, n. 1, pp. 163-173.

HORBACH J., RAMMER C. RENNINGS K. (2012), "Determinants of eco-innovations by type of environmental impact- The role of regulatory push/pull, technology push and market pull”, Ecological Economics, vol. 78, pp. 112-12

HORBACH J. (2016), "Empirical determinants of eco-innovation in European countries using the community innovation survey", Environmental Innovation and Societal Transitions, vol. 19, pp. 1-14.

JOVÉ-LLOPIS E., SEGARRA-BLASCO A. (2018), "Eco-innovation strategies: A panel data analysis of Spanish manufacturing firms", Business Strategy and the Environment, vol. 27, pp. 1209-1220.

LIAO Y.C., TSAI K.H. (2019), "Innovation intensity, creativity enhancement, and eco-innovation strategy: The roles of customer demand and environmental regulation", Business Strategy and the Environment, vol. 28, pp. $316-326$

PORTER M. (1991), “America’s Green Strategy”, Scientific American, vol. 264, pp. 168.

PORTER M., VAN DER LINDE C. (1995), "Toward a new conception of the environment-competitiveness relationship", Journal of Economic Perspectives, vol. 9, n. 4, pp. 97-118.

RENNINGS K. (2000), "Redefining Innovation, eco-innovation research and the contribution from ecological economics", Ecological Economics, vol. 32, n. 2, pp. 319-332.

RUSSO M.V., FOUTS P.A. (1997), "A resource-based perspective on corporate environmental performance and profitability", Academy of Management Journal, Vol. 40, n. 3, pp. 534-559

TRIGUERO A., MORENO-MONDÉJAR L., DAVIA M.A. (2013), "Drivers of different types of eco-innovation in European SMEs", Ecological Economics, vol. 92, pp. 25-33.

WAGNER M. (2008), "Empirical influence of environmental management on innovation: Evidence from Europe", Ecological Economics, vol. 66, n. 2, pp. 392-402.

ZULBELTZU-JAKA, ERAUSKIN-TOLOSA A., HERAS-SAIZARBITORIA I. (2018), "Shedding light on the determinants of eco-innovation: A meta-analytic study", Business Strategy and the Environment, vol. 27, pp. 1093-1103 



\title{
Coopetition strategy as management innovation: Evidence from the alliance between Luna Rossa \& Emirates team New Zealand
}

\author{
GiOvanni BATTISTA DAGNINO* ANNA MinÀ
}

\begin{abstract}
Objectives. This paper investigates how coopetition strategy emerges and develops as a management innovation due to the evolution of the context. By presenting and discussing the alliance between Luna Rossa and Emirates Team New Zealand during 2012-2013 in the context of the America's Cup ${ }^{1}$, we aim to disentangle the emergence and development of coopetition strategy as management innovation as a consequence of institutional, technological, and competitive changes seen as the key variables guiding the evolutions of the context. Our key research question is as follows: how does coopetition strategy emerge and develops as a management innovation thereby affecting the firm's decision to cooperate with rivals (or to coopete)?

Actually, in the last two decades the swift evolution of the context in which firms operate have led scholars to identify the conditions driving the emergence of new opportunities, as well as the pitfalls of firms' rapidly-vanishing competitive advantages (D'Aveni, 2010). In more detail, scholars have considered that the evolution of the context may be generated by institutional, technological and competitive conditions ${ }^{2}$. Given the dramatic impact that such conditions have on context evolution, increasing managerial and scholarly interest has emerged towards the "process for continuous management innovation" (Hamel, 2006: 1), namely the introduction of management practices, processes and structures that are new to the firm and aim at gaining or maintaining competitive advantage (Birkinshaw et al., 2008). Actually, the activation of new management practices or processes is seen as a way to answer, as timely and effectively as possible, to the transformation in the context in which firms operate.

Birkinshaw and Mol (2006: 81) suggest that "management innovation has over time dramatically transformed the way many functions and activities work in organizations." However, only in the last decade management innovation has turned into a cornerstone of strategic inquiry (Birkinshaw et al., 2008; Mol and Birkinshaw, 2009), and research has eventually shown its relevance and impact in creating value (Hamel, 2006). Arguably, three are the key elements that characterize management innovation. First, management innovation requires the introduction of novelty in managerial activities (Hargrave and Van de Ven, 2006; Van de Ven and Poole, 1995) and, unfortunately, it turns virtually impossible to defend it by means of patents (Teece, 1980, Birkinshaw et al., 2008). Novelty implies significant change as a result of a commitment to deconstruct management orthodoxies and develop new, unprecedented approaches that may fit better the firm's aim to gain competitive advantage. The feature of novelty sets the stage for an important crucial aspect that allows to distinguish between management innovation and change". Second, "few organizations have well established and specialized expertise in the area of management innovation" (Birkinshaw, Hamel and Mol, 2008: 830). It means that usually management innovation is the "invention and implementation of a management practice, process, structure or technique that is new to the state of the art" (Birkinshaw et al., 2008: 825) in order to attain a given purpose. As a consequence, management innovation originates organizational tension to innovate. This usually happens by encompassing two complementary aspects: the ends of organizations and the means through which they sustain themselves and achieve their objectives (Quinn and Rohrbaugh, 1983). In more detail, given a firm goal, management innovation implies that firms modify their logics, functions and actions they are used to adopt
\end{abstract}

Full Professor of Management -University LUMSA - Palermo - Italy

e-mail: g.dagnino@lumsa.it

- Associate Professor of Management -University LUMSA - Palermo - Italy

e-mail: a.mina1@lumsa.it

1 This case study is also explored in Minà (2018) to conceptualize the role of coopetitive dynamic capabilities and their evolution.

2 Institutional conditions shape "what arrows a firm has in its quiver as it struggles to formulate and implement strategy" (Ingram and Silverman, 2002, p. 20). Technology conditions impact on the way firms operate in their businesses to gain competitive advantages, since the emergence of new technological standards impinge on the firm's ability to deal with them and survive (Palmers et al., 2001, p. 30). Finally, competitive conditions regard the features of the context in which firms "are likely to find themselves in zero-sum relations with one another" (Barnett, 1997, p. 128), for instance, the entrance of a firm in the competitive arena, or the reduction (or inversion) of entry barriers.

3 While change regards the adoption of modifications that are "predictable managerial response to certain circumstances" (Khanagha et al., 2013, p. 52), management innovation concerns the adoption of structures, processes and practices that are " "new to the firm" (Birkinshaw et al., 2008). Therefore, change is a management innovation only if firms significantly transform their "regular and predictable behavior patterns" (Nelson and Winter, 1982, p. 14). 
in the past and experiment with a different track to attain their aforementioned goal. Third, since it alters "how managers do what they do" (Hamel, 2006: 4), management innovation is expected to create ambiguity and uncertainty (Birkinshaw et al., 2008). This occurs is because new logics, functions and activities may not work as expected. In fact, usually little or no clarity exists on how a management innovation will influence a firm's performance.

An intriguing kind of management innovation that has emerged in the last decade is to establish coopetition strategy or a consistent path of cooperation with rivals (Dagnino, 2009; Minà and Dagnino, 2016; Minà et al., 2020). While strategic management scholars have traditionally assumed that firm interactions are mainly characterized by competition (Porter, 1980; Barney, 1986, 1991). In coopetition firms recognize the condition of having a partial convergence of interests (Dagnino, 2009), according to which they compete and cooperate at the same time and are engaged in a win-win game (Bengtsson and Kock, 1999, 2000; Bengtsson et al., 2016; Levanti et al., 2018).

The choice between the adoption of a sheer competitive or cooperative stance or of a coopetitive posture has important implications for firms' interactions with rivals. Actually, competition strategy implies that rivals have conflicting interests since they offer similar products or services that are interchangeable for the customers (Dagnino and Minà, 2016; Ritala et al., 2014). Therefore, each rival's action significantly affects the firm's counteraction. On the other hand, coopetition strategy implies that, despite rivals may have conflicting interests and are potentially interchangeable for customers, they acknowledge that they need each other if they want to create jointly additional value vis-à-vis the one that they can produce on their own (Minà et al., 2020). In more detail, rivals are perfectly aware of the fact that "they should cooperate to create a pie and compete when it comes to dividing it up" (Brandenburger and Nalebuff, 1996: 5). Nonetheless, coopetition strategy has its drawbacks since, on one hand, it may lead to the emergence of managerial tensions at both the organizational and working team levels (Fernandez et al., 2014). And, on the other hand, it may entail the generation of uncertain outcomes as an allied firm could eventually decide to start a learning race with the rival partner(s) (Hamel, 1991), thereby putting the cooperation part of coopetition at stake.

The common ground of these two literatures (i.e., coopetition and management innovation) is that coopetition involves the introduction of a new kind of strategy and, therefore, new management practices, processes and structures, that are related to a firms' different strategic posture. Additionally, coopetition is also a source of managerial tensions at different organizational levels and may generate ambiguity and uncertainty (Levanti et al., 2018). Overall, we second that the above-mentioned considerations about coopetition eventually corroborate the idea that coopetition strategy may be considered a management innovation in stretching organizational value creation.

Notwithstanding that, when changes in the context rapidly occur and unlock room for starting cooperation among rival firms, it may take time until firms really evaluate the advantages and the constraints stemming from their decision to adopt a coopetitive strategy. For example, technological changes may open space for cooperation with rivals if firms have complementary resources to develop a new product (Park et al., 2014; Wu, 2014). In such case, innovation in strategy might become crucial for "reinvent its business processes for the sake of speed and efficiency" (Hamel, 2006, p. 1).

Methodology. We use fresh qualitative design of a relevant sporting alliance occurring between two top-notch teams in the sailing business taking place in the setting of the $34^{\text {th }}$ edition of the Americas Cup held in San Francisco, California, in 2013. We selected the alliance between Luna Rossa and Team New Zealand during the 2012-2013 America's Cup competition because it depicts competitive relationships among participants to the contest for the world's most important and traditional sailing race. Actually, sport has the benefit of offering a "controlled living laboratory" when it comes to assess coopetitors' advantages. Actually, it is worth noting that sports business is considered an excellent scenery to tackle various management problems: early studies have covered various sports, such as NBA basketball (Ertug and Castellucci, 2013), MLB baseball (Cotton et al., 2011), Formula 1 prototype car racing (Marino et al., 2015) and sailing America's Cup World Series (Ross and Sharapov, 2015).

The study of the elements underlying the firms' decision to adopt a coopetition strategy intended as management innovation and how it can lead to generate additional value for the participant firms is at the core of this paper. Actually, we consider that a qualitative research design is more suitable to examine this issue rather than quantitative based methodologies. In fact, qualitative research is conceived as most appropriate "in the critical, early phases of a new management theory" (Gibbert et al., 2008: 1465), when it is not easy to detect the key variables and which relationships occur among them (Yin, 1994; Eisenhardt, 1989; Eisenhardt and Graebner, 2007). Interestingly, our methodological choice to adopt a qualitative analytical framework is also consistent with Khanagha et al. (2013), that explore the impact of management innovation on the firm's choice of adopting a technology as a consequence of a changed technological environment. In fact, it allows us to assess the emergence and development of coopetition strategy as management innovation as concerns the firm's decision to adopt a new definite strategic course and a specific sports technology.

Findings. We contribute to coopetition literature by providing fresh evidence of how it is connected to management innovation, as well as to the introduction of new specific practices, processes and structures (i.e., the selection process of the rival partner, the demarcation of the specific areas of competition and cooperation, and the post-agreement cooperation in San Francisco), and the balance of tensions between the teams (by means of informal adjustments, gentlemen's agreement and mutual fairness). The paper is concerned with the understanding of how coopetition strategy emerges and develops as a management innovation thereby enhancing firm viability and performance. 
We offer three key contributions. First, we contribute to the study of coopetition strategy by showing that context evolution (institutional, technological and competitive) may open new fertile spaces for coopetition strategy to emerge and develop as a relevant management innovation that is able to respond to such changes in an effective fashion. In doing so, we used qualitative evidence of a relevant sporting alliance occurring between two top-notch teams in the sailing business and taking place in the setting of the $34^{\text {th }}$ edition of the Americas Cup held in San Francisco in 2013. On the other hand, we acknowledge that, while the case at hand focuses on evidence that begin with a significant change in institutional (America's Cup protocol) and technological (the new foiling technology in sailing) conditions, that in turn affect the emergence and development of coopetition, we posit that this condition falls short to cover all the options available as the initial event igniting change might be change in competitive conditions. In fact, change in competitive conditions (e.g., new market formation, market faster growth, value creation to stakeholders, and market entry or exit) have an important impact on technological and institutional conditions and therefore on the emergence and development of coopetition strategy. This is the case of the coopetitive relationship established between Amazon and Apple on e-book readers since 2010 that were guided by the objective to "sharing resources and content among competitors to create larger customer value than otherwise possible” (Ritala et al., 2014, p. 245). And the condition above opens avenue for further research on studying change in competitive conditions that may significantly affect the technological and institutional feature in which the coopetition strategy is going to rise and evolve.

Second, since the very onset of the endeavor, Luna Rossa leadership was perfectly aware of the delay they had vis$\grave{a}$-vis the other teams that wanted to challenge Oracle for securing the America's Cup. This temporal disadvantage was to be bridged in some way if they wanted to viably compete for the Luis Vuitton Cup within the $34^{\text {th }}$ edition of the Americas' Cup. Consequently, Luna Rossa developed a stiff strategic commitment to pursue a coopetition with another team (Team New Zealand), as well as to build a motivated first-class racing crew. In such a way, we emphasize the crucial role a top management committed coopetition mindset is expected to assume in defining, igniting and aligning a clear coopetition strategy. An unambiguous coopetition strategy can, in turn, allow the drawing and adoption of new practices, processes and structures within and between the organizations involved and concurrently promote the balance of emerging tensions and ambiguities.

Third, the in-depth scrutiny of the alliance between Luna Rosa and Team New Zealand in the $34^{\text {th }}$ edition of the America's Cup contributes to the literature of coopetition strategy by providing new evidence of how coopetition strategy is intimately connected to management innovation, as well as to the introduction of new specific practices, processes and structures (e.g., the selection process of the rival partner, the demarcation of the specific areas of competition and cooperation, and the post-agreement cooperation in San Francisco), and the balance of tensions between the teams (by means of informal adjustments, gentlemen's agreement and mutual fairness). While a notable part of the extant body of study on coopetition strategy is conceptual or grounded in empirical cross-sectional analyses, in this paper we supply relevant support to understand the emergence and development path of coopetition strategy extracted from a favorable real-world setting, such as the one of the sports business.

Research limits. As any other research endeavor, this paper bears some limitations. First, we acknowledge that focusing on a single, even revelatory, case study brings about limits of external validity or extensibility of results to other cases and contexts (Yin, 1994). Though that, we recognize that generalizability of case studies may be augmented by using strategic selection of cases. In fact, if properly used, atypical, revelatory or extreme cases "often reveal more information because they activate more actors... and more basic mechanisms in the situation studied" (Flyvbjerg, 2006). Second, since researchers' own subjective feeling may influence the process and outcome of the case study, we are also conscious that this investigation is, to a certain extent, subject to researcher bias. Finally, on the ground of the result obtained, we underscore the opportunity to continue carrying on inquiry in this direction by digging deeper into the drivers of coopetitive partnership emergence and development, especially by examining such fertile settings as strategic alliances between rival organizations.

Practical implications. Luna Rossa developed a stiff strategic commitment to pursue a coopetition strategy with Team New Zealand, as well as to build a motivated first-class racing crew. In such a way, the study emphasizes the crucial role that a top management's committed coopetition mindset may assume in defining, igniting and aligning a clear coopetition strategy.

Originality of the study. The contribution of this study is original in that it is positioned midway between the literatures of coopetition strategy and management innovation and contributes to reconnecting both of them. On the one hand, it contributes to the coopetition research stream by providing intriguing evidence that coopetition strategy is indeed a management innovation, thereby significantly influencing the firms' ability to introduce and adopt new practices, processes and structures and cope with tensions and ambiguities. On the other hand, it adds to management innovation studies by maintaining that static efficiency preserving a set resources and capabilities is not sufficient per se to establish coopetition strategy. By hunting for new sets of resources and capabilities that can be accessed and exploited by simultaneously competing and cooperating with partners, coopetition strategy implies the search for dynamic efficiency guided by soundly committed leadership.

Key words: coopetition; management innovation; alliance; Luna Rossa; Emirates Team New Zealand 


\section{References}

BARNETT W.P. (1997), “The dynamics of competitive intensity”, Administrative Science Quarterly, vol. 42, pp. 128160.

BARNEY J.B (1991), "Firm resources and sustained competitive advantage”, Journal of Management, vol. 17, n. 1, pp. 99-120.

BARNEY J.B. (1986), "Strategic factor markets: Expectations, luck, and business strategy", Management Science, vol. 32 , n. 10, pp. 1231-1241.

BENGTSSON M., KOCK S. (1999), "Cooperation and competition in relationships between competitors in business networks", Journal of Business \& Industrial Marketing, vol. 14, n. 3, pp. 178-194.

BENGTSSON M., KOCK S. (2000), "Coopetition" in business Networks - to cooperate and compete simultaneously", Industrial Marketing Management, vol. 29, n. 5, pp. 411-426.

BENGTSSON M., KOCK S., LUNDGREN-HENRIKSSON E.L., NASHOLM M.H. (2016), "Coopetition research in theory and practice: Growing new theoretical, empirical, and methodological domains", Industrial Marketing Management, vol. 57, pp. 4-11.

BIRKINSHAW J., MOL M.J. (2006), "How management innovation happens", MIT Sloan Management Review, vol. 47, n. 4, pp. 81-88.

BIRKINSHAW J., HAMEL G., MOL M.J. (2008), "Management innovation", Academy of Management Review, vol. 33 , n. 4 , pp. 825-845.

BRANDENBURGER A., NALEBUFF B. (1996), Co-opetition, HarperCollinsBusiness, London, UK.

COTTON R.D., SHEN Y., LIVNE-TARANDACH R. (2011), "On becoming extraordinary: The content and structure of the developmental networks of Major League Baseball Hall of Famers", Academy of Management Journal, vol. 54 , n. 1, pp.15-46.

D’AVENI R.A. (2010), Beating the commodity trap, Harvard Business School Publishing, Boston, MA.

DAGNINO G.B. (2009), "Coopetition Strategy: A New Kind of Interfirm Dynamics for Value Creation”, Dagnino G.B., Rocco E. (Eds.), Coopetition strategy: Theory, experiments and cases, pp. 1-21, Routledge, London, UK.

EISENHARDT K.M. (1989), "Building theories from case study research”, Academy of Management Review, vol. 14, n. 4, pp. 532-550.

EISENHARDT K.M., GRAEBNER M.E. (2007), "Theory building from cases: Opportunities and challenges", Academy of Management Journal, vol. 50, n. 1, pp. 25-32.

ERTUG G., CASTELLUCCI F. (2013), "Getting what you need: How reputation and status affect team performance, hiring, and salaries in the NBA", Academy of Management Journal, vol. 56, n. 2, pp. 407-431.

FERNANDEZ A.S., LE ROY F., GNYAWALI D.R. (2014), "Sources and Management of Tension in Co-opetition: Case Evidence from Telecommunications Satellites Manufacturing in Europe", Industrial Marketing Management, vol. 43, n. 2, pp. 222-235.

GIBBERTM., RUIGROK W., WICKI B. (2008), "What passes as a rigorous case study?", Strategic Management Journal, vol. 29, n. 13, pp. 1465-1474.

HAMEL G. (1991), "Competition for competence and interpartner learning within international strategic alliances", Strategic Management Journal, vol. 12, n. S1, pp. 83-103.

HAMEL G. (2006), "The why, what, and how of management innovation”, Harvard Business Review, vol. 84, n. 2, pp. $72-86$.

HARGRAVE T.J., VAN DE VEN A.H. (2006), “A collective action model of institutional innovation”, Academy of Management Review, vol. 31, n. 4, pp. 864-888.

INGRAM P., SILVERMAN B. (2002), "Introduction”, Ingram P., Silverman B. (Eds.), The new institutionalism in strategic management, pp. 1-30, Elsevier, Amsterdam.

KHANAGHA S., VOLBERDA H., SIDHU J., OSHRI I. (2013), "Management innovation and adoption of emerging technologies: The case of cloud computing", European Management Review, vol. 10, n. 1, pp. 51-67.

LEVANTI, G., MINÀ, A., PICONE, P.M. (2018). La gestione delle relazioni coopetitive quale" fattore abilitante" la crescita delle PMI, Poselli M, Ferrari E.R. (Eds) Percorsi di ricerca sui processi di creazione e diffusione del valore nelle PMI. Un approccio multidisciplinare, (pp. 113-142), Giappichelli Editore, Torino.

MARINO A., AVERSA P., MESQUITA L., ANAND J. (2015). Driving performance via exploration in changing environments: Evidence from formula one racing. Organization Science, vol. 26, n. 4, pp. 1079-1100.

MINÀ A., DAGNINO G.B. (2016), "In search of coopetition consensus: shaping the collective identity of a relevant strategic management community”, International Journal of Technology Management, vol. 71, n. 1-2, pp. 123154.

MINÀ A., (2018), Coopetition Strategy: An Inquiry into Coopetition Drivers, Management, and Capabilities. Giappichelli Editore, Torino.

MINÀ A., DAGNINO G.B., VAGNANI, G. (2020), “An interpretive framework of the interplay of competition and cooperation", Journal of Management and Governance, pp. 1-35.

MOL M.J., BIRKINSHAW J. (2009), "The sources of management innovation: When firms introduce new management practices", Journal of Business Research, vol. 62, n. 12, pp. 1269-1280.

NELSON R.R., WINTER S.G. (1982), “The Schumpeterian tradeoff revisited”, American Economic Review, vol. 72 , n. 1, pp. 114-132. 
PALMER J.C., WRIGHT R.E., POWERS J. B. (2001), "Innovation and competitive advantage in small businesses: Effects of environments and business strategy", Journal of Small Business Strategy, vol. 12, n. 1, pp. 30-41.

PARK B.J.R., SRIVASTAVA M.K., GNYAWALI D.R. (2014), "Walking the tight rope of coopetition: Impact of competition and cooperation intensities and balance on firm innovation performance", Industrial Marketing Management, vol. 43, n. 2, pp. 210-221.

PORTER M.E. (1980), Competitive Strategy, Free Press, New York.

QUINN R.E., ROHRBAUGH J. (1983), "A spatial model of effectiveness criteria: Towards a competing values approach to organizational analysis”, Management Science, vol. 29, n. 3, pp. 363-377.

RITALA, P., GOLNAM, A., \& WEGMANN, A. (2014). Coopetition-based business models: The case of Amazon. com. Industrial Marketing Management, 43(2), 236-249.

ROSS J.M., SHARAPOV D. (2015), "When the leader follows: Avoiding dethronement through imitation", Academy of Management Journal, vol. 58, n. 3, pp. 658-679.

TEECE D.J. (1980), “The diffusion of an administrative innovation”, Management Science, vol. 26, n. 5, pp. 464-470.

VAN DE VEN A.H., POOLE M.S. (1995), "Explaining development and change in organizations", Academy of Management Review, vol. 20, n. 3, pp. 510-540.

WU J. (2014), "Cooperation with competitors and product innovation: Moderating effects of technological capability and alliances with universities”, Industrial Marketing Management, vol. 43, n. 2, pp. 199-209.

YIN R.K. (1994), Case Study Research. Design and Methods, $2^{\text {nd }}$ edition. Sage, Thousand Oaks, CA. 



\title{
The employment of nonfamily managers in family firms: An empirical investigation of normative heterogeneities in top management team (TMT) from a sample of European firms
}

\author{
ALFREDO D'ANGELO*
}

\begin{abstract}
Objectives. Benefits and challenges associated with the involvement of nonfamily members in family firms have long been investigated and recently synthesized in the review carried out by Tabot et al. (2018). The authors admitted the need for ".... a finer grained distinction among the differing roles associated with nonfamily CEOs, managers, and employees" (p.74) to advance knowledge on nonfamily members in family firms. The aim of this study is to shed light on the perceived attractiveness that different types of CEOs may play on the employment nonfamily managers in family firms.

The ability of family firms to successfully utilize nonfamily managers is contingent on level of involvement of such managers (Chua et al., 2003) and other normative heterogeneities of top management team (TMT) (Richard and Shelor, 2002). Therefore, we further examine the role played by the firms decision-making structure and the effect that the age of the TMT members on nonfamily managers employment in family firms. By combining signaling theory (Spence, 1973) with social identity theory (Tajfel, 1982), we aim to contribute to better understand the processes and mechanisms that influence the recruiting, selection, and hiring of nonfamily managers.
\end{abstract}

Methodology. By building on signaling theory (Spence, 1973) and social identity theory (Tajfel, 1982), we put forward three main hypotheses as follows:

HP1. Family firms employ a lower proportion of nonfamily managers than non-family firms.

HP2. The presence of an external CEO either promoted from within the company or brought in as external hires is positively associated with the proportion of nonfamily managers employed in family firms.

HP3. The presence of a decentralized decision-making structure is positively associated with the proportion of nonfamily managers employed in family firms.

HP4. The age of the management team is negatively associated with the proportion of nonfamily managers employed family firms.

The data used in this study come from the first edition of the survey "The performances of European firms: A benchmark analysis" published in 2016 by Assolombarda Confindustria. This survey, originated from the EFIGE's (EFIGE, 2010) study, provides firm-level data from five European regions, namely Lombardia (Italy), BadenWürttemberg and Bayern (Germany), Cataluña (Spain) and Rhône-Alpes (France). The sample had data referring to manufacturing industry at four technology levels, i.e. high-, medium high-, medium low-and low-tech. Data from the questionnaire covered the period 2011-2013. The original dataset comprised 644 large and small companies - Italy $($ Lombardia $)=241$; Spain $($ Cataluna $)=103$; Germany (Baden-Württemberg) $=99$; Germany $($ Bayern) =100; France (Rhône-Alpes $)=101$, and we selected family firms according to a self-declared measure. We obtained a final sample of 395 family firms to empirically test of our working hypotheses.

Variables and measures. Dependent Variable. Following Fang et al. (2016) who claimed that "the absolute number of nonfamily managers in a family firm does not necessarily capture the level of nonfamily management, because the size of the management team can also vary" (p.1026), we divided the number of nonfamily managers by the total number of managers in each firm to obtain the measure of nonfamily management.

Independent Variable. Our first independent variable measures the presence of an external CEO either promoted from within the company or brought in as external hires. A categorical variable with family CEO as baseline category was used. Our second variable measuring decentralized decision making structure is a dummy variable that takes the value " 1 " where managers feel they can take autonomous decisions in some business areas or " 0 " where the CEO/owner takes most decisions in every area. As age represents an ideal demographic attribute to explore TMT heterogeneity (Richard and Shelor, 2002), we used the average age of the board members for our third independent variable.

Control Variables. Consistent with previous studies (e.g., Chrisman et al., 2014; Fang et al., 2016), we controlled for past performance, firm age, industry and countries. Past performance by firm productivity, measured by the log of firms' value-added per employee in the previous year. Firm age is operationalized by the number of years since the

\footnotetext{
Associate Professor of Management - Università Cattolica del Sacro Cuore - Milano - Italy e-mail: alfredo.dangelo@unicatt.it
} 
firms' foundation. Finally, we control for technological levels in four industries and nation-specific effects including country dummies.

Findings. After controlling for past performance, firm age, industry and countries, the results reported in Table 1 confirm our three hypotheses. First, when compared to the presence of family CEO, the presence of an external CEO either promoted from within the company or brought in as external hires is positively associated with the proportion of nonfamily managers employed in family firms.

Second, the presence of a decentralized decision-making structure is positively associated with the proportion of nonfamily managers employed in family firms.

Third, the age of the TMT members is positively associated with the proportion of nonfamily managers employed in family firms.

Tab. 1: Main results of OLS regression.

\begin{tabular}{|l|c|}
\hline \multicolumn{1}{|c|}{ Dependent variable: Nonfamily management } & POS and SIG $(* *)$ \\
\hline Constant & NEG and SIG $(* * *)$ \\
\hline Family firms & POS and SIG $(* * *)$ \\
\hline External CEO: & POS and SIG $(* * *)$ \\
\hline 1. brought in as external hires & POS and SIG $(*)$ \\
\hline 2. promoted from within the company & NEG and SIG $(* *)$ \\
\hline Decentralized decision making & POS and SIG $(*)$ \\
\hline Age of the board members & POS and SIG $(* * *)$ \\
\hline & NEG and NO SIG \\
\hline Past performance & YES \\
\hline Firm size & YES \\
\hline Firm age & \\
\hline Industry & Countries \\
\hline
\end{tabular}

Note: $* * * p<0.01, * * p<0.05, * p<0.1$

Research limits. Further analysis need to be carried out to test the endgeneity nature of some independent variables.

Another limitation of our research is its cross-sectional design. Although cross-sectional designs in this type of research are currently standard practice, claims about causality cannot be substantiated with such a method.

Practical implications. Our findings have some important managerial implications. Our results show that there are several normative heterogeneities in family firms that might impact on decisions regarding the employment of nonfamily managers. Our results highlight that the presence of an external CEO either promoted from within the company or brought in as external hires is positively associated with the proportion of nonfamily managers employed in family firms. In other words, family firms who wish to attract nonfamily managers to increase their skills basis have to think whether to prefer the presence of family CEOs over the other alternatives. Our results highlight that a decentralized decision-making structure and a younger TMT are positively associated with the proportion of nonfamily managers employed in family firms. In other words, family firms need to implement a HR policy more inclined to open up their decision-making structure to young managers so to attract a higher proportion of nonfamily managers.

Originality of the study. The current study contributes to the family firm by combining signaling theory (Spence, 1973) with social identity theory (Tajfel, 1982) to better understand the processes and mechanisms that influence the recruiting, selection, and hiring of nonfamily managers. Our study provide indications on how the preferences of nonfamily CEO, a decentralized decision-making structure and a younger TMT might uniquely influence the recruitment of external managerial labor usually associated with a greater quality of skills and knowledge.

Keywords: Family firms; external managers; top management team.

\section{References}

ASSOLOMBARDA Confindustria Milano Monza e Brianza (2016), The performances of European firms: A benchmark analysis. Research, n. 2.

CHRISMAN J.J., MEMILI E., MISRA K. (2014), 'Nonfamily managers, family firms, and the winner's curse: The influence of noneconomic goals and bounded rationality", Entrepreneurship Theory and Practice, vol. 38, n. 5, pp. 1103-1127. 
CHUA J.H., CHRISMAN J.J., SHARMA P. (2003), "Succession and non-succession concerns of family firms and agency relationship with non-family managers", Family Business Review, vol. 16, n. 2, pp. 89-107.

EFIGE. (2010), European firms in a global economy: Internal policies for external competitiveness. Retrieved from www.efige.org

FANG H., RANDOLPH R., MEMILI E., CHRISMAN J. (2016), "Does size matter? The moderating effects of firm size on the employment of nonfamily managers in privately held family SMEs", Entrepreneurship Theory and Practice, vol. 40, n. 5, pp. 1017-1039.

RICHARD O.C., SHELOR R.M. (2002), "Linking top management team age heterogeneity to firm performance: Juxtaposing two mid-range theories", International Journal of Human Resource Management, vol. 13, n. 6, pp. 958-974.

SPENCE M. (1973), “Job market signaling”, Quarterly Journal of Economics, vol. 87, n. 3, pp. 355-374.

TABOR W., CHRISMAN J.J., MADISON K., VARDAMAN J.M. (2018), "Nonfamily members in family firms: A review and future research agenda", Family Business Review, vol. 31, n. 1, pp. 54-79.

TAJFEL H. (1982), Social Identity and Intergroup Relations, Cambridge University Press, Cambridge: 



\title{
Which came first: on the evolution of environmental identity and entrepreneurial identity in environmental entrepreneurship
}

\author{
CHIARA DE BERNARDI ${ }^{*}$
}

\begin{abstract}
Environmental entrepreneurship has gained attention in the last decades due to its inner nature of combining economic and ecological objectives. For this reason, environmental entrepreneurship is often considered by scholars a compelling and extreme context. Although in recent years the number of publication on environmental entrepreneurs and on their motivations to begin this path has increased, few studies have examining the role of identity in this realm. Although scholars have started to explore environmental identity and self-identity, the topic is still poorly understood. Using the lens of identity theory, aware that individuals hold multiple identities depending on the varied roles significant to their individual self-meaning, the author explores the role of environmental identity and entrepreneurial identity for wine environmental entrepreneurs. Specifically, they aim to understand their evolution over time and how they are ranked by the entrepreneurs. An exploratory qualitative longitudinal study is carried out in the Italian wine industry, being a context where environmentally friendly practices matter and which has experienced a shift to a more sustainable production in recent years.
\end{abstract}

- A couple of sentences will be added in order to provide a short overview of the main findings and contributions

\section{Introduction and literature review}

"Is a good time to focus on environmental entrepreneurship" (York, 2018, p.18). Although climate change and the issues related to the natural environmental are leading to an environmental crisis, this has raised the need, and opportunity, to explore the role of environmental entrepreneurship in solving environmental degradation (O'Neil and Ucbasaran, 2016). Even if several definitions of this kind of entrepreneurship exist, all agree on the positive contribution to the environmental problems. For instance, according to Lenox and York (2011) environmental entrepreneurs are those "individuals who create new, often for-profit, ventures that help address environmental challenges" (p.1). Dean and McMullen (2007), instead, defined it as the "process of discovering, evaluating, and exploiting economic opportunities that are present in market failures" (p.58). In the last decade, this has become a domain of enquiry in the entrepreneurial academic realm, with research evolving around, for instance, the drivers and orientation of environmental entrepreneurs (e.g. Hörish et al., 2017) and their relationship with natural resources (e.g. Casaló and Escario, 2018; Fisher, 2012). Entrepreneurial behavior with an environmental orientation and its antecedents, has thus attracted academic interest (De Bernardi and Pedrini, 2020). Over the last decade, passion has received an increasing attention, and many scholars have recognized its pivotal role in pushing individuals to engage in specific behaviors. In the realm of entrepreneurship, Cardon and colleagues (2009) have explored the role of entrepreneurial passion, a "consciously accessible, intense positive feelings experienced by engagement in entrepreneurial activities associated with roles that are meaningful and salient to the self-identity of the entrepreneur" (p.517). On the steps of the studies about entrepreneurial passion, De Bernardi and Pedrini (2020) have studied the role of passion in entrepreneurs with an environmental orientation. Specifically, since environmental entrepreneurs seem to feel unique emotions related to the natural environment, they have studied the role of environmental passion, "a positive emotion that results in an individual wanting to engage in pro-environmental behaviors" (Robertson and Barling, 2013, p.80), and how diverse intensities of environmental passion lead to different identities which, in turn, trigger environmentally oriented entrepreneurial behaviors.

Even if the number of high-quality papers on environmental entrepreneurship has grown in the last years, entrepreneurs have a fundamental role in societal transition toward sustainability (Hörish, 2015), and much more may be explored. Moved from the belief that as individuals, we are all intertwined with climate change, York (2018) provided an overview on the conception of environmental entrepreneurship as a field, highlighting three main paths to further elaborate on it: an understanding of the "why, how, and when entrepreneurial action create simultaneous economic and ecological benefits" (p.23). Among these three suggestions, we believe the study of the why individuals

\footnotetext{
Research Fellow - IUSS Scuola Universitaria Superiore di Pavia - Italy

e-mail: chiara.debernardi@iusspavia.it
}

Sinergie-SIMA 2020 Conference

Grand challenges: companies and universities working for a better society

Electronic Conference Proceedings

7-8 September 2020 - University of Pisa-Sant'Anna School of Advanced ISBN 97888943937-6-7 
choose to pursue environmental entrepreneurship is challenging, as it allows - at least partially - to have a more comprehensive picture of this entrepreneurial profile. Thus, moved from the awareness that various types of identity shape individual behavior, York (2018) proposes identity theory as a suited lens for examining this question, and he also suggests the exploration of the various identities that comprise an entrepreneur's self and seek to understand how and why these identities become salient in the venturing process over time. Environmental entrepreneurs are often conceived as hybrid entrepreneurs, which combine both commercial and ecological objectives. However, as individuals in primis, but also as entrepreneurs, and as environmentalists, they may hold different identities.

Identity plays a fundamental role in determining individuals' behaviors and actions (Stets and Burke, 2000). The answer to the "who am I?" concern is rooted in the categorization of the self as an "occupant of a role, and the incorporation, into the self, of the meanings and expectations associated with that role and its performance" (Stets and Burke, 2000, p.225). Individuals thus act consistently with a given role, being this role meaningful to their self-identity. Once identities are integrated into the self, once they become central, individuals are strongly motivated to act aligned with those identities (Burke and Reitzes, 1981). This explain the relevance of identity as a critical element of personal behaviors. All people do not only own a single identity, but multiple, because they "inhabit multiple roles and identify with multiple social groups" (Powell and Baker, 2014 p.1408). An individual's identity becomes central to the individual when the feelings, beliefs and values associated with that identity are crucial (Gruber and MacMillan, 2017), and, once central, triggers individuals' behaviors which they deem appropriate. Being individuals made of different identities, depending on their relevance, identities appear to be hierarchically organized, such that an identity placed higher is more salient and central to the self-meaning than those placed lower (Stryker and Burke, 2000). Identities becomes central when their importance is higher compared to the other identities (Murkiens et al., 2014). Even if scholars suggest that, over the lifetime of individuals, their identities' centrality may change thus causing different hierarchies in different periods of life, assuring that, in any case, the individual self-meaning is temporally both distinctive and coherent (Cardon et al., 2009), it may also happen that individuals do not have a single identity that becomes central and dominant, but identities can co-exist and occur simultaneously shaping a central hybrid identity (De Bernardi and Pedrini, 2020; Fauchart and Gruber, 2011; Murnieks et al., 2014).

Identity theory is broadly used in the context of entrepreneurship to explain why entrepreneurs engage in specific behaviors and ventures' creation processes. According to Wry and York (2017), "role and personal identities affect the type of opportunities an entrepreneur recognizes" (p.12). In addition, if some studies confirm that entrepreneurs have a single central identity which lead them to act as entrepreneurs (Murkiens and Mosakowsi, 2007), others suggest that multiple identities and not a single one, become central to the individuals in how they manage their firm (Cardon et al., 2009; Shepherd and Haynie, 2009). Recently, scholars have applied the lens of identity theory to shed light on entrepreneurial behaviors and their differences. For instance, while Powell and Baker (2014), explored how and why firms vary in their strategic response to the same adversity, explaining that entrepreneurs use firms as vehicles to defend their identity and that they enact distinctly different definitions of adversity, Wry and York (2017) developed a theoretical model based on identity theory to explain how, why, and with what consequences social entrepreneurs mix competing logics and tensions as they create new social enterprises. Entrepreneurs may either identify with the venture's creation or the venture's goal, or both. For instance, Cardon and colleagues (2009) shed light on three role identities when creating a venture: an inventor identity, a founder identity, and a developer identity. Thus, depending on which identity is central to the entrepreneurs they mostly follow the related behaviors. For instance, the developer entrepreneur will be pushed to engage in activities such as "nurturing, growing and expanding the venture once it has been created" (p. 516). On the other side, Fauchart and Gruber (2011), provided a fundamental study which reveals how identities shape key decisions of entrepreneurs in the creation of new firms. The authors identify three types of pure identities: darwinian, communitarian, and missionary. While the darwinian entrepreneurs appears to be the most common, competition and profit-driven entrepreneurs, the communitarian and missionary deviate from this linear conception. Specifically, the first ones, strongly conceive the role of community, which support and is supported by the firm "because of mutually beneficial relationship" (p.936). Missionary, instead, being driven by a view of their firm as a political object, behave advancing a cause important for the society. Entrepreneurs act appropriately with their identities and this consistency is reflected in the decisions they take. Moreover, according to Stryker and Burke (2000), a further step in elaborating identity theory would be to detail how emotions fit into this framework. On this line, Gruber and MacMillan (2017), adopting an identity theory perspective based on entrepreneurs' emotions and meanings, explain why they behave differently depending on the behavior's appropriateness deemed. The role of emotions has been often used in relation to identity since the enactment of identity depends on the production of positive emotions and feeling, in contrast to negative emotions experienced if engaging in discordant acts. Cardon and colleagues (2009) has started to analyze the role of entrepreneurial passion, being passion considered to be an antecedent of entrepreneurs' personal inclinations to engage in behaviors that represent central features of their individual identities (Stryker and Burke, 2000), and further refined it analyzing its source (Cardon et al., 2017). In fact, entrepreneurs invest time and energy in activities to which they attribute a high importance (Vallerand et al., 2007).

The cited studies reflect some of the different shades of entrepreneurship analyzed through identity theory. Although the differences between traditional and social entrepreneurship have been extensively studied (Fauchart and Gruber, 2011; Wry and York, 2017), the recognition of environmental entrepreneurship as "a differentiated area of study within entrepreneurship" and "impactful on both academic theory and useful construct to address environmental issues", implies new studies to explore this context with the aim of understanding the role identities and emotions play 
in environmental entrepreneurship. York and colleagues (2016) recognized that the current literature has paid relatively little attention to explicating "how hybrid organizations may address environmental sustainability" (p.2). Moved from the awareness and already proven academic knowledge that climate change will modify economic and organizational boundaries, attention need to be paid on changes in the role of entrepreneurs. Their analysis on ventures' creation by environmental entrepreneurs investigated the source and consequences of their basic motivation desire to address natural environmental degradation -, highlighting that the emergence of central identities is critical in explaining why individuals engage in environmental entrepreneurship. Specifically, they found evidence of three different hybrid founder identities: commercial dominant, ecological dominant, and blended. If, on one side, environmental entrepreneurs may be driven exclusively by the desire to exploit commercial opportunity (commercial dominant), on the other side, they may also be inspired by the motivation to tackle environmental issues (ecological dominant), thus engaging in entrepreneurship as a mean to reinforce their ecological identity. Lastly, a third group of entrepreneurship expressed motivation based on both commercial and ecological identities. In addition to it, De Bernardi and Pedrini (2020) have explored the role of environmental passion in pro-environmental entrepreneurial behaviors. The authors explained how the intensity of passion lead to a certain identity and, consequently, to a specific entrepreneurial behavior. Entrepreneurs identities swing between an environmental self-identity and an environmental one. If environmental self-identity makes the individual sees "himself or herself as the type of person who will act environmentally-friendly" (Van der Werff et al., 2013, p.56), and thus it is more action-related, environmental identity is conceptualized as a "sense of connection to some part of the nonhuman natural environment that affects the way people perceive and act towards the world" (p.56). Thus, the study shows evidence that entrepreneurs, in addition to their entrepreneurial motivation, may also have an environmental passion able to trigger different identities. In this perspective, previous studies have confirmed the capacity of identity theory to move beyond traditional economic view of entrepreneurship, understanding entrepreneurial behaviors as an emphasis of entrepreneurs' recognition of specific behaviors as appropriate (Gruber and MacMillan, 2017).

According to previous studies, entrepreneurs appears to be individuals with different identities, hierarchically organized. While scholars have ascertained the role of entrepreneurial identity in entrepreneurial activities, demonstrating that entrepreneurs act consistently with roles that are meaningful to their identity, and thus placing higher their entrepreneurial identity when engaging in entrepreneurial behaviors, no knowledge has been developed on the role of environmental identity in this relationship. Moved from the recognition that further research on hybrid organizations could further scrutinize the nuances of entrepreneurs' identity and how it impacts ventures' path (York et al., 2016), from the identity theory perspective which "encourages investigation of different role identities within the entrepreneurial process" (Fauchart and Gruber, 2011, p.937), from the awareness that entrepreneurs may shift over time (Wry and York, 2017), and from the recognition that few scholars have analyzed why some individuals, and not others, engage in the creation of simultaneously economic and ecological venture creation (York, 2018), the author embraces the call by York (2018) who suggest to understand the "various identities that comprise an entrepreneur's self and seek to understand how and why these identities become salient in the venturing process over time" (p.23). Specifically, an investigation of the ongoing relationship between environmental identity on one side, and entrepreneurial identity on the other side, is carried out. The aim of the research is thus not only to understand the role of entrepreneurs' identities at the beginning, but also to detect any potential changes - and the reasons behind these changes - occurred over the time. Aligned with the suggestion of York et al. (2016), the research does not aim to investigate the role of identity in influencing entrepreneurial behaviors, but rather "how is identity changed through entrepreneurship" (p.34).

Thus, the research aims to explore the following research questions:

a. does environmental identity (and/or self-identity) play a role in shaping environmental entrepreneurial behavior?

b. how does environmental identity (and/or self-identity) co-exist with entrepreneurial identity?

c. when does environmental identity is placed higher than entrepreneurial identity? And what about the contrary?

$d$. is environmental entrepreneurial behavior able to change the identity hierarchy? When does it happen?

Methodology. A qualitative approach has been used by the author to answer their research question. The exploratory research design is, in fact, recommended for subtle and/or poorly understood phenomena (Strauss and Corbin, 1998; Yin, 2003). Following the tenets of grounded theory (Glaser and Strauss, 1967), the research has been settled in a specific setting that would have assisted the theory building. The Italian wine industry choice is two-fold. First of all, it is a green industry (Barbosa et al., 2018), and viticulture is currently "experiencing a gradual shift to more sustainable patterns" (Villanueva-Rey et al., 2014, p.330). However, if the transition to green practices is a challenge, the shift represents an opportunity to increase sales. In fact, if on one side, according to Schimmenti and colleagues (2016), the industry shows a significant interest for sustainability, on the other side, it also confirms its position in terms of volume and number of wineries (Gilinsky et al., 2015). In addition, Italy is one of the most important producers of wine, and it has placed fourth in the area under vines destined for the production of wine grapes, table grapes or died grapes, in production or awaiting production (OIV, 2019). Secondly, being an industry characterized by a large number of environmental concerns (Christ and Burrit, 2013), it is also a context where "personal feeling on the natural environment are lived by entrepreneurs and are easily observable" (De Bernardi and Pedrini, 2020, p.3). Thus, the author expects that environment-related emotions and motivations occur and both entrepreneurial and environmental identity may arise. With a combination of environmental and commercial aspects, the chosen context is theoretically relevant (Eisenhardt and Graebner, 2007). 
The author selected the setting and cases because they were particularly suitable for extending understanding of the relationships related to their research question. They followed Eisenhardt and Graebner's (2007) suggestions for 'theoretical sampling': decisions regarding who to talk with were determined mainly by theoretical appropriateness and information-richness rather than representativeness. The theoretical sampling is a well-suited approach to collect different and varied data about the relevant identities of entrepreneurs and to determine their range of variability (Glaser and Strauss, 2006). Multiple cases offer the opportunity to create more generalizable theory.

Given the research question, the nature of the study is longitudinal. Data collection included primary and secondary data sources, where, respectively, primary data were identified through semi-structured interviews, while secondary data sources included wineries' websites and online interviews (videos) available on their websites. Pursuing data relevant to the themes (Glaser and Strauss, 1967), the author started to examine the wineries' websites, and choose entrepreneurs who seem to care about green matters. For instance, exploring the website, they could collect archival data, such as online documentation, able to provide an overview of the winery, its history, its products and its production orientation, all useful information in order to augment the level of known information before the interviews. The author then mostly selected informants which chose an organic or biodynamic wine production, in contrast with the traditional one. Being the interviews semi-structured, an initial protocol was used to ensure consistency across all interviews (York et al., 2016). However, follow-up questions were asked to deeply clarify initial answers and obtain further details. Using emerging terms from informants, these additional questions were asked in order to explore entrepreneurs' identity evolution over time. Additional informants were also identified through the snowball sampling technique, by asking at the end of interviews suggestions for new interviewees. Sometimes, this happened as a spontaneous recommendation by the entrepreneurs. The informants are in all cases the current entrepreneurs of the winery. While some of them were the founders of the firms, others belong to the second generation who have decided to carry on with the activity. Anonymity has been guaranteed to all of them. Interviews typically lasted 1 hour and were conducted in different moments across 2017, 2018 and 2020, for a total of X months data collection. They were carried out in Italian, recorded and verbatim transcribed.

Data will be collected until theoretical saturation is reached (Glaser and Strauss, 1967; Strauss and Corbin, 1998). At the date of today, 18 interviews have been collected. Table 1 shows the profile of the interviewed entrepreneurs.

Tab. 1: profile of entrepreneurs.

\begin{tabular}{|l|l|l|l|l|l|l|}
\hline Case & Gender & Age & Agriculture & Generation & Region & Educational background \\
\hline$\# 01$ & Male & 45 & Biodynamic & $3^{\text {rd }}$ generation & Piedmont & n.a. \\
\hline$\# 02$ & Male & 67 & Organic & $1^{\text {st }}$ generation & Piedmont & n.a. \\
\hline$\# 03$ & Male & 33 & Conventional & $3^{\text {rd }}$ generation & Piedmont & Enology \\
\hline$\# 04$ & Male & 55 & Conventional & $2^{\text {nd }}$ generation & Piedmont & Engineering \\
\hline$\# 05$ & Female & 52 & Conventional & $4^{\text {th }}$ generation & Piedmont & Viticulture \\
\hline$\# 06$ & Female & 36 & Organic & $2^{\text {nd }}$ generation & Piedmont & Law \\
\hline$\# 07$ & Female & 34 & Conventional and Organic & $2^{\text {nd }}$ generation & Piedmont & Economics \\
\hline$\# 08$ & Male & 38 & Organic & $2^{\text {nd }}$ generation & Val d'Aosta & Enology \\
\hline$\# 09$ & Female & 34 & Organic & $1^{\text {st }}$ generation & Piedmont & Enology \\
\hline$\# 10$ & Male & 43 & Biodynamic & $3^{\text {rd }}$ generation & Piedmont & Agriculture \\
\hline$\# 11$ & Male & 31 & Organic and Biodynamic & $2^{\text {nd }}$ generation & Piedmont & Law \\
\hline$\# 12$ & Female & 46 & Biodynamic & $1^{\text {st } g e n e r a t i o n ~}$ & Piedmont & Enology/viticulture \\
\hline$\# 13$ & Male & 52 & Biodynamic & $2^{\text {nd }}$ generation & Emilia-Romagna & Mechanic \\
\hline$\# 14$ & Male & 47 & Biodynamic & $1^{\text {st }}$ generation & Abruzzo & Chemistry \\
\hline$\# 15$ & Male & 73 & Biodynamic & $1^{\text {st }}$ generation & Emilia-Romagna & n.a. \\
\hline$\# 16$ & Male & 49 & Biodynamic & $1^{\text {st }}$ generation & Trentino-Alto Adige & Management \\
\hline$\# 17$ & Male & 35 & Biodynamic & $1^{\text {st }}$ generation & Trentino-Alto Adige & n.a. \\
\hline$\# 18$ & Female & 47 & Biodynamic & $1^{\text {st }}$ generation & Abruzzo & n.a. \\
\hline
\end{tabular}

Source: Data from first interviews done by the author.

Having in mind the theoretical background on environmental entrepreneurship and identity theory, the author started in trying to identify identity meanings by analyzing the interviews. Following the principles of grounded theory (Glaser and Strauss, 1967), the goal is to uncover the evolution of entrepreneurs' identities over time, their potential changes, and the reasons behind these changes. Reading the interviews line by line, each author began to independently analyze and code the interviews, trying to create a dataset of codes.

- This section has to be completed once the author has collected all the interviews. -

Preliminary findings. Once all the interviews will be carried out and theoretical saturation reached, the findings will be analyzed and different types of identities and evolution of them probably identified.

As of today, the author thinks that reporting some quotes by entrepreneurs may provide a first sight of results or, at least, of some potential dynamics able to explain the existence and/or co-existence of environmental identity and 
entrepreneurial identity over time. A first light on the ways in which identity is changed through entrepreneurship may be shed.

"My passion has grown day by day. Since I was a child I always went there to harvest grapes. I loved the scent, the aroma of grapes... these are things which have always belonged to me, and I love it. During my holidays I always went there, in the vineyards, to work. So, let's say, when I had this possibility to go back from the city and take control of it, I couldn't miss the chance. You start caring about the vines, then you start producing some bottles of wine, and one thing leads to another. Little by little my passion grows. But a very strong natural component is at the basis of everything... I don't know, it's something I was born with. I don't know how to explain... it was already inside me. [...] When I have started, I did not conceive myself as an entrepreneur. I thought, it comes by itself, or by inertia. If I have to sell you a bottle of wine, I am not able to do it, I don't want to do it. No way! But, at the end, it's something which comes, which arises by itself. And this is also why, over the years, you see the quality of your wine is increasing. So, it gives you a lot of satisfaction. The wine, first of all, speaks by itself, because of high quality. Then, through the satisfaction you have, you can develop a bit of "entrepreneurial spirit". But, again, it's something which arrives by itself..." (Entrepreneur \#1)

"This kind of agriculture changes you. Because you start to not be interested in money and on the idea to exploit at most as you can the land you have... it's different." (Entrepreneur \#13)

"I have breath farming air since I was a child. Then, I have decided to stay home. But at the beginning I just wanted to be a farmer, I did not want to produce wine... I though those people were crazy. But it was obviously something I had in my DNA. [...] To produce wine and to be in this world it's a consequence of the fact that I wanted to be free. The entrepreneurial motivation, sure. And the wine was the consequence. But to be in contact with nature, the freedom: these were the real driving motivations. " (Entrepreneur \#2)

"Today (2017) we are not used to follow someone else. We are used to a selfish behavior when the individual comes first. But here, you have to serve nature. And you understand that, depending on how you behave with plants, they answer you differently. [...] I was working as an accountant because I thought this was my path. But then I have decided to take over the business... and my father was very upset. I was 22 years old, I was working in Milano, but I have realized I did not want to live there anymore, so I have moved to Novara and I was commuting. So, at the beginning I was working in the company for pleasure, but then I have decided it had to become my life." (Entrepreneur \#7)

"I have always been an emotional person with regards to nature, to the pollution, to these topics. [...] But approaching biodynamic gave me the ability to open my mind, to have a more open mind to face certain content." (Entrepreneur \#14)

"My husband and I have always loved the countryside. [...] We started to look for a firm. We wanted a winery. The most important thing for us was to change lifestyle, we wanted to move from the city to the country. [...] I totally have not an entrepreneurial passion when I have started this. However, I can say I think we have an aptitude for it. But the basic motivations were others. Even if we are from Genova, we did not want to buy something to make it grow and earn money. Our first aim was to live in a rural place, in a rural environment. Because this kind of life allows you to have a sustainable lifestyle, for us, in primis, and then for the environment." (Entrepreneur \#9)

"Surely I am different than before. But mostly because your lifestyle is completely different. Before I was a lawyer and now I am a farming entrepreneur. My identity has not changed... how can I say... I deeply believe in what I do, and I have principles. I could say my values have not changed, but the awareness is higher. To work the land, being in contact with nature, let you understand the role and the importance of certain things. So, I would say I am more aware." (Entrepreneur \#11)

"The biodynamic agriculture has surely strengthened my relationship with nature. When I was cultivating organic, I felt I was missing a piece. I wanted a meaning, a real sense. [...] It's something which allows you to not damage the planet, to give your contribution." (Entrepreneur \#11)

"My identity is different. It has been strengthened. Yes, definitely. Because it is reciprocity. [...] There is a complete understanding of nature. Who cultivate biodynamic has a vision of the human being not within nature, but the human being as equal to nature. There no possibility to divide the human being from nature." (Entrepreneur \#12)

"It's a sales logic. The commercial part is the most important part, at the end, because it gives you the opportunity to keep the firm alive. It's like when you go to do an exam. When you study and you're ready, you have two/three scenarios. The first one, if you are ready, they can evaluate you on what you have studied, and you receive a good grade. But then, there is the student who is ready, but is not able to express himself at his best, and vice-versa, the 
one who has not studied, but is has a good pitch. And in a firm, it's the same. You can have a good wine, but then you have to sell it. The commercial part is fundamental." (Entrepreneur \#4)

Discussion. On the steps of Fauchart and Gruber (2011) and of York and colleagues (2016), the author believes the research will be able to extend the knowledge of identity theory within the context of environmental entrepreneurship. Through the findings the author will be able to develop a model which explains the entrepreneurial behavior when entrepreneurial identity and environmental identity come into play. Propositions will be outlined.

However, a discussion seems now premature.

- Thus, this section will be written after the data analysis. -

Conclusions and guiding questions. Even if this section will be later developed, the main results' expectations may be here early discussed. Through the recall of entrepreneurs who have been interviewed a couple of years ago and through interviewing new entrepreneurs, the author expects to be able to develop propositions about the role of identities when shaping entrepreneurial behavior, and vice-versa.

First of all, they expect environmental identity to have a role for entrepreneurs when engaging in environmental entrepreneurial behavior. However, if some entrepreneurs may be mostly driven by their entrepreneurial propensity, and so their identity hierarchy sees entrepreneurial identity in the first place, they may, during time and engaging in the wine-making behaviors, change their identities' order, with environmental identity becoming dominant. This process may be true, for instance, for wine entrepreneurs who have decided to change their wine production from a conventional agriculture to an organic or biodynamic one. Thus, environmental identity may be the reason why they environmental behavior is amplified. Or again, through an engagement in more environmentally friendly behavior, they may develop an environmental identity which they did not know to own before. In contrast to them, other entrepreneurs may show, since the beginning, a strong environmental identity and they engage in entrepreneurial behaviors with a strong environmental orientation - e.g. they have started their winery with a biodynamic approach. Thus, the author expects to understand how these identities have evolved over time, and if a co-existence of the two of them has occurred.

Finally, other categories of entrepreneurs may be the ones of wine makers who only declares to have or an entrepreneurial identity or an environmental identity. For instance, entrepreneurs may be driven by their passion for nature and they find the wine industry as the pure mean to follow their environmental identity. Even if they become entrepreneurs, they do not want to perform that role. Their actions follow their inner environmental identity. They are not entrepreneurs.

The brief discussion here above represents only some suggestions of the concepts and processes which may arise from the interviews, and the author foresees to find new, or already addressed by the current literature, concepts which may have a role in this hierarchy-based identity process, and which may explain part of the theoretical model proposed.

- The section will be refined.

\section{References}

BARBOSA F.S., SCAVARDA A.J., SELLITTO M.A., LOPES MARQUES D.I. (2018), "Sustainability in the winemaking industry: An analysis of Southern Brazilian companies based on a literature review", Journal of Cleaner Production, vol. 192, pp. 80-87.

BURKE P.J., REITZES D.C. (1981), “The link between identity and role performance”, Social Psychology Quarterly, vol. 44, n. 2, pp. 83-92.

CARDON M.S., WINCENT J., SINGH J., DRNOVSEK M. (2009), "The nature and experience of entrepreneurial passion", Academy of Management Review, vol. 34, n. 3, pp. 511-532.

CARDON M.S., GLAUSER M., MURNIEKS C.Y. (2017), "Passion for what? Expanding the domains of entrepreneurial passion", Journal of Business Venturing Insights, vol. 8, pp. 24-32.

CASALÓ L.V., ESCARIO J.J. (2018), "Heterogeneity in the association between environmental attitudes and proenvironmental behavior: A multilevel regression approach", Journal of Cleaner Production, vol. 175, pp. 155-163.

CHRIST K.K., BURRITT R.L. (2013), "Critical environmental concerns in wine production: an integrative research", Journal of Cleaner Production, vol. 53, pp. 232-242.

DE BERNARDI C., PEDRINI M. (2020), "Entrepreneurial behavior: getting eco-drunk by felling environmental passion", Journal of Cleaner Production, vol. 256, forthcoming.

DEAN T.J., MCMULLEN J.S. (2007), “Toward a theory of sustainable entrepreneurship: reducing environmental degradation through entrepreneurial action", Journal of Business Venturing, vol. 22, n. 1, pp. 50-76.

EISENHARDT K.M., GRAEBNER M.E. (2007), "Theory Building from Cases: Opportunities and Challenges", Academy of Management Journal, vol. 50, n. 1, pp. 25-32.

FAUCHART E., GRUBER M. (2011), "Darwinians, communitarians, and missionaries: the role of founder identity in entrepreneurship", Academy of Management Journal, vol. 54, n. 5, pp. 935-957.

FISHER G. (2012), "Effectuation, Causation and Bricolage: A Behavioural Comparison of Emerging Theories in Entrepreneurship Research", Entrepreneurship Theory and Practice, vol. 36, n. 5, pp. 1019-1051. 
GILINSKY JR. A., NEWTON S.K., ATKIN T.S., SANTINI C., CAVICCHI A., CASAS A. E., HUERTAS R. (2015), "Perceived efficacy of sustainability strategies in the US, Italian and Spanish wine industries: a comparative study", International Journal of Wine Business Research, vol. 27, n. 3, pp. 164-181.

GLASER B., STRAUSS A. (1967), The Discovery Grounded Theory: Strategies for Qualitative Inquiry. London, UK: Weidenfeld and Nicolson.

GLASER B., STRAUSS A. (2006), The Discovery of Grounded Theory: Strategies for Qualitative Research. New Brunswick, NJ: Aldine Transaction.

GRUBER M., MACMILLAN I.C. (2017), "Entrepreneurial behavior: a reconceptualization and extension based on identity theory", Strategic Entrepreneurship Journal, vol. 11, n. 3, pp. 271-286.

HÖRISH J. (2015), "The role of sustainable entrepreneurship in sustainability transitions: A conceptual synthesis against the background of the multi-level perspective", Administrative Sciences, vol. 5, pp. 286-300.

HÖRISH J., KOLLAT J., BRIEGER S.A. (2017), "What influences environmental entrepreneurship? A multilevel analysis of the determinants of entrepreneurs' environmental orientation”, Small Business Economics, vol. 48, pp. 47-69.

LENOX M., YORK J.G. (2011), Environmental entrepreneurship. Oxford Handbook of Business and the Environment. Oxford University Press. Co-edited by Andrew J. Hoffman and Tima Bansal.

MURKIENS C.Y., MOSAKOWSKI E.M. (2007), Who am I? Looking inside the "entrepreneurial identity”, Frontiers of Entrepreneurship Research. Babson Park, MA: Babson College.

MURNIEKS C.Y., MOSAKOWSKI E., CARDON M.S. (2014), "Pathways of passion: identity centrality, passion, and behaviour among entrepreneurs", Journal of Management, vol. 40, n. 6, pp. 1583-1606.

O’NEIL I., UCBASARAN. D. (2016), "Balancing "what matters to me" with "what matters to them": Exploring the legitimation process of environmental entrepreneurs", Journal of Business Venturing, vol. 31, n. 2, pp. 133-152.

OIV - International Organisation of Vine and Wine Intergovenmental Organisation. 2019. Statistical Report on Wine Vitiniculture. Retrived online: http://www.oiv.int/public/medias/6782/oiv-2019-statistical-report-onworldvitiviniculture.pdf.

POWELL E.E., BAKER T. (2014), "It's what you make of it: founder identity and enacting strategic responses to adversity", The Academy of Management Journal, vol. 57, n. 5, pp. 1406-1433.

ROBERTSON J.L., BARLING J. (2013), “Greening organizations through leaders' influence on employees' proenvironmental behaviours", Journal of Organization Behavior, vol. 34, n. 2, pp. 176-194.

SCHIMMENTI E., MIGLIORE G., DI FRANCO C.P., BORSELLINO V. (2016), "Is there sustainable entrepreneurship in the wine industry? Exploring Sicilian wineries participating in the SOStain program", Wine Economics and Policy, vol. 5, pp. 14-23.

SHEPHERD D., HAYNIE J.M. (2009), "Birds of a feather don't always flock together: Identity management in entrepreneurship", Journal of Business Venturing, vol. 24, pp. 316-337.

STETS J.E., BURKE P.J. (2000), "Identity Theory and Social Identity Theory”, Social Psychology Quarterly, vol. 63, n. 3, pp. 224-237.

STRAUSS A., CORBIN J. (1998), Basics of Qualitative Research: Procedures and Techniques for Developing Grounded Theory. 2nd ed. Thousand Oaks, CA: Sage.

STRYKER S., BURKE P.J. (2000), "The past, present, and future of an identity theory", Social Psychology Quarterly, vol. 63, n. 4, pp. 284-297.

VALLERAND R.J., SALVY S., MAGEAU G.A., ELLIOT A.J., DENIS P.L., GROUZET F.M., BLANCHARD C. (2007), "On the role of passion in performance", Journal of Personality, vol. 75, n. 3, pp. 505-534.

VAN DER WERFF E., STEG L., KEIZER K. (2013), "The value of environmental self-identity: the relationship between biospheric values, environmental self-identity and environmental preferences, intentions and behavior", Journal of Environmental Psychology, vol. 34, pp. 55-63.

VILLANUEVA-REY P., VÁZQUEZ-ROWE I., MOREIRA M.T. (2014), "Comparative life cycle assessment in the win sector: biodynamic vs. conventional viticulture activities in NW Spain", Journal of Cleaner Production, vol. 65, pp, 330-341.

WRY T., YORK J. (2017), “An identity based approach to social enterprise”, Academy of Management Review, vol. 42, n. 3, pp. 437-460.

YIN R.K. (2003), Case study research. Thousand Oaks, CA: Sage.

YORK J.G. (2018), “It's getting better all the time (can't go no worse): the why, how and when of environmental entrepreneurship", International Journal of Entrepreneurial Venturing, vol. 10, n. 1, pp. 17-31.

YORK J.G., O’NEIL I., SARASVATHY S.D. (2016), "Exploring environmental entrepreneurship: identity coupling, venture goals, and stakeholder incentives", Journal of Management Studies, vol. 53, n. 5, pp. 695-737. 



\title{
La risposta emotiva del consumatore alle attività promozionali
}

\author{
FranCESCA De CANIO* DAVIDE PELLEGRINI*
}

Obiettivi. Il presente lavoro di ricerca propone, da un punto di vista teorico ed empirico, l'analisi della risposta emotiva del consumatore a diverse alternative promozionali oggi disponibili sul mercato. Infatti, fin dalla loro proliferazione sul mercato negli anni '80 nel trasporto aereo (Ieva e Ziliani, 2017), i programmi fedeltà hanno assunto un ruolo sempre più rilevante nelle strategie delle imprese di produzione e di distribuzione, al punto tale da essere, oggi, considerati lo strumento più efficace nella creazione della relazione impresa-consumatore (Kang et al., 2015). Tra i principali ruoli strategici giocati dai programmi fedeltà ci sono, da un lato la possibilità di raccogliere informazioni circa il comportamento d'acquisto del consumatore (Lee et al., 2014; Kumar e Shah, 2004), e dall'altro l'incremento delle vendite, la customer retention, e una forte risposta emotiva che porta il consumatore ad identificarsi con l'impresa e sentirsi membro attivo della stessa (Duffy, 2003). La maggior parte dei programmi fedeltà, è infatti in grado di coinvolgere simultaneamente molteplici meccanismi psicologici, quali ad esempio: speciale senso dello status, migliorare le sensazioni dei clienti di appartenenza sociale, gratitudine, reciprocità, o di offrire una combinazione di questi vantaggi (da Henderson et al., 2011). Negli ultimi anni, anche grazie alla massiva diffusione della tecnologia e degli strumenti digitali, stiamo assistendo ad una enorme proliferazione di forme alternative di programmi fedeltà, fisici, digitali ed ibridi. Così, i classici modelli promozionali sono sempre più associati a nuovi programmi fedeltà, che sfruttando il potenziale del digitaleraggiungono un numero sempre più ampio di consumatori (Breugelmans et al., 2015). A questo si associa una sempre più diffusa partecipazione dei consumatori ai programmi fedeltà. Uno studio della Nielsen (2016) su 30.000 consumatori provenienti da oltre 60 paesi, ha evidenziato come $i$ consumatori siano sempre più variety seekers nella partecipazione ai programmi fedeltà, spingendo le imprese a sviluppare più schemi promozionali contemporaneamente, per riuscire ad ingaggiare il maggior numero di consumatori. Va inoltre sottolineato che i consumatori sottoscrivono un numero sempre maggiore di programmi fedeltà (Henderson et al., 2011) e l'88\% di questi è in possesso di almeno 5 carte fedeltà (CodeBroke, 2018). Un altro studio ha inoltre evidenziato che il 53\% dei consumatori investe due ore al giorno alla ricerca di coupon e sconti (Valassis, 2017). Data quindi la rilevanza strategica dei programmi fedeltà e la diffusa proliferazione degli stessi (Christino et al., 2019; Capizzi e Ferguson, 2005), con una relativa perdita di efficacia nella generazione della customer loyalty, la letteratura ha iniziato a confrontare i diversi programmi fedeltà per verificare i pro e i contro di ciascuno di essi (e.g. Henderson et al., 2011). In tale contesto, questo studio si propone quindi, di studiare l'efficacia emotiva conscia prodotta dai diversi programmi fedeltà, focalizzandosi su tre particolari schemi: la raccolta punti, lo sconto alla cassa tramite couponing e l'emergente cash-back. Infatti, ogni schema promozionale ha vantaggi e svantaggi di breve e di lungo periodo, e non esiste uno programma fedeltà più efficace di un altro, ma una molteplicità di programmi promozionali, in grado di generare specifici risultati. In tale contesto, l'obiettivo della ricerca è verificare quale dei tre programmi fedeltà considerati riesca a riscuotere una migliore risposta emotiva di tipo "conscia".

I programmi fedeltà basati sulla raccolta punti sono ampiamente usati dalle imprese di molteplici settori, dall'accumulo delle miglia aeree, alle raccolte punti su soglie di spesa dei principali retailers della grande distribuzione organizzata (Kwong et al., 2011) o della ristorazione (Jang e Mattila, 2005). Tali strumenti promozionali, prevedono l'ottenimento di uno sconto o di un premio sulla vendita in seguito al raggiungimento di particolari soglie di punti che vengono generalmente stornate da una tessera associativa legata a ciascun consumatore (Bijmolt e Verhoef, 2017). Tuttavia, pur essendo uno strumento promozionale molto apprezzato, il consumatore teme spesso di non riuscire ad ottenere il vantaggio che gli spetterebbe a seguito dello sforzo assunto per raccogliere i punti. La raccolta punti, quindi, è uno strumento che, fornisce all'impresa che lo adotta informazioni utili sul comportamento di acquisto o consumo del consumatore; tuttavia pur accogliendo l'attenzione del consumatore essa presenta il limite legato all'incertezza di riuscire davvero ad ottenere un premio o uno sconto in linea con le aspettative del consumatore (Kwong et al., 2011).

Altro schema promozionale molto diffuso è il couponing. Tale strumento promozionale prevede uno sconto immediato in fase di pagamento attraverso "la bruciatura" di un coupon. Il coupon può essere cartaceo elo digitale, e

\footnotetext{
Assegnista di Ricerca in Economia e Gestione delle Imprese - Università degli Studi di Modena e Reggio Emilia - Italy e-mail: francesca.decanio@unimore.it

- Associato in Economia e Gestione delle Imprese - Università degli Studi di Parma - Italy e-mail: davide.pellegrini@unipr.it
} 
può essere distribuito direttamente dall'impresa (es. su un prodotto/servizio, su un brand, su una spesa) o da una piattaforma esterna che funge da infomediario (es. Groupon, Spiiky) (Ieva et al., 2018). Questo strumento permette da un lato la percezione immediata del vantaggio derivante dal suo utilizzo (pago subito una somma inferiore a quella indicata sull'etichetta/listino), ma dall'altro, non consente una specifica customizzazione dell'attività promozionale, differenziando il vantaggio -sconto- su ciascun consumatore (Capizzi e Ferguson, 2005).

Un ultimo strumento promozionale preso in considerazione in questo studio è il cash-back. Tale schema promozionale, nasce e si diffonde con lo sviluppo della digitalizzazione, e seppur ancora giovane, si sta diffondendo molto rapidamente (Vana et al., 2018). Una piattaforma, web o app, pubblicizza offerte di cash-back - generalmente sconti a valore o in percentuale sull'ammontare speso - che viene rimborsato allo stesso dopo l'acquisto - normalmente con ricarica sulla carta di pagamento. Due i principali vantaggi derivanti dall'utilizzo del cash-back: la probabilità che i consumatori effettuino un secondo acquisto con lo schema cash-back sono molto alte e l'acquisto viene ripetuto in tempi inferiori; più alto è anche l'importo medio speso dal consumatore (Vana et al., 2018). Il cash-back prevede tuttavia l'intermediazione di una piattaforma digitale per cui si allunga la relazione impresa-piattaforma-consumatore. Inoltre, come evidenziato dal recente studio di Christino et al. (2019) non tutti i consumatori sono potenziali fruitori di questo schema promozionale, ma, probabilmente a causa della necessità di dover interagire con una piattaforma digitale $i$ più giovani e coloro che posseggono un titolo di studio pari o superiore alla laurea sono più propensi a partecipare a questa tipologia di programma fedeltà.

Metodologia. Lo studio, svolto in collaborazione con la divisione Neuroscienze di Nielsen - UK - ha visto il coinvolgimento di 180 partecipanti, di nazionalità italiana, di età compresa tra i 21 e i 54 anni, divisi in sei gruppi. Ciascun gruppo è stato assegnato a uno specifico studio definito dalla combinazione tra le tre tipologie promozionali precedentemente indicate - raccolta punti, sconto alla cassa e cash-back - e di uno specifico stimolo - esposizione visiva al messaggio promozionale o esposizione concettuale. Quest'ultima in particolare ha previsto una doppia esposizione audio-visiva dove alla visione di un cartello pubblicitario è seguito l'ascolto della descrizione dello schema promozionale in oggetto. Gli stimoli testati sono riportati in figura 1.

Fig. 1: Combinazione degli stimuli

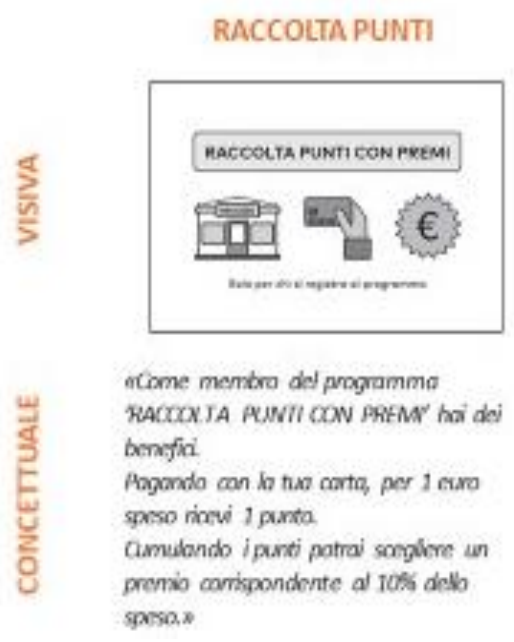

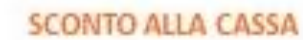

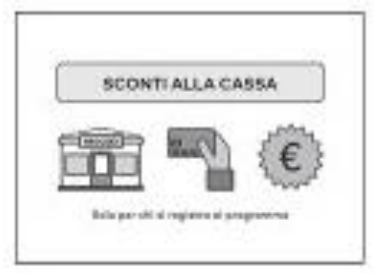

"Cone mentro del procrammo scawt NUA CASSA' hoi dei berrejia Spende meno ocquistondo con to tuo corte.

Ala cusso hai uno sconto imvnediato diel $10 \%$ swimporto spesa.
CASH-BACK

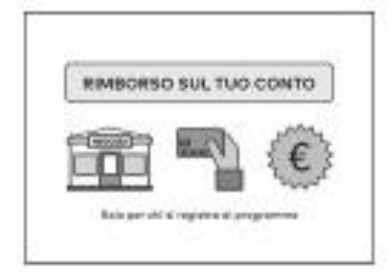

Whame membro do' progromma

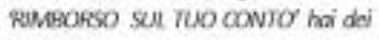
henefici.

Ad agni paganmonto en lo carta ricevi

indictro $10 \%$ delimporto spese.

La somno sond dikponibils nol two conts

bavario entro pochi giomil

Fonte: nostra elaborazione

$\grave{E}$ stato quindi adottato un modello di analisi quasi-sperimentale, non potendo controllare per tutte le tipologie di programmi fedeltà oggi adottate dalle imprese nei più svariati settori industriali, e per tutte le altre fonti di disturbo potenzialmente interferenti con il disegno sperimentale (Shadish et al., 2002). La popolazione osservata, è stata quindi suddivisa in sei gruppi, omogenei per età e sesso. Ciascun gruppo è stato identificato sulla base di una specifica combinazione tra la tipologia di promozione indagata, e la tipologia di stimolo al quale ciascun soggetto, appartenente al gruppo, è stato sottoposto, come riportato nello schema proposto in tabella 1:

Tab. 1: Disegno sperimentale

\begin{tabular}{|l|c|c|}
\hline & \multicolumn{2}{|c|}{ Stimolo } \\
\hline Programma Fedeltà & Visivo & Concettuale (Audio-visivo) \\
\hline Raccolta punti & Gruppo 1 & Gruppo 2 \\
\hline Sconto alla cassa - Coupon & Gruppo 3 & Gruppo 4 \\
\hline Cash-back & Gruppo 5 & Gruppo 6 \\
\hline
\end{tabular}

Fonte: nostra elaborazione 
Lo studio è stato condotto attraverso una doppia rilevazione neuroscientifica della risposta inconscia dei soggetti appartenenti a ciascun gruppo mediante eye-tracking ed elettroencefalogramma. A seguito dell'esposizione del soggetto allo stimolo, della durata complessiva di circa 10 minuti, allo stesso è stato chiesto di compilare un questionario per misurare la risposta emotiva "conscia" derivante dalla partecipazione all'esperimento a seguito della stimolazione. Il questionario è stato somministrato in una stanza controllata rispetto ad interferenze auditive, per ridurre al minimo possibili interferenze esterne, e secondo la metodologia della compilazione assistita. Il questionario basato su una doppia metodologia di rilevazione multiple choice - domanda aperta a campo limitato è stato suddiviso in quattro sezioni. Nella prima sezione del questionario sono state chieste alcune informazioni relative al programma fedeltà oggetto di stimolo (visivo/concettuale) al quale il soggetto è stato sottoposto. Nella seconda sezione del questionario è stato indagato il gradimento del rispondente rispetto alle tre tipologie di programma fedeltà oggetto di indagine indipendentemente al gruppo di appartenenza e dello stimolo ricevuto. La terza sezione del questionario, ha raccolto le informazioni socio-demografiche dei rispondenti. Nella quarta sezione basata su brevi risposte aperte sono stati indagati i punti di forza e i limiti di ciascun programma fedeltà oggetto dello stimolo dello studio neuroscientifico.

I risultati del questionario raccolto a seguito dello studio neuroscientifico sono stati utilizzati per misurare la risposta emotiva conscia della popolazione oggetto dello studio sulle diverse tipologie di schemi promozionali.

Risultati. In seguito all'esposizione ad uno dei tre possibili modelli promozionali secondo una delle due modalità di esposizione, visiva o concettuale è emerso quanto riportato in tabella 2.

Tab. 2: Preferenza per il programma fedeltà

\begin{tabular}{|l|l|}
\hline Programma Fedeltà & \multicolumn{1}{c|}{ \% Preferenza } \\
\hline \multirow{3}{*}{ Raccolta punti } & $\begin{array}{l}\text { Raccolta punti: } 23 \% \\
\text { Sconto alla cassa: } 50 \% \\
\text { Cash-back: } 27 \%\end{array}$ \\
\hline \multirow{3}{*}{ Sconto alla cassa - Coupon } & $\begin{array}{l}\text { Raccolta punti: } 8 \% \\
\text { Sconto alla cassa: } 73 \% \\
\text { Cash-back: } 19 \%\end{array}$ \\
\hline \multirow{3}{*}{ Cash-back } & $\begin{array}{l}\text { Raccolta punti: } 14 \% \\
\text { Sconto alla cassa: } 46 \% \\
\text { Cash-back: } 40 \%\end{array}$ \\
\hline
\end{tabular}

Fonte: nostra elaborazione

I risultati evidenziano che lo sconto alla cassa è la forma promozionale preferita dalla maggior parte dei rispondenti, indipendentemente dalla dinamica promozionale al quale il soggetto è stato esposto. In particolare, il $73 \%$ di coloro sottoposti al messaggio promozionale inerente il couponing lo hanno indicato come programma fedeltà preferito. Anche il 50\% dei soggetti sottoposti allo stimolo (visivo o concettuale) della raccolta punti, hanno indicato la redemption del coupon in cassa come lo strumento promozionale preferito. Similmente anche il $46 \%$ dei soggetti sottoposti al messaggio promozionale inerente il cash-back hanno indicato lo sconto alla cassa come la modalità promozionale preferita. Viceversa la raccolta punti risulta essere poco gradita dai consumatori, riscuotendo la percentuale di preferenza più bassa in ciascuno dei gruppi oggetto del disegno sperimentale. Il cash-back, invece, seppur nuovo e ancora poco conosciuto da molti consumatori, è stato ben apprezzato dagli stessi che lo hanno identificato come seconda opzione. In particolare, $i$ consumatori esposti allo stimolo inerente il cash-back hanno evidenziato un discreto livello di preferenza per questa modalità promozionale, probabilmente in seguito all'acquisizione di una certa familiarità con la dinamica promozionale del cash-back dovuta alla stimolazione in laboratorio dovuta alla partecipazione allo studio neuroscientifico. Rilevante anche il risultato riscontrato nel gruppo esposto al programma fedeltà della raccolta punti, il quale, ha indicato di preferire il cash-back nel $27 \%$ dei casi.

A livello conscio, inoltre, è emerso che la scarsa preferenza per la raccolta punti è dovuta a problemi inerenti la varietà dei premi e la capacità degli stessi di incontrare i gusti dei consumatori, confermando quanto precedentemente riscontrato in letteratura (Kwong et al., 2011):

- " "perche' i premi messi in palio dalla ditta potrebbero non piacermi"

- " "non so quali sono i premi"

- "poi i premi potrebbero non piacermi”.

Viceversa, coloro che scelgono le raccolte punti lo fanno per una consolidata abitudine nell'interagire con la dinamica promozionale stessa:

- "siamo abituati a questo tipo di incentivo ... a incominciare dalla spesa quotidiana"

- "perchè tutti collezioniamo punti”.

- Nell'81\% dei casi lo sconto alla casa mediante l'utilizzo di un coupon, è stata considerata come la modalità promozionale preferita. Tale evidenza si riscontra anche nei commenti dei rispondenti che evidenziano come l'immediatezza del beneficio derivante dalla fruizione del coupon in cassa, porti a preferire tale dinamica 
promozionale:

- "perche hai subito il vantaggio della promozione"

- "il beneficio è immediato"

- " $\quad$ per lo sconto immediato"

- "La promozione garantisce un beneficio IMMEDIATO”

- " "perchè è un offerta, beneficio immediato”.

Infine, il 37\% di coloro che hanno preferito il cash-back hanno evidenziato l'innovatività alla base di questo strumento promozionale. Inoltre, il poter disporre di una somma di denaro da poter utilizzare anche per altri scopi, non direttamente relazionabili con il retailer, rendono interessante questo modello promozionale:

- "credo sia il più conveniente ed il più innovativo"

- "e' la più innovativa”

- "una cosa diversa dal normale"

- $\quad$ "perchè è meglio avere un rimborso economico sul conto piuttosto che sconti o buoni utilizzabili presso la stessa azienda"

- " "posso utilizzare la somma per tutto".

Si evidenzia, infine, che per le tre dinamiche promozionali, i rispondenti, hanno evidenziato per poter accedere ai programmi fedeltà, sia in qualche modo necessaria una registrazione del consumatore, attraverso l'attivazione di una carta fedeltà, un account presso il retailer elo presso la piattaforma di cash-back. Questo aspetto, di primaria importanza per le imprese che adottano schemi promozionali per avere maggiore conoscenza sul comportamento di acquisto elo consumo dei consumatori (Lee et al., 2014; Kumar e Shah, 2004), è invece considerato negativamente dai consumatori e deve essere gestito con estrema cura.

Limiti della ricerca. Seppur la ricerca indaga tre diverse tipologie di programmi fedeltà, oggigiorno esistono molteplici altre tipologie promozionali, non indagate in questo studio. Inoltre, lo studio è stato sviluppato sul consumatore italiano, pertanto lo studio non controlla per possibili differenze cross-cultural nella risposta emotiva del consumatore. Infine in questo abstract si evidenziano le principali risultanze della risposta emotiva conscia del consumatore, senza calibrare la stessa con la risposta inconscia determinata dall'esposizione al programma fedeltà.

Implicazioni pratiche. Dal punto di vista manageriale lo studio evidenzia che, la risposta emotiva "conscia" del consumatore lo porta a preferire lo sconto immediato alla cassa piuttosto che la raccolta punti. Per questo motivo $i$ retailers dovrebbero riversare gli investimenti in attività promozionali verso gli sconti in cassa, essendo questi, maggiormente apprezzati dai consumatori. Viceversa, lo studio evidenzia uno scarso apprezzamento del consumatore rispetto alla raccolta punti. A causa, probabilmente, di un diverso momento temporale tra l'accreditamento del punto e la sua "redemption", i consumatori non la considerano una forma promozionale efficace. Per questo motivo, $i$ retailers dovrebbero ridistribuire le raccolte punti semestrali o annuali, in short-collections, in grado di catturare l'attenzione del consumatore in maniera costante. Inoltre, poiché molto spesso, il limite della raccolta punti risiede nel "premio", non sempre di gradimento del consumatore, o in taluni casi, addirittura "ignoto" ai più, $i$ retailers dovrebbero incrementare la comunicazione sia, sulle modalità per la raccolta dei punti (es. soglie per il raggiungimento del punto) elo sulla raccolta dei punti veloci (es. in seguito all'acquisto di particolari prodotti sponsor), nonché il catalogo dei premi, sia cartaceo che digitale, suddiviso per soglie punti e per tipologia di premio: materiale (es. kit cucina, valigia/trolley, spugna bagno, etc.), esperienziale (es. biglietto cinema, ingresso parchi divertimenti, abbonamento a riviste, test-drive, etc.), economico (es. sconto a valore ( $€$ ) sulla spesa, \% sconto su prodotti a marchio, buono sconto su rivenditori partner, etc.), sociale (es. materiale scuola, donazioni ad enti benefici, organizzazione eventi per enti benefici, etc.). Inoltre, pur riscuotendo un discreto apprezzamento dal consumatore, il cash-back è apprezzato solo da coloro che hanno avuto modo di capirne le dinamiche, per questo motivo, visto anche l'emergere di queste nuove forme promozionali ibride, sviluppatesi con la diffusione del digitale, i retailers dovrebbero investire nella comunicazione di questa nuova forma di programma fedeltà. In particolare, l'innovatività alla base di questo strumento promozionale, diffusosi grazie alla diffusione del digitale, potrebbe riuscire ad "ingaggiare" i consumatori più giovani, ad oggi, tra $i$ target più complessi di consumatori per i retailers.

Originalità del lavoro. L'originalità di questo lavoro di ricerca risiede nella comparazione diretta di tre diverse tipologie promozionali, mettendone in luce punti di forza e di debolezza dal punto di vista della risposta emotiva del consumatore alle stesse. Infatti, la sempre maggiore diffusione di modelli di programmi fedeltà "ibridi" derivanti dalla volontà dei retailers di trovare nuove forme promozionali in grado di "ingaggiare" il consumatore e attirarlo verso il proprio punto vendita, necessità, di riscontro empirico nell'efficacia delle stesse. La possibilità di verificare, quale strumento promozionale, sia a livello conscio, in grado di generare una più positiva risposta emotiva da parte del consumatore, risulta essere un argomento rilevante sia dal punto di vista teorico, che dal punto di vista manageriale. L'originalità della ricerca risiede, inoltre, nella metodologia di indagine utilizzata. Infatti, lo studio, supervisionato da un team di neuroscienziati della Nielsen - divisione UK - ha esposto il campione di consumatori ad una doppia forma 
comunicazionale di tipo - solo visivo - visivo/uditivo, verificandone la ricettività alla dinamica promozionale e la relativa risposta emotiva.

Parole chiave: programmi fedeltà; risposta emotiva; comportamento del consumo; cash-back; raccolta punti; sconto alla cassa.

\section{Bibliografia}

BREUGELMANS E., BIJMOLT T.H., ZHANG J., BASSO L.J., DOROTIC M., KOPALLE P., WÜNDERLICH N.V. (2015), “Advancing research on loyalty programs: a future research agenda", Marketing Letters, vol. 26, n. 2, pp. 127-139.

BIJMOLT T.H., VERHOEF P. C. (2017), "Loyalty programs: Current insights, research challenges, and emerging trends", in Handbook of marketing decision models, pp. 143-165, Springer, Cham.

CAPIZZI M.T., FERGUSON R. (2005), "Loyalty trends for the twenty-first century", Journal of Consumer Marketing, vol. 22, n. 2, pp. 72-80.

CHRISTINO J.M.M., SILVA T.S., CARDOZO E.A.A., DE PÁDUA CARRIERI A., DE PAIVA NUNES P. (2019), "Understanding affiliation to cashback programs: An emerging technique in an emerging country", Journal of Retailing and Consumer Services, vol. 47, pp. 78-86.

CODEBROKE (2018), “2018 Loyalty Program Consumer Survey. How today’s consumers want to engage with loyalty programs". https://codebroker.com/resources2/doc/CodeBroker_2018_Mobile_Loyalty_Survey_Results.pdf

DUFFY D.L. (2003), "Internal and external factors which affect customer loyalty", Journal of Consumer Marketing, vol. 20, n. 5, pp. 480-485.

HENDERSON C.M., BECK J.T., PALMATIER R.W. (2011), "Review of the theoretical underpinnings of loyalty programs", Journal of Consumer Psychology, vol. 21, n. 3, pp. 256-276.

IEVA M., DE CANIO F., ZILIANI C. (2018), "Daily deal shoppers: What drives social couponing?", Journal of Retailing and Consumer Services, vol. 40, pp. 299-303.

IEVA M., ZILIANI C. (2017), "Towards digital loyalty programs: insights from customer medium preference segmentation", International Journal of Retail \& Distribution Management, vol. 45, n. 2, pp. 195-210.

JANG D., MATTILA A.S. (2005), "An examination of restaurant loyalty programs: what kinds of rewards do customers prefer?”, International Journal of Contemporary Hospitality Management, vol. 17, n. 5, pp. 402-408.

KANG J., ALEJANDRO T.B., GROZA M.D. (2015), "Customer-company identification and the effectiveness of loyalty programs”, Journal of Business Research, vol. 68, n. 2, pp. 464-471.

KUMAR V., SHAH D. (2004), "Building and sustaining profitable customer loyalty for the 21st century", Journal of Retailing, vol. 80, n. 4, pp. 317-329.

KWONG J.Y., SOMAN D., HO C.K. (2011), "The role of computational ease on the decision to spend loyalty program points", Journal of Consumer Psychology, vol. 21, n. 2, pp. 146-156.

LEE J.J., CAPELLA M.L., TAYLOR C.R., GABLER C.B. (2014), "The financial impact of loyalty programs in the hotel industry: A social exchange theory perspective”, Journal of Business Research, vol. 67, n. 10, pp. 21392146.

SHADISH W.R., COOK T.D., CAMPBELL D.T. (2002), Experimental and quasi-experimental designs for generalized causal inference, Wadsworth Cengage learning, Belmont, CA.

VALASSIS (2017), "New Valassis Survey: Consumers Prioritize Savings in Age of Convenience", Link: http://www.valassis.com/about-us/newsroom/item/170830/new-valassis-survey-consumers-prioritize-savings-inage-of-convenience?utm_campaign=ACS\%20-

$\% 20$ Weekly\%20Drips\&utm_source=hs_email\&utm_medium $=$ email\&utm_content $=67855258 \&$ hsenc=p2ANqt z-_UsV_m2M9Z3kqKUF5g4y9MXZ-

WSsxDWOd6X2x0CHv7_vO2PQE0J4Chi4JyRX3pEBjNIDa2qLbpty1ShME9x1SOUdQFuw\&_hsmi=6785555 5

VANA P., LAMBRECHT A., BERTINI M. (2018), "Cashback Is cash forward: Delaying a discount to entice future Spending", Journal of Marketing Research, vol. 55 n. 6, pp. 852-868. 



\title{
The challenges of Covid19 in the tourism industry. The case of the Italian context
}

\author{
Valentina Della Corte* Giovanna Del Gaudio* GiUliana Nevola * \\ ENRICO DI TARANTO*
}

Objectives. This paper has the challenge to verify whether and to what extent the crisis, related to Covid19, impacted the Italian tourism industry and how firms have reacted for its management.

Crisis and its management have been defined by some scholars and applied in various context. The most common definition of tourism crisis is the one given by Glaesser (2006, p.6), for whom it can be defined as "an event which causes disruption in normal functioning of tourism-related businesses, damages all the reputation of the safety, attractiveness, and comfort of a touristic destination by negatively affecting the perceptions of visitors, as a result, negatively affects tourism economy and causes reduced tourist arrival and spending, delay doing business in the tourism sector". Starting from this contribution, lots of authors have defined tourism crisis on a political (O'Brien, 2012), organizational (Pauchant and Douville, 1994), environmental (Pearson and Mitroff, 1993) or pandemic (Yang and Chen, 2009) according to the different sources that lead to crisis situations. All these contributions focus on a crisis process, which unexpectedly causes disruptions in normal functioning of tourism-related businesses (Glaesser, 2006).

The paper is organized as follows: after a literature review with reference to bibliometric analyses in the field, we go through the methods and models we decided to adopt (data collection and data analysis), getting to the main findings. The paper ends with its conclusions and hints for further research related to the crisis management, and how firms react to a global crisis that involves all the world community through a sustainable approach that ensures security, a safe environment and a full comfortable experience. The pandemic emergency has revealed new needs to be satisfied, travellers look for safe experiences.

Methodology. The paper uses a double methodology. Firstly, the paper addresses the issue of crisis management in the tourism field through a bibliometrical analysis helpful to avoid the subjectivity. Secondly, the paper proceeds with a Delphi method with experts to estimate the future trends and firms' behaviours.

The bibliometric analysis is focused on monitoring the scientific field of crisis management in the hospitality industry with specific reference to pandemic crisis as well as on delimiting research areas to determine its conceptual structure and its evolution. Through bibliometric mapping, the paper draws a spatial representation of the conceptual structure.

The analysis is performedthrough the R-package bibliometrix (Aria and Cuccurullo, 2016). This tool is specifically designed for quantitative research in Scientometrics and Bibliometrics. It provides various routines for analysis and supports all the main steps of a classical bibliometric workflow.

The paper uses ISI WOS that provides data on documents published in the social sciences and the cited references they contain. For limiting the scope and following the purpose of the paper, we define a twenty-two-year timespan (1990-2020). We used the search terms in topic field: "crisis management", "pandemic crisis" and "tourism".

A set of 947 papers was exported using the following couple of words "crisis management" and "tourism", "pandemic" and "destination management", "disaster" and tourism from scientific journals belonging to categories as business and business finance, economics and management, communication and food science technology, hospitality leisure, sport tourism or humanities multidisciplinary cultural studies and development studies, and education and research. Figure 1 shows the first five journals in Tourism Management and Tourism Economics represent the main sources of the documents.

\footnotetext{
Full Professor of Management - University of Naples Federico II - Italy e-mail: valentina.dellacorte@unina.it

$\mathrm{PhD}$ in Business Administration - University of Naples Federico II - Italy

e-mail: giovanna.delgaudio@unina.it

PhD Candidate in Business Administration - University of Naples Federico II - Italy

e-mail: giuliana.nevola@unina.it

$\mathrm{PhD}$ in Business Administration - University of Naples Federico II - Italy

e-mail: enrico.ditaranto@gmail.com
} 


\begin{tabular}{|c|c|c|c|c|}
\hline TOURISM MANAGEMENT & 1 & 87 & 87 & $\begin{array}{l}\text { Zone } \\
1\end{array}$ \\
\hline CURRENT ISSUES IN TOURISM & 2 & 47 & 134 & $\begin{array}{l}\text { Zone } \\
1\end{array}$ \\
\hline ANNALS OF TOURISM RESEARCH & 3 & 45 & 179 & $\begin{array}{l}\text { Zone } \\
1\end{array}$ \\
\hline JOURNAL OF TRAVEL RESEARCH & 4 & 45 & 224 & $\begin{array}{l}\text { Zone } \\
1\end{array}$ \\
\hline TOURISM ECONOMICS & 5 & 32 & 256 & $\begin{array}{l}\text { Zone } \\
1\end{array}$ \\
\hline TOURISM GEOGRAPHIES & 6 & 20 & 276 & $\begin{array}{l}\text { Zone } \\
1\end{array}$ \\
\hline TOURISM MANAGEMENT PERSPECTIVES & 7 & 20 & 296 & $\begin{array}{l}\text { Zone } \\
1\end{array}$ \\
\hline $\begin{array}{l}\text { 2ND INTERNATIONAL SCIENTIFIC CONFERENCE TOURISM IN SOUTHERN AND } \\
\text { EASTERN EUROPE 2013: CRISIS - A CHALLENGE OF SUSTAINABLE TOURISM } \\
\text { DEVELOPMENT? }\end{array}$ & 8 & 18 & 314 & $\begin{array}{l}\text { Zone } \\
1\end{array}$ \\
\hline ASIA PACIFIC JOURNAL OF TOURISM RESEARCH & 9 & 18 & 332 & $\begin{array}{l}\text { Zone } \\
1\end{array}$ \\
\hline JOURNAL OF SUSTAINABLE TOURISM & 10 & 18 & 350 & $\begin{array}{l}\text { Zone } \\
?\end{array}$ \\
\hline
\end{tabular}

To build the conceptual structure of the topic, we selected as unit of analysis the keywords associated to the manuscript (Figure 2)

In this specific work, taking in consideration the co occurrence network, four main topics are identified: crisis, tourism, economic-crisis and management. The term crisis is associated to words as terrorism, travel, climate change, economic growth, and destination but there are no connections with pandemic events or health emergency, the term crisis is often linked to the impact, most of documents indeed describe the impact of a crisis due to different reason, main attention is given to terrorism and climate change on tourism demand and international tourism, , tourism demand and economic growth(Cheng, L., \& Zhang, J., 2020). Literature puts in evidence the strong connection among economy and tourism, and how this sector is always affected in period of crisis. In Italy the tourism counts 146 billions euros equal to $12 \%$ of GDP generated by a supply chain of 216,000 hospitality firms and 12,000 travel agencies that are experiencing a decreasing of 260 million tourist attendances (Assoturismo 2020) and it's estimated a loss of 53 billion in the transport sector (the aviation sector fell by 93\%);64 billion in the hotel and catering industry; 8.1 billion rental and leasing; 2 billion "billed" by travel agencies and tour operators, 10.8 billion in entertainment (museums, cinemas and theatres) and 7.6 billion in sports and leisure.

In the upper right quadrant the tourism theme appears characterized by high density and centrality. In the selected documents tourism is well developed and connected in the research field, it is often associated to themes as perception, quality, satisfaction, tourism behavior. The literature evidences how socio political context ( Sharahbani,et al.2019) and how natural and man made disaster impact tourism (Huang, et al., 2020)impact on traveller behavior, their perception.

In the third lower left quadrant the main topic identified is the management characterized by a low density and centrality, despite its location on the matrix the management theme is often associated to recovery, crisis, resilience, disaster, (Filimonau and De Coteau, 2020). The principles of disaster management should be integrated with those of destination management to favour the resilience character of destinations to natural disaster. Most of the documents selected are focused on destination and crisis management depending on political, and natural disaster, but very poor attention is paid to health crisis. The poor association to health crisis justifies the position of the theme in the lower left quadrant.

In the fourth lower right quadrant the economic crisis it the main topic characterized by high centrality and low density that means the theme is related to the research field but is not well developed., it's a transversal theme to the main topic.

Economic crisis is often related to the consumption behaviour and personal income affecting the decision making of travellers. Xie and Tveterås,2020 measure the impact of an economic decline caused by non tourism industry on a price competitiveness in the tourism sector. 
Fig. 2

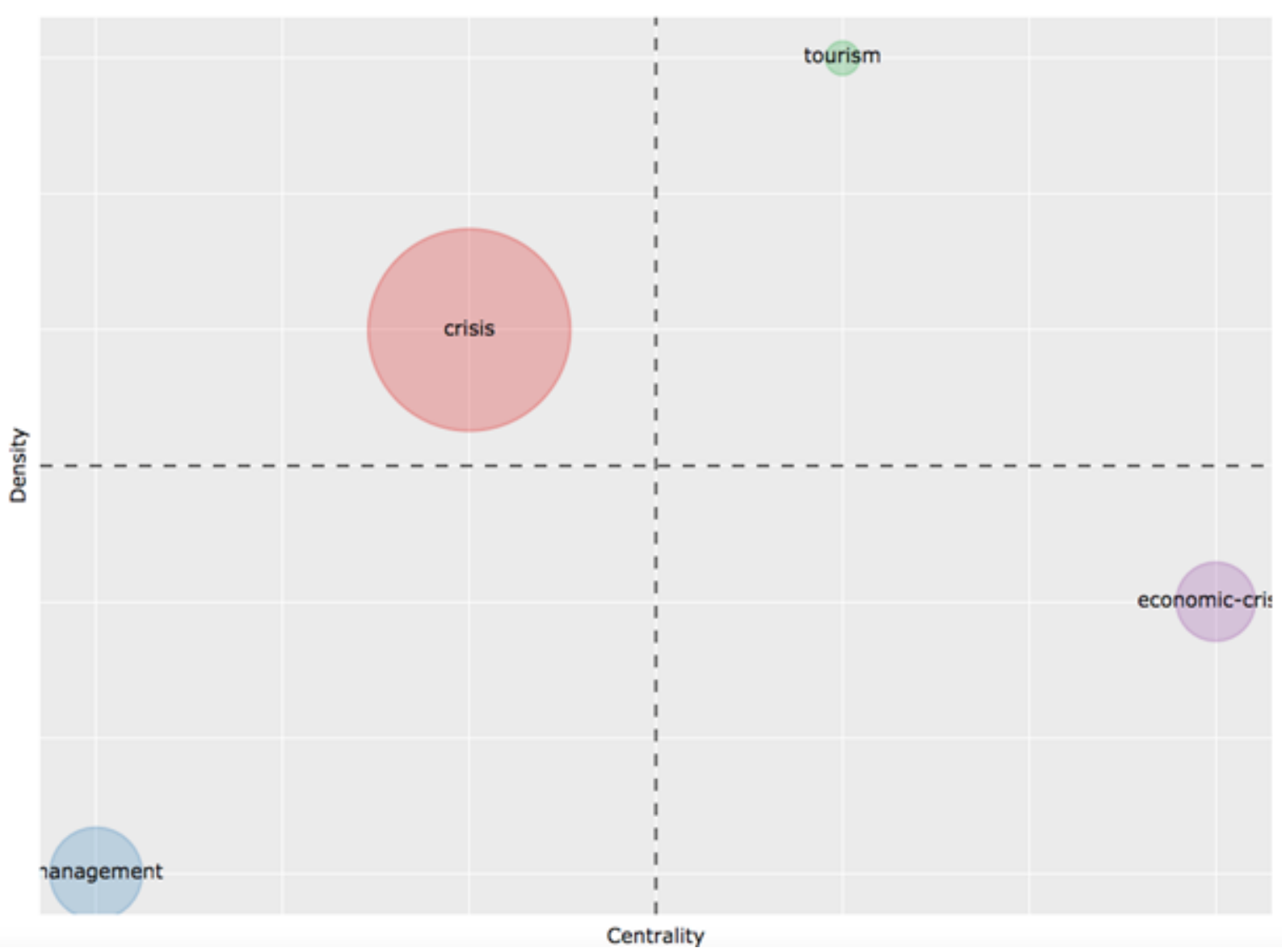

In Figure 2, each vertex represents a Keyword Plus. The size of a vertex is proportional to the frequency of its keyword while the edges represent the existence of a co-occurrence between two keywords and their thickness the strength of co-presence. In order to identify the most important keywords in the whole network, there is the need to consider their "centrality" with respect to the network itself. According to the computed eigenvector values, the most "central" words are "tourism", "management", "crisis", "impact", "economic crisis", "demand" The vertex colours represent the clusters obtained by community detection Louvain algorithm. We have divided the keywords in the reference lists in three main clusters: one is related to tourism industry and economic crisis, the second one to the crisis management and the third to the crisis and their impact.

The results of bibliometrical review have shed light on a set of indicators used in literature to define the actions contained under the umbrella crisis management, For this reason, from a methodological point of view, we use a panel of experts, both academics and manager, on tourism to discuss on the validity of indicators for the specific crisis of Covid19.

The panel of experts were organized through online webinars to collect data regarding the perspectives of managers and academic. The panels were conducted in three different period of the the pandemic crisis: at the beginning of the of the pandemic, during the full lockdown and during the re-start phase. During the panel a series of questions were subministrated to firms to understand their perceptions concerning the following aspect as the travel behaviour, their forecast on the reopening of tourism business, the investment that they will support in terms of digital marketing and sustainability (See Appendix 1). A specific set of questions was addressed to the food and beverage management taking in consideration structural investments and decor of dining room.

Findings. Due to the overlapping between bibliometrix and Delphi method, the paper shows interesting findings at both theoretical and managerial level. From the theoretical point of view, the paper highlights how the topic of pandemic crisis management in the tourism industry with specific reference to pandemies has evolved over the years. The findings highlight that Avian Flu, pandemic influenza and severe acute respiratory syndrome (SARS) have been the main health crises with huge impact on international tourism (Olayemi, et al.,2020). The bibliometric analysis also reveals that, although crisis management has been dealt with tourism industry, the main contributions refer to environmental events and terrorist attacks (K1liçlar, et al.,2018). With reference to pandemic or health crisis, these reveal their own specificity and each crisis is different from the other main consequences and impacts of these crises. Firstly, nonessential travel were postponed and both tourism destination and tourism firms faced the challenges to better promote safer places. Secondly, tourists focused the attention on hygienic norms and the tourism industry was 
more attentive to the health and security of travellers, becoming more sensible to sustainability aspects.A sustainable behaviour is considered the main way to response economic crisis, firms are called to analyse and compare previous crisis that affected the tourism industry and to find new solutions to face the state of uncertainty due to health emergency and to answer to the emerging needs.

Hospitality firms witness their fears related to the forced drop of the demand due to the pandemic crisis and the lack of operative measures established by the government. Companies were more focused on domestic market and on strategy to adopt to increase the domestic demand and in identifying operative measures to ensure security and a safe environment. Despite the huge economic crisis companies showed themselves more flexible to challenges and changes more opened to technology. In hospitality firms check in online and digital keys are only two of more popular measures and panel sections were useful to share and to propose new measures to be adopted.

It is necessary to restart not only from emergencies but also from the strategic assets of the future which are represented by the combination of sustainability and digitalization. Tourism companies and destinations must necessarily respond to the challenges of sustainability and digitalization. These two pillars, today, must be revitalized in the light of the concepts of safety and well-being. In light of the new rules and trends, it is also necessary to review the patterns and practices already applied in the sector.

Research limits. The research is not without its limitations. Firstly, future research should aim to investigate factors which could possibly mediate or moderate the effects of travel behavior such as travel intention. Secondly, this research was made at the first and second stage of pandemic crisis. Future and closed longitudinal surveys should be repeated. Thirdly, the constructs used in the study only explained a small part of travel behavior. A larger pool of items related to travel behavior should be considered in future studies.

Finally, our study was an early attempt at exploring the variables impacting the travel behavior after pandemic crisis.

Practical implications. The collaboration between managers and academic is an important contribution for the research, in this way academic world is closer the to firms and their needs.This study gives a relevant contribution on the new perspectives after the pandemic crisis. Firstly, it comes out that open innovation is important in this sector with different actors of the industry, customer, local community, etc. This exists not only in operational activities but mainly in the most creative process of product construction.

Originality of the study. This work combines empirical and literature resources together showing how partnership between firms and academic world contribute to implement and apply new management and marketing strategies.

This work takes in consideration the tourism business concerns related to the health emergency and offers some practical solutions implemented by tourism managers.

Key words: crisis management; tourism; destination, bibliometrix

\section{References}

ARIA M, CUCCURULLO C.. (2016), "bibliometrix: AR tool for comprehensive bibliometric analysis of scientific literature", Scientometrics, vol. 11, n. 1, pp. 1-17.

CHENG L., ZHANG, J. (2020), "Assessment of coupling coordination between tourism development and economic growth after the 2008 Wenchuan earthquake: Beichuan”, China. Asia Pacific Journal of Tourism Research, vol. 25 , n. 6, pp. 592-609.

FILIMONAU V., DE COTEAU D. (2020), "Tourism resilience in the context of integrated destination and disaster management (DM2)", International Journal of Tourism Research, vol. 22, n. 2, pp. 202-222.

GLAESSER D. (2006), Crisis management in the tourism industry. Routledge.

HUANG L., YIN X., YANG Y., LUO M., HUANG S.S. (2020), "Blessing in disguise": The impact of the Wenchuan earthquake on inbound tourist arrivals in Sichuan, China, Journal of Hospitality and Tourism Management, vol. 42, pp. 58-66.

KILIÇLAR A., UŞAKLI A., TAYFUN A. (2018), "Terrorism prevention in tourism destinations: Security forces vs. civil authority perspectives", Journal of destination marketing \& management, vol. 8, pp. 232-246.

O'BRIEN A. (2012), "Wasting a good crisis: Developmental failure and Irish tourism since 2008", Annals of Tourism Research, vol. 39 n.2, pp. 1138-1155

OLAYEMI L. O., BOODOOSINGH R., SAM, F. A. L. (2020), "Is Samoa Prepared for an Outbreak of COVID-19?", Asia-Pacific Journal of Public Health.

PANATI G., GOLINELLI G.M. (1991), Tecnica economica industriale e commerciale, La Nuova Italia Scientifica, Roma.

PEARSON C.M., MITROFF I.I. (1993), "From crisis prone to crisis prepared: A framework for crisis management" Academy of Management Perspectives, vol. 7 n.1, pp. 48-59. 
PORTER M.E. (1980), Competitive advantage. Tecniques for analyzing industries and competitors, The Free Press, New York.

SHAHRABANI S., TEITLER-REGEV S., SYNA H.D., TSOUKATOS E., AMBROSIO V., LOUREIRO S.M.C., VOULGARIS F. (2019), The effects of socio-political context on Tourism. EuroMed Journal of Business.

XIE J., TVETERÅS S. (2020), "Economic decline and the birth of a tourist nation", Scandinavian Journal of Hospitality and Tourism, vol. 20 n.1, pp. 49-67.

YANG H. Y., CHEN K.H. (2009), “A general equilibrium analysis of the economic impact of a tourism crisis: A case study of the SARS epidemic in Taiwan”, Journal of Policy Research in Tourism, Leisure and Events, Vol. 1 n. 1 , pp. 37-60.

\section{Appendix 1}

Questionannaire

Company name:

Organization size (number of employees):

Organization category:

Organization age:

To whom is your hotel generally targeted?

a) mostly couples with no childern

b) mostly families

c) mostly single

d) mostly seniors

e) mostly business man

f) mostly students

g) no specific target

Please select your level of agreements for the statements below referring to the practices of crisis management during/After Covid19

- Firing employees to reduce labor force Practice

strongly disagree

disagree

some how agree

agree

strongly agree

- Using unpaid vacation to reduce labor force Practice strongly disagree

disagree

some how agree

agree

strongly agree

- Decreasing number of working days per week Practice strongly disagree

disagree

some how agree

agree

strongly agree

- Freezing pay rates Practice

strongly disagree

disagree

some how agree

agree

strongly agree

- Replacing high-tenure employees with new employees Practice strongly disagree

disagree

some how agree

agree

strongly agree 
- Increased reliance on outsourcing

strongly disagree

disagree

some how agree

agree

strongly agree

- Marketing to domestic tourists in joint campaigns with local merchants (such as Visa, MasterCard) or local policy makers strongly disagree

disagree

some how agree

agree

strongly agree

- Marketing to domestic tourists with focus on specific attributes of the location strongly disagree

disagree

some how agree

agree

strongly agree

- Price drop on special offers

strongly disagree

disagree

some how agree

agree

strongly agree

- Reducing list price Practice

strongly disagree

disagree

some how agree

agree

strongly agree

- Marketing to foreign tourists with specific focus on the location's distinctive features and relative safety strongly disagree

disagree

some how agree

agree

strongly agree

- Marketing and promoting new products or services (family events, catering) strongly disagree

disagree

some how agree

agree

strongly agree

- Marketing to new segments

strongly disagree

disagree

some how agree

agree

strongly agree

- Cost cuts by limiting hotel services Practice strongly disagree

disagree

some how agree

agree

strongly agree

- Cost cuts by postponing maintenance of the building (cosmetics)

strongly disagree

disagree

some how agree

agree

strongly agree 
- Cost cuts by postponing maintenance to the engineering systems Practice strongly disagree disagree

some how agree agree

strongly agree

- Extending credit or postponing scheduled payments strongly disagree disagree

some how agree

agree

strongly agree

- Organized protest against the lack of government support strongly disagree

disagree

some how agree

agree

strongly agree

- Industry-wide demand for governmental assistance with current expenses strongly disagree

disagree

some how agree

agree

strongly agree

-Industry-wide demand for a grace period on tax payments strongly disagree

disagree

some how agree

agree

strongly agree

- Industry-wide demand for a grace period on local tax (municipality) payments

strongly disagree

disagree

some how agree

agree

strongly agree

- I have high accessibility to crisis management resources strongly disagree disagree

some how agree

agree

strongly agree

- The organisation has an adequate budget in its strategic plans in case of a crisis situation strongly disagree

disagree

some how agree

agree

strongly agree

- The organisation has an adequate crisis management plan strongly disagree

disagree

some how agree

agree

strongly agree

- I am well informed about the resources and tools allocated for crisis response strongly disagree

disagree

some how agree

agree

strongly agree 
The organisation views crisis management as a corporate goal strongly disagree disagree

some how agree

agree

strongly agree

- The members of the organisation are trained to handle a crisis situation strongly disagree

disagree

some how agree

agree

strongly agree

- The organisation will quickly recover after a crisis situation

strongly disagree

disagree

some how agree

agree

strongly agree

- The organisation rewards employees for their part in detecting and reporting potential crisis signs strongly disagree

disagree

some how agree

agree

strongly agree

- Key employees of the organisation are well informed about the resources and tools allocated for crisis response strongly disagree

disagree

some how agree

agree

strongly agree

- I am authorised to use the budget of the organisation in order to cope with a crisis strongly disagree

disagree

some how agree

agree

strongly agree

- The organisation's culture will encourage its ability to manage a crisis strongly disagree

disagree

some how agree

agree

strongly agree

- How could destination management organizations support the tourism industry?

- Do you think the 2019 tourism season can jump? Yes No

If no, in which month do you think it starts again?

- Do you think it will change the way you hotel do business? Yes No

If yes, how?

- Do you belong to some category associations? yes no

If yes, how do you think they can be supportive?

Your role in the organization:

Your age:

Your educational backgroud:

o Less than high school degree 
THE CHALLENGES OF COVID19 IN THE TOURISM INDUSTRY. THE CASE OF THE ITALIAN CONTEXT

o High school graduate (high school diploma or equivalent including GED)

o Some college but no degree

o Associate degree in college (2-year)

o Bachelor's degree in college (4-year)

o Master's degree

o Doctoral degree

o Professional degree $(J D, M D)$ 



\title{
The revival of corporate magazine in building stakeholder engagement
}

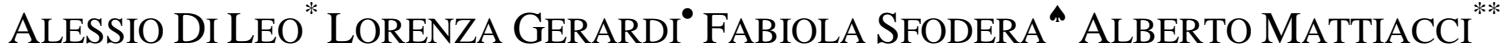

\begin{abstract}
Objectives. The recent explosion of competition and other issues on the market has upset the balance of companies and led to a crucial recognition: selling products or providing services it's no longer enough. Market exchange today lies on a fragile and contradictory ground: the offering blowup has eroded value offering, and the impact of digital on consumers' purchase intentions affected their indifference to advertising and gave them more empowerment (Füller et al., 2009; Spaid and Flint, 2014), "In this era of horizontal and inclusive power, the oversupply and the decline of confidence in traditional institutions - equal to 20,8\% according to Eurispes (2019) bring companies at the center of a big challenge: the stakeholder relations management and the creation of trust are new opportunities to create a competitive advantage (Harrison et al., 2010), "The missing value offered by companies can be found today in the settlement between society and business, rewinding the evidences of the Multi-Stakeholder Theory (Freeman, 1984) in a modern sustainable approach in order to maximize the value for both the company and its stakeholders. Corporate sustainability should be interpreted not as an additional constraint, but as a key factor for the company's attractiveness, to increase its competitive advantage over its competitors. From this perspective, corporate sustainability is a new model of corporate management and governance based on the satisfaction of stakeholders' expectations (Golinelli, 2000), "The pressure towards corporate sustainability has built a context in which companies grow in power and influence through the impact they have on society, through the creation of awareness of its activities and the promotion of its benefits for stakeholders (Carroll and Buchholtz, 2003).

According to Andriof et al. (2017), companies need to establish an interactive relationship with stakeholders, characterized by mutual involvement and oriented towards the creation of a common interest between business and society based on transparency and responsibility. The expression "Stakeholder Management" loses its worth, because it is stained with an enterprise-centric orientation that is outdated in light of the recent conceptualization of the enterprise-network. Within the most recent re-elaborations of the Stakeholder Theory, the focus of companies has therefore shifted from the identification of stakeholders to the relations entertained with them, which must be mutual and bidirectional. Stakeholder Marketing represents for companies a way of managing marketing that no longer looks to consumers as the only holders of a "stake", but considers the interests of the community, governments, groups, employees, institutions and society in general (Hillebrand et al., 2015).

The profound changes we are experiencing, together with the spread of the internet and, above all, social media, have changed the relationship of influence between businesses and their stakeholders, especially for consumers. While in the past companies communicated directly to consumers to change their preferences with a top-down approach, today consumers make demands on companies based on their values and it becomes crucial for companies to create new narrative opportunities in business storytelling (Pulizzi, 2012; Schaltegger and Wagner, 2011), "In fact, adopting socially responsible behaviour, responding to the economic, environmental and social expectations of creates an undoubted competitive advantage for companies. In fact, a product value is also given by its non-material characteristics, such as the origin of the components or raw materials, the assistance services and the working conditions of those who produced it (Choi and Ng, 2011), "This is why it is important for a company to communicate its values and information about the services and products provided and its overall approach to sustainability.

Communicating a coherent and precise corporate culture is an essential step for companies wishing to communicate with their stakeholders. After the massive proliferation of debates about social media ethics and responsibility, the corporate storytelling survives the decline of social media reliability by searching new opportunities in the corporate magazine revival (Carbonell et al., 2017), "According to the Edelman Trust Barometer (2018), about $60 \%$ of people worry about incorrect information and fake news on social media and trust more traditional media like
\end{abstract}

\footnotetext{
$\mathrm{PhD}$ Researcher in Marketing - Sapienza University of Rome - Italy e-mail: alessio.dileo@uniroma1.it

- Master's Degree in Marketing - Sapienza University of Rome - Italy e-mail: lorenzagerardi@hotmail.it

- Researcher in Marketing - Sapienza University of Rome - Italy e-mail: fabiola.sfodera@uniroma1.it

** Full Professor in Marketing - Sapienza University of Rome - Italy e-mail: alberto.mattiacci@uniroma1.it
} 
press. Despite their high penetration rates, social media tends to lack in-depth content consumption. The problems related to the media convergence may become useful to rethink digital channels as integrations of traditional media in a cross-media strategy (Hearn et al., 2009), “

Today, the use of corporate magazines is one of the most widespread value communication tools used by companies, both in print and digital format, to keep the stakeholders constantly informed about their activities and/or to promote their image to the target audience. The contents of corporate magazines concern the information that the company chooses to communicate inside and outside the organization, with the aim of stimulating conversation around the brand and generating involvement in its stakeholders, including, employees, shareholders, and suppliers.

This study aims at investigating the impact of the corporate magazine storytelling in the creation of shared value for different stakeholders and in the company positioning on the market. In fact, printed media is still a decisive factor for creating engagement and trust between the firm and its stakeholder, for building a dialogical and lasting relationship between the firm and its audience. Cross-channel storytelling, in this scenario, can deepen engagement and brings to light the usefulness of corporate magazines in the managing of corporate positioning and reputation (Vendelø, 2008). The research hypothesis is that there is a positive relationship between the publication of a corporate magazine and the improvement of the company's reputation and its relations with stakeholders.

Methodology. The research is still a "work-in-progress" but the preliminary results are encouraging to report the first evidence. Based on the study of the current research about the Multi-Stakeholder Approach and the creation of willingness (Cronin et al., 2008), authors created a series of three steps used for the analysis.

The first step focused on a comparative analysis of the companies ranked by '2019 Italy Reptrak Awards', and by the ASCAI project 'Edicola Imprese'. The matching of these two rankings allowed to identify companies with appropriate available data to define performance indicators regarding to their corporate magazine. The first report analyzed, '2019 Italy Reptrak Awards', is the largest study on the top companies with the best reputation in Italy. It is a sub-report of the Global RepTrak100, an annual study conducted by Reputation Institute, that study how stakeholders perceive companies and how those perceptions affect purchasing behavior. The reputation is measured based on an algorithm called the RepTrak Pulse, established by perceptions of Esteem, Admiration, Trust, and overall Feeling. It measures the public's perception of the world's top companies on the seven key rational dimensions of reputation: products and services, innovation, workplace, governance, citizenship, leadership and performance. The 2019 Italy Reptrak is based on the analysis of 388 companies from 15 industry sectors, with more than 40.000 total cases, whereof 150 companies have been awarded as "Most Reputable Companies in Italy". Then, these companies were matched with the ranking 'Edicola Imprese' ASCAI (Associazione per lo sviluppo della comunicazione aziendale in Italia), that groups the best editorial products published by Italian corporates in both printed and digital formats.

The two criteria used to select the sample are: (i) the corporate reputation management, and (ii) the editing of corporate magazine, based on their combined affiliation to 2019 Italy RepTrak and ASCAI Edicola Imprese. Based on these criteria, 9 company groups were included in the sample.

Then, in the second step, five variables were selected to analyze the communication behavior of the companies in the sample: (i) innovation and co-creation, (ii) corporate culture, (iii) governance, (iv) corporate social responsibility, (v) corporate magazine. For the 'corporate magazine' variable four sub-variables were defined: (i) longevity, (ii) format, (iii) periodicity, (iv) readers.

Afterwards, in the third step an in-depth study of the contents available on the websites of the companies were carried out to define the relation between the four main variables - innovation and co-creation, corporate culture, governance, corporate social responsibility - and the corporate magazine. The analysis led to the creation of three category of corporate magazine communication: (i) firm-centric corporate magazine, (ii) employers-centric corporate magazine, and (iii) society-centric corporate magazine.

Findings. A first screening of the sample shows that the 9 company groups included in the sample have an overall portfolio of 35 sub-brands and refer to 5 different sectors, with a prevalence of the banking-insurance sector (44\%) and the automotive sector (33\%), "The average turnover of the companies amounted to more than 135 billion in 2019.7 out of 9 companies are listed on the stock exchange and therefore subject to Consob (Italian Authority for the Supervision of Financial Markets) controls. All the companies in the sample publicly communicate data and reports on governance and sustainability on their official website.

Tab. 1: Sample of the study

\begin{tabular}{|c|c|c|c|}
\hline RANK REPTRACK & SCORE REPTRACK & COMPANY & CORPORATE MAGAZINE \\
\hline 26 & 76,03 & Piaggio \& C. spa & Wide Piaggio Group Magazine \\
\hline 49 & 73,42 & Pirelli & Fatti \& Notizie \\
\hline 106 & 67,63 & Gruppo Unipol & Changes \\
\hline 110 & 66,53 & Gruppo Intesa San Paolo & Mosaico \\
\hline 120 & 64,55 & Enel spa & E-magazine \\
\hline 123 & 63,55 & Poste Italiane & Lettera $\mathrm{P}$ \\
\hline 133 & 60,44 & Wind & Voice Up \\
\hline 149 & 42,31 & Autostrade per l'Italia spa & Autostrade Informa \\
\hline 150 & 35,28 & Gruppo Monte dei Paschi di Siena & Montepaschi News \\
\hline
\end{tabular}

Source: Author's elaboration 
A first screening of the investigation (see Table 2) shows that the majority of the sample was recently founded (from 2000 onwards), with 5 out of 9 magazines founded in the last decade and prove the recent trend of the corporate magazine as an integration of marketing strategy. 6 out of 9 corporate magazines are published both in paper and digital format, demonstrating that the corporate magazine online migration doesn't mean the paper format have been eliminated, but there is a co-presence of format. In some cases, the online and offline formats have different contents depending on the channel. The periodicity of the magazine differs according to the type of format: daily frequency for blog, once every two or three months in case of high value edition. The majority of these corporate magazines communicate with a small target: 4 out of 5 magazines have less than 10.000 readers. Looking at the 9 company groups in the sample (Table 2), only 3 use the corporate magazine to increase stakeholders' engagement to create dialogue with stakeholders on relevant topics like innovation and social issues.

Tab. 2: Corporate magazine analysis

\begin{tabular}{|c|c|c|c|c|}
\hline \multirow{2}{*}{ LONGEVITY } & High & Medium & Low & Tot \\
\hline & 2 & 2 & 5 & 9 \\
\hline \multirow{2}{*}{ FORMAT } & Paper & Digital & Paper and digital & Tot \\
\hline & 0 & 3 & 6 & 9 \\
\hline \multirow{2}{*}{ PERIODICITY } & Daily or weekly & Monthly & Bi-monthly & Tot \\
\hline & 3 & 2 & 4 & 9 \\
\hline \multirow{2}{*}{ READERS } & $>50.000$ & $51.000-100.000$ & $<100.000$ & Tot \\
\hline & 5 & 2 & 2 & 9 \\
\hline
\end{tabular}

Source: Author's elaboration

The results of the second step of the analysis are listed below.

The 'innovation \& co-creation' dimension refers to innovation strategies that include the stakeholders' participation to the process and outsourcing activities. One important finding was that only 5 company in the sample have a 'sustainability section on its corporate website. Around 44\% doesn't communicate about innovation strategies. The majority ( 5 out of 9 companies) uses innovation to anticipate customers' needs.

The 'corporate culture' dimension includes the strategies for the creation of a shared corporate culture, focused on employer's engagement. 8 out of 9 companies don't talk in their corporate websites about corporate culture and don't show the activities and events related to the employee engagement. The most relevant information released by companies in relation to their employees refers to total number and ethnic composition. 3 out of 9 companies affirm to create a belonging feeling in employers and tend to create an inclusive, open and flexible work environment. Data, however, do not confirm this assumption.

The 'governance' dimension focus on relation strategies with stakeholders, such as clients, suppliers, communities and commercial partners. Among the websites examined, every corporate presented: an annual corporate governance relation with its historic archive, an ethical code, a charter of values and self-regulatory code; and an internal auditing declaration. Companies show their commitment to transparency and inclusivity with regard to their organizational, management and control models. In their ethical codes, companies confirm their compliance with the rules and standards, rejection and condemnation of illegitimate behaviors, excellence research, market competitiveness and the respect for human resources. All the corporates talk about sustainable development with respect for future generations' rights; their sustainable plan is often focused on the GRI standards (Global Reporting Initiative), ISO 14001, ISO 37001, ISO/IEC 2700.

The 'corporate social responsibility' variable focus on the strategies to ensure the corporate social sustainability and to have a positive impact on the environment. The majority of the companies in the sample talks about corporate social responsibility in their websites. Around 66\% draws up a sustainability report or an ESG (Environmental, Social and Governance) integrate plan. In most cases CSR (Corporate Social Responsibility) refer to the environmental sustainability, and few companies include in their strategies economic and social projects. 2 out of 9 corporates declare their contribution to the Sustainable Development Goals and declare and show a full sustainability integration in their business.

Discussion and conclusion. Based on companies' behavior in the editing of a corporate magazine, the 9 company groups in the sample have been clustered into 3 different categories: (i) society-centric corporate magazine, (ii) employees-centric corporate magazine, and (iii) society-centric corporate magazine.

The first cluster includes companies that own a corporate magazine that is strictly business-oriented, i.e. the content focuses on facts, events and initiatives related to the company, through a top-down communicative approach. The corporate magazines examined and belonging to this cluster were not recently founded, and almost all of them experienced structural changes during the migration from offline to online. The changes, however, concerned multimedia elements (photos, videos, infographics) and social elements (sharing functions, blogs, likes, favorites) that were added to previous content. Only in one case, a company's digital transposition had an impact on the issues addressed and on the communication structure of the corporate magazine, which has become a constantly updated news magazine. The corporate magazines in this cluster seem to be intended for a very restricted audience of interlocutors and is difficult to find on the official websites of companies, which separate it in this way from their corporate communication strategy and limit it to a means of informing staff about company activities and news. 
The corporate magazines published by the companies belonging to the second cluster follow the model of the original corporate magazine, the employee magazine: these are internal corporate magazines, that deals with topics focused or written by employees. The contents within these corporate magazines cover, for example, employees' experiences outside the company, their passions, the artistic and cultural skills, and personal successes. These contents are part of sections such as 'Voice of colleagues', 'Colleagues report'. The magazine's availability also confirms an internal communication track. The corporate magazines analyzed are, in fact, available only on the intranet of the companies, with the exception of a single supplement reserved for an extranet that requires users to register in order to consult the magazine. The majority of the companies in the sample belongs to the banking-financial sector. To increase transparency for external stakeholders, banks probably prefer other forms of corporate communication. The combination of newsletters and corporate magazines within the companies in this cluster reveals little intention to engage in dialogue with stakeholders, of which only a small part - consisting of employees - is taken into account and addressed with a one-way communication and information approach. This type of relationship management is lacking, with respect to the remaining stakeholders who are precluded from. The totality of the sample migrated from offline to online in the early 2000s, with a consequent renewal of the graphic design of corporate magazines, but only one case out of three makes the new digital support and new multimedia content an innovative thematic organization.

The companies belonging to the third cluster use the corporate magazine as a tool for strengthening, deepening and conveying the corporate identity and values of the group, placing them in constant constructive discussion with readers. The corporate magazines therefore follow themes linked to the environment and society, whether in the technological, economic, environmental or willingness fields. The totality of the cluster declares that the objective of a corporate magazine's editorial staff is to build a corporate image that is as coherent and transparent as possible. These companies seem to have a long-term strategic vision. One corporate magazine out of three was in fact created at the encouragement of the Reputational \& Emerging Risk Observatory, a structured group monitoring of emerging and reputational risks with a strategic and proactive approach to future business opportunities. The interest in the reputational assets of these companies combines with the dialogical approach that emerges from all corporate magazines, aimed at overcoming the ineffective guise of news announcements to become authoritative magazines open to the external stakeholders.

All of the companies in the sample are featured in some of the most important reputation ranks (Italy RepTrak, TOP200 MedioBanca, TOP 15 Banks, TOP 15 Insurance players, Global RepTrak 100), and therefore integrate reputation management in their strategies as a driver of business. The companies in the third cluster are not significantly high-ranked compared to the others, so a low consideration of the reputation factor doesn't seem to be the answer to explain the data. A somewhat more realistic hypothesis could be the Italian industrial tradition: the corporate magazine has always been an internal communication tool, its role was the communication of the welfare, as in the case of the Olivetti Miracle. In Italian companies, corporate magazine remains rooted to its traditional information newsletter function, in a nostalgic and romanticized view of an in-house magazine.

In conclusion, a good communication of social responsibility practices in corporate media not only help to highlight what the company has done, but also helps stakeholders and other companies to understand the effort of the companies. Sharing contents nurtures an alignment of values and develops social practices that can be taken as examples and implemented more successfully and refined by others. At the same time, these communications allow stakeholders to better understand the company's values, thereby improving the corporate reputation. Obviously, to achieve these benefits, it is essential that the company communicate its results and actions correctly, and actively through its corporate channels.

Research limits. This study was based on a small sample that has prevent the findings from being extrapolated and generalizable. The main factor that affected the sample size was the choice to match 'Edicola Imprese' with '2019 Italy RepTrak': the first rank is an ASCAI project that explores every corporate magazine with in-depth data, but it brings together only a few of all the Italian corporate magazines. The analysis was challenging also because corporate magazine accessibility is often reserved to employers through the internal company intranet.

Practical implications. Multi-Stakeholder approach is essential for today's business to have a powerful purpose that looks beyond profit. Today, the majority of companies are aware of the value created through stakeholder engagement. Corporate have an impact on the environment, and it needs to find into the environment recognition and human capital. This research helps to understand the framing of the corporate magazine in the corporate communication strategy. The recent content marketing trend is considered in the study as one of the reasons of the corporate magazine revival.

Originality of the study. The study contributes to analyze how a product such as the corporate magazine, traditionally intended for internal communication - and aimed at creating cohesion and feelings of belonging through the employees - becomes in today's scenario part of a corporate communication strategy designed to manage stakeholders' engagement and corporate positioning in social activities. The research covers in its analysis the revival of corporate magazine, and the recent trend of fragmented information as new business opportunities for the corporate communication. Corporate magazines, in fact, help to communicate with company's stakeholder in order to highlight projects, actions and goals in macro issues that would concern the target audience. 
The press is still a good instrument for building stakeholders' trust and loyalty. Like radio and cinema, this media engages the audience completely and spoon-feeds the content with a little demand of interaction. Compared to other media like web and television, print offers its content in a permanent way, giving the reader more time to process the information and the opportunity to choose the best moment for reading by a careful and interested reader, a very specific target.

Key words: corporate magazine; stakeholder marketing; corporate communication; multi-stakeholder approach; stakeholder theory

\section{References}

ANDRIOF J., WADDOCK S., HUSTED B., RAHMAN S.S. (2017), Unfolding stakeholder thinking: theory, responsibility and engagement, Routledge.

CARBONELL J., SÁNCHEZ-ESGUEVILLAS A., CARRO B. (2017), "From data analysis to storytelling in scenario building. A semiotic approach to purpose-dependent writing of stories", Futures, vol. 88, n. 1, pp. 15-29.

CARROLL A., BUCHHOLTZ A. (2003), Business and Society: Ethics and Stakeholder Management, Cengage Learning, Stamford

CHOI S., NG A. (2011), "Environmental and economic dimensions of sustainability and price effects on consumer responses", Journal of Business Ethics, vol. 104, n. 2, pp. 269-282.

CRONIN P., RYAN F., COUGHLAN M. (2008), “Undertaking a literature review: a step-by-step approach", British journal of nursing, vol. 17, n. 1, pp. 38-43.

EDELMAN (2018), Trust Barometer. Chicago, Edelman.

EURISPES U.S. (2019), Rapporto Italia 2019. Roma.

FREEMAN R. (1984), Strategic Management: A Stakeholder Approach, Cambridge University Press, Cambridge

FÜLLER J., MÜHLBACHER H., MATZLER K., JAWECKI G. (2009), "Consumer empowerment through internetbased co-creation”, Journal of management information systems, vol. 26, n. 3, pp. 71-102.

GOLINELLI G.M. (2000), “L'approccio sistemico al governo dell'impresa, Cedam, Padova.

GREENITALY (2019), Una risposta alla crisi, una sfida per il futuro, Symbola

HARRISON J.S., BOSSE D.A., PHILLIPS R.A. (2010), "Managing for Stakeholders, Stakeholder Utility Functions and Competitive Advantage", Strategic Management Journal, vol. 31, n. 1, pp. 58-74

HEARN G., FOTH M., GRAY H. (2009), "Applications and implementations of new media in corporate communications", Corporate Communications: An International Journal. vol. 14, n. 1, pp. 49-61

HILLEBRAND B., DRIESSEN P.H., KOLL O. (2015), "Stakeholder marketing: Theoretical foundations and required capabilities", Journal of the Academy of Marketing Science, vol. 43, n. 4, pp. 411-428.

PULIZZI J. (2012), “The rise of storytelling as the new marketing”, Publishing research quarterly, vol. 28, n.2, pp. $116-123$.

REPUTATION INSTITUTE (2019), Italy RepTrak Awards 2019

SCHALTEGGER S., WAGNER M. (2011), "Sustainable entrepreneurship and sustainability innovation: categories and interactions", Business strategy and the environment, vol. 20, n. 4, pp. 222-237.

SPAID B.I., FLINT D.J. (2014), "The meaning of shopping experiences augmented by mobile internet devices", Journal of Marketing Theory and Practice, vol. 22, n. 1, pp. 73-90.

VENDELØ M.T. (1998), "Narrating corporate reputation: becoming legitimate through storytelling", International Studies of Management \& Organization, vol. 28, n.3, pp. 120-137. 



\title{
Business models and sustainable firms: A focus on B corps in Italy
}

\author{
EleONORA Di MARIA*VALENTINA DE MARCHI`AMBRA GALEAZZO^ELENA BONEL ${ }^{* *}$
}

\begin{abstract}
Objectives. An increasing number of companies are becoming aware of the need to combine economic goals with the achievement of social and environmental goals (Porter and Kramer, 2006). Research on sustainability in the business domain highlights the opportunities of integrating profit - within a shareholder perspective - with a more open approach, focused on the stakeholder view (Buysse and Verbeke, 2003). In particular, sustainability contribute to gain a competitive advantage (Orsato, 2006), where firms can benefit from an explicit strategic orientation that includes environmental and social objectives. Studies on the Triple Bottom Line (Elkington, 1997) pointed out the advantages but also the challenges - in combining multiple strategic goals.

This strategic path can be enabled through business model innovation, whereby value production and distribution are characterized by distinctive features (Geissdoerfer et al., 2018). Growing literature on business model innovation connected to sustainability (Bocken et al., 2014; Bocken and Geradts, 2020) shows the variety of business models that might be adopted as well as the different drivers of value creation and value appropriation (Evans et al., 2017). Sustainable-oriented firms may develop business model innovations in order to achieve sustainability, putting different emphasis on the environmental and social perspectives, thus leading to different performance results (Ritala et al., 2018).

Leveraging hybrid organizational forms (Doherty et al., 2014), companies change their strategies by transforming their internal processes and products based on a sustainability perspective. Hybrid organizations emerge (Haigh and Hoffman, 2012) as new organizational forms that take into account the variety of goals and domains of actions with respect to traditional organizations. Such organizations include social and environmental changes as objectives, within a framework of constant interaction with stakeholders as well as with the market, competitors, and industry institutions. It is specifically because of this combination of purposes that those firms are competing differently from wellestablished businesses, dealing also with the consequences of managing this apparent paradox of corporate sustainability (Hahn et al., 2017).

In this scenario, B Corps are emerging (Stubbs, 2017) - a movement originated in the United States, then spread internationally - which represent business models formalizing sustainability investments through voluntary certification processes, thus increasing visibility to social entrepreneurship. As hybrid organizations, these firms have been recognized by some scholars as having a role of public nature, since their activities are geared to the achievement of goals that go beyond mere entrepreneurial interests (Vaughan and Arsneault, 2018).

In the European context, Italy is the second country after the United Kingdom in terms of number of B Corp enterprises, consistently with entrepreneurial dynamics that have shown - especially in the small business realm - the attention towards social and territorial context. Past studies show that cohesive Italian companies are better able to face changes in competitive scenario, thanks to a strong focus on their internal (employees) and external (local community) social context. There is a new geography of value in which the different forms of organization between profit and non-profit are directed at producing shared value (Sturabotti, Venturi, 2016). It appears to be relevant in research, to pursue a better understanding of how companies get started on this journey, the transformations it entails at strategic level, and the impacts at the organizational and networking ones, as well as the role of human resources.

An increasing number of firms strives to simultaneously achieve economic, social and environmental objectives (Triple Bottom Line) (Elkington, 2013). Companies decide to craft their strategies so as to transform environmental and social constraints into new sources of competitive advantage, thus improving their market reputation and transforming their offer and business models, as well as their cost structure.
\end{abstract}

Full professor of Management - University of Padova - Italy e-mail: eleonora.dimaria@unipd.it

- Associate professor of Management - University of Padova - Italy e-mail: valentina.demarchi@unipd.it

- Post-doc research fellow in Management - University of Padova - Italy e-mail: ambra.galeazzo@unipd.it

** Assistant Professor of Management - University of Padova - Italy e-mail: elena.bonel@unipd.it

Sinergie-SIMA 2020 Conference

Grand challenges: companies and universities working for a better society 7-8 September 2020 - University of Pisa-Sant'Anna School of Advanced Studies Pisa (Italy) - Online Conference
Electronic Conference Proceedings ISBN 97888943937-6-7

DOI 10.7433/SRECP.EA.2020.01 
In particular, literature on business models (BM) for sustainability focuses on redesigning BMs so as to enable the company to gain economic value by delivering social and environmental value to a wider group of stakeholders (Schaltegger et al., 2012). Such move to a more sustainable model requires significant changes in business goals, not only in terms of specific processes and products that could be innovated to close the loop or improve energy efficiency, but rather more broadly, on every aspect of how the business is run.

Three groups of sustainable business models can be identified (Ritala et al., 2018): environmental, social and economic ones. An environment-oriented BM focuses specifically on the management of resources within the company and its value chain, with the aim of promoting environmental sustainability (also in terms of circular economy), which implies profound changes in how companies deal with product development, supply chain management and production processes. Socially oriented BM groups have focused on the impact of business activities on the social dimension, by changing the behavior of consumers and society at large through an innovative value proposition, as well as by pushing customers' commitment to innovation and new consumption habits. The economic dimension of BMs purports the inclusion of both dimensions of sustainability (social and environmental) in the company's economic goals (profitability), but through an economic logic: how value is produced and how the organization is structured to incorporate in its own internal processes a wider set of actors, and their respective goals.

Each of these sustainable BMs create value in different ways, giving relatively more or less importance to the economic, social or environmental dimensions (Lüdeke-Freund et al., 2018). From this point of view, the relationship between the characteristics of the BMs and the results achieved is important and deserves further attention, specifically in the context of hybrid organizations.

One type of business where there is an explicit focus on sustainability is represented by the B Corp model (Stubbs, 2017; Waddock and McIntosh, 2011). B Corps are firms that voluntary invest in certifying their strategic orientation toward sustainability as part of their mission and strategic behavior. B Corp can be understood as hybrid organizational forms, because of their role in promoting shared objectives and public benefits (André, 2015). These companies are committed to formalizing and measuring the simultaneous achievement of the Triple Bottom Line. They therefore represent a new way of doing business, where the top management is committed to a multiplicity of stakeholders, in order to achieve social and environmental sustainability goals through its business (which nonetheless remains profit-oriented).

Though literature on B Corps is attracting greater attention, it is unclear how the paths adopted by B Corps and the results they achieved differ from the multiple paths of sustainable business model innovation described in the literature (Evans et al., 2017b; Ritala et al., 2018; Wilburn and Wilburn, 2015). Moreover, in this theoretical debate further attention has to be devoted to explicitly address the networking dimension within the strategic behavior of $B$ Corps. Studies on sustainability and innovation, as well as on circular economy more recently, highlight the relevance of collaboration in supporting sustainable outcomes and innovation results (Brown et al., 2019; De Marchi, 2012). Since B Corps also emerge as an international movement gathering firms "with a purpose" (Bauer and Umlas, 2017), this issue should be considered when examining how B Corps behave and what results they achieved. More specifically our research questions are as follows: What are the BMs adopted by these companies? What are the motivations for such a formalization process towards sustainability, its implications in terms of the needed resources, and the collaboration network to leverage on? What are the results?

Answering these questions can provide a better understanding of these companies' developmental path, and of the factors on which to leverage at institutional and territorial level, so as to support the conversion processes of an entrepreneurial system in terms of sustainability.

Methodology. Having these aims in mind, a research was carried out between October 2018 and January 2019 within the project MOBIS (New Business and Social Impact Assessment: sustainability pathways for SMEs) funded by the Veneto Region in Italy. The sample consists of 167 Italian companies, either certified B Corps (BC) and/or Società Benefit (SB). The former are companies certified by the non-profit company B Lab, as they achieved a high standard in social and environmental performance; the latter are a new corporate form introduced in the Italian legislation in 2016 and similar to the US-model of Benefit Corporation, whereby elements of sustainability impinging on governance commitments are included in the firm's statute and corporate purpose statement. BC and SB in the Italian context are tightly linked due to the transformation of voluntary certified B Corps into SB. For simplicity, the sampled firms of both kinds will henceforth be termed B Corps (BCS).

It was sent an email to the top management of Italian B Corps asking them to fill out an online survey (CAWI). The survey included questions regarding the company's characteristics, business model and measurement of the economic, environmental and social impact resulting from acquiring a B Corp status. 47 BC companies completed the survey in full (specifically, respondents comprised 17 B Corps, 15 companies that are both a B Corp and a SB, and 15 $S B s)$. These firms are mainly non-family owned (70.2\%), they are not part of a business group (75.1\%), they have at least one woman among top managers (66\%), and a quarter has a structured R\&D department (25.5\%). In terms of performance, most of the companies in the sample claim to have improved return on investment (ROI) (51.1\%) and market share (51.1\%) over the last three years. Almost half (44.7\%) have hired new staff, increasing the company size over the last three years. In terms of geographical location, 78.7\% of the B Corp and SB are located in the North of Italy, $12.8 \%$ in the Centre and $8.5 \%$ in the South. 
Findings. We will examine the motivations to become BCs and the three main changes faced by BCs: changes in the business model; organizational change and implications concerning collaborative relationships with stakeholders outside the company and, finally, changes in human resources management.

Referring to the reasons driving these companies to become BCs, survey results indicate that, among the most recurrent motivations, $62.2 \%$ of the firms in the sample aim at being part of an international network of companies, $59.6 \%$ want to do business by assuming an ethical stance, and $44.7 \%$ want to improve the company's trust and reputation among their stakeholders. These data suggest that certification or change of legal status are legitimate tools for stakeholders, that allow a company to focus not only on maximizing profits, but also on supporting social policies and environmental protection. They also point out the relational significance of achieving a BC status, as can be inferred by the top five motivations quoted in the sample, which are all leveraging on social-relational issues (Table 1).

Tab. 1: Top motivations quoted in the sample for becoming a BC. Firms could pick any top three from the list

\begin{tabular}{|l|c|}
\hline Top motivations quoted for becoming a BC & \% \\
\hline Become part of an international network of companies belonging to a global movement & 62.2 \\
\hline Manage the firm with an ethical attitude & 59.6 \\
\hline Improve stakeholders' trust and company's reputation & 44.7 \\
\hline Stimulate innovation and innovative practices in the field & 40.4 \\
\hline Respond to stakeholders' expectations as related to sustainability & 19.1 \\
\hline Attract and keep more productive and motivated personnel & 10.6 \\
\hline Generate more profits & 8.5 \\
\hline Enter new markets & 8.5 \\
\hline Attract investments or obtain tax incentives and contributions & 8.5 \\
\hline Reduce costs & 6.4 \\
\hline Improve product quality & 4.3 \\
\hline Manage risk, immaterial activities and processes & 4.3 \\
\hline Alignment with existing regulations & 4.3 \\
\hline Improve relationships with NGOs & 0.0 \\
\hline
\end{tabular}

Source: Our elaboration.

Referring to changes in the business model, companies were asked to report what the objectives of their business model were after transitioning to BC status, providing a maximum of three preferences. Most companies (51.1\%) claim they have developed new consulting services supporting the spread of sustainable models on a large scale, so as to maximize the benefits of sustainability (e.g. sustainability incubators and crowd-sourcing platforms focused on sustainable initiatives). $38.3 \%$ of the companies report to have converted the company structure in order to achieve social and environmental objectives, $31.9 \%$ assumed a coordinating role within the supply chain towards sustainability. These are all BMs oriented to the economic realm. On the other hand, other adopted business models were environmental-oriented: $25.5 \%$ have encouraged sustainable consumption, aiming at product durability and longevity to reduce replacement cycles changes towards clean energy and processes (14.9\%), maximizing materials' productivity and energy efficiency (14.9\%), providing a combination of products and services that allow the customer to use but not necessarily physically possess the product (e.g. car sharing) (10.5\%) and value creation from waste (circular economyreuse; recycling; reprocessing) (8.5\%) (Fig. 1). It appears relevant here to point out that if $63 \%$ of respondents have taken up some form of BM that is environmentally-oriented, at the same time, a staggering $83 \%$ has seen a change in their economic orientation too, by assuming the status of change agent and sustainability leader among their peers in the industry, thus marking the importance that BCs have at the systemic level in spreading the logic and practicalities of social and environmental responsibility.

Fig. 1: Main foundations of Business Model for new BCs (3 choices per respondent possible)

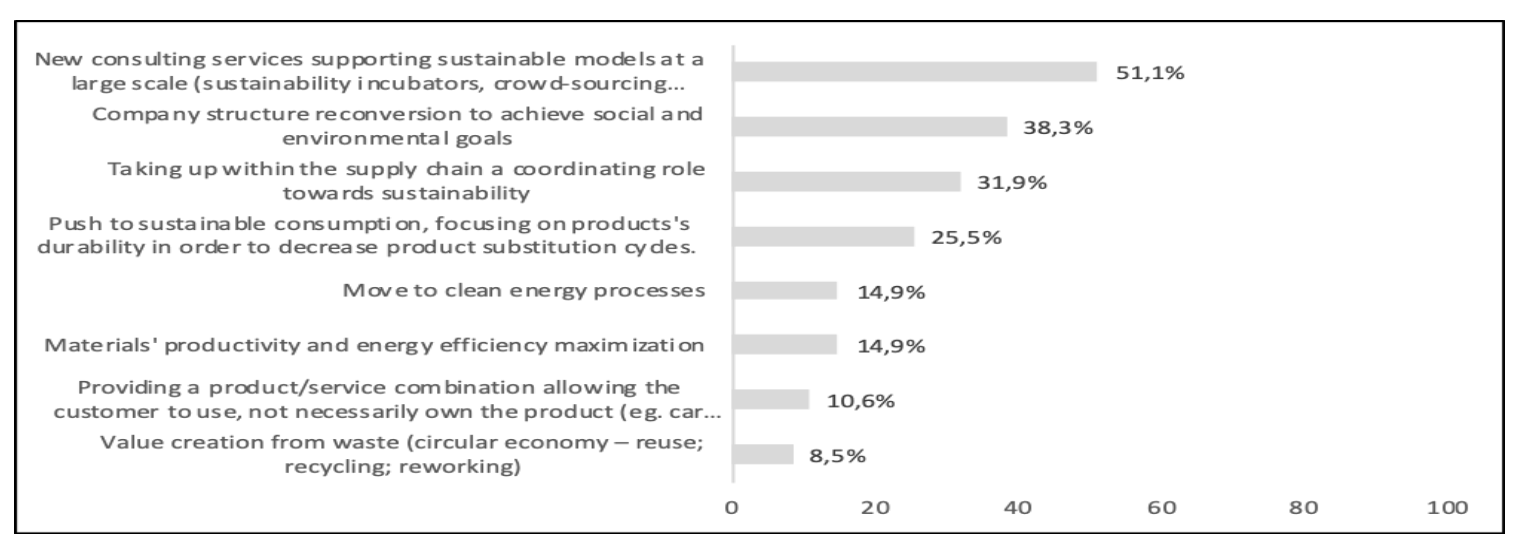

Source: our elaboration 
Referring to organizational changes, companies were asked to indicate on a seven-point Likert scale $(1=$ not at all, $7=$ extremely) the main changes implemented in the processes related to production and value in order to become a BC. Figure 2 outlines the set of possible changes that received a score of at least $5(5=v e r y, 6=v e r y ~ m u c h, 7=e x t r e m e l y)$ by respondents. Survey results show that BCs were mainly engaged in modifying marketing and commercial practices (19.2\%), information processes (collection/elaboration of internal information) (17\%), and substituting the existing suppliers with sustainable ones, or in adapting the existing ones to the business demands of sustainability (14.9\%). A more radical change, such as the transformation of the source and mode of revenue generation has affected about $10 \%$ of the sample. Less important changes related to the cost structure (8.5\%), customer relations (8.5\%), the endowment of technological instruments (digital technologies) (8.5\%), customers and/or market segments (6.4\%) and management of the post-sales service (4.3\%). Finally, in rare cases, companies were affected by changes in the production process (2.1\%), the development of new products $(2.1 \%)$ and logistics and distribution channels (2.1\%), which suggests that products are not subject to change, except in the choice of the materials with which they are manufactured (Fig. 2).

Fig. 2: Changes implemented in processes to become B Corps

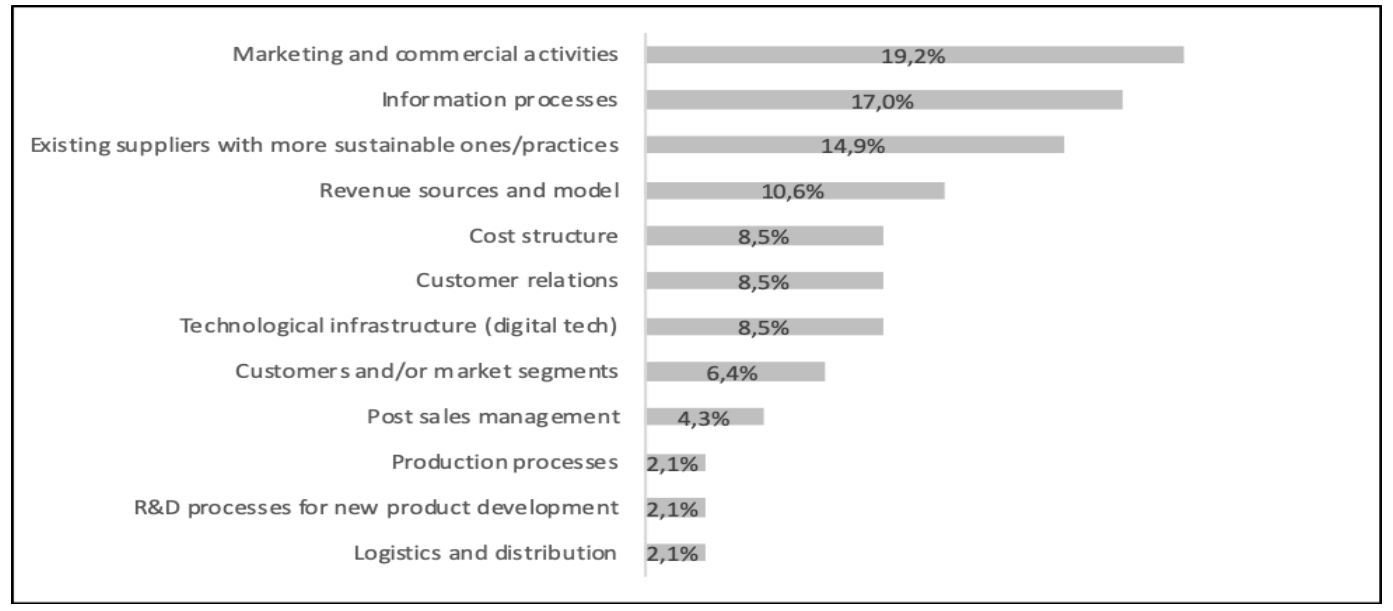

Source: our elaboration

With regard to the collaboration with stakeholders outside the company, the survey shows that, in the certification process, BCs mainly encountered difficulties in finding the information required (too time-consuming and costintensive) (38.3\%) and in interpreting and compiling the B Impact Assessment (BIA) (36.2\%), considering the fact that certification has little relevance in the target market of these companies (31.9\%) (Table 2).

Tab. 2: Main difficulties encountered in the B Corp certification process

\begin{tabular}{|l|c|}
\hline $\begin{array}{l}\text { Main difficulties encountered in becoming a certified B Corp } \\
\text { (multiple answers allowed) }\end{array}$ & $\%$ \\
\hline Information collection for the BIA (B Impact Assessment) is very costly and time consuming & 38.3 \\
\hline The BIA (B Impact Assessment) is too detailed and difficult to understand, completion takes too long & 36.2 \\
\hline Certification has little relevance in our market & 31.9 \\
\hline Lack of internal skills in carrying out the BIA (B Impact Assessment) & 17.0 \\
\hline Difficulties related to supply process/finding adequate suppliers & 12.8 \\
\hline Difficulty in individuating adequate distribution channels & 6.4 \\
\hline Inadequate information system & 6.4 \\
\hline Difficulty in finding skilled personnel & 2.1 \\
\hline
\end{tabular}

Source: Our elaboration.

It should also be noted that the main issues for gaining a certification are mostly process-related, as $74.5 \%$ of respondents found the BIA difficult to complete (either because too lengthy or costly), taking into consideration that only $17 \%$ of respondents maintained they lacked the skills to perform the assessment (Table 2). This points to the need of support in the certifying process as survey results show that firms search for collaboration with other BCs the B Lab and/or consultants (see Figure 3 below). The process knowledge acquired through the certification is in turn one that is applied to the supply chain, as BCs tend to become advisors to other firms, as well as change and facilitating agents within their supply chain (see Figure 1).

Since the certification is renewed every two years, and since certified BCs can be randomly picked for a yearly inspection by B Lab - the certification body, it can be inferred that a certified B Corp must necessarily structure itself so as to have dedicated personnel for such activities, and so that the necessary flow of information concerning certification is transparent and easy to retrieve. 
For what concerns the implications of collaborations with non-business stakeholders to become a BC, the sample showed the marked relevance of peer groups and focal points of reference along the transformation process, as $60 \%$ of respondents assigned a Likert score of 6 and 7 (very and extremely high) to the degree of collaboration with other transitioning companies and with the certifying body, where relevant. In particular, companies extensively collaborated with B Lab (34\%), other companies certified as B Corps (25.5\%), as well as with specialized consultants (23.4\%). Collaborations with non-profit organizations (10.6\%), certification bodies (6.4\%), universities and research centers (6.4\%), materials' suppliers (6.4\%), government agencies (4.3\%), machinery/technology suppliers (4.3\%) were less important (Fig. 3).

Fig. 3: Collaborations the BC resorted to during the new status acquisition process

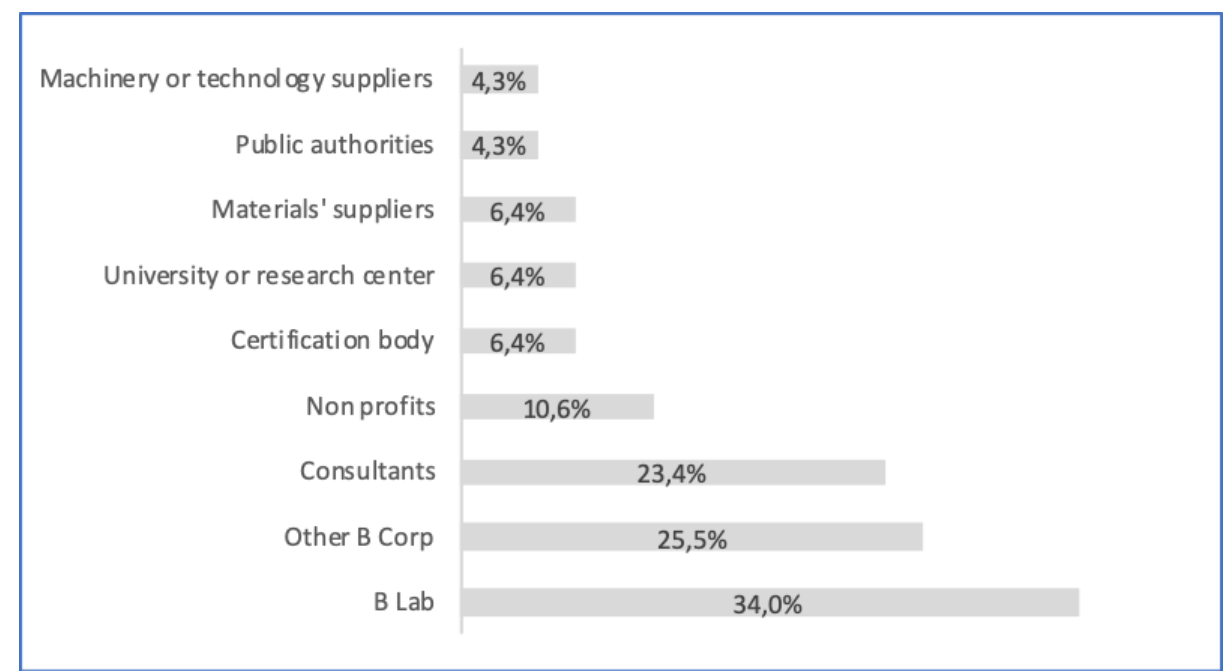

Source: our elaboration.

Another aspect of organizational change concerns the communication of the new B Corp status. The survey shows that companies consider it very important to communicate these milestones mainly to employees (57.5\%), client/consumers (55.3\%), shareholders/shareholders (51.1\%) and other trading partners (46.8\%) (Figure 4). This involves a change in the marketing function, which must find different ways and tools to enhance communication, focusing not only on products and services, but also on the economic, social and environmental benefits of a BC status, as also emerges from Figure 2.

Fig. 4: Importance of communicating new BC status to different stakeholders, least to most important

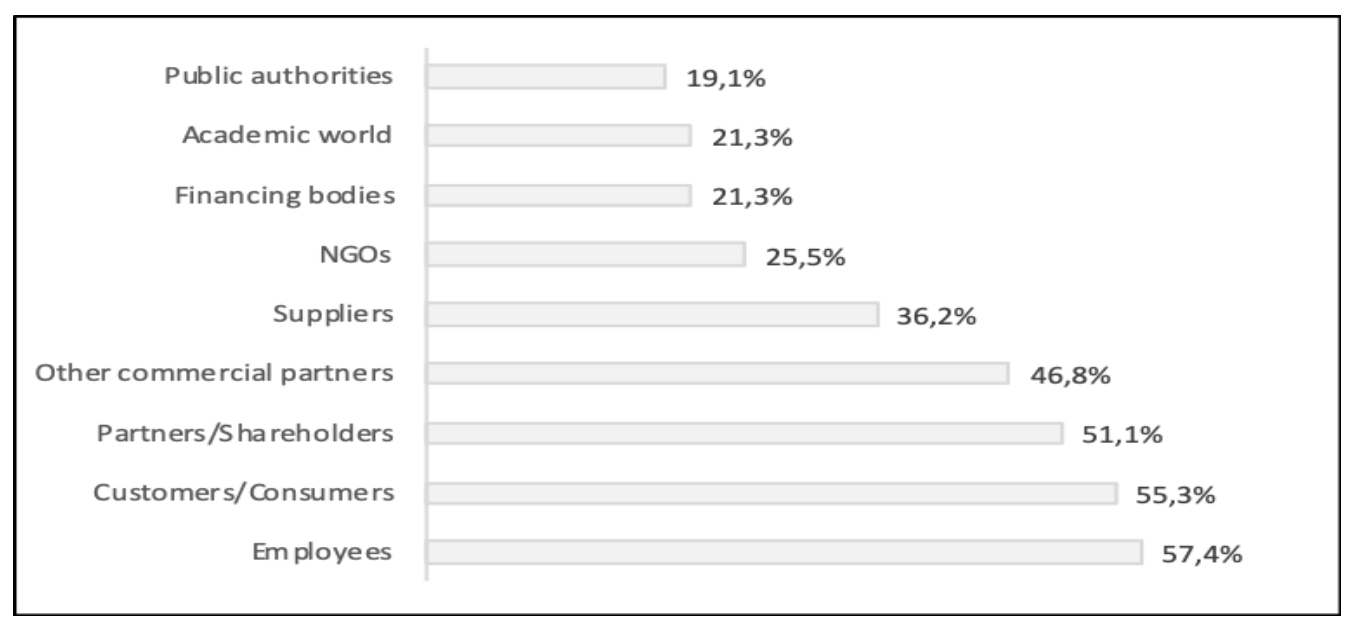

Source: our elaboration

Changes in HRM practices after attaining BC status are quite relevant since, as pointed out above, about $58 \%$ of companies consider it relevant (reporting a Likert value of $6=$ very much or $7=$ extremely) to communicate the transition to their employees (Figure 4). These data show that employees' buy-in is fundamental in the management of an ethically focused company. Customers and shareholders come next as the most relevant parties to inform, whereas public authorities and financing bodies rank lower, highlighting the fact that becoming a BC is a goal not necessarily related to accruing fiscal/regulatory of financing benefits, as already pointed out above (see Table 1). 
Figure 5 also shows how employees are not passive to the process - simply taking note of the communication - but rather are actively involved in it. In fact, $19.5 \%$ of companies consider it very important (scoring values greater than or equal to 5 on a scale of 1 to 7) to update the skillset of their employees with administrative and management functions, $8.5 \%$ consider it very important to update the skills of technical employees, $6.4 \%$ intend to acquire related new professional and administrative/management figures and, finally, only $2.1 \%$ intend to acquire new technical figures. These results suggest that BCs mainly need human resources with management and administrative soft skills, rather than technical skills (Figure 5).

Fig. 5: Relevant buckets of HRM investments to acquire a BC status (\%).

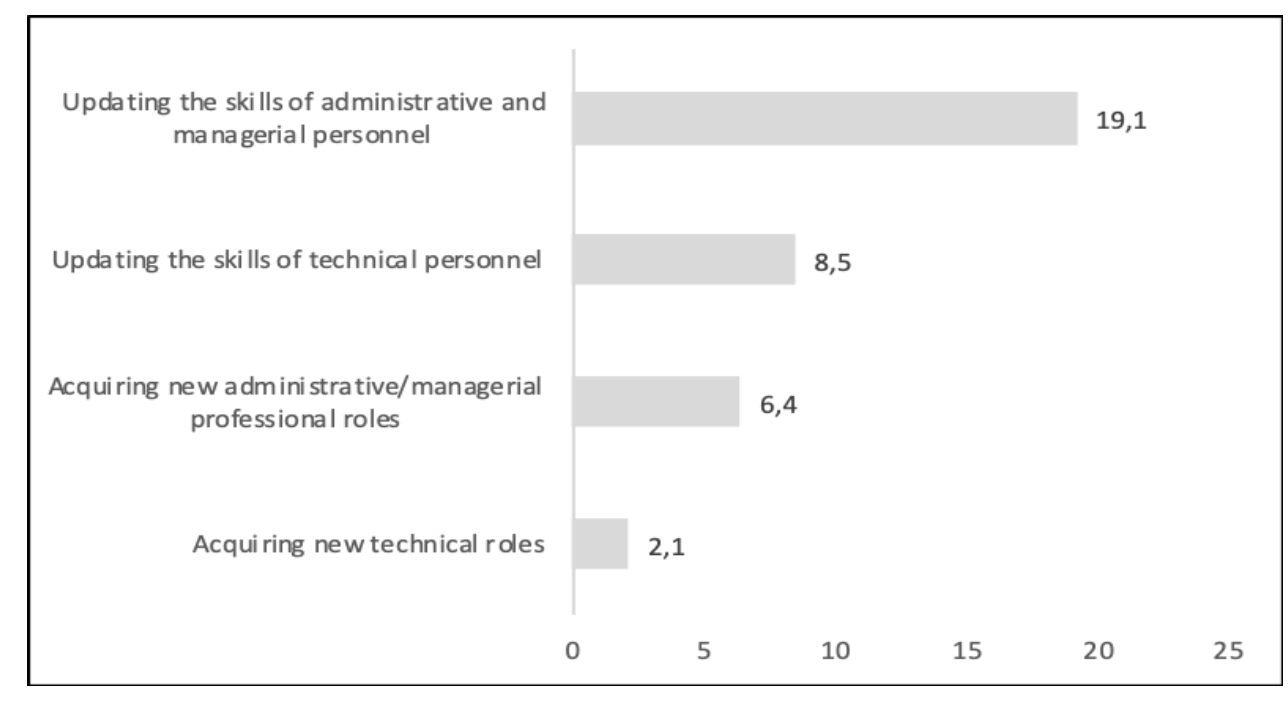

Source: our elaboration

Our research shows the variety of business models adopted by B Corps, contributing to the flourishing literature on sustainability business models (Schaltegger et al., 2012; Ritala et al., 2018), but also the leading role that B Corps perceive to have within their value chain and, in general, the other economic actors they are connected with. This result is supported by the relevance of networking as part of the B Corp behavior, in order to develop sustainable business models and to support the transition to a more formalized approach toward sustainability, in line evidence of contribution focusing on resources that firms need to become 'greener' (e.g., Cainelli et al., 2015).

Companies involved in this certification process transform marketing activities, information processes and supply chain relations, focusing on the fundamental involvement of employees. They are motivated by ethical and networking factors. A key element that emerges from our study is communication, in order to transfer the strategic orientation of $B$ Corp toward the market, but also as a means to involve customers and to legitimate a different value proposition and value creation.

The process of becoming a B Corp needs to be rolled out at multiple levels within a firm, and its partners network. The research points out that managing the certification process requires a change in HRM and marketing policies within the firm. On the one hand, firms mainly reinforce their internal skills (more than acquiring new human resources) in order to cope with the administrative and informative efforts connected with certification. On the other hand, B Corps have extensively changed their internal processes - with attention on marketing and commercial activities - to align strategic goals, market opportunities, and certification requirements.

Research limits. The paper presents a preliminary research encompassing a small sample of top management respondents. More research is needed to achieve a greater response rate. Future research should expand the analysis at the international level, by evaluating similarities and differences in business models of B Corps, given country characteristics might facilitate or hinder firms effort (see e.g., Alonso-Martínez et al., 2019). Additional research could also deepen the analysis by industry in order to evaluate how B Corps in different industrial contexts compete and adopt (different) business models.

Practical implications. From a managerial point of view, our study highlights the relevance of approaching sustainability within the B Corp framework by involving human resources as key actors in achieving firm aims, but also as target of the sustainability effort of the B Corp. Together with employees, also external stakeholders are important, but specifically other firms that have followed the same path of certification. In addition to B Lab, investing in networking could lead firms to overcome the challenges of the certification process, through knowledge exchange with other firms involved in the B Corp community. Firms who want to benefit from being a B Corp has to be prepared in terms of transparency and accountability of the internal processes. For policy makers, results point out how involved firm need consistent information flows and contacts with both the organizations for certification (B Lab), and with other 
firms undergoing the same process. This paper also contributes in terms of the empirical setting that was selected, since Italy is a leading country in the spread of B Corps in Europe.

Originality of the study. The paper enriches theoretical debate on sustainable business model innovation and on B Corps, by shedding new light on how firms can approach economic, social and environmental sustainability, contributing to the lines opened up by Stubbs (2017) and Waddock and McIntosh (2011) among others. Moreover, the paper stresses also the challenges in becoming a B Corps and the investments in terms of networking and human resource management to be implemented for sustainability.

Key words: business models, sustainability, B Corp, strategy, social impact

Funding: This work was supported by Veneto Region POR F.S.E. 2014-2020. Code: 4285-1-1267-2017.

\section{References}

ALONSO-MARTÍNEZ D., DE MARCHI V., DI MARIA E. (2019) Which country characteristics support corporate social performance? Sustainable Development

ANDRÉ R. (2015), "Benefit corporations at a crossroads: As lawyers weigh in, companies weigh their options", Business Horizons, vol. 58, n. 3, pp. 243-252.

BAUER J., UMLAS E. (2017), "Making Corporations Responsible: The Parallel Tracks of the B Corp Movement and the Business and Human Rights Movement", Business and Society Review, vol. 122, n. 3, pp. 285-325.

BOCKEN N.M.P., GERADTS T. (2020), "Barriers and Drivers to Sustainable Business Model Innovation: Organization Design and Dynamic Capabilities", Long Range Planning, in press.

BOCKEN N.M.P., SHORT S.W., RANA P., EVANS S. (2014), "A literature and practice review to develop sustainable business model archetypes", Journal of Cleaner Production, vol. 65, pp. 42-56.

BROWN P., BOCKEN N., BALKENENDE R. (2019), "Why Do Companies Pursue Collaborative Circular Oriented Innovation ?", Sustainability, vol. 11 n. 2, pp. 1-23.

BUYSSE K., VERBEKE A. (2003), "Proactive environmental strategies: A stakeholder management perspective", Strategic Management Journal, vol. 24, n. 5, pp. 453-470.

CAINELli G., DE MARCHI V., GRANDINETTI R. (2015) Does the development of environmental innovation require different resources? Evidence from Spanish manufacturing firms. Journal of Cleaner Production, vol. 94, pp. 211-220.

DE MARCHI V. (2012), "Environmental innovation and R\&D cooperation: Empirical evidence from Spanish manufacturing firms", Research Policy, vol. 41, n. 3, pp. 614-623.

DOHERTY B., HAUGH H., LYON F. (2014), "Social enterprises as hybrid organizations: A review and research agenda", International Journal of Management Reviews, vol. 16, n. 4, pp. 417-436.

ELKINGTON J. (1997), Cannibals with Forks. The Triple Bottom Line of 21 st Century Business, John Wiley \& Sons, Ltd., available at:https://doi.org/0865713928.

ELKINGTON J. (2013), "Enter the triple bottom line”, pp. 1-16, in Henriques A., Richardson J., The Triple Bottom Line: Does it All Add Up, Routledge, London.

EVANS S., VLADIMIROVA D., HOLGADO M., VAN FOSSEN K., YANG M., SILVA E.A., BARLOW C.Y. (2017), "Business Model Innovation for Sustainability: Towards a Unified Perspective for Creation of Sustainable Business Models", Business Strategy and the Environment, vol. 26, n. 5, pp. 597-608.

GEISSDOERFER M., VLADIMIROVA D., EVANS S. (2018), "Sustainable business model innovation : A review", Journal of Cleaner Production, vol. 198, pp. 401-416.

HAHN T., FIGGE F., PINKSE J., PREUSS L. (2018), "A Paradox Perspective on Corporate Sustainability: Descriptive, Instrumental, and Normative Aspects", Journal of Business Ethics, vol. 148, n. 2, pp. 235-248.

HAIGH N., HOFFMAN A.J. (2012), "Hybrid organizations. The next chapter of sustainable business.", Organizational Dynamics, vol. 41, n. 2, pp. 126-134.

LÜDEKE-FREUND F., CARROUX S., JOYCE A., MASSA L., BREUER H. (2018), “The sustainable business model pattern taxonomy-45 patterns to support sustainability-oriented business model innovation", Sustainable Production and Consumption, vol. 15, pp. 145-162.

ORSATO R.J. (2006), “Competitive Environmental Strategies”:, California Management Review, vol. 48, n. 2, pp. 127143.

PORTER M.E., KRAMER M.R. (2006), "Strategy and society: the link between competitive advantage and corporate social responsibility", Harvard Business Review, vol. 84, n. 12, pp. 78-92.

RITALA P., HUOTARI P., BOCKEN N., ALBAREDA L., PUUMALAINEN K. (2018), "Sustainable business model adoption among S\&P 500 firms: A longitudinal content analysis study", Journal of Cleaner Production, vol. 170, pp. 216-226.

RITALA P., HUOTARI P., BOCKEN N., ALBAREDA L., PUUMALAINEN K., (2018), “Sustainable business model adoption among S\&P 500 firms: A longitudinal content analysis study", Journal of Cleaner Production, vol. 170,pp. 216-226. 
SCHALTEGGER S., FREUND F.L., HANSEN E.G., (2012), "Business cases for sustainability: the role of business model innovation for corporate sustainability", International Journal of Innovation and Sustainable Development, vol. 6, n. 2. http://doi.org/10.1504/IJISD.2012.046944

STUBBS W. (2017), "Sustainable Entrepreneurship and B Corps", Business Strategy and the Environment, vol. 26, n. 3 , pp. 331-344.

STUBBS W. (2017), "Characterising B Corps as a sustainable business model: An exploratory study of B Corps in Australia”, Journal of Cleaner Production, vol. 144, pp. 299-312.

STURABOTTI D., VENTURI P. (2016), "Nuove geografie del valore e imprese cohesive", Impresa Sociale, vol. 7, ottobre, pp. 5-13.

VAUGHAN S.K., ARSNEAUlT S. (2018), "The Public Benefit of Benefit Corporations", PS - Political Science and Politics, vol. 51, n. 1, pp. 54-60.

WADDOCK S., MCINTOSH M. (2011), "Business unusual: Corporate responsibility in a 2.0 World", Business and Society Review, vol. 116, n. 3, pp. 303-330.

WILBURN K., WILBURN R. (2015), "Evaluating CSR accomplishments of founding certified B Corps", Journal of Global Responsibility, vol. 6, n. 2, pp. 262-280. 


\title{
Initial coin offering (ICO): il ruolo dei contenuti linguistici del white paper
}

\author{
GUIDO Di MATTEO ${ }^{\circ}$ FrANCESCA MASCIARELLI ${ }^{*}$
}

\begin{abstract}
Obiettivi. Startup e investitori privati stanno dimostrando un crescente interesse per forme innovative di raccolta fondi.

ICO è l'abbreviazione di Initial Coin Offering, e rappresenta un'innovazione nel campo della finanza imprenditoriale (Fish, 2019; Block, Colombo et al., 2018).

Il modo più semplice per definire una ICO è che può essere considerata una attività di finanziamento che consente ai progetti online e alle startup di raccogliere i fondi necessari con il sostegno di venture capitalists.

La definizione include molte somiglianze con la nozione di campagna di crowdfunding: con il crowdfunding, un imprenditore raccoglie finanziamenti esterni da un vasto pubblico (la "folla"), in cui ogni individuo fornisce una quantità molto piccola, invece di sollecitare un piccolo gruppo di investitori "sofisticati" (Belleflamme, Lambert, \& Schwienbacher, 2014).
\end{abstract}

Le Initial Coin Offering come accade per un crowdfund, di solito si svolgono nelle prime fasi di un progetto a contenuto tecnologico. La differenza è che spesso un crowdfund è una donazione, mentre una ICO è costituita da investitori che desiderano vedere un profitto sugli investimenti. Alcuni accademici definiscono le ICO come "Crowd Sales" distinguendole in questo modo dal crowdfunding.

Allo stesso tempo, come suggerisce il nome, un'offerta iniziale di moneta è il processo mediante il quale una società vende le sue azioni al pubblico, molto simile alle IPO comuni o all'offerta pubblica iniziale di azioni regolari.

La vendita pubblica di token, colloquialmente nota come "Initial Coin Offering", è un nuovo potente strumento per creare comunità decentralizzate, dare il via agli effetti della rete, incentivare i partecipanti, fornire liquidità più veloce agli investitori e accumulare capitali per i creatori (Batiz-Benet, Santori, \& Clayburgh, 2017).

Rispetto alle IPO tradizionali che sono molto standardizzate e che richiedono un notevole lavoro legale, le ICO sono molto diverse.

Nelle IPO, gli investitori pagano per le azioni di una società utilizzando moneta fiat o denaro in cambio di un certo livello di controllo nella società.

Le ICO sono diverse, non è necessario che una banca d'investimento gestisca l'attività di raccolta fondi, le azioni e i diritti di voto sono esclusi agli investitori e non vi è alcun coinvolgimento del governo. Inoltre, i progetti o le startup hanno raramente una storia aziendale o beni piazzati sul mercato.

Le ICO consentono alle startup di raccogliere grandi quantità di finanziamenti con il minimo sforzo evitando l'ottemperanza a regole stringenti e i costi di intermediazione (Kaal e Dell'Erba, 2018; Sameeh, 2018).

In particolare, una ICO può essere descritta come un meccanismo attraverso il quale le nuove imprese raccolgono capitali vendendo gettoni (token) a una folla di investitori (Fish, 2019; Li e Mann, 2018; Willet, 2013). Un token, generalmente, è una criptovaluta, un mezzo digitale di scambio di valore basato sulla distributed ledger technology (DLT). I token diventeranno unità funzionali future del progetto dell'impresa sotto forma di diritto alla proprietà, royalties o altre funzioni di utilità (Sameeh, 2018).

Il "Distributed Ledger Technology" è un database distribuito su diversi nodi o dispositivi IT, che è coinvolto singolarmente nella replica di rete e nel salvataggio di una copia del libro mastro. Non vi è alcuna autorità centrale al comando, nessun arbitro, e qualsiasi nodo che procede con la registrazione e il salvataggio, lavora in modo indipendente.

Attualmente, il tipo più comune di DLT è la tecnologia blockchain (BCT). Le startup Blockchain hanno adottato le offerte iniziali di monete (ICO) come strumento per raccogliere capitali iniziali. I cripto-token offerti in queste vendite hanno lo scopo di ricoprire un insieme molto vario di ruoli su diverse piattaforme (Conley, 2017).

L'idea alla base della BCT è che permette agli attori di un sistema (chiamati nodi) di effettuare transazioni digitali utilizzando una rete P2P che memorizza queste transazioni in modo distribuito attraverso la rete (Back et al., 2014). Questa tecnologia innovativa ha fornito alle ICO l'opportunità di raccogliere grandi quantità di denaro.

Quando si valutano le ICO per dimensione, possiamo considerare sia la quantità di denaro raccolto nella ICO,

- PhD student in Economia e Management - Università G. d'Annunzio di Pescara - Italy e-mail: guido.dimatteo@unich.it

* Associato di Economia e Management - Università G. d'Annunzio di Pescara - Italy e-mail: francesca.masciarelli@unich.it 
sia il ritorno sull'investimento. A volte le ICO con un relativo ritorno sull'investimento non rappresentano i progetti che guadagnano di più e viceversa. La ICO di Ethereum nel 2014, tra i primi pionieri, ha raccolto 18 milioni di dollari in 42 giorni. Ethereum è stato essenziale per lo sviluppo delle ICO, grazie alle sue innovazioni per quanto riguarda le applicazioni decentralizzate. Più recentemente, le ICO hanno generato importi significativamente maggiori in termini di fondi totali raccolti. La più grande ICO in questo senso è Filecoin, un progetto di cloud storage decentralizzato. Durante una ICO di un mese terminata nel settembre del 2017, Filecoin è riuscito a raccogliere circa 257 milioni di dollari (Frankenfield, Investopedia.com).

Nel 2018 sono state concluse 2.284 offerte iniziali di monete e gli investitori potevano scegliere, in media, tra 482 vendite di token. L'importo totale raccolto nel 2018 èstato di quasi 11,4 miliardi di dollari (database ICObench, che comprende oltre 5.100 ICO da agosto 2015).

Basandomi sulla "Signaling theory" (Spence, 1973), il cui scopo è quello di ridurre l'asimmetria informativa nel rapporto investitore/impresa, l'obiettivo della mia ricerca è capire come $i$ White Paper possano contribuire a ridurre lo scetticismo degli investitori.

Spence ha dimostrato che, in determinate condizioni, agenti ben informati possono migliorare il loro esito di mercato segnalando le loro informazioni private ad agenti scarsamente informati (G.Akerlof, M.Spence e J.Stiglitz 2001).

La signaling theory è l'idea che una parte (l'agente) trasferisca le informazioni su se stessa a un'altra parte (principale). Nel modello di segnalazione del mercato del lavoro di Michael Spence, i dipendenti (potenziali) inviano un segnale sul loro livello di abilità al datore di lavoro migliorando le proprie competenze. Il valore informativo deriva dal fatto che il datore di lavoro ritiene che vi sia una correlazione positiva dei salari con abilità crescenti.

In un contesto simile, la signaling theory è stata utilizzata per spiegare quali tipi di informazioni non tecniche portano gli investitori a convogliare i loro contributi economici in startup. La letteratura accademica si è concentrata principalmente sui "segnali" di startup riguardanti gli aspetti tecnici, le caratteristiche del consiglio di amministrazione e del top management, il genere, la presenza di venture capitalist o investitori informali e il coinvolgimento dei fondatori.

Questa ricerca vuole arricchire la letteratura esistente riguardante la teoria della "segnalazione" introducendo l'analisi dei contenuti linguistici del white paper (WP), più precisamente come le emozioni positive che emergono dai white paper possano influenzare la quantità di denaro raccolto.

Il white paper è un documento ufficiale che descrive il problema che il progetto sta cercando di risolvere. I WP sono rilevanti per fornire informazioni ai potenziali investitori in ICO e rappresentano uno strumento cruciale per rendere gli investitori più fiduciosi e, di conseguenza, potrebbero rappresentare un fattore importante per determinare l'importo dei finanziamenti raccolti.

I white paper contengono una serie di informazioni sui protocolli IT, la blockchain pubblica adottata, la fornitura di token, il meccanismo di determinazione dei prezzi e distribuzione e $i$ dettagli sul progetto da sviluppare, infine un business plan, inclusa la descrizione del team (Adhami and Martinazzi, 2018).

Si può affermare, quindi, che questo strumento fornisce informazioni dettagliate sul piano di un progetto, dettagli tecnici, budget, obiettivi, e le modalità con le quali i token saranno distribuiti.

Più specificamente il contenuto di qualsiasi libro bianco dovrebbe includere diversi punti: introduzione, dichiarazione di non responsabilità, sommario, descrizione del mercato e del problema, descrizione del prodotto e come si vuol risolvere detto problema, gettoni (quanti, perché, come, quando), come i fondi raccolti stanno per essere utilizzati, il team e la road map (www.cointelegraph. com).

Mentre i precedenti lavori accademici hanno esplorato come $i$ white paper tecnici attirano maggiori quantità di finanziamenti (Fish, 2019), ben poco si è approfondito su come i contenuti non tecnici possano contribuire a ridurre l'asimmetria delle informazioni nel rapporto investor-investee company.

Questa ricerca vuole indagare se l'uso di segnali riguardanti le "parole emozionali positive" menzionate nel documento (WP) possa aiutare a prevedere la quantità di denaro raccolto da un'impresa.

Di conseguenza, due domande salienti emergono: come le parole emotive menzionate nei white paper possono influenzare il successo delle ICO? Più specificamente, come le emozioni positive utilizzate nel documento possono migliorare la raccolta fondi?

Metodologia. Questo studio mira a introdurre un'analisi linguistica quantitativa per studiare come l'uso di parole emotive positive, può migliorare la fiducia degli investitori e, di conseguenza, la quantità totale di token venduti e fondi raccolti.

Per esplorare queste domande, ho usato un metodo quantitativo empirico, compilando manualmente il campione utilizzando i dati, principalmente, dal sito icobench che è considerata la piattaforma più importante per attribuire un rating alle ICO. Per promuovere i progetti, il team dell'imprenditore, solitamente, si registra su varie piattaforme di monitoraggio delle ICO, che poi attribuiranno un rating ai progetti in base alle informazioni raccolte.

Lee (2018) ha considerato Icobench il principale hub online per il rating delle ICO utilizzando $i$ relativi dati e $i$ rating da uno-a-cinque, scoprendo che la probabilità di una raccolta fondi di successo aumenta del 19,8\% a fronte di un aumento dell'1\% del rating medio degli analisti, dopo aver controllato altre caratteristiche del progetto.

Ho aggiunto ulteriori informazioni ricavate da diverse piattaforme come www.icodrops.com, www.coinmarketcap.com, www.tokenmarket.net, www.foundico.com, www.icomarks.com, www.icorating.com, www.trackico.io, www.findico.io, al fine di raccogliere le ICO top 100 (migliore valutazione) effettuate tra il 2015 e il 
2019 considerando i tre paesi migliori al mondo per numero di ICO: Stati Uniti, Singapore e Regno Unito.

La valutazione (rating) di una ICO è il risultato della combinazione di:

- $\quad$ un algoritmo di valutazione sviluppato da Icobench che utilizza più di 20 criteri diversi su cui ogni ICO può guadagnare più di 30 punti;

- $\quad$ un rating che esperti indipendenti danno alla ICO seguendo i suoi suggerimenti metodologici di valutazione.

Quando una ICO è elencata per la prima volta sul sito, un algoritmo di valutazione automatica chiamato "Benchy" calcola il suo punteggio sulla base di diversi criteri oggettivi considerando: team, informazioni ICO, presentazione del prodotto, marketing e social media. Inizialmente, il punteggio Benchy rappresenta il 100\% del rating di una ICO su ICObench, ma nel momento in cui gli "esperti" di ICObench cominciano a "pesare" con le loro opinioni, l'importanza del punteggio Benchy diminuisce notevolmente (https://icobench.com/ratings).

Ho raccolto, quindi, le prime 100 ICO terminate tra Stati Uniti, Singapore e gli Stati Uniti, collezionando $i$ rispettivi white paper.

Ho adottato un'analisi di regressione lineare generalizzata per ricavare le relazioni tra la quantità di finanziamento raccolta (variabile dipendente) e lo score di "emozione positiva" (variabile indipendente) ottenuta dal software LIWC.

LIWC (Linguistic Inquiry and Word Count) è un programma trasparente di analisi del testo che conta le parole in categorie psicologicamente significative. I risultati empirici tramite l'utilizzo di LIWC dimostrano la sua capacità di rilevare il significato in un'ampia varietà di contesti sperimentali, tra cui mostrare attenzione, emotività, relazioni sociali, stili di pensiero e differenze individuali (Tausczik e Pennebaker, 2010).

La ricerca suggerisce che LIWC identifica con precisione le emozioni nell'uso del linguaggio. Ad esempio, le parole di emozione positiva (come: buono, bello, di successo) vengono utilizzate per scrivere su un evento positivo, e parole di emozioni più negative (come: ferito, brutto, cattivo) vengono utilizzate per scrivere su un evento negativo (Kahn et al., 2007). Le valutazioni fornite da LIWC, relativamente all'utilizzo di parole che esprimono emozioni positive e negative, corrispondono alle valutazioni dell'uomo in merito agli estratti di testo (Alpers et al., 2005).

\section{Variabili}

Variabile dipendente: quantità di denato raccolta (ln)

L'importo dei finanziamenti raccolti nella ICO è la variabile dipendente (in USD). Questo tipo di variabile dipendente è generalmente utilizzata nella ricerca sulla finanza imprenditoriale (Mollick, 2014). I dati sono stati estratti da Icobench quando disponibili. Ho usato una trasformazione logaritmica naturale per considerare l'asimmetria della variabile (Anglin et al., 2018; Blocco et al., 2018).

Variabile indipendente: emozioni positive (posemo)

Lo studio esplora $i$ potenziali segnali delle emozioni positive, che rappresentano la variabile di ricerca indipendente.

Le parole usate nei primi 100 white paper per gli Stati Uniti, Singapore e il Regno Unito sono state analizzate utilizzando il software LIWC (Linguistic Inquiry Word Count). LIWC legge un determinato testo e conta la percentuale di parole che riflettono emozioni diverse, stili di pensiero, preoccupazioni sociali e persino parti del discorso. Poiché LIWC è stato sviluppato da ricercatori con interessi in psicologia sociale, clinica, sanitaria e cognitiva, le categorie linguistiche sono state create per catturare gli stati sociali e psicologici delle persone (http://liwc.wpengine.com/howit-works/).

Il modo in cui LIWC classifica le parole "posemo" viene descritto qui di seguito vedendo, per esempio, uno stralcio del white paper NAGA che è una ICO americana valutata 4.1 da Icobench.

Tab. 1: Estratto dal white paper della ICO NAGA

If a user shares his trades with the community and gets copied by others, SwipeStox pays a compensation bonus to the trade initiator. As a result, the SwipeStox trader has the unique potential to earn money while trading on the SwipeStox platform. The compensation is directly credited to the user's account and can be withdrawn at any time. If a trader decides to copy a trade, there is the possibility to copy one single trade or to copy all the trades of a single trader (auto-copying). SwipeStox provides a stand-alone offering in comparison to other social trading networks, like eToro or Ayondo, which just offer the possibility to just copy all trades of a single trader within the network. On SwipeStox each trader can be the expert. SwipeStox also offers its users the possibility to follow other users, and to subscribe to and comment on news and user interactions. In addition, the platform offers a full robo-advisory solution. The algorithms and artificial intelligence of CYBO is described below. SwipeStox' simple and easy to use interface, combined with various features have led to high user loyalty with users spending on average more than 23 minutes on the platform, a figure which exceeds the average daily usage of apps such a Facebook, Snapchat, Twitter, or Instagram.

LIWC mette in evidenza le parole "posemo" (in rosso) nel documento e, di conseguenza, il software darà la percentuale di parole che riflette questo tipo di emozione (in questo caso: $2,71 \%$ ).

Variabili di controllo: caratteristiche dell'impresa

Per escludere effetti distorsivi e per esplorare ulteriori determinanti riferite all'ammontare di denaro raccolto 
nelle ICO, l'analisi include variabili di controllo. Due variabili si riferiscono alle caratteristiche dell'impresa, mentre una si riferisce al rating assegnato da Icobench.

Membri del team (ln)

Ho considerato il logaritmo naturale del numero di componenti nel team ICO. Icobench fornisce nome e cognome, foto e la URL del profili linkedin di tutta la squadra.

Categoria

Icobench identifica 29 categorie ICO elencate di seguito:

Tab. 2

\begin{tabular}{|l|l|l|}
\hline 1-Arte & 11-Elettronica & 21-Altro \\
2-Intelligenza Artificiale & 12-Energia & 22-Piattaforme \\
3-Banca & 13-Intrattenimento & 23-Immobiliare \\
4-Big Data & 14-Salute & 24-Vendita al dettaglio \\
5-Servizi aziendali & 15-Infrastrutture & 25-Contratti Smart \\
6-Casino \& Gioco d'azzardo & 16-Internet & 26-Software \\
7-Carità & 17-Investimenti & 27 Sport \\
8-Comunicazione & 18-Legale & 28-Turismo \\
9-Criptovalute & 19-Produzione & 29-Realtà virtuale \\
10-Istruzione & 20-Media & \\
\hline
\end{tabular}

Variabili di controllo: caratteristiche stabilite da valutatori esterni

Ico rate $(\ln )$

Ho usato il logaritmo naturale del rating ICO assegnato da Icobench. Tutte le ICO sono classificate con le stesse condizioni, con lo stesso algoritmo di valutazione che considera quattro aree diverse: il Team, le informazioni sulle Ico, la presentazione del prodotto/progetto, il marketing e social media.

Risultati. Nella tabella seguente viene illustrata la matrice di correlazione. Possiamo notare una correlazione negativa tra l'importo dei finanziamenti raccolti e l'uso di emozioni positive nei white paper.

Tab. 3

\begin{tabular}{|l|l|l|l|l|}
\hline CORRELATION & $\ln A M O U \sim D$ & POSEMO & $\ln$ TEAM $\sim$ & $\ln R A T E$ \\
\hline $\ln$ AMOUNTRA D & 1.0000 & & & \\
\hline POSEMO & -0.0931 & 1.0000 & & \\
\hline $\ln T E A M M E M B ~ S$ & -0.0144 & -0.1209 & 1.0000 & \\
\hline $\ln$ RATE & 0.0236 & -0.0341 & -0.0842 & 1.0000 \\
\hline
\end{tabular}

In questa ricerca, ho adottato un modello lineare generalizzato per trovare possibili relazioni tra le variabili. Nel primo modello sono state incluse solo le variabili di controllo.

Tab. 4

\begin{tabular}{|l|c|c|c|c|c|c|}
\hline \multicolumn{3}{|c|}{ Model 1 } & \multicolumn{3}{c|}{$\begin{array}{c}\text { No. of obs }=103 \\
\text { Log pseudolikelihood }=-180.1868396\end{array}$} \\
\hline lnAMOUNTRA D & Coef. & Robust Std. Err. & $\mathrm{z}$ & $\mathrm{P}>|\mathrm{z}|$ & \multicolumn{2}{c|}{$[95 \%$ Conf. Interval] } \\
\hline lnTEAMMEMB S & -.021974 & .3961703 & -0.06 & 0.956 & -.7984535 & .7545055 \\
\hline lnRATE & 1.219464 & 3.062748 & 0.40 & 0.691 & -4.783411 & 7.22234 \\
\hline Categories (1-29) & yes & yes & yes & yes & yes & yes \\
\hline
\end{tabular}

Nel secondo modello sono state incluse tutte le variabili.

Tab. 5

\begin{tabular}{|l|c|c|c|c|c|c|}
\hline \multicolumn{3}{|c|}{ Model 2 } & \multicolumn{3}{c|}{$\begin{array}{c}\text { No. of obs }=103 \\
\text { Log pseudolikelihood }=-178.8665086\end{array}$} \\
\hline lnAMOUNTRA D & Coef. & Robust Std. Err. & $\mathrm{z}$ & $\mathrm{P}>|\mathrm{z}|$ & \multicolumn{2}{c|}{$[95 \%$ Conf. Interval] } \\
\hline POSEMO & -.2673694 & .1611828 & -1.66 & 0.097 & -.5832818 & .0485431 \\
\hline $\ln$ TEAMMEMB S & -.1072171 & .4218471 & -0.25 & 0.799 & -.9340221 & .719588 \\
\hline $\ln$ RATE & 1.342171 & 2.955611 & 0.45 & 0.650 & -4.450719 & 7.135062 \\
\hline Categories (1-29) & yes & yes & yes & yes & yes & yes \\
\hline
\end{tabular}

Sorprendentemente possiamo notare una correlazione negativa tra le emozioni positive e la quantità di denaro raccolta. Come interpretare una correlazione negativa? Perché le emozioni positive menzionate nei white paper non sembrano condizionare la raccolta fondi? 
Dobbiamo ricordare che l'obiettivo dell'impresa è generare fiducia degli investitori. Il WP è uno strumento utile per generare fiducia, soprattutto se gli investitori utilizzano un linguaggio positivo.

L'autorità di mercato australiana ha emesso un documento in cui afferma che "le ICO hanno il potenziale per dare un importante contributo alle opzioni a disposizione delle imprese per raccogliere fondi e alle opzioni di investimento disponibili per gli investitori", tuttavia specificando che "una ICO deve essere condotta in modo da promuovere la fiducia degli investitori e rispettare le leggi pertinenti” (Adhami, Ii e Martina Giudic 2018).

L'obiettivo delle nuove imprese è ridurre l'asimmetria dell'informazione. Esse ritengono che scrivere un buon libro bianco sia un modo per raggiungere il suo obiettivo, soprattutto se si inseriscono parole emotive positive. Probabilmente l'investitore è molto più preparato culturalmente in termini di rischio finanziario e non viene ingannato dalla pura dialettica. I potenziali investitori sono a conoscenza delle zone grigie relative al sistema di regolamentazione finanziaria.

Il risultato è che le parole positive citate nel WP sono spesso insufficienti, mancando spesso informazioni che ispirano fiducia. Pertanto le parole emotive positive non svolgono un ruolo abbastanza grande per diminuire il livello di asimmetria informativa tra gli investitori e il team ICO.

Limiti della ricerca. Diverse questioni, riguardanti l'accessibilità e la qualità dei dati, limitano la generalizzabilità dei risultati. La maggior parte dei dati sono stati raccolti manualmente e alcune ICO sono state escluse a causa della mancata reperibilità del WP o della quantità di denaro raccolto.

Non sono stato in grado, ad oggi, di raccogliere dati per alcune variabili che potrebbero influenzare l'importo raccolto nelle ICO come il tipo di piattaforma, hard e soft cap, investimento minimo, bonus, whitelist/KYC, aree soggette a restrizioni, tempo prevendita/Ico e statistiche relative all'attività dei social media.

Inoltre, il numero di osservazioni è limitato a tre paesi e solo cento ICO. I risultati saranno statisticamente più significativi aggiungendo un numero più cospicuo di osservazioni.

La ricerca futura potrebbe esplorare ulteriori variabili riguardanti ulteriori stati psicologici nell'analisi del testo come tristezza, rabbia e ansia.

Inoltre, gli accademici potrebbero elaborare delle survey per raccogliere dati. I ricercatori, nello specifico, potrebbero contattare $i$ ceo delle ICO tramite Linkedin, Twitter, Facebook, Reddit, Telegram per raccogliere informazioni riguardanti non solo aspetti tecnici, ma anche aspetti psicologici.

Esplorare la relazione tra ICO e $i$ risultati post ICO potrebbe rappresentare un altro spunto interessante di ricerca. La maggior parte delle imprese, infatti, utilizza questo strumento finanziario per sviluppare un prodotto nuovo, le stesse startup non hanno un prodotto già funzionante al momento del lancio di una ICO (Fish, 2019).

Implicazioni pratiche. Questo studio contribuirà alla letteratura sulla finanza imprenditoriale introducendo un'analisi linguistica quantitativa relativa al whitepaper delle ICO. Più specificamente la ricerca mira a catturare gli stati psicologici degli investitori riflettendo le diverse tipologie di emozioni. La ricerca avrà anche implicazioni pratiche per i professionisti, in quanto informano le startup potenziali su come redigere un libro bianco in grado di attirare finanziamenti più consistenti.

Originalità del lavoro. Basandomi sulla "Signaling theory" (Spence, 1973), il cui scopo è quello di ridurre l'asimmetria informativa nel rapporto investitore/impresa, l'originalità della mia ricerca risiede nel capire come $i$ White Paper possano contribuire a ridurre lo scetticismo degli investitori.

Il presente lavoro vuole arricchire la letteratura esistente riguardante la teoria della "segnalazione" introducendo l'analisi dei contenuti linguistici del white paper (WP), più precisamente come le emozioni positive che emergono dai white paper possano influenzare la quantità di denaro raccolto.

Parole chiave: Initial Coin Offering (ICO), White Paper, Criptovalute, Signaling Theory, Asimmetria informativa, Emozioni positive.

\section{Bibliografia}

ADHAMI S., GIUDICI G., MARTINAZZI S. (2018), "Why do businesses go crypto? An empirical analysis of initial coin offerings", Journal of Economics and Business, vol. 100, pp. 64-75.

AHLERS G.K.C., CUMMING D., GÜNTHER C., SCHWEIZER D. (2015), "Signaling in Equity Crowdfunding”. Entrepreneurship Theory and Practice, vol. 9 n. 4, pp. 955-980.

ARTHURS J.D., BUSENITZ L.W., HOSKISSON R.E., JOHNSON R.A. (2009), "Signaling and initial public offerings: The use and impact of the lockup period", Journal of Business Venturing, vol. 24, n. 4, pp. 360-372.

BLOCK J.H., COLOMBO M.G., CUMMING D.J., VISMARA S. (2018), "New players in entrepreneurial finance and why they are there", Small Business Economics, vol. 50, n. 2, pp. 239-250.

BUSENITZ L.W., FIET J.O., MOESEL D.D. (2005), "Signaling in Venture Capitalist-New Venture Team Funding Decisions: Does It Indicate Long-Term Venture Outcomes? Entrepreneurship”, Theory and Practice, vol. 29, n. 1, pp. 1-12. 
CONNELLY B.L., CERTO S.T., IRELAND R.D., REUTZEL C.R. (2011), "Signaling Theory: A Review and Assessment”, Journal of Management, vol. 37, n. 1, pp. 39-67.

DEEDS D. L., DECAROLIS D., COOMBS J. E. (1997), "The impact of firmspecific capabilities on the amount of capital raised in an initial public offering: Evidence from the biotechnology industry", Journal of Business Venturing, vol. 12, n. 1, pp. 31-46.

FISCH C. (2019), "Initial coin offerings (ICOs) to finance new ventures", Journal of Business Venturing, vol. 34, n.1, pp. 1-22.

FISCH C., MASIAK C., VISMARA S., BLOCK J. (2019), "Motives and profiles of ICO investors", Journal of Business Research, in press.

IBBA S., PINNA A., LUNESU M., MARCHESI M., TONELLI R. (2018), "Initial Coin Offerings and Agile Practices", Future Internet, vol. 10, n.11, pp. 103-124

LI J., MANN W. (2018), "Initial Coin Offering and Platform Building" SSRN Electronic Journal.

MAAS T. (2019), "Initial Coin Offerings: When Are Tokens Securities in the EU and US?", SSRN Electronic Journal.

SPENCE M. (1973), “Job Market Signaling”, The Quarterly Journal of Economics, vol. 87, n. 3, pp. 355-374.

TAUSCZIK Y.R., PENNEBAKER J.W. (2010), “The Psychological Meaning of Words: LIWC and Computerized Text Analysis Methods", Journal of Language and Social Psychology, vol. 29, n. 1, pp. 24-54. 


\title{
Il consumer journey nel turismo: elaborazione di un framework integrale sulla base della letteratura esistente
}

\author{
VALENTINA Dini ${ }^{*}$ LAMBERTO ZOLLO`CRISTIANO CIAPPEI^ RICCARDO RIALTI ${ }^{* *}$
}

\begin{abstract}
Obiettivi. L'avvento della digitalizzazione e lo sviluppo dell'ecosistema digitale hanno innescato un processo di emancipazione del consumatore: soggetto consapevole, attento e prudente nell'effettuazione delle proprie scelte di acquisto. Negli ultimi venti anni, va sempre più di moda il concetto di "consumer empowerment". Il consumatore è visto come un soggetto dinamico e partecipativo, ottenendo così un ruolo attivo nella co-creazione delle esperienze generate dall'impresa. Inoltre, $i$ cambiamenti epocali quali, la globalizzazione, l'evoluzione delle tecnologie dell'informazione e della comunicazione, l'utilizzo di Internet come strumento pubblicitario, sono fattori che hanno reso i consumatori sempre più capaci e informati che, oggigiorno, non si lasciano persuadere da un semplice messaggio a fini promozionali (Nosi,2019). La vera sfida del marketing è sempre stata quella di trovare $i$ touchpoint più efficaci, ovvero i punti di contatto in cui il consumatore è maggiormente aperto e influenzabile. Fino a qualche anno fa questa ricerca era basata sull'utilizzo del Modello Funnel, evoluzione del classico modello AIDA (Lewi,1898).

Questo modello è stato sviluppato prima di internet, quando l'approccio dell'impresa al mercato era condotto da strategie di tipo push, basate sul modello one-to-many (comunicazione di massa), in cui il marketing e la comunicazione dovevano aumentare il coinvolgimento e l'attenzione del consumatore.

La metafora dell' "imbuto" (funnel) è utilizzata per evidenziare come, la numerosità dei potenziali acquirenti di un determinato brand (estremità più larga dell'imbuto), si riduca progressivamente con l'avanzare delle fasi caratterizzanti il percorso del consumatore verso l'acquisto.

Questo paradigma si fonda sulla linearità e monodirezionalità delle azioni e sulla progressiva riduzione delle alternative di scelta. In via generale è possibile includere le seguenti fasi:

- Awareness (Consapevolezza): rappresenta la fase più alta dell'imbuto, in cui i consumatori vengono coinvolti attraverso campagne di marketing. L'obiettivo è la lead generation, ovvero la costruzione di una lista di contatti di clienti realmente interessati all'offerta.

- Interest (Interesse): il cliente inizia ad informarsi sull'impresa, sul brand e sui prodotti. Le aziende hanno la possibilità di dare avvio alle relazioni con i potenziali clienti.

- Consideration (Considerazione): i lead, in questa fase, vengono considerati prospect, individui che possono potenzialmente trasformarsi in futuri clienti. L'azienda sfrutta una molteplicità di canali e di strumenti promozionali allo scopo di costruire e rafforzare le relazioni precedentemente intraprese.

- $\quad$ Intent (Intenzione): i potenziali clienti si dimostreranno realmente interessati all'acquisto.

- Evaluation (Valutazione): l'obiettivo di questa fase è quello di influenzare il processo decisionale, convincendo l'acquirente che il prodotto in oggetto sia migliore rispetto alle alternative presenti sul mercato.

- Purchase (Acquisto): consiste nella transazione vera e propria. Il consumatore si è trasformato in un vero e proprio cliente dell'azienda.

Oggigiorno, lo schema del Purchasing Funnel sembra non esser più appropriato, infatti, è un modello che non riesce a catturare tutti i punti di contatto con i consumatori e i fattori chiave che portano un soggetto alla decisione di acquisto. Il processo che porta il consumatore all'acquisto non è più caratterizzato da sequenzialità e linearità di azioni: $i$ consumatori moderni possono infatti entrare in qualsiasi fase del funnel o addirittura saltarne alcune, possono rimanere in uno stadio per un tempo indeterminato oppure muoversi avanti e indietro (Bonchek e France, 2014). Questo contesto rende il "path to purchase" impossibile da rappresentare come un percorso lineare e strutturato
\end{abstract}

\footnotetext{
Laureanda in Governo e Direzione d'Impresa - Università degli Studi di Firenze - Italy

e-mail: valentina.dini@stud.unifi.it

- Ricercatore (Assistant Professor) in Economia e Gestione delle Imprese - Università degli Studi di Firenze - Italy e-mail: lamberto.zollo@unifi.it

- Ordinario di Economia e Gestione delle Imprese - Università degli Studi di Firenze - Italy e-mail: cristiano.ciappei@unifi.it

** Assegnista di ricerca (Post-doc Researcher) di Economia e Gestione delle Imprese - Università degli Studi di Firenze - Italy e-mail: riccardo.rialti@unifi.it
} 
secondo una successione di fasi. In questo scenario acquista maggior importanza la Customer Experience (CX). In definitiva, ciò che conta, è l'esperienza vissuta dal cliente formatasi attraverso ogni singola interazione diretta o indiretta con l'azienda (Meyer e Schwager, 2007).

In questo scenario, alla fine dello scorso decennio, McKinsey sviluppa un nuovo modello. Le prospettive passano attraverso una serie di touchpoint prima, durante e dopo un acquisto (Bonchek e France, 2014). Tale modello cerca di comprendere il viaggio emozionale ed esperienziale del cliente che risulta essere influenzato notevolmente da diverse tipologie di consumer-driven touchpoint, a differenza del Modello Funnel, dove la maggior parte delle azioni che conducevano all'acquisto, dipendevano dall'azienda.

Lemon e Verhoef (2016) identificano quattro categorie di touchpoint:

- $\quad$ Brand-owned touchpoint: comprendono le interazioni con i clienti che si manifestano durante l'esperienza di acquisto e che sono progettate, gestite e controllate dall'impresa stessa. Includono tutti $i$ brand-owned media (come pubblicità, siti web, programmi fedeltà) e tutti gli elementi del marketing mix controllati dal marchio (come attributi del prodotto, packaging, prezzo, servizi).

- $\quad$ Partner-owned touchpoint: consistono nelle interazioni con i clienti che si manifestano durante l'esperienza di acquisto e che sono congiuntamente progettati, gestiti o controllati dall'impresa e da uno o più partners (come agenzie di marketing, partner di distribuzione multicanale, partner di canali di comunicazione).

- Customer-owned touchpoint: consistono nelle azioni del cliente che fanno parte della sua Customer Experience complessiva e che non sono influenzate né controllate dall'impresa o dai suoi partners. Possono essere un esempio, la scelta del metodo di pagamento durante l'acquisto oppure i bisogni e $i$ desideri avvertiti dal cliente nella fase di pre-purchase.

- Social/external touchpoint: in questi touchpoint si riconosce l'importanza del ruolo di altri fattori nella Customer Experience: $i$ clienti, infatti, sono circondati da punti di contatto esterni (come altri clienti, media, ambienti) che possono influenzare il processo di acquisto nelle sue tre fasi.

Il modello circolare di McKinsey riporta quattro fasi principali: una prima fase di considerazione iniziale di un set di brand o di prodotti, che fanno perno sulla percezione dei clienti e dipendono dai touchpoint più recenti (Initial Consideration). Il consumatore inizierà poi una fase di valutazione, attraverso un processo di analisi e ricerca delle informazioni riguardanti i prodotti presi in considerazione (Active Evaluation); in questa fase verranno aggiunti e/o sottratti brand in base alle valutazioni effettuate (Court et. al., 2009). Nella ricerca svolta nel 2009 da McKinsey è emerso che due terzi dei touchpoint della fase di valutazione attiva, coinvolgono attività di consumer-driven marketing, (recensioni su Internet, raccomandazioni e passaparola di amici e familiari, interazioni in-store e ricordi di esperienze passate), mentre un terzo coinvolge il marketing guidato dall'azienda. Il marketing tradizionale rimane quindi importante, ma il cambiamento nel modo in cui i consumatori prendono decisioni significa che $i$ marketer devono muoversi in modo aggressivo, al di là della comunicazione puramente push-style, devono quindi imparare ad influenzare i consumer-driven touchpoint, come il passaparola e i siti di informazione Internet. La terza fase identifica il momento decisivo di acquisto del prodotto ritenuto migliore (Buy), seguito da un periodo in cui il cliente matura l'esperienza post-acquisto del prodotto (Experience). Fondamentale è porre l'attenzione su quest'ultima fase che rappresenta il momento in cui l'impresa può influenzare le decisioni successive di acquisto del soggetto: sulla base di un'esperienza post-vendita positiva si svilupperà la fedeltà del cliente (Loyalty loop). Più del 60 per cento dei consumatori di prodotti per la cura della pelle del viso, per esempio, continuerà ad effettuare ricerche anche dopo aver concluso l'acquisto (Court et. al., 2009). È fondamentale sottolineare che questa fedeltà al marchio deve tradursi in active loyalty, ovvero in passaparola positivi e raccomandazioni sui prodotti offerti dall'azienda. Nell'odierna era digitale, $i$ sostenitori di una marca non sono solo i clienti, ma possono essere tutti $i$ consumatori che appartengono alla community, o che semplicemente sono attratti dal brand. Ad esempio, si consideri tutti $i$ membri della community running di Nike+, che però non possiedono prodotti Nike, o il mezzo milione di fan della pagina Facebook di Tesla che non possiedono una Tesla (Bonchek e France, 2014). Antonio Lucio, Chief Brand Officer di Visa, ritiene che la soluzione migliore sia quella di spostare l'attenzione dalla transazione alla relazione. Dopo aver esplorato il Customer Decision Journey, ha sviluppato il Customer Engagement Journey. Islam e Rahman (2016) sostengono che tale concetto si riferisca alla disponibilità di un cliente a partecipare attivamente e interagire con il marchio o con l'organizzazione in diversi touchpoint. Una concettualizzazione che aderisce al carattere di multidimensionalità, poiché comprende l'aspetto cognitivo, quello emozionale, comportamentale e sociale.

Il contesto descritto evidenzia l'importanza del Consumer Journey e dei touchpoint che condizionano le scelte del consumatore. Abbiamo quindi svolto una ricerca sulla base della letteratura esistente, integrando le diverse variabili identificate negli anni; lo studio si concentra sull'individuazione delle variabili che influenzano il turista nella scelta di un determinato viaggio, analizzando ogni singola fase del modello circolare di Consumer Journey di McKinsey.

Analizzando l'Initial Consideration, Gitelson e Kerstetter (1990) soffermano la loro attenzione sulla relazione tra variabili sociodemografiche e benefici ricercati in vacanza e la relazione tra tali benefici e il successivo comportamento di viaggio, arrivando a concludere che esiste una relazione tra due variabili sociodemografiche (età $e$ genere) e i benefici ricercati (intesi come motivi che spingono a viaggiare, quali per esempio, relax o possibilità di esplorare). Successivamente, Chen e Wu (2009) analizzano l'influenza delle motivazioni di viaggio (rilassamento, novità, fuga e socializzazione), dei vincoli di viaggio (rischi percepiti, impegni di tempo e ragioni personali) e delle variabili sociodemografiche che impattano sulle intenzioni di viaggio all'estero degli anziani. Dal loro studio emerge come l'età, il livello di reddito, la ricerca di relax e di novità e le ragioni personali (intese come vincoli di viaggio) influiscono sulla decisione ultima del soggetto anziano di viaggiare. Proseguendo l'analisi della letteratura esistente 
abbiamo osservato che, anche Hudson et. al. (2013), svolgono un'analisi delle relazioni esistenti tra la tipologia di generazione e il comportamento di viaggio, arrivando alla conclusione che esistono, somiglianze e differenze rilevanti, tra le diverse generazioni, in termini di comportamento di viaggio. In tutti e tre questi studi emergono sostanziali differenze nei motivi che spingono un soggetto a viaggiare, in relazione all'età o al genere del medesimo soggetto. Negli studi Gnoth (1997) è possibile identificare il processo di motivazione che caratterizza un soggetto. Gli impulsi (pull e push) originano $i$ bisogni (o motivi) che generano energia nel soggetto, attivandolo verso una determinata azione. Il processo di motivazione è generato dall'esistenza di motivi, dalla presenza di valori e di percezioni caratterizzanti il soggetto e dalla situazione oggettiva in cui si trova lo stesso. Heckhausen (1989) evidenzia che $i$ motivi sono una categorizzazione dell'energia che muove le persone ad agire, mentre la motivazione permette a questi motivi di essere espressi in modo diverso dai diversi individui. Sulla base di questa precisazione, si sofferma l'attenzione sulle motivazioni "push" e "pull” (Crompton, 1979; Dann, 1981; Pearce e Caltabiano, 1983; Jang e Cai, 2002; Klenosky, 2002; Xu e Chan, 2016). La letteratura riguardo questo argomento è molto sviluppata ma è possibile individuare un filo conduttore che riunisce tutti gli studi: i fattori "push" sono legati ai bisogni dei soggetti e sono quei fattori che spingono a viaggiare (Klenosky, 2002), mentre i fattori "pull” tirano verso una destinazione piuttosto che un'altra. Questi ultimi sono legati alla scelta della destinazione una volta che si è presa la decisione di partire, ne sono degli esempi, il paesaggio, l'informazione, la conoscenza (Xu e Chan, 2016).

Hp1. I motivi spingono un soggetto a prendere in considerazione la partenza verso una destinazione turistica.

Hofstede (1980) sostiene che, la cultura è per la collettività umana ciò che è la personalità per un individuo, quindi, la cultura determina l'identità di un gruppo mentre la personalità determina l'identità dell'individuo. Le variabili che influenzano il comportamento di un individuo sono principalmente variabili demografiche, influenze socioculturali ma anche il pensiero inconscio di un soggetto, influenzato da storie raccontate in famiglia o da amici, miti o narrazioni (Martin, 2009). Quest'ultimo elemento è in accordo con gli studi di Levy (1981) che, partendo dal presupposto che la narrazione, le storie, i racconti e le fiabe influenzano il pubblico solo se riescono a creare un simbolo, si sofferma sull'analisi delle storie, miti, racconti di famiglia per dimostrare come questi influenzano, per esempio, lo stile di vita, il genere di alloggi ricercati, l'abbigliamento. Iversen et. al. (2018) analizzano la cultura legata ai valori delle persone, e non alla nazionalità, dato l'effetto della globalizzazione che riduce l'omogeneità culturale di una nazione. La globalizzazione, l'immigrazione e l'emergere di nazioni multietniche generano differenze e somiglianze tra paesi, ma anche all'interno dello stesso paese (Cleveland e Laroche, 2007). I consumatori all'interno dei singoli paesi stanno diventando, culturalmente, sempre più eterogenei, mentre, su base globale, stanno diventando sempre più omogenei. L'emergere di una cultura globale si viene a sovrapporre a un insieme sempre più frammentano di culture nazionali (Carpenter et. al., 2012). Questi studi tentano di apprendere la cultura globale dei consumatori, poiché essa è la principale determinante dell'atteggiamento e del comportamento di consumo.

\section{Hp2. La cultura influenza il soggetto nella considerazione iniziale del viaggio.}

Dall'analisi della letteratura esistente emerge che lo stile di vita sia un'altra variabile determinante il comportamento dei consumatori. Shewe e Calantone (1978) richiamano la necessità di segmentare il mercato secondo gli elementi psicografici (quali, stile di vita, opinioni e interessi), così da comprendere il lato psicologico dei consumatori in termini di modo di vivere. La psicografia, utilizzata per la ricerca sulla segmentazione dello stile di vita, misura: le attività delle persone (quindi, come trascorrono il loro tempo libero), i loro interessi (a cosa attribuiscono importanza nelle loro immediate vicinanze) e le loro opinioni (la visione di sé stessi e del mondo che li circonda). Crask (1981) sostiene che lo stile di vita influisce sulla vacanza e sul comportamento di viaggio. Gonzàlez e Bello (2000) identificano differenze in termini di stile di vita e comportamenti di viaggio e segmentano il mercato in: "Home-loving", "Idealistic", "Autonomous", "Hedonistic", "Conservative”. Inoltre, il contributo di Plog (2002) permette di identificare diverse tipologie di turisti, in particolare i suoi studi si soffermano sull'individuazione delle caratteristiche dei soggetti definiti allocentrici rispetto a quelle degli psicocentrici, individuando nei primi la continua ricerca di nuove esperienze, forte senso di fiducia in sé stessi e un elevato livello di adattabilità.

Hp3. Lo stile di vita incide sulla considerazione iniziale del viaggio.

Dopo aver individuato le variabili che possono influenzare la prima fase del Consumer Journey, siamo passati ad analizzare la seconda fase, "Active evaluation", caratterizzata dalla ricerca attiva di informazioni sulle possibili destinazioni di viaggio. Siamo partiti dallo studio di Um e Crompton (1990) in cui si evidenzia che il processo di scelta del turista è influenzato da tre stimoli esterni: stimoli significativi, stimoli simbolici e stimoli sociali. Pizam et. al. (2001), sostengono che il processo decisionale sia influenzato da variabili interne ed esterne, quali: influenze socioculturali, influenze legate al "family decision-making" e influenze situazionali. Sulla base di questi studi siamo arrivati a concludere che le caratteristiche di una destinazione, cioè l'attrattività del luogo, influenzano il processo di scelta del turista. In accordo con Belk (1975), gli autori sostengono che i fattori identificativi di una situazione (variabili situazionali) sono: l'ambiente fisico (posizione geografica, clima), l'ambiente sociale (le persone presenti e le loro caratteristiche), la prospettiva temporale, la definizione delle attività (orientamento o intento che spinge a viaggiare) e gli stati precedenti (stati d'animo che influenzano la valutazione). Goodrich (1978) analizza l'importanza 
della relazione esistente tra percezioni e preferenze del soggetto: l'atteggiamento è funzione degli attributi percepiti di un determinato oggetto e dell'importanza di questi attributi per il soggetto stesso. Ovviamente, all'aumentare delle percezioni positive aumenterà la possibilità di acquisto; tali percezioni dipendono dall'attrattività, quindi, da quell'elemento che in letteratura è chiamato "Destination image" (immagine di destinazione). Baloglu e McCleary (1999) sostengono che questa dipende da fattori personali (sia sociali, quindi età o istruzione, che psicologici, cioè valori, motivazione e personalità) ma anche da fattori stimolo (esperienze precedenti e ricerca di informazioni). Cho (2010) afferma che la destination image sia l'elemento che genera le percezioni, che a loro volta influiscono sul comportamento futuro.

\section{Hp4. La "Destination image” influenza il processo di scelta del consumatore.}

Un secondo elemento rilevante in questa fase del Consumer Journey è legato agli stimoli sociali, alle interazioni con amici e familiari o in generale alle informazioni rilevate dai forum o dalle recensioni in siti web. Abbiamo posto la nostra attenzione sugli effetti del WOM (Word of Mouth) e dell'E-WOM (Electronic-Word of Mouth). In letteratura esistono diversi studi che analizzano gli effetti del passaparola, ne sono degli esempi: Carl (2006), Pan e Fesenmaier (2006), Livtin et. al. (2007), Cox et. al. (2009), Bronner e Hoog (2011). In tutti questi studi si evidenzia l'influenza dell'E-WOM sul processo decisionale di un turista, infatti, la ricerca attiva di informazioni permette ai soggetti di ridurre il rischio e l'incertezza di una determinata scelta.

\section{Hp5. L'E-WOM influenza la scelta della destinazione.}

Il consumatore dopo aver individuato la destinazione del viaggio passerà all'acquisto. In questa fase abbiamo deciso di concentrare l'attenzione su due possibilità di acquisto: l'acquisto di un pacchetto offerto dall'agenzia di viaggio o l'acquisto autonomo attraverso l'utilizzo di siti web. Nel loro processo di acquisto, i consumatori possono utilizzare diverse combinazioni di canali online e fisici per cercare informazioni sui prodotti ed effettuare l'acquisto. In questo scenario è utile richiamare due comportamenti che possono caratterizzare il consumatore: webrooming e showrooming. Con il primo termine si intende la ricerca di informazioni dei prodotti online per poi procedere con un acquisto in store; il secondo, invece, descrive il comportamento contrario e quindi, la visita nel negozio fisico e l'acquisto successivo online (Flaviàn et. al., 2016). Abbiamo identificato quindi due grandi problemi che caratterizzano da una parte il sito web e dall'altra l'agenzia di viaggi. L'e-shopping, per i servizi di viaggio, ha due principali vantaggi: offre ai consumatori un maggiore livello di convenienza, poiché non devono affrontare problemi di trasporto e fisici ma possono effettuare prenotazioni e ricevere biglietti e conferme di prenotazione a casa. Inoltre, le prenotazioni on-line consentono di risparmiare tempo. Esistono però, anche fattori negativi legati all'e-shopping poiché i consumatori non possono comunicare con altri consumatori e non possono negoziare (Christou e Kassianidis, 2002). Sulla base di questa affermazione riteniamo necessario richiamare le variabili che possono influenzare il processo di acquisto di un soggetto, sia nel caso di acquisto in store che in caso di acquisto online. Per quanto riguarda l'agenzia di viaggi, fondamentale sarà garantire una struttura idonea, personale di contatto adeguato, un pacchetto turistico capace di soddisfare le richieste e un prezzo ragionevole (Sànchez et. al., 2004). Per quanto riguarda il sito web abbiamo fatto riferimento alle variabili analizzate negli studi di Tarafdar e Zhang (2005) soffermando la nostra attenzione sul contenuto informativo, facilità d'uso del sito e la personalizzazione.

Hp6. Le caratteristiche dell'agenzia di viaggi incidono sulla scelta di acquisto in store, piuttosto che online.

Hp7. Le caratteristiche del sito web sono rilevanti per la scelta di acquisto online, piuttosto che in store.

Al termine del viaggio è importante assicurarsi che il soggetto abbia sviluppato un'esperienza positiva, poiché questa genererà passaparola positivi attivando l'active loyalty. Bignè et. al. (2001) analizzano il rapporto tra immagine di destinazione, intenzioni comportamentali e valutazione post-acquisto del soggiorno. Si concentrano sul rapporto tra qualità e soddisfazione e tra queste ed il comportamento del turista, confermando che la qualità ha un'influenza positiva sulla soddisfazione e sull'intenzione a tornare, e che la soddisfazione determina la volontà di raccomandare la destinazione. I risultati di studi precedenti hanno dimostrato che i clienti soddisfatti sono suscettibili di un comportamento positivo nel post-acquisto (raccomandare, riacquistare). Anche Alcaniz et. al. (2005) analizzano l'influenza dell'immagine di destinazione sulla qualità percepita, e l'influenza di quest'ultima sulla soddisfazione del consumatore, che influenzerà a sua volta il comportamento post-acquisto. Hernández-Lobato et. al. (2006) affermano che la destination image influenza la soddisfazione del turista mentre la fedeltà è influenzata sia dalla soddisfazione che dall'immagine. É possibile concludere che qualità del viaggio, soddisfazione e comportamento post-acquisto sono le variabili rilevanti in questa fase del Consumer Journey.

Hp8. La qualità percepita e la soddisfazione del consumatore influenzano direttamente l'esperienza postacquisto.

Hp9. La qualità percepita e la soddisfazione influenzano direttamente il comportamento post-acquisto generando passaparola positivi.

Al fine di testare le nostre ipotesi abbiamo concettualizzato il seguente framework (Figura 1). 
Fig. 1: Modello concettuale

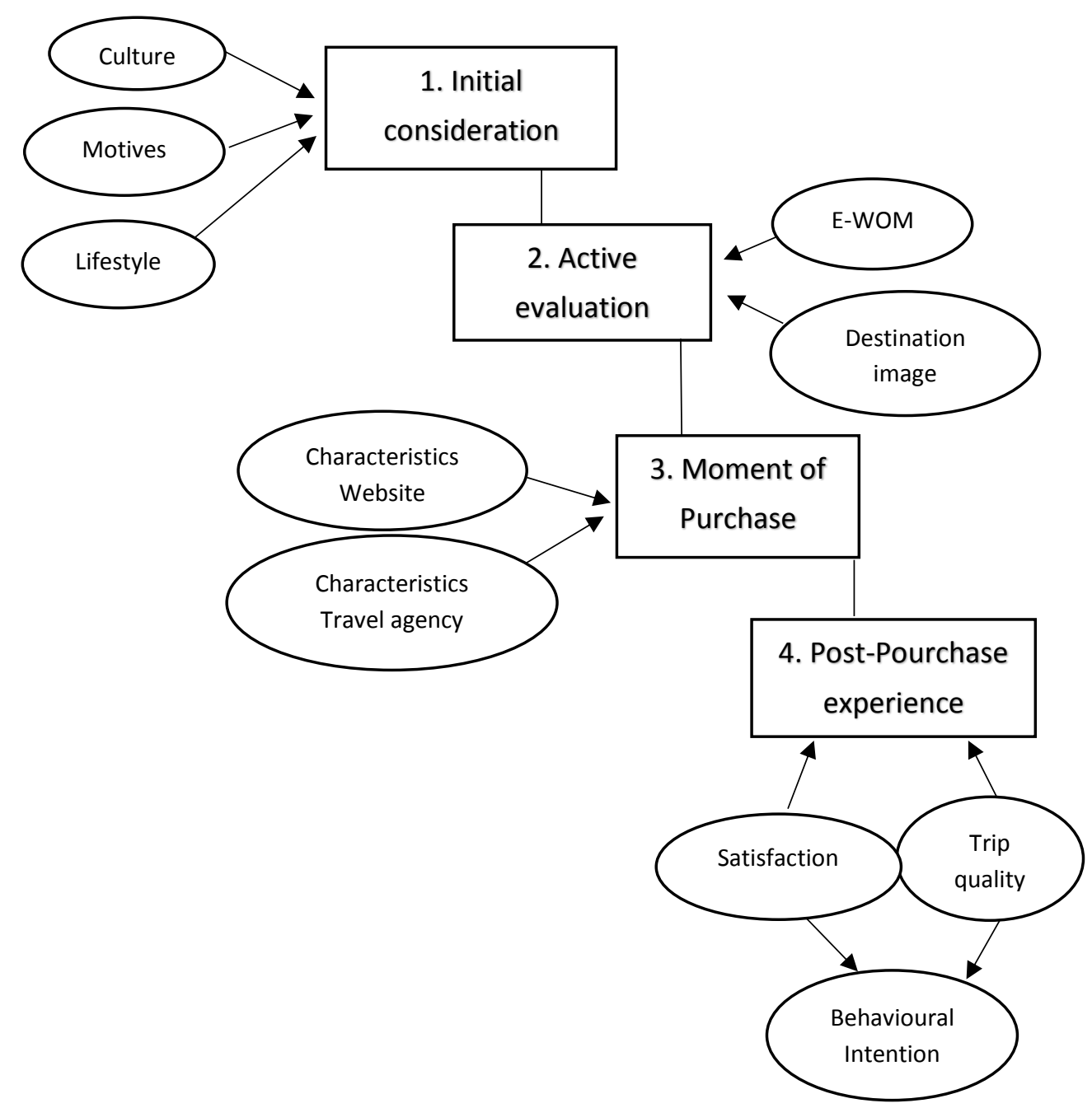

Fonte: Elaborazione propria degli Autori

Le variabili raffigurate dalle ellissi rappresentano le "proxy" ipotizzate come predittrici degli step caratterizzanti il Consumer Journey (raffigurati dai rettangoli)

Metodologia. Al fine di analizzare l'influenza di ciascuna variabile latente individuata nel Consumer Journey, verrà effettuata un'analisi statistica attraverso l'uso di un questionario di indagine. Ogni costrutto verrà misurato da un insieme di items o domande, individuate e convalidate in letteratura, che serviranno per realizzare il questionario. Quest'ultimo verrà realizzato attraverso il servizio Google Survey, offerto dalla piattaforma Google Drive. Il questionario sarà quindi diffuso in Italia utilizzando piattaforme social network (quali Facebook, Instagram, Whatsapp); non esisterà nessun tipo di vincolo per quanto riguarda la categoria di soggetti a cui sarà sottoposto e le voci saranno valutate su una scala di tipo Likert. Le risposte saranno poi analizzate attraverso la metodologia S.E.M. (Structural Equation Modeling) delle equazioni strutturali con lo scopo di verificarne l'attendibilità e le relazioni tra le variabili.

Tutte le domande del nostro questionario strutturato sono state prese dalla letteratura esistente e gli items sono riportati nell'appendice.

Risultati. Non è ancora possibile evidenziare i risultati del nostro studio poiché è una proposta work in progress.

Limiti della ricerca. Il presente studio non sarà senza limitazioni. Il campione di analisi non comprenderà tutte le nazioni, ma sarà presa in esame solo l'Italia. La ricerca futura potrà quindi ripetere tale analisi in altre nazioni così da estendere le implicazioni generate. Inoltre, il campione di riferimento sarà stratificato per età, genere e livello di istruzione e non terrà in considerazione il livello di reddito. La ricerca futura è inviata a replicare l'analisi tenendo in considerazione anche le componenti economiche che possono influire sul Consumer Journey.

Implicazioni pratiche. La presenza di consumatori sempre più informati ed esigenti e gli effetti generati dalla globalizzazione rendono il processo di segmentazione del mercato da parte delle imprese sempre più difficoltoso. Le possibilità sono svariate ma nessuna di queste è mai stata reputata come ottimale, o comunque migliore rispetto alle 
altre. In questa proposta, l'obiettivo è stato quello di analizzare il Consumer Journey in ambito turistico, contribuendo quindi, alle ricerche sulla segmentazione del mercato, e offrendo una visione d'insieme delle variabili che influenzano l'intero processo di acquisto del consumatore. I risultati di questa analisi forniranno spunti di riflessione interessanti per approfondire ancora più nel dettaglio le variabili effettivamente rilevanti nel Consumer Journey. Inoltre, tali risultati permetteranno ai manager e ai marketer di avere una visione complessiva del processo di acquisto effettuato dal consumatore.

Originalità del lavoro. A differenza della letteratura esistente, in questo studio si tenta di indagare ciascuna fase del Consumer Journey, partendo dalla considerazione iniziale e arrivando fino al momento in cui si genera la fedeltà e la lealtà del consumatore. Pertanto, abbiamo preso in considerazioni sia gli aspetti interiori (quali, motivi, cultura, stile di vita), che quelli esterni, come l'E-wom o le caratteristiche del sito web o dell'agenzia di viaggi.

Le nostre analisi permetteranno di mostrare ai marketer e manager quali variabili influiscono maggiormente sul Consumer Journey e quindi su quali variabili dover investire, per migliorare o rafforzare la notorietà del proprio brand.

Parole chiave: Consumer Journey; Digital Touchpoint; Tourism Marketing; Destination image; Loyalty

\section{Bibliografia}

ALCANIZ E.B., GARCÌA I.S., BLAS S.S. (2005), "Relationships among residents' image, evaluation of the stay and post-purchase behaviour", Journal of Vacation Marketing, vol. 11, n. 4, pp. 291-302.

BALOGLU S., MCCLEARY K.W., (1999), “A model of destination image formation”, Annals of Tourism Research, vol. 26, n. 4, 868-897.

BELK R.W., (1975), "Situational variables and consumer behavior”, Journal of Consumer Research, vol. 2, n. 3, pp. 157-164.

BIGNÉ J.E., SÀNCHEZ M.I., SÀNCHEZ J., (2001), "Tourism image, evaluation variables and after purchase behaviour: inter-relationship", Tourism Management, vol. 22, n. 6, pp. 607-616.

BONCHEK M., FRANCE C. (2014) "Marketing can no longer rely on the funnel", Harvard Business Review, https://hbr.org/

BRONNER, F., HOOG, R. (2011), "Vacationers and eWOM: Who posts, and why, where, and what?", Journal of Travel Research, vol. 50, n. 1, pp. 15-26

CARL W.J. (2006), “What's all the buzz about?”, Management Communication Quarterly, vol. 19, n. 4, pp. 601-634.

CARPENTER J., MOORE M., DOHERTY A.M., ALEXANDER N. (2012), "Acculturation to the global consumer culture: a generational cohort comparison”, Journal of Strategic Marketing, vol. 20, n. 5, pp. 411-423.

CHEN C.F., WU C.C. (2009), "How motivations, constraints, and demographic factors predict seniors' overseas travel propensity", Asia Pacific Management Review, vol. 14, n. 3, pp. 301-312.

CHO V. (2010), "A Study of the Non-economic Determinants in Tourism Demand", International Journal of Tourism Research, vol. 12, n. 4, pp. 307-320.

CHRISTOU E., KASSIANIDIS P. (2002), "Consumer's perceptions and adoption of online buying for travel products", Journal of Travel \& Tourism Marketing, vol. 12, n. 4, pp. 93-107.

CLEVELAND M., LAROCHE M. (2007), "Acculturation to the global consumer culture: Scale development and research paradigm", Journal of Business Research, vol. 60, n. 3, pp. 249-259.

COURT D., ELZINGA D., MULDER S., VETVIK O.J. (2009), "The consumer decision journey", McKinsey\&Company, https://www.mckinsey.com/.

COX C., BURGESS S., SELITTO C., BUULTJENS J., (2009), “The role of user-generated content in tourists' travel planning behavior", Journal of Hospitality Marketing \& Management, vol. 18, n. 8, pp. 743-764.

CRASK M.R. (1981), "Segmenting the vacationer market: identifying the vacation preferences, demographics, and magazine readership of each group", Journal of Travel Research, vol. 20, n. 2, pp. 29-34.

CROMPTON J.L. (1979), "Motivations for pleasure vacation”, Annals of Tourism Research, vol. 6, n. 4, pp. 408-424.

DANN G.M.S. (1981), “Tourist motivation an appraisal”, Annals of Tourism Research, vol. 8, n. 2, 187-219.

FLAVIÀN C., GURREA R., ORÙS C. (2016), "Choice confidence in the webrooming purchase process: The impact of online positive reviews and the motivation to touch", Journal of Consumer Behaviour, vol. 15, n. 5:459-476.

GITELSON R.J., KERSTETTER D.L. (1990), "The relationship between sociodemographic variables, benefits sought and subsequent vacation Behavior: A case study”, Journal Of Travel Research, vol. 28, n. 3, pp. 24-29.

GNOTH J. (1997), "Tourism motivation and expectation formation", Annals of Tourism Research, vol. 24, n. 2, pp. 283-304.

GOODRICH J.N. (1978), "The relationship between preferences for and perceptions of vacation destinations: Application of a choice model", Journal of Travel Research, vol. 17, n. 2, pp. 8-13.

GONZÀLEZ A.M., BELLO L. (2000), "The construct 'lifestyle' in market segmentation", European Journal of Marketing, vol. 36, n. 1/2, pp. 51-85. 
HERNÁNDEZ-LOBATO L., SOLIS-RADILlA M.M., MOLINER-TENA M.A., SÁNCHEZ-GARCÍA J. (2006), "Tourism Destination Image, Satisfaction and Loyalty: A Study in Ixtapa-Zihuatanejo, Mexico", Tourism Geographies, vol. 8, n. 4, pp. 343-358.

HOFSTEDE G., (1980), “Culture and Organizations”, International Studies of Management \& Organization, vol. 10, n. 4, pp. 15-41.

ISLAM J.U., RAHMAN Z. (2016), "The transpiring journey of customer engagement research in marketing", Management Decison, vol. 54, n. 8, pp. 2008-2034.

IVERSEN N.M., HEM L.E., MEHMETOGLU M. (2016), "Lifestyle segmentation of tourists seeking naturebased experiences: the role of cultural values and travel motives", Journal of Travel \& Tourism Marketing, vol. 33, n. sup1, pp. S38-S66.

JANG S.C., CAI L.A. (2002), "Travel motivations and destination choice: A study of British outbound market", Journal of Travel \& Tourism Marketing, 13:3, pp. 111-133

KLENOSKY D.B. (2002), "The "pull" of tourism destinations: A means-end investigation", Journal of Travel Research, 40, pp. 385-395

LEMON K.N., VERHOEF P.C. (2016), "Understanding customer experience throughout the customer journey", Journal of Marketing, vol. 80, n. 6, pp. 69-96.

LEVI S.J. (1981), "Interpreting consumer mythology: a structural approach to consumer behavior", Journal of Marketing, vol. 45, n. 3, pp. 49-61.

LI X., LI X.R., HUDSON S. (2013), "The applications of generational theory to tourism consumer behavior: An American perspective", Tourism Management, vol. 37, pp. 147-164.

LITVIN S., GOLDSMITH R.E., BING P. (2007), "Electronic word-of-mouth in hospitality and tourism management", Tourism Management, vol. 29, n. 3, pp. 458-468.

MARTIN D. (2009), "Uncovering unconscious memories and myths for understanding international tourism behavior", Journal of Business Research, vol. 63, n. 4, pp. 372-384.

MEYER C., SCHWAGER A. (2007), "Understanding customer experience”, Harvard Business Review, https://hbr.org/

NOSI C. (2019), "Consumer journey: Gestire strategicamente la consumer experience per competere".

PAN B., FESENMAIER D.R., (2006), “Online information search”, Annals of Tourism Research, vol. 33, n. 3, pp. 809832.

PEARCE P.L., CALTABIANO M.L. (1983), “Inferring travel motivation from travelers' experiences”, Journal of Travel Research, vol. 22, n. 2, pp. 16-20.

PLOG S. (2002), "The power of psychographics and the concept of venturesomeness", Journal of Travel Research, vol. 40, n. 3, pp. 244-25.

SÀNCHEZ J., CALLARISA L., RODRÌGUEZ R.M., MOLINER M.A. (2006), "Perceived value of the purchase of a tourism product", Tourism Management, vol. 27, n. 3, pp. 394-409

SCHEWE C.D., CALANTONE R.J. (1978), "Psychographic Segmentation of Tourists", Journal of Travel Research, vol. 16, n. 3, pp. 14-20.

TARAFDAR M., ZHANG J. (2005), "Analysis of Critical Website Characteristics: A Cross-Category Study of Successful Websites", Journal of Computer Information Systems, vol. 46, n. 2, pp. 14-24.

UM S. CROMPTON J. L., (1990), “Attitude determinants in tourism destination choice”, Annual of Travel Research, vol. 17, pp. 432-448.

XU J.B., CHAN S. (2016), “A new nature-based tourism motivation model: Testing the moderating effects of the push motivation", Tourism Management Perspectives, vol. 18, pp. 107-110. 
Appendice: Item del questionario

\section{Initial consideration:}

1. Motives: 5 items per "Novità e conoscenza", 5 items per "Sviluppo personale", 5 items per "Fuga e relazioni". (Li, M. e Cai, L. A. (2012), "The effects of personal values on travel motivation and behavioral Intention", Journal of Travel Research, 51(4):473-487).

Novità e Conoscenza (Novelty and Knowledge):

"Quanto ti stimolano i seguenti aspetti nella prospettiva di un ipotetico viaggio?"

- $\quad$ Sperimentare qualcosa di diverso

Experiencing something different

- $\quad$ Sentire l'atmosfera speciale della destinazione di vacanza

Feeling the special atmosphere of the vacation destination

- $\quad$ Osservare altre persone nella zona

Observing other people in the area

- Imparare cose nuove o aumentare la conoscenza

Learning new things or increasing knowledge

- Visitare luoghi legati ai miei interessi personali

Visiting places related to my personal interests

Scala di risposta da 1 (per niente) a 5 (molto). Cronbach Alpha $=0.803$

Sviluppo personale (Self-Development):

"Quanto sono importanti le seguenti opportunità nella prospettiva di un ipotetico viaggio?"

- $\quad$ Sensazione di armonia/pace interiore

Feeling inner harmony/peace

- $\quad$ Sviluppare le mie abilità e capacità

Developing my skills and abilities

- $\quad$ Capire di più su di me

Understanding more about myself

- Guadagnare un senso di realizzazione

Gaining a sense of accomplishment

- $\quad$ Avere esperienze imprevedibili

Having unpredictable experiences

Scala di risposta da 1 (per niente) a 5 (molto). Cronbach Alpha $=0.842$

Fuga e Relazione (Escape and Relationship):

"Quanto ti influenzano i seguenti aspetti nella prospettiva di un ipotetico viaggio?"

- $\quad$ Essere lontano dalla routine quotidiana

Being away from daily routine

- $\quad$ Scaricare la pressione del lavoro

Release my work pressure

- $\quad$ Essere libero di agire nel modo in cui mi sento

Being free to act the way I feel

- $\quad$ Riposo e Relax

Resting and relaxing

- $\quad$ Fare qualcosa con la mia famiglia/ amici

Doing something with my family/friends

Scala di risposta da 1 (per niente) a 5 (molto). Cronbach Alpha $=0.745$

2. CULTURE: 10 items per "Cosmopolitismo", 5 items per "Interazioni sociali", 3 items per "Apertura e desiderio di emulare la cultura globale del consumatore". (Carpenter, J., Moore, M., Doherty, A. M., Alexander, N. (2012),

"Acculturation to the global consumer culture: a generational cohort comparison", Journal of Strategic Marketing, 20:5, 411423).

Cosmopolitismo (Cosmopolitanism):

"Quanto sei d'accordo con ciascuna di queste affermazioni?"

- $\quad$ Sono interessato a saperne di più sulle persone che vivono in altri paesi

I am interested in learning more about people who live in other countries

- $\quad$ Mi piace conoscere altri modi di vita

I like to learn about other ways of life

- $\quad$ Mi piace stare con persone di altri paesi per scoprire i loro punti di vista e approcci unici

I enjoy being with people from other countries to learn about their unique views and approaches

- Mi piace provare ristoranti che offrono cibo diverso da quello della mia cultura

I like to try restaurants that offer food that is different from that in my own culture

- $\quad$ Mi piace scambiare idee con persone di altri paesi o di altre culture

I enjoy exchanging ideas with people from other cultures or countries

- $\quad$ Mi piace osservare persone di altre culture per vedere quello che posso imparare da loro

I like to observe people of other cultures to see what I can learn from them

- Trovo stimolanti le persone di altre culture 
I find people from other cultures stimulating

- $\quad$ Mi piace provare cibo straniero

I enjoy trying foreign food

- Quando viaggio, mi piace immergermi nella cultura delle persone che sto visitando

When travelling, I like to immerse myself in the culture of the people I am visiting

- $\quad$ Entrare in contatto con persone di altre culture mi ha aiutato tanto

Coming into contact with people of other cultures has greatly benefited me

Scala di risposta da 1 (pienamente in disaccordo) a 5 (pienamente d'accordo). Cronbach Alpha=0.95.

Interazioni sociali (Social interactions):

"Quanto sei d'accordo con ciascuna di queste affermazioni?"

- Durante le vacanze, preferisco stare nel mio paese d'origine, piuttosto che visitare un altro paese

While vacationing, I would prefer to stay in my home country, rather than visit another country

- $\quad$ Preferisco trascorrere le mie vacanze al di fuori del paese in cui vivo

I prefer spending my vacations outside of the country that I live in

- Visitare l'estero è una delle cose che preferisco

Visiting foreign countries is one of my favourite things

- $\quad$ Spesso penso di andare in paesi diversi e fare qualche viaggio

I often think about going to different countries and doing some travelling

- $\quad$ Mi sento a casa in altri paesi

Ifeel at home in other countries

Scala di risposta da 1 (pienamente in disaccordo) a 5 (pienamente d'accordo). Cronbach Alpha=0.89.

Apertura e desiderio di emulare la cultura globale del consumatore (Openness and desire to emulate global consumer culture)

"Quanto sei d'accordo con ciascuna di queste affermazioni?"

- Penso che le persone della mia età siano praticamente le stesse nel mondo. (Ad esempio, un ventenne in Russia è praticamente come un ventenne negli USA o in Svezia o altrove).

I think people my age are basically the same around the world. For example, a 20-something in Russia is basically the same as a 20something in the USA, Sweden, or anywhere else

- $\quad$ Penso che il mio stile di vita sia quasi lo stesso delle persone della mia fascia d'età in altri paesi

I think that my lifestyle is almost the same as that of people of my age-group in other countries

- $\quad$ Penso che il mio stile di vita sia quasi uguale a quello delle persone della mia classe sociale in altri paesi.

I think my lifestyle is almost the same as that of people of my social class in other countries

Scala di risposta da 1 (pienamente in disaccordo) a 5 (pienamente d'accordo). Cronbach Alpha $=0.88$

3. LIFESTYLE: 4 items per "Esperienza culturale", 3 items per "interesse a viaggiare", 3 items "Varietà". (Lee, S.H., Sparks, B. (2006), "Cultural influence on travel lifestyle: A comparison of Korean Australians and Koreans in Korea", Tourism Management, 28:505-518).

Esperienza culturale (Cultural experience):

"Prenderei la decisione di partire, per scoprire:"

- $\quad$ Cibi e bevande locali

The local foods and drinks

- $\quad$ Un posto nuovo con nuove culture e nuovi modi di vivere

A new place with new cultures and new ways of living

- $\quad$ La popolazione e i costumi locali

The local people and customs

- Luoghi di formazione

Educational places

Scala di risposta da 1 (pienamente in disaccordo) a 5 (pienamente d'accordo). Cronbach Alpha=0.78. 
Interesse a viaggiare (Travel interest):

"Quanto sei d'accordo con ciascuna delle seguenti affermazioni?"

- $\quad$ Farei un viaggio piuttosto che rimanere a casa

Taking a trip rather than stay at home

- $\quad$ Spenderei molto più denaro in viaggi piuttosto che in qualsiasi altra cosa

Spending a windfall of money on holiday travel more than something else

- Ho interesse a viaggiare

Interest in travelling

Scala di risposta da 1 (pienamente in disaccordo) a 5 (pienamente d'accordo). Cronbach Alpha $=0.80$

Varietà (Variety):

"Partirei per:"

- Visitare posti con una vasta gamma di negozi

Visiting places with a range of shopping

- Visitare posti in occasioni di festival

Visiting places on the occasion of a festival

- Visitare luoghi con una grande varietà di attività e attrazioni

Visiting places with a large variety of activities and sights

Scala di risposta da 1 (pienamente in disaccordo) a 5 (pienamente d'accordo). Cronbach Alpha=0.67.

Active evaluation:

1. Destination image (cognitive): 10 items. (Agapito, D., Valle, P. O., Mendes, J. C., (2013), "The Cognitive-Affective-Conative model of destination image: A confirmatory analysis", Journal of Travel \& Tourism Marketing, 30:5, 471-481).

"Quanto prendi in considerazione i seguenti elementi per valutare la scelta della destinazione turistica?

- Residenti amichevoli e ricettivi

Friendly and receptive residents

- Interessante patrimonio culturale

Interesting cultural heritage

- $\quad$ Buoni ristoranti

Good restaurants

- Buona gastronomia

Good gastronomy

- Interessanti eventi culturali

Interesting cultural events

- $\quad$ Porto turistico piacevole

Pleasant marina

- $\quad$ Centro storico attraente

Attractive historical center

- $\quad$ Buon rapporto qualità-prezzo

Good value for money

- $\quad$ Buone possibilità di shopping

Good shopping opportunities

- Buona sistemazione

Good accommodation

Scala di risposta da 1 (per niente) a 5 (molto). Cronbach Alpha $=0.818$.

2. E-WOM: 5 items per "Rank", 3 items per "Ratings", 5 items per "InfoQuality". (Filieri, R. (2014), "What makes online reviews helpful? A diagnosticity-adoption framework to explain informational and normative influences in e-WOM", Journal of Business Research, 68:1261-1270).

RANK (Overall Product Ranking):

"Attraverso le recensioni o le informazioni ricercate sui forum:"

- $\quad$ Ho ridotto il numero di destinazioni alternative che stavo pensando di visitare

Has reduced the number of alternative products/services that I was considering buying

- $\quad$ Ho identificato rapidamente le migliori (o peggiori) destinazioni

Has helped me to rapidly identify the best (and the worst) products/services

- Ho indirizzato la mia decisione di acquisto verso una specifica destinazione

Has guided my purchase decision to a specific product/service

- Ho facilitato la mia decisione di acquisto

Has facilitated my purchase decision

- Ho potuto identificare la destinazione che potesse soddisfare le mie esigenze

Has enabled me to identify the product/service that could satisfy my needs

Scala di risposta da 1 (pienamente in disaccordo) a 5 (pienamente d'accordo). Cronbach Alpha= 0.909 .

RATINGS (Customer Ratings):

"Le recensioni su internet:"

- Mi hanno aiutato a conoscere la destinazione 
Customer ratings have helped me to learn about the product

- Hanno migliorato la mia comprensione della qualità delle caratteristiche della destinazione

Have improved my understanding of the quality of the product's features

- Sono state utili per valutare la qualità delle caratteristiche/specifiche della destinazione

Were useful in order to evaluate the quality of product specifications/features

Scala di risposta da 1 (per niente) a 5 (molto). Cronbach Alpha $=0.899$.

INFOQUALITY (Information quality):

"Ritieni che:"

- Le informazioni delle recensioni on-line erano credibili

The information from online reviews was credible

- Le informazioni delle recensioni online erano rilevanti per le mie esigenze

The information from online reviews was relevant to my needs

- Le informazioni delle recensioni online si basavano su fatti reali

The information from online reviews was based on facts

- Le informazioni delle recensioni online erano sufficientemente dettagliate

The information from online reviews was of sufficient depth (degree of detail)

- Le informazioni delle recensioni online erano sufficientemente ampie (riguardavano diverse tematiche)

The information from online reviews was of sufficient breadth (spanning different subject areas)

Scala di risposta da 1 (pienamente in disaccordo) a 5 (pienamente d'accordo). Cronbach Alpha $=0.854$.

Moment of purchase:

1. Caratteristiche dell'agenzia di viaggi: 4 items per "Valore funzionale dell'agenzia di viaggi", 4 items per "Valore funzionale del personale di contatto dell'agenzia di viaggi", 3 items per "Valore funzionale del prezzo". (Sànchez, J., Callarisa, L., Rodrìguez, R. M., Moliner, M. A. (2006), "Perceived value of the purchase of a tourism product", Tourism Management, 27:394-409).

Valore funzionale dell'agenzia di viaggi (Functional value of the travel agency (installations)

"Al fine di concludere l'acquisto presso l'agenzia di viaggi piuttosto che autonomamente su un sito Web, quanto sono importanti le seguenti caratteristiche?"

- $\quad$ La distribuzione degli interni che favorisce confidenzialità e privacy

The distribution of the interior favoured confidentiality and privacy

- La struttura ordinata e ben organizzata

The establishment was neat and well organised

- $\quad$ Le strutture spaziose, moderne e pulite

The installations were spacious, modern and clean

- La struttura è ben posizionata (facilmente reperibile, centrale/buoni collegamenti di trasporto)

The establishment was well located (easily found, central and/or with good transport links)

Scala di risposta da 1 (per niente) a 5 (molto). Cronbach Alpha $=0.84$

Valore funzionale del personale di contatto dell'agenzia di viaggi (Functional value of contact personnel of the travel agency (professionalism).

“Al fine di concludere l'acquisto presso l'agenzia di viaggi, quanto influiscono le seguenti affermazioni riguardanti il personale interno all'agenzia?"

- $\quad$ Erano professionisti ed erano informati su nuove tendenze ed elementi

They were good professionals and they were up-to-date about new items and trends

- Conoscevano bene il proprio lavoro

They knew their job well

- Il loro consiglio era prezioso

Their advice was valuable

- Conoscevano i pacchetti turistici

The knew the tourism packages

Scala di risposta da 1 (per niente) a 5 (molto). Cronbach Alpha $=0.89$

Valore funzionale del prezzo (Functional value price):

"L'agenzia ha soddisfatto le tue esigenze, perché:"

- $\quad$ È stato un buon acquisto per il prezzo pagato

It was a good purchase for the price paid

- Il pacchetto turistico acquistato era a prezzi ragionevoli

The tourism package purchased was reasonably priced

- $\quad$ Il prezzo era un criterio principale per la decisione

The price was the main criterion for the decision

Scala di risposta da 1 (pienamente in disaccordo) a 5 (pienamente d'accordo). Cronbach Alpha=0.85

2. Caratteristiche del sito Web: 10 items per "Contenuto informativo", 5 items per "Facilità d'uso", 3 items per "Personalizzazione". (Tarafdar, M., Zhang, J. (2005), "Analysis of Critical Website Characteristics: A Cross-Category Study of Successful Websites", Journal of Computer Information Systems, 46:2, 14-24). 
"Al fine di concludere l'acquisto sul sito web, quanto reputi importanti le seguenti caratteristiche?"

- La gamma delle informazioni è elevata

The range of information is high

- Le informazioni sono applicabili alle attività del sito

The information is applicable to the website's activities

- $\quad$ Le informazioni sono dettagliate

The information is detailed

- $\quad$ Le informazioni sono aggiornate

The information is current

- Le informazioni sono accurate

The information is accurate

- $\quad$ È facile trovare le informazioni

It is easy to locate the information

- Le informazioni sono utili

The information is useful

- Le informazioni sono organizzate sistematicamente

The information is systematically organized

- Il significato delle informazioni è chiaro

The meaning ofthe information is clear

- Il layout delle informazioni è facile da capire

The layout of the information is easy to understand

Scala di risposta da 1 (per niente) a 5 (molto). Cronbach Alpha $=0.91$.

Facilità d'uso (Usability:

"Al fine di concludere l'acquisto sul sito web, quanto reputi importanti le seguenti caratteristiche?"

- Il sito è divertente da usare

The website is entertaining (it's fun to use).

- Il sito è emozionante e interessante

The website is exciting and interesting.

- Il sito è facile da usare

The website is easy to use.

- L'uso di multimedia è efficacie per le mie attività sul sito

The use of multimedia is effective for my tasks at the website.

- Il sito ha un layout attraente

The website has an attractive layout

Scala di risposta da 1 (per niente) a 5 (molto). Cronbach Alpha=0.88.

Personalizzazione (Customization)

"Al fine di concludere l'acquisto sul sito web, quanto reputi importanti le seguenti caratteristiche?"

- Il sito ha caratteristiche di personalizzazione

The website has personalization characteristics

- $\quad$ Il sito offre informazioni personalizzate

The website offers customized information

- $\quad$ Il sito permette la progettazione di prodotti personalizzati

The website has provisions for designing customized products

Scala di risposta da 1 (per niente) a 5 (molto). Cronbach Alpha $=0.87$

Post-Purchase experience:

1. Trip Quality: 6 items per "Ospitalità", 3 items per "Trasporti". (Chen, C.F., Tsai, D.C. (2007), "How destination image and evaluative factors affect behavioral intentions?", Tourism Management, 28:1115-1122).

Ospitalità (Hospitality).

"Al termine del tuo viaggio, analizzando la qualità generale dell'esperienza, quanto incidono i seguenti fattori sulla tua valutazione?"

- $\quad$ Prezzo del soggiorno

Price of accommodation

- Prezzo delle attività

Prices of activities

- Alimenti e bevande dell'alloggio

Food and beverage of accommodation

- $\quad$ Servizi del personale alberghiero

Services of accommodation workers

- $\quad$ Prezzi del cibo e delle bevande

Prices of food \& beverage

- $\quad$ Sicurezza delle attività

Safety of activities

Scala di risposta da 1 (per niente) a 5 (molto). Cronbach Alpha $=0.85$. 
Trasporto (Transport):

“Al termine del tuo viaggio, analizzando la qualità dell'esperienza, quanto incidono i seguenti elementi sulla tua valutazione?"

- Accessibilità

Accessibility

- $\quad$ Trasporti interni

Internal transport

- $\quad$ Parcheggi e spazi

Parking facilities and space

Scala di risposta da 1 (per niente) a 5 (molto). Cronbach Alpha $=0.77$.

2. Satisfaction: 3 items. (Hernández-Lobato, L., Solis-Radilla, M. M., Moliner-Tena, M. A., Sánchez-García, J. (2006), "Tourism destination image, satisfaction and loyalty: A study in Ixtapa-Zihuatanejo, Mexico”, Tourism Geographies, Vol.8, No.4:343358).

"Al termine del tuo viaggio, per sentirti pienamente soddisfatto, quanto influiscono i seguenti elementi?"

- $\quad$ Soddisfazione del soggiorno

Satisfaction with the stay 0.87

- $\quad$ Soddisfazione dei servizi di ristorazione

Satisfaction with the restaurant services 0.95

- $\quad$ Soddisfazione dei servizi alberghieri

Satisfaction with the hotel services 0.89

Scala di risposta da 1 (per niente) a 5 (molto). Cronbach Alpha $=0.93$.

3. Behavioural Intentions: 3 items. (Zabkar, V., Brencic, M. M., Dmitrovic, T. (2010), "Modelling perceived quality, visitor satisfaction and behavioural intentions at the destination level", Tourism Management, Vol.31, n. 4:537-546).

“Al termine del tuo viaggio, reputando l'esperienza di alta qualità e soddisfacente, quanto sei d'accordo con le seguenti affermazioni?

- $\quad$ Se dovessi decidere nuovamente, sceglierei ancora questa destinazione

If had to decide again I would choose the destination again

- $\quad$ Raccomanderò la destinazione ad amici e parenti

Will recommend the destination to friends and relatives

- $\quad$ Parlerò bene della destinazione ad amici e parenti

Will speak highly of the destination to friends and relatives

Scala di risposta da 1 (pienamente in disaccordo) a 5 (pienamente d'accordo). Cronbach Alpha=0.90. 



\title{
Museums' management innovation in the time of COVID-19 Crisis and opportunities
}

\author{
ANNAMARIA ESPOSITO* ANGEla BeSANA ${ }^{*}$ \\ M. CRISTINA VANNINI^ CHIARA FiSICHELLA ${ }^{* *}$
}

Introduction and Objectives. Cultural institutions have been hit hard by the lockdown that led to the complete stop of the supply of cultural services in praesentia and world's museums have been forced to temporarily close their doors to protect their visitors.

If it is still not possible to understand how and when the activity can resume at full speed, this moment also appears as an interesting opportunity to reflect on management innovation, and on how to rethink the cultural offer in a digital key. In fact, in recent months, cultural institutions have reacted by making their repertoire available online or by increasing digital virtual tours in the case of museums, up to experimenting with some cultural productions made at a distance: from traditional visits to digital access and personalized experience. Museums and cultural sites have therefore temporarily turned visitors into users doubling their online activities and increasing the number of their social media followers.

In addition to a way to to maintain their cultural role and to preserve jobs for their employees, this represented an attempt to offer, in a short time, a response to compensate for a demand for sociability and use of cultural content that is perhaps greater now than ever. However, it seems not only appropriate, but urgent, to reflect on how this experience can lead to a redefinition of the consolidated model of construction, supply and use of the cultural offer, opening up to a phase of coherent digital transformation.

The paper helps the reader to better understand the challenges and key issues arising from digital innovations and the changes in the environment of museums, as well as providing some useful strategies for museum management, including small museums, in view of the "new normal".

Starting from those premises, the paper aims at pointing out how pandemic expressed a strong push towards museum innovation. Particularly, it contributes to detect the changes that are occurring in the museum environment, both on cultural offer and cultural demand.

Methodology. This study was conducted taking into account two different points of view, the offer and the demand in the museum environment. Considering the offer, we studied the changes that have emerged in museum practices by analysing the behaviours in responding to the Covid-19 crises, and especially by observing the emergence of digital innovation in cultural offer and by examining relationships and dialogue with the public via social media. Considering the demand, we studied the public expectations and possible reactions to the changes that museums are about to activate.

To answer the research questions, research methodology has been divided into three phases:

a) literature analysis, which has been focused on a series of observation points. Regarding to the offer we considered issues related to museum environments, digital museology (Hafsteinsson, Larsen 2011; Rudloff 2013), digital heritage (Marty, Parry 2008; Parry 2007, 2010), digital cultural heritage (Cameron, Kenderdine 2007; Villaespesa, Navarrete, 2019), virtual exhibitions (Kim, 2018) and the adoption of more user-oriented communication strategies such as personalization and participation via web and social media (Holdgaard, Klastrup, 2014; Olesen, 2016; Budge, Burness, 2018; Myrczik, 2018). Regarding to the demand, we focused on visitors' behaviour and experience (Falk, 2009; Runnel, Pruulmann-Vengerfeldt, 2014; Antón, Camarero, Garrido, 2017).

b) Online survey on the demand side. We considered the questionnaire designed by Soluzionimuseali - consulting society for museums, public and private bodies in Milan- to explore visitor intentions and the willingness of the public

\footnotetext{
Associate Professor of Marketing - IULM University of Milan - Italy e-mail: annamaria.esposito@iulm.it

- Associate Professor of Economics - IULM University of Milan - Italy e-mail: angela.besana@iulm.it

- Adjunct Professor - IULM University of Milan - Italy e-mail:_m.cristina.vannini@ soluzionimuseali.com

** Adjunct Professor - IULM University of Milan - Italy e-mail: c.fisichella@virgilio.it
} 
to return to take advantage of the museum offer at the end of the lockdown. The questionnaire included a mixture of closed and open questions to allow us gathering as much information as possible to collect and appreciate the most spontaneous motivations, aspirations, and concerns of the respondents. So, in the midst of the Italian lockdown period, we launched that online sentiments survey on visitors' attitudes about returning to the museums, especially regarding expenditure and travelling attitudes. The sample was collected among social networks channel gathering 723 useful replies.

c) On the supply side, Pearson correlation index and Financial Ratio Analysis. The choice of the sample was concentrated on Italian and international museums (in Findings cited) with diversified revenues from ticketing, memberships, edutainment and merchandising in praesentia. A comparative approach between these performances for different targets of visitors and online availability with the supply of virtual tours was useful to give evidence of the poles of cultural supply in Covid-19 times. The analysis of revenues was concerning sponsorships and (public and private) grants, too, in order to estimate the advocacy of fund-givers and fundraisers before, during and after the lockdown. Both the analysis on the demand side and on the supply side, they will show clusters of visitors and museums, all of them returning economic data about expenditures and revenues and about marketing and fundraising.

Findings. Considering the offer, lockdown has changed the face of museums and exhibitions thanks to digital. Covid-19 crises forced digital fruition of cultural offer. In these last two months, million visitors have surfed various platforms to experience museums and exhibition virtual tour. For example, the exhibition at the Scuderie del Quirinale "Raffaello 1520-1483" since March 26 has reached 2 million visitors, the Uffizi Decameron and all the virtual reality tours of the museum rooms that have registered only on Facebook 1.7 million views and 44,888 followers (on Instagram 468,586), again to the Walks of the Director, Christian Greco, of the Museo Egizio has, so far, counted 102,365 total views (Pirrelli, 2020). Museums have strengthened social activity on Facebook, Instagram, Twitter, YouTube, on websites, on web TV and on Google Art \& Cultures, expanding their audience.

The virtual experiences and cultural activities carried out by some big Italian museums and cultural institutions have entered the homes of the Italians to show high definition digital artistic heritage. These are significant results especially considering that the situation was still very fragmented last year: in 2019 almost $80 \%$ of the museums had at least partially digitized their collection but only 30\% had already published part of it online. Furthermore, in 2019, $67 \%$ of museums had a Facebook account but only $26 \%$ had an Instagram account. According to the report of the Osservatorio Innovazione digitale dei Beni e delle Attività culturali del Politecnico di Milano (2020) out of a sample of 420 Italian museums, $76 \%$ did not have a strategic plan formalized with respect to digital innovation and one museum out of 2 declared that they carried out less than $10 \%$ of digital investments.

It emerges that digital innovation is one of the crucial challenges for museums in the next years. This process is led by the Italian Ministry of Cultural Activities and Tourism thanks to the "Three-year Plan for the Digitization and Innovation of Museums" that aims at activating new forms of access and use of heritage data, mediated or enabled by technological solutions. As the matter of the fact, apart from digital innovation that complemented the on-site visitfrom the QR code to the audio guides- the most digitized activity, was cataloguing, followed by ticketing and security. This means that much remains to be done especially regarding to digital communication.

But what does digital museum innovation consist of? Considering the digital transformation in museums, it is possible to categorize it in some factors (Tu, 2019): digital archives, virtual reality, augmented reality and artificial intelligence.

The digital archive is the first step of the digital transformation of a museum and is the basis of making his repertoire available online. Many museums are investing in the construction of digital archives: in Italy Galleria degli Uffizi is one of this. From 2018 is it possible to access to their paintings and sculptures from their website but the digital archives are not still completed.

A virtual museum adopts virtual reality technology to provide to visitors a virtual visit of the museum. Among the big ones, Musei Vaticani, Louvre, Pinacoteca di Brera, British Museum, Prado, Van Gogh Museum are some example of museums that permits virtual visit, although we have assisted to the proliferation of many "home-made" medium and little museums virtual tours. However, a virtual visit of the existent architecture of a museum and his rooms is the basic way of using virtual reality. In fact, there are three different participation methods - immersive, interactive and imaginary - and four kinds of quasi-reality systems: distributed virtual reality system, enhanced virtual reality system, immersive virtual reality system, and desktop virtual reality system (Tu, 2019). An example of a museum with an innovative virtual reality visit is The Finnish Virtual Art Gallery: their virtual reality application shows examples of their Finnish artists' works by simulating a gallery located in a space base, presumably orbiting between the Moon and Mars.

Augmented reality (Dieck, et al. 2016) is an enrichment of reality with additional digital data: images, video, text or sounds. Augmented reality mainly includes various kinds of displays: mobile handheld, video spatial and spatial enhanced, and wearable displays (Tu, 2019). Augmented reality is very important for inclusion and accessibility: for example, the MuSa Accessible Museum is an app created by Università degli Studi di Milano with ANS (National Subvedent Association) for broaden the audience of works of art as much as possible through collaboration between people with disabilities and others. The project is still ongoing and will end in 2021. More, also small museums can enhance augmented reality content: VareseMusei is an example of it.

Artificial Intelligence is the future in museum management and museum visitor experience. For instance, thanks to artificial intelligence, every visitor can have a personalized assistant listening carefully to one's requests, who can 
learn from one's questions and understand which type of narration is more in line with one's visiting style. An example of AI application on museum visitor experience is the Museyoum application.

Considering that many visitors of Italian museums are tourists, digital will continue to be - after lockdown - an important as complementary offer, as well as digital communication. These digital experiences can be considered among the new cornerstones of visitor satisfaction. In any case, museums must not forget to design emotional inmuseum visitors experience.

For once, museums seem ready to take action in adjusting their demands to the expectations of the public. Maybe, they have always willing to do so but, at last, the renovation in the structural scheme imposed by the recovery from the pandemic, might have create the grassroots to achieve the change.

Considering the demand side, thanks to the survey and by recalling the past-Covid 19 habits and willingness to spend, we have been able to foresee what the public expects and how he is going to react to the changes that museums are about to activate.

A need of emotions more than experiences, is what emerges in the analysis, either this is due to the period of confinement or it is a real plea for entering the space of knowledge and culture with an immersive comprehension that goes beyond digital and technological filters: direct, almost physical contact that allows to establish an intimate dialogue with the objects on displays and to adapt the story of the objects themselves with the very one of the viewers.

To this respect, limitation to the access of the public is welcome since, especially in the most famous museums or in the so-called block-buster exhibitions, experience of masterpieces in crowded rooms does not represent the optimal way to intimacy. Limitation in number of visitors represent a change in the interior environment and in economic terms but this is to be explored further.

Broad segmentation in the respondents is marked by what kind of exhibit - temporary or permanent - is preferred by the public: if on the one hand contemporary and visual art are preferred by many for reasons that we will be going to explain, on the other hand it is true that museums and exhibitions are seen as "escape-rooms" or "portals" enabling some sort of time-warp in which visitors like to lose themselves as a regenerative exercise from their ordinary everyday routine or as a gratification or a self-training experience. In this sense, though, again, it is not the technological aspect the one that makes the time-warp happen but the setting of the environment, the sequence in the display path and the direct contact with the objects.

Barriers to technology and virtuality can be justified by the over-exposure people have experienced during the Covid-19 lockdown, when our lives had to meet ends with our computers and technology more than ever before: not-sosmart-working experiences, ultra-time spent in webinars, conferences, meetings, tutorials, videos, gaming of any kind both for the purpose of our jobs or for leisure and need to keep in touch - albeit virtual - with relatives and friends. Situation whose consequence is to have arose the expertise of normally not-so-skilled people in recognising the quality levels of the virtual and technological offers. Compliant with the level of quality and of further support to knowledge, some of the respondents are willing to pay a fee in terms of subscription or pay-per-use; it is not accepted that beauty and culture might be tamed by unexperienced or untalented occasional technological experiments.

This is why it is important that from now on museums will be given the chance to work on a common and well established digital strategy campaign in order not to let the digital divide (and the resources in terms of competencies and of economics to achieve it) set apart more wealthy museums from the less ones and, by that, their respective audiences.

Quarantine isolation gave more sense to the quest of sociality museums are called to develop. Although the experience of visiting exhibits is an individual fulfilment, respondents recognise museums as social spaces, in which communities of individuals with the same elective affinities can share, compare, and build on common values.

Museums are recognised as meaningful places under multifaceted points of view: besides the traditional aims of preservation of cultural heritage both tangible (the objects) and intangible (the stories and the expertise connected to them), the reach of many other goals in the societal domain is expected by the various stakeholders such as social impact, advocacy and therapeutic wellbeing, contributing to include museums and their cultural offer in the welfare sphere. In this sense, museums must learn to open themselves not only with the help of digital technology but properly to go out of their physical spaces in a physical way: bring the objects and the stories in the open-air.

The counterbalance of the positive results collected by the survey is the general sentiment of the respondents about travelling and spending in the forthcoming months of the so-called recovery or reopening after Covid-19. The analysis confirms a picture of proximity tourism and of decrease in family budgets to be dedicated to leisure and cultural activities.

From an economic standpoint, the analysis economic performances confirmed diversified targets and revenues before the lockdown. During the lockdown, museums had resources enough only to concentrate to a unique and homogeneous audience of online visitors with some very interesting calls for advocacy of students and specific online visitors who had to fulfil their research issues (for example, for secondary school students with their final exams in June 2020). Social media were a pivotal communication tool in order to solicit and connect with specific issues. During lockdown, a prompt communication tried to retained sponsors and grant-makers, who are now confronting themselves with a dramatic economic crisis which could change their minds on cultural sense and sensibility.

Research limits. On the supply side, the paper considers an ongoing situation and studies big museums with mature marketing, fundraising and the highest rankings for number visitors and just some small and medium-sized museums. So, sample and time represent limitations of the study. In addition, referring to Pearson correlation index and 
Financial Ratio Analysis, data are not at all available for analysis of ongoing economic performances. Financial issues are dramatically evident in every day's accounting of these organizations for ordinary contingencies and for extraordinary costs of 'healthy' museums. Furthermore, we use the financial analysis, and in the meanwhile, we are invoking new performance indicators for museums. We are conscious that could seem an oxymoron.

On the demand side, considering the data collection process, the main problem lies in the fact is the consistency of the sample collected in relation to the size of the Italian population,

Both the analysis on the demand side and on the supply side, they may concern different samples, but they are joint as respondents clearly ranked topics of the most visited museums, including those ones, whose economic performances were investigated for Pearson correlation.

Practical implications. The scenario described above opens up to different problems, among which funding, digital skills, museum performance indicators. Indeed, museums need grant funding to survive the period after lockdown in order to cope with a longer-term reduction in visitor numbers, philanthropy, national and international collaborations and other sources of income. It is not clear yet how museums might have access to the "Fondo Cultura" established by the last Decreto Legge 19 Maggio 2020, n. 34 or if the proposed budget for Culture by the EU Commission will be confirmed. In the present circumstances, museums could not have sufficient funds to invest in digital innovation nor to bridge the digital divide and provide staff with training needed to master digital communication and social media. So, fundraising and new competencies in digital communication will be the next challenges to keep up with post COVID-19 changes.

In addition, museums should not forget that digital products are created for the public who deserve the same importance that museums recognize in the art that they preserve. This is why, it is crucial that museums research what visitors do and what they want. This allows museums to offer products available on-line or digitally and services to be made used of both in presentia and virtually that make visitors enjoy the feeling to be free from traditional boundaries of museum walls and appreciate new horizons, accessing the collection or some specialized contents that may involve payment as would the purchase through the online shop. However, museums should consider that, according to our survey, digital visit of museum is not so widespread in this period. In addition, the largest number claim to have enjoyed cultural content during the lockdown sometimes or rarely. It also affects the opinion on the general quality of the offer, considered just sufficient.

According to Navarrete (2018), implementing digital applications helps museums to develop new products and services, new processes to research, display and manage collections, new organizational structures to accommodate a changed environment, reaching new markets, and tapping into existing resources to generate new capital. This will benefit also the lucky few onsite visitors of museums that will have the chance to enjoy cultural treasures without being jostled by crowds of tourists.

In the described-above scenario the biggest innovation - and challenge - will be to find new performance indicators for museums that do not depend on ticketing and on the number of visitors. Although these measures are relevant, there are still many concerns about how to measure efficiency or effectiveness in the museum sector (Zorloni, 2010).

Recent studies provided some evidence that museums performance is influenced by innovation (López et al., 2018; Jung, Vakharia, 2019), and that the concept of performance in museums go beyond financial indicators, being also related to non-financial areas. This suggests the need for a review of current thinking and recent developments in managing performance in museums.

Originality of the study. This is the first analysis of the demand and offer system in museum environment and their economic and social performances in a pandemic, though some comparisons can be done with the Spanish Fever times: at the beginning of last century cultural organizations had to restrict their cultural supply and only local and family exhibitions took place. The study considers the result of a survey that depict the expectation of the public in post pandemic restarting times and highlights the need of the development of new performance indicators for museums.

Key words: museum; digitalization; cultural offer; cultural demand; pandemic., performance indicators

\section{References}

ANTÓN C., CAMARERO C., GARRIDO M.J. (2017), "Exploring the experience value of museum visitors as a cocreation process", Current Issues in Tourism, DOI: 10.1080/13683500.2017.1373753

BERTACCHINI E.E., DALLE NOGARE C., SCUDERI, R. (2018), “Ownership, organization structure and public service provision: the case of museums", Journal of Cultural Economics, vol. 42, n. 4, pp. 619-643.

BIEHL-MISSAL B., VOM LEHN D. (2015), "Aesthetics and atmosphere in museums: A critical marketing perspective", In M. Henning (Ed.), The International Handbooks of Museum Studies: Museum Media, Oxford: Wiley-Blackwell, pp. 235-258.

BOYD C.P., HUGHES R. (2020), Emotion and the Contemporary Museum, Singapore: Springer Nature.

BUDGE K., BURNESS A. (2018), "Museum objects and Instagram: agency and communication in digital engagement”, Continuum, vol. 32, n. 2, pp. 137-150. 
COURPASSON D., DANY F., DELBRIDGE F.R. (2016), "Politics of place: The meaningfulness of resisting places" Human Relations, vol. 30, n. 4, pp. 1-23.

DEPARTMENT FOR CULTURE, MEDIA AND SPORT (2013), "Museum performance indicators", available at: https://data.gov.uk/dataset/0f9ae4fc-ecad-4bec-a241-2a4cb4372f07/museum-performance-indicators

DIECK M.C., JUNG T.H., DIECK D. (2016), "Enhancing Art Gallery Visitors' Learning Experience Using Wearable Augmented Reality: Generic Learning Outcomes Perspective." Current Issues in Tourism, vol. 21, n. 17, pp. 2014-2034.

FALK J.H. (2009). Identity and the Museum Visitor Experience. Walnut Creek, CA: Left Coast Press.

FARRELl B., MEDVEDEVA M. (2010), Demographic Transformation and the Future of Museums, Chicago, IL: American Association of Museums.

FERILLI G., GROSSI E., SACCO P.L., TAVANO BLESSI G. (2016), “Museum environments, visitors' behaviour, and well-being: beyond the conventional wisdom”, Museum Management and Curatorship, vol. 32, n. 1, pp. 80102.

HOLDGAARD N., KLASTRUP L. (2014), "Between control and creativity: challenging co-creation and social media use in a museum context", Digital Creativity, vol. 25, n. 3, pp.190-202.

JUNG Y., VAKHARIA N. (2019), "Open Systems Theory for Arts and Cultural Organizations: Linking Structure and Performance", The Journal of Arts Management, Law, and Society, vol. 49, n. 4, pp. 257-273.

Kim, S. 2018. "Virtual Exhibitions and Communication Factors." Museum Management and Curatorship, vol. 33, n. 3, pp. 243-260.

LÓPEZ B., RECUERO M.F., VIRTO N. SAN-MARTÍN S. (2018), “The cornerstones of museum performance. A cross-national analysis", Museum Management and Curatorship, vol. 34, n. 2, pp. 211-233.

MYRCZIK E. P. (2018), "Cultivating digital mediation: The implementation of publicly funded digital museum initiatives in Denmark", International Journal of Cultural Policy, DOI: 10.1080/10286632.2018.1495714

NAKAMOTO, S. (2009), "Bitcoin: A peer-to-peer electronic cash system", available at https://bitcoin.org/bitcoin.pdf

NAVARRETE T. (2019), "Digital heritage tourism: innovations in museums", World Leisure Journal, vol. 61, n. 3, pp. 200-214.

PIRRELli M. (2020), "Mostra o museo, la visita virtuale buca lo schermo", 24ArtEconomy, avallabile at https://www.ilsole24ore.com/art/mostra-o-museo-visita-virtuale-buca-schermo-ADgp9aM

ROGERS P.L. (2020), "Barriers to adopting emerging technologies in education", Journal of Educational Computing Research, vol. 22, n. 4, pp. 455-472.

RUNNEL P., PRUULMANN-VENGERFELDT P. (Eds) (2014), Democratising the museum: reflections on participatory technologies, Frankfurt am Main: Peter Lang Verlag.

SACCO P.L. (2016), "How do museums create value?", Money Matters: The Economic Value of Museums, Proceedings of the 24th NEMO Conference.

SANDELL R. (Ed.), (2005), Museums, society, inequality, London and New York: Routledge.

TIM, Y., PAN, S. L., OUYANG T., (2018), "Museum in the Age of Digital Transformation", PACIS 2018 Proceedings, available at https://aisel.aisnet.org/pacis2018/102

TU S. (2019), “Analysis on the Development Trend and Application Technology of Digital Museum”, Proceedings of the 1st International Symposium on Innovation and Education, Law and Social Sciences (IELSS 2019), DOI:10.2991/ielss-19.2019.26

ZORLONI A. (2010), "Managing performance indicators in visual art museums", Museum Management and Curatorship, vol. 25, n. 2, pp. 167-180.

\section{Websites}

http://data.gov.uk 



\title{
Green enablers and disablers in fashion green luxury consumption
}

\author{
MONICA FARAONI LAMBERTO ZOLLO` RAFFAELE FILIERI^
}

Objectives. Sustainability has become a topic of major interest in all areas of consumption. However, still today there is no consensus among scholars about the meaning of sustainability in the context of luxury (Dean, 2018). The conflicts between luxury and sustainability are made clear "by the association of luxury consumption with ostentation, excessive consumption, overproduction, indulgence and personal pleasure" (Athwal et al., 2019, p. 407) while sustainability consumption is generally coupled with moderation and ethical values (Naderi and Strutton 2015). Some researchers underlined how it would seem natural to ascertain the irrelevance of sustainability in the world of luxury (Davies and Streit 2013; Henninger et al. 2017; Hu et al. 2018; Joy et al. 2012; Ko and Megehee 2012). As noted by Moraes et al. (2017) "conspicuous consumption" - that is luxury - "is necessarily superfluous and therefore negative”. The reticence of a large part of the literature to combine the concepts of luxury and sustainability has meant that the study concerning the combination of these two concepts was inevitably limited, and this is what drives us to investigate this issue. In particular, in the study of the relationship between the attitude and the purchasing intention of sustainable products there are many motivating factors or green enablers that favor the buying process as there are many cognitive dissonances or green disablers that can negatively interact on this process. Many researchers study the value of luxury as a driver of sustainable behavior based on high quality products, superior durability and deeper value (e.g. Hennigs et al., 2013; Shukla et al., 2012; Wiedmann et al, 2007; Wiedmann et al, 2009). Environmental concerns, the search for novelties (Choi et al., 2019) and self-identification as "green" consumers (Sparks et al., 1992; Shaw et al., 2003) are the basis of motivating factors or green enabler factors. Self-identity, was defined by Sparks et al. (1992) as a key predictor of behavior. According to Sirgy's Self-congruity Theory (1986), individuals who perceive themselves as green consumers are more likely to consider purchasing sustainable products positively because these items meet their selfdefinition needs, and allow them to derive a personal satisfaction from them; On the other hand, this entails an individual's willingness to change. The concept of Perceived readiness is well rooted in the organizational literature as a effective variable capable of predicting behavioral change (Arli et al., 2018). The authors argue that in countries where being "green" is not yet perceived as a social norm, engaging in sustainable consumer behavior requires a change in behavior. Furthermore, "this mood facilitates and accelerates the formation of the intention to act" (Arli et al., 2018, p. 392). In order to transform their attitude into an environmentally friendly one, consumers have to endure personal sacrifices and lifestyle changes (Haller et al, 2008); and this becomes easier when consumers believe that their decisions can make a difference in relation to environmental issues. Literature is rich in studies which establish a positive relationship between perceived consumer effectiveness (Straughan et al. 1999) and "green" purchasing attitudes and behaviors (for example, Roberts, 1996; Straughan et al., 1999). On the other hand, the literature identifies multiple barriers that work as obstacles to the choice of sustainable products such as the lack of alignment between the ethical and sustainable values of the luxury products and the inconsistent associations between luxury and environmental values: the former, in fact, are usually associated with elements such as ego, power and status (Cervellon et al., 2013), while the latter are normally related to altruism (Griskevicius et al., 2010). This can generate a perceived contradiction in the consumer mind (Kapferer et al., 2014) that is sometimes fueled by the phenomena of perceived greenwashing (Beckham et al., 2014) or the recognition, by consumers, of a corporate communication that conveys positive but false information regarding the environmental practices and or the environmental benefits of the products being marketing to them (Parguel et al., 2011). If a brand deceives its customers through greenwashing, these practices may involve negative word of mouth which discourages other consumers from purchasing the company's products and, consequently, reduces the general purchase intention (Chen et al., 2014; Leonidou et al., 2017). Therefore, greenwashing not only increases the skepticism of those who perceive it but also of many other consumers, especially nowadays, when information spreads at an exponential speed due to the massive presence and influence of social media (Lim et al., 2013). Zhang et al. (2018) in fact affirm how a decrease in the greenwashing perception by

\footnotetext{
Associate Professor of Management - University of Florence - Italy e-mail: monica.faraoni@unifi.it

- Assistant Professor of Management - University of Florence - Italy e-mail: lamberto.zollo@unifi.it

- Professor of Digital Marketing - Audencia Business School - France e-mail: rfilieri@audencia.com
} 
consumers may correspond to an increase in the purchase intention. Finally, the perceived green risk, the expectation of negative environmental consequences associated with the purchasing behavior could negatively influence the buying process (Mitchell, 1999; Chang and Chen, 2008). Another literature stream identifies differences in behaviors related to cultural factors and on the role of self-oriented or other-oriented motives. Belk (1988) underlines the significance of the relationship, between the sense of self and the possession of material goods: in fact, he defines possession as an "extended self". Bendell and Kleanthous (2007, p.5) suggest that today's luxury consumers want the brands "reflect their concerns and aspirations for a better world" and give "convincing answers to questions of environmental and social responsibility". They also suggest how a transition from the so-called "Self-orientation" to the so-called "Sustainable-orientation" is now occurring: therefore, in their view, luxury consumption today places a greater emphasis on sustainability rather than on the extension of the self. Other studies sustain that at the basis of sustainable luxury consumption there are other-oriented motives such as those in favor of the environment and philanthropy in emerging countries where visibility and imitative behavior are the masters (Ramchandani et al., 2012). Consumers spend to show that they are "green" consumers (Cervellon et al., 2011; Dugan, 2008) and, to show their concern for the environment and for society in general (Cervellon et al., 2013). A final relevant topic for understanding the phenomenon concerns cross-cultural issues. Given that the luxury market is, by its nature, international and that all luxury brands are present on a global level (Godey et al., 2013), consumers have developed a growing interest in luxury goods even in emerging markets (Athwal et al., 2019; Shukla, 2012; Yau et al., 2014). Monkhouse et al. (2012), for example, highlight how sustainability attitudes, behaviors and perceptions are strongly influenced by social pressure and carry out studies that investigate the behavior of consumers belonging to collectivist cultures (such as China) and individualist cultures (such as Western Europe) is important for the understanding of the way societies respond to sustainable luxury. Rojas-Mendez et al. (2015), studies show how in the consumption of sustainable luxury, materialistic values are not relevant in western countries, while the same seem to be the enablers factors in the emerging Eastern markets (Sharma, 2010). The considerations just made, regarding the state of the art and the identification of the existing literature gaps in the consumption of sustainable luxury, have allowed us to develop our research question, which we will try to answer through empirical analysis, as follows:

$\boldsymbol{R Q}:$ What are the drivers and the barriers that favor / prevent the consumption of sustainable luxury and how do they differ according to the culture they belong to?

In this regard, some research hypotheses have been developed as illustrated in Figure 1.

Fig. 1: Conceptual Model

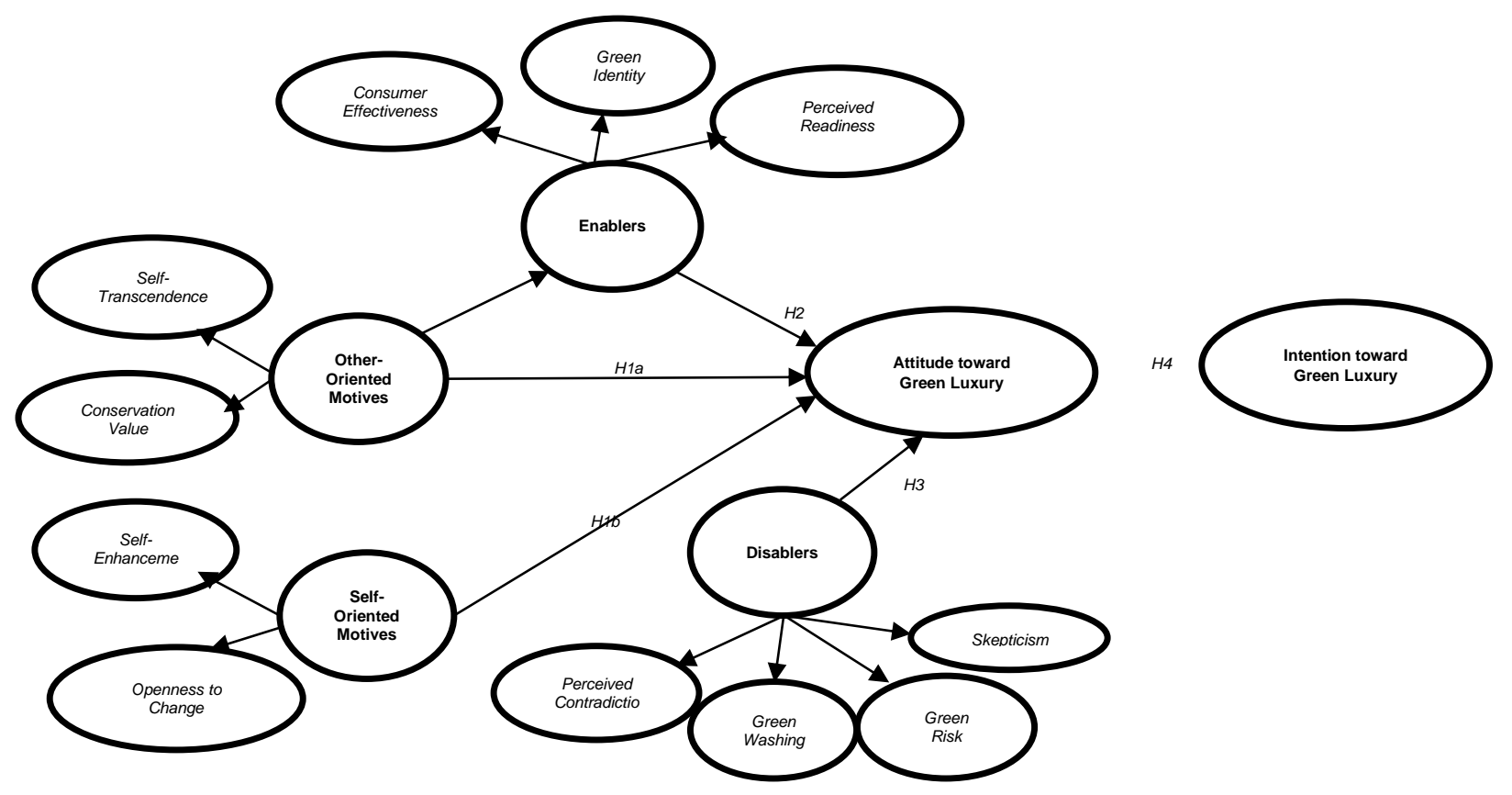

The hypothesized relationships are indicated by $H 1, H 2, H 3$ and $H 4$. Variables in latin represent first-order constucts associated to the second-order constructs in bold.

Methodology. In this section we present the methodology adopted to empirically test our hypothesized model shown in Figure 1.

Sample. We used Prolific (Rialti et al., 2019) to collect data from real consumers of luxury fashion brands. Our survey was distributed from June 2019 to September 2019 and consisted of 46 items taken from previous validated literature and adapted to our specific context of analysis - green luxury consumption. We were able to collect 464 usable responses from the Individualistic sample (Italian) and 328 valid responses from the Collectivistic one (Asian), 
for a total sample of 792 respondents. The former sample was composed of 357 (77\%) women and 107 (23\%) men, mainly Millennials - aged 18-24 (42\%) and aged 25-39 (34\%); while the Asian sample was composed of 193 (59\%) women and 135 (41\%) men, mostly Millennials - aged 18-24 (34\%) and 25-39 (54\%).

Measures. Others-oriented motives was interpreted as a multi-dimensional construct composed of two first-order constructs (Stern et al., 1998): self-transcendence values, a three-item scale (i.e., "It's important to protect the environment and preserve the nature"); and conservation values, a three-item scale (i.e., "Self-discipline, self-restraint, resistance to temptation are important values for me").

Self-oriented motives was similarly capture as a multi-dimensional construct composed of two-first-order dimensions (Stern et al., 1998): self-enhancement values, a three-item scale (i.e., "For me wealth, material possession, and money are important"); and openness to change, a three-item scale (i.e., "I want to live an exciting life with stimulating experiences").

Our hypothesized "enablers" green luxury variable is interpreted as a second-order construct composed of three first-order variables: green self-identity, a three-item scale originally developed by Sparks et al. (1992) and recently adopted by Arli et al. (2018) (i.e., "I think of myself as someone who is very concerned with 'green issues",); perceived readiness, a three-item scale by Arli et al. (2018) (i.e., "At the moment, one of my main responsibilities is to think about environmentally-friendly products"); and perceived consumer effectiveness, a five-item scale by Choi and Johnson (2019) (i.e., "Each consumer's shopping choice can have a positive effect on society by purchasing products sold by socially responsible companies”).

Our hypothesized "disablers" green luxury variable is conceived as a second-order construct composed of four first-order variables: green luxury skepticism, a four-item scale by Leonidou et al. (2017) (i.e., "I don't think these products meet high environmental standards"); perceived greenwashing, a five-item scale by Zhang et al. (2018) (i.e., "The products leave out or mask important information, making the green claims sound better than they are"); perceived contradiction, a two-item scale by Kapferer et al. (2013) (i.e., "Luxury has no future in a sustainable driven world"); and perceived green risk, a five-item scale by Chen et al. (2012) (i.e., "There is a chance that using these products will negatively affect the environment").

We measured green luxury attitude with the three-item scale by Paul et al. (2016) (i.e., "I have a favourable attitude toward purchasing the green version of a luxury product”). Finally, our dependent variable - green luxury purchase intention - was captured through the four-item scale by Bian et al. (2012) (i.e., "My willingness to buy this luxury brand would be high if I were shopping for a green luxury brand”). Items were rated on a seven-point Likerttype scale ranging from strongly disagree (1) to strongly agree (7).

Data analysis. This study uses a variance-based structural equation modeling approach (Hair et al., 2017; 2020) to test the research model (Figure 1). Specifically, we used partial least square path modeling (PLS) with the SmartPLS software (v.3; Ringle et al., 2015). PLS represents an appropriate statistical technique for many reasons, such as: 1) our samples size are relatively small (464 and 328 respondents for the Italian and Asian samples, respectively); 2) our hypothesized research model presents complex relationships concerning the direct, indirect, and mediating effects; 3) our main focus was the prediction of the dependent variable (green luxury purchase intention), so a predictive purpose method is mostly suitable; 4) finally, we used latent variables' scores obtained from SmartPLS in the subsequent analysis for predictive purposes (Henseler et al., 2016; Sarstedt et al., 2016).

Findings. As the first step of our PLS-SEM method, we followed Hair et al. 's (2020) guidelines to test the research model by conducting a confirmatory composite analysis (CCA). First, the indicators' reliability was confirmed because all items' outer loadings ( $\lambda$ ) were higher than 0.70 as required in the Italian and Asian samples; second, constructs' reliability was measured through Cronbach's alpha $(\alpha)$ and composite reliability $(C R)$. As shown in Table $1 a$ and $1 b$, all the constructs showed $\alpha$ and CR values higher than 0.70 as required in both samples. Table $1 a$ and $1 b$ show also the convergent validity of the constructs through the average variance extracted (AVE) of the variables. As reported, all the constructs had AVEs values higher than 0.50 as required.

Tab. 1a: Construct reliability (Asian sample)

\begin{tabular}{|c|c|c|c|}
\hline $\begin{array}{l}\text { Second-order Constructs } \\
\text { First-order Constructs }\end{array}$ & Cronbach's Alpha & Composite Reliability & Average Variance Extracted (AVE) \\
\hline Other_Oriented Motives & 0,725 & 0,799 & 0,505 \\
\hline Self Transendence & 0,72 & 0,83 & 0,62 \\
\hline Conservation & 0,7 & 0,819 & 0,603 \\
\hline Self-Oriented Motives & 0,739 & 0,823 & 0,52 \\
\hline Self-Enhancement & 0,722 & 0,801 & 0,578 \\
\hline Openness to change & 0,809 & 0,887 & 0,723 \\
\hline "Enablers" & 0,927 & 0,938 & 0,58 \\
\hline Perc. Consumer Effectiveness & 0,914 & 0,936 & 0,745 \\
\hline Green Self-Identity & 0,891 & 0,932 & 0,821 \\
\hline Perc. Readiness & 0,857 & 0,913 & 0,778 \\
\hline "Disablers" & 0,908 & 0,921 & 0,515 \\
\hline Perc. Contradiction & 0,849 & 0,93 & 0,869 \\
\hline Perc. Greenwashing & 0,875 & 0,909 & 0,667 \\
\hline Perc. Green Risk & 0,844 & 0,889 & 0,617 \\
\hline Green Luxury Skepticism & 0,836 & 0,891 & 0,673 \\
\hline Green Luxury Attitude & 0,835 & 0,901 & 0,753 \\
\hline Green Luxury Purchase Intention & 0,876 & 0,917 & 0,735 \\
\hline
\end{tabular}


Tab. 1b: Construct reliability (Italian sample)

\begin{tabular}{|c|c|c|c|}
\hline $\begin{array}{l}\text { Second-order Constructs } \\
\text { First-order Constructs } \\
\end{array}$ & Cronbach's Alpha & $\begin{array}{l}\text { Composite } \\
\text { Reliability }\end{array}$ & Average Variance Extracted (AVE) \\
\hline Other_Oriented Motives & 0,747 & 0,826 & 0,522 \\
\hline Self Transendence & 0,746 & 0,856 & 0,667 \\
\hline Conservation & 0,720 & 0,844 & 0,645 \\
\hline Self-Oriented Motives & 0,745 & 0,826 & 0,515 \\
\hline Self-Enhancement & 0,722 & 0,831 & 0,621 \\
\hline Openness to change & 0,795 & 0,880 & 0,709 \\
\hline "Enablers" & 0,929 & 0,939 & 0,584 \\
\hline Perc. Consumer Effectiveness & 0,918 & 0,938 & 0,752 \\
\hline Green Self-Identity & 0,877 & 0,924 & 0,803 \\
\hline Perc. Readiness & 0,902 & 0,939 & 0,837 \\
\hline "Disablers" & 0,913 & 0,926 & 0,520 \\
\hline Perc. Contradiction & 0,708 & 0,859 & 0,753 \\
\hline Perc. Greenwashing & 0,867 & 0,904 & 0,654 \\
\hline Perc. Green Risk & 0,876 & 0,911 & 0,673 \\
\hline Green Luxury Skepticism & 0,794 & 0,867 & 0,627 \\
\hline Green Luxury Attitude & 0,842 & 0,905 & 0,760 \\
\hline Green Luxury Purchase Intention & 0,855 & 0,903 & 0,703 \\
\hline
\end{tabular}

Source: Athors' elaboration.

Structural model. To empirically test the hypothesized relationships of our research model (see Figure 1), we used the bootstrapping procedure of SmartPLS (v.3). Specifically, the software computed 5000 samples and $95 \%$ biascorrected and accelerated lower-level confidence intervals (LLCI) and upper-level confidence intervals (ULCI) around the effect estimates. The results of the Asian sample are reported in Table $2 a$.

Tab. 2a. Results of the bootstrapped procedure (Asian sample).

\begin{tabular}{|c|c|c|c|c|c|c|c|}
\hline & Original Sample $(O)$ & Sample Mean (M) & Standard Deviation (STDEV) & T Statistics (|O/STDEV|) & P Values & $2.5 \%$ & $97.5 \%$ \\
\hline Att -> Int & 0,772 & 0,772 & 0,027 & 28,348 & 0,000 & 0,712 & 0,819 \\
\hline Disablers -> Att & $-0,304$ & $-0,304$ & 0,062 & 4,942 & 0,000 & $-0,419$ & $-0,180$ \\
\hline Disablers -> Contradiction & 0,587 & 0,587 & 0,045 & 12,926 & 0,000 & 0,486 & 0,666 \\
\hline Disablers -> Green Risk & 0,828 & 0,828 & 0,025 & 33,730 & 0,000 & 0,770 & 0,869 \\
\hline Disablers -> GreenWashing & 0,884 & 0,884 & 0,013 & 66,351 & 0,000 & 0,854 & 0,906 \\
\hline Disablers -> Skepticism & 0,750 & 0,751 & 0,035 & 21,658 & 0,000 & 0,664 & 0,805 \\
\hline Enablers -> Att & 0,361 & 0,361 & 0,053 & 6,827 & 0,000 & 0,255 & 0,460 \\
\hline Enablers -> Green Identity & 0,899 & 0,900 & 0,011 & 85,331 & 0,000 & 0,875 & 0,917 \\
\hline Enablers -> PCE & 0,867 & 0,867 & 0,019 & 46,738 & 0,000 & 0,824 & 0,898 \\
\hline Enablers -> Readiness & 0,826 & 0,826 & 0,017 & 47,841 & 0,000 & 0,788 & 0,857 \\
\hline Other_Oriented -> Att & $-0,080$ & $-0,079$ & 0,055 & 1,450 & $\underline{0,147}$ & $-0,185$ & 0,028 \\
\hline Other_Oriented -> Conserv & 0,770 & 0,769 & 0,035 & 22,010 & $\overline{0,000}$ & 0,683 & 0,823 \\
\hline Other_Oriented -> Enablers & 0,423 & 0,423 & 0,051 & 8,361 & 0,000 & 0,318 & 0,517 \\
\hline Other_Oriented -> Self Trans & 0,853 & 0,854 & 0,018 & 47,397 & 0,000 & 0,807 & 0,882 \\
\hline Self-Oriented $->$ Att & 0,077 & 0,077 & 0,057 & 1,369 & $\underline{0,171}$ & $-0,038$ & 0,187 \\
\hline Self-Oriented -> Openness & 0,876 & 0,877 & 0,016 & 54,442 & 0,000 & 0,840 & 0,904 \\
\hline Self-Oriented -> Self-Enha & 0,769 & 0,769 & 0,030 & 25,966 & 0,000 & 0,696 & 0,816 \\
\hline
\end{tabular}

Source: Authors' elaboration.

Other-oriented values had a positive impact on green luxury attitude $(\beta=+0.110 ; p<0.01)$, thus supporting H1a. As reported in Table $2 a$, this relationship was significantly mediated by green enablers: first, other-oriented values significantly influenced green enablers $(\beta=+0.423 ; p<0.01)$; second, green enablers significantly influenced green luxury attitude $(\beta=+0.361 ; p<0.01)$; third, the original relationship between other-oriented values and consumers' attitude became non-significant $(\beta=-0.080 ; p=0.147)$ as shown by the LLCI and ULCI interval [-0.185; 0.028] which comprised zero. Hence, H2 was statistically supported and green enablers resulted as a full mediator of the relationship. On the contrary, self-oriented motives had not a significant impact on green luxury attitude $(\beta=+0.077$; $p=0.171)$, thus not supporting H1b. As hypothesized, green disablers had a negative impact on green luxury attitude $(\beta=-0.304 ; p<0.01)$, empirically supporting H3. Finally, consumers' green luxury attitude strongly impacted on their intention $(\beta=+0.772 ; p<0.01)$, thus fully supporting H4. As Table 2 a reports, the outer loadings - indicating the statistical associations between the second-order constructs and their sub-dimensions - were all strong and significant, much higher than 0.500 as required (Hair et al., 2017). In this way, we were able to statistically validate the two "new" multi-dimensional constructs of green luxury "enablers" and "disablers" which were significantly associated with consumers' effectiveness, green identity, and perceived readiness (enablers); and consumers' perceived contradiction, greenwashing, green risk, and skepticism (disablers). Finally, our hypothesized model had a satisfactory predictive power which is indicated by the $R$-squared value of the dependent variable: as shown in Figure $2 a$, the $R^{2}$ of consumers' intention toward green luxury was equal to $59.5 \%$. 
Fig. 2a: Results of the structural model (Asian/collectivistic sample)

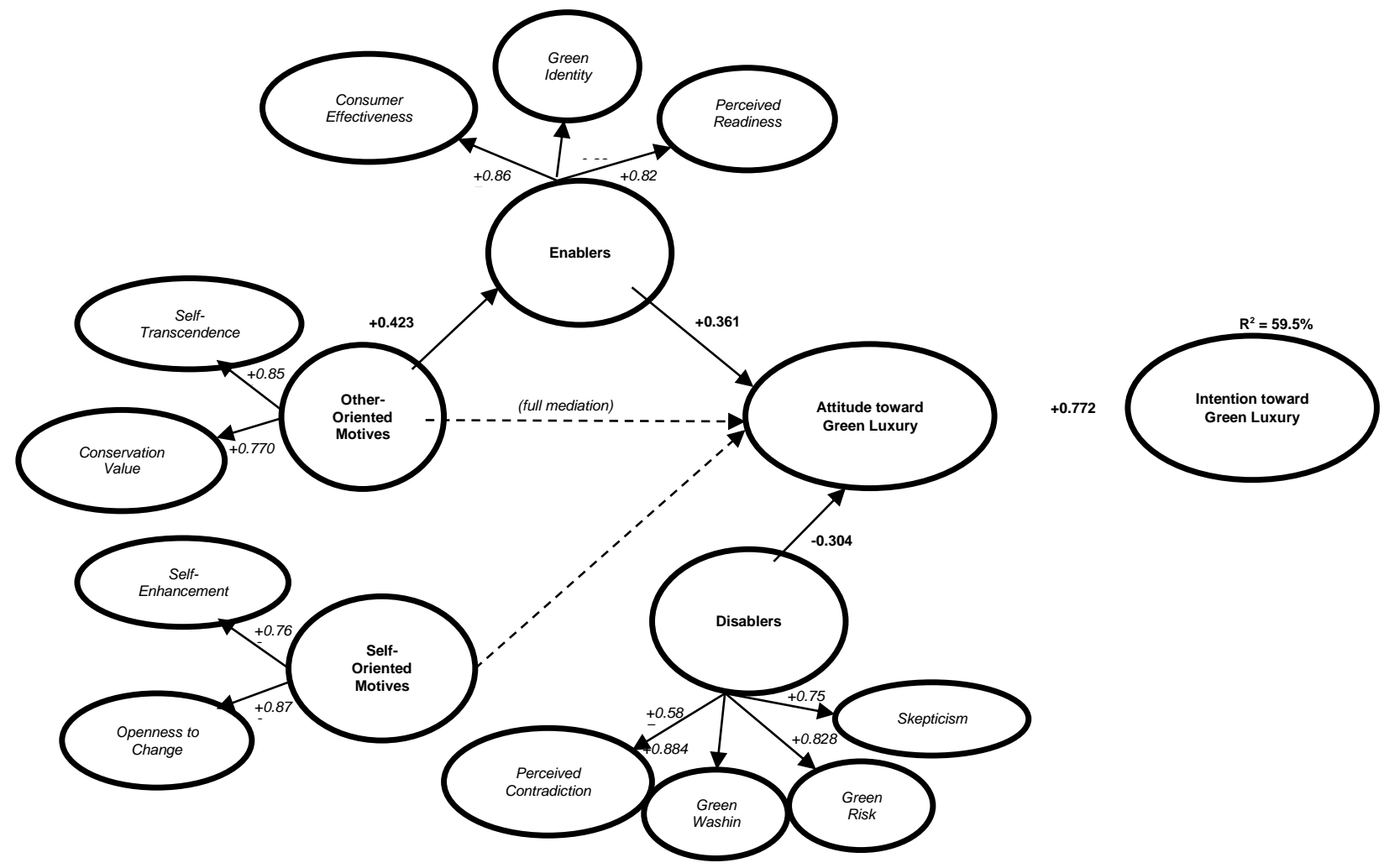

Standardized beta of path coefficients are reported in bold; factors loadings are reported in lating; $\mathbf{R}^{2}$ indicates the amount of variance explained by the predictor variables; dotted lines refer to non-significant paths. Source: Authors' elaboration.

The empirical results of the Italian sample are reported in Table $2 b$.

Tab. 2b: Results of the bootstrapped procedure (Italian sample)

\begin{tabular}{|c|c|c|c|c|c|c|c|}
\hline & Original Sample $(O)$ & Sample Mean (M) & Standard Deviation (STDEV) & T Statistics (|O/STDEV|) & P Values & $2.5 \%$ & $97.5 \%$ \\
\hline Att $->$ Int & 0,805 & 0,806 & 0,019 & 42,367 & 0,000 & 0,763 & 0,838 \\
\hline Disablers $\rightarrow>$ Att & $-0,249$ & $-0,249$ & 0,050 & 4,952 & 0,000 & $-0,345$ & $-0,149$ \\
\hline Disablers -> Contradiction & 0,610 & 0,610 & 0,040 & 15,306 & 0,000 & 0,520 & 0,679 \\
\hline Disablers -> Green Risk & 0,895 & 0,896 & 0,012 & 74,267 & 0,000 & 0,867 & 0,915 \\
\hline Disablers -> GreenWashing & 0,895 & 0,895 & 0,010 & 88,241 & 0,000 & 0,872 & 0,912 \\
\hline Disablers -> Skepticism & 0,709 & 0,710 & 0,034 & 20,680 & 0,000 & 0,633 & 0,766 \\
\hline Enablers -> Att & 0,156 & 0,155 & 0,049 & 3,162 & 0,002 & 0,055 & 0,250 \\
\hline Enablers -> Green Identity & 0,868 & 0,868 & 0,011 & 80,570 & 0,000 & 0,845 & 0,887 \\
\hline Enablers $->$ PCE & 0,854 & 0,854 & 0,014 & 59,146 & 0,000 & 0,821 & 0,878 \\
\hline Enablers -> Readiness & 0,865 & 0,865 & 0,012 & 69,657 & 0,000 & 0,838 & 0,886 \\
\hline Other_Oriented -> Att & 0,014 & 0,015 & 0,047 & 0,298 & $\underline{0,766}$ & $-0,078$ & 0,106 \\
\hline Other_Oriented -> Conserv & 0,786 & 0,786 & 0,028 & 28,244 & 0,000 & 0,718 & 0,831 \\
\hline Other_Oriented -> Enablers & 0,430 & 0,430 & 0,037 & 11,648 & 0,000 & 0,357 & 0,499 \\
\hline Other_Oriented -> Self Trans & 0,859 & 0,860 & 0,015 & 56,473 & 0,000 & 0,824 & 0,885 \\
\hline Self-Oriented -> Att & 0,174 & 0,174 & 0,047 & 3,672 & 0,000 & 0,077 & 0,266 \\
\hline Self-Oriented -> Openness & 0,849 & 0,850 & 0,014 & 59,514 & 0,000 & 0,816 & 0,873 \\
\hline Self-Oriented -> Self-Enha & 0,782 & 0,782 & 0,025 & 31,730 & 0,000 & 0,723 & 0,822 \\
\hline
\end{tabular}

Source: Authors' elaboration.

Similarly to the Asian sample, other-oriented values showed a positive impact on green luxury attitude ( $\beta=$ $+0.102 ; p<0.01$ ), thus supporting Hla. As shown in Table $2 b$, this relationship was significantly mediated by the green enablers variable: first, other-oriented values significantly influenced green enablers $(\beta=+0.430 ; p<0.01)$; second, green enablers significantly influenced green luxury attitude $(\beta=+0.156 ; p<0.01)$, although showing a lower impact in respect to the Asian sample; third, the original relationship between other-oriented values and consumers' attitude became non-significant $(\beta=+0.014 ; p=0.766)$ as shown by the LLCI and ULCI interval [-0.078; 0.106] which comprised zero. Hence, also in the Italian sample H2 was statistically supported and green enablers resulted as a full mediator of the relationship. Instead, in this sample self-oriented motives had a significant and positive impact on green luxury attitude $(\beta=+0.174 ; p<0.01)$, thus providing empirical support for H1b. Similarly to the Asian sample, green disablers had a negative impact on green luxury attitude $(\beta=-0.249 ; p<0.01)$ - although slightly lower than the other sample - empirically supporting H3. Finally, consumers' green luxury attitude showed a stronger impact on their 
intention $(\beta=+0.805 ; p<0.01)$ in respect to the Asian sample, thus statistically supporting H4. As reported in Table $2 b$, also in this case the outer loadings were significant and high, thus supporting our empirical validation of the multidimensional constructs, specifically "green enablers" and "green disablers". Finally, also the Italian hypothesized model had a satisfactory predictive power, indicated by the R-squared value of the dependent variable: as shown in Figure $2 b$, the $R^{2}$ of consumers' intention toward green luxury was equal to $64.9 \%$. In this way, the Italian sample had a higher predictive power in respect to the other sample.

Fig. 2b: Results of the structural model (Italian/individualistic sample)

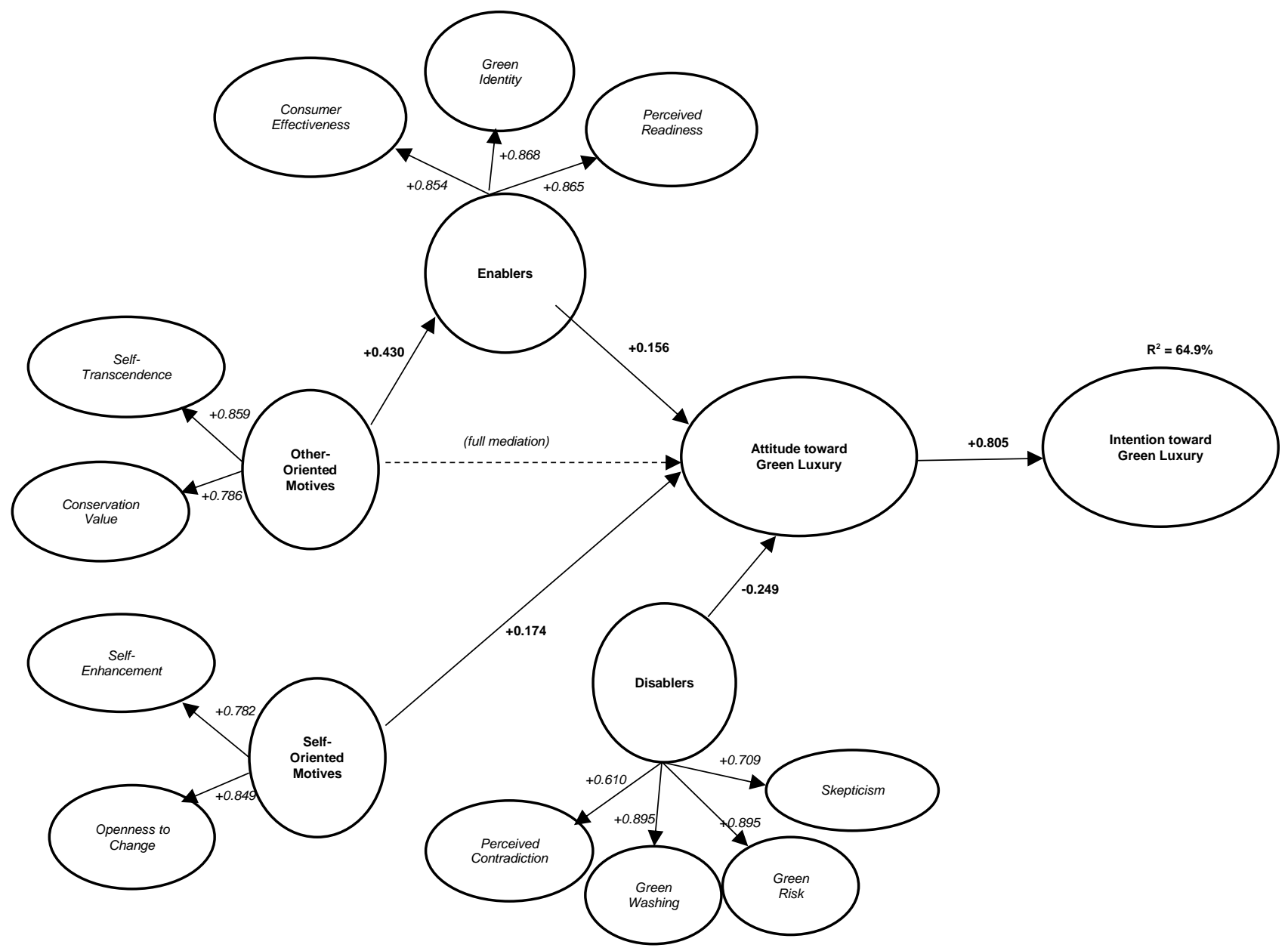

Standardized beta of path coefficients are reported in bold; factors loadings are reported in lating; $\mathrm{R}^{2}$ indicates the amount of variance explained by the predictor variables; dotted lines refer to non-significant paths. Source: Authors' elaboration.

Research limits. Our work is not without limitations. First of all, the sample is not probabilistic as it does not include all nationalities, in particular only Italy is represented as individualist countries. Being cross-sectional, the sample was neither homogeneous nor made up of subjects belonging to the same social group and was stratified only by age, gender and income. Future research is invited to replicate the analysis also including other countries, in order to have more representative and balanced samples. Second, the results reveal that the green enablers the second-degree construct does not represent an activator strong enough to increase consumers' purchasing intent. It will therefore be necessary to focus on other variables besides those considered. The second construct that explains the attitude-behavior gap - green luxury skepticism - could also be expanded in so as to deepen the understanding of this gap. Thirdly, the results, despite the anonymous self-compilation and the neutralized administration via electronic devices, can be subject to certain levels of social desirability bias (desirability bias) especially with regard to questions related to personal values as the respondents may be inclined to avoid giving answers that are not desirable in the home society. Future research is invited to repeat the analysis so that these biases can be minimized. In particular, the quantitative analysis could be combined with a qualitative analysis, for example through a focus group, so as to be able to collect a wider range of information to understand in greater depth what the factors that facilitate and which those that prevent the formation of attitudes and purchase intentions. This technique could be very useful for identifying new ones quantitative variables on which to focus, at a later time, through a new quantitative investigation.

Practical implications. The goal of our work is to investigate the motivational levers that can mature and evolve consumer attitudes in concrete behaviors and choices for the purchase of sustainable luxury goods. In recent years, 
consumers have shown greater sensitivity to social and environmental issues and luxury consumers are no exception. In terms of practical implications we can focus on individualistic and collectivistic societies different results. In individualist countries, the communication of luxury brands should enhance self-transcendence and conservation value in order to increase attitude and intention of green consumers. Direct, explicit, verbal, informative and functional communication on the benefits and practical advantages in terms of safeguarding the environment that the consumer can derive from the purchase would certainly be effective. Even in collectivist countries, one should focus on expressions that enhance self-transcendence, but also conservation value. Unlike the individualistic sample, selforiented values did not significantly impact on attitude of green consumers. With regard to green enablers, or "activators" of sustainable behaviors, these have a significant mediating effect in the purchasing behavior of individualist consumers as in collectivist societies. Finally, disables factors also plays an important role - in fact, they negatively affects attitude in both samples. The green risk and greenwashing perceptions are strongly related to the disablers construct. The first consists in the expectation of negative environmental consequences associated with the purchase of products defined as sustainable and this is obviously associated with a lack of consumer confidence in the sustainable claims of the products made by the company. Reducing one would also reduce the other, significantly reducing the overall effect and consequently allowing an increase in attitudes and purchase intent. Faced with these considerations, we suggest marketers to make the information clearer: it is not enough to say that the materials used are sustainable and innovative but it is necessary to specify in detail which types of materials have been used and what concrete advantages they can bring to the safeguard of the planet. In both countries, it is also necessary to act on the perceived contradiction, or on the perception of a contradiction between luxury and sustainability. This can be carried out, by integrating the communication regarding the motivational purchasing levers, with elements relating not only to environmental issues but also related to how luxury and sustainability can go hand in hand.

Originality of the study. The results of this study provide several significant contributions that improve the existing body of literature on sustainable luxury consumption. The hypotheses of the conceptual model, empirically tested in Italy - as representative of countries characterized by individualistic culture - and in 9 different Asian countries - as representatives of countries characterized by collectivist culture - were found to be almost totally supported.

The previous literature has mainly concentrated on the two issues separately or, when it has done so jointly, it has proved to be very contradictory and has not fully explained the purchasing behavior of consumers. Our work has therefore bridged a literary gap, comparing the enabling and impeding factors for the formation of purchasing attitudes and intentions in different cultures.

Key words: first; second; third; fourth; fifth; sixth

\section{References}

ARLI D., TAN L.P., TJIPTONO F., YANG L. (2018), “Exploring consumers’ purchase intention towards green products in an emerging market: The role of consumers' perceived readiness", International Journal of Consumer Studies, vol. 42, n. 4, pp. 389-401.

ATHWAL N., WELLS V.K., CARRIGAN M., HENNINGER C.E. (2019), "Sustainable Luxury Marketing: A Synthesis and Research Agenda", International Journal of Management Reviews, vol. 21, n. 4, pp. 405-426.

BECKHAM D., VOYER B.G. (2014), "Can sustainability be luxurious? A mixed-method investigation of implicit and explicit attitudes towards sustainable luxury consumption", Advances in Consumer Research, vol. 42, pp. 245-250

BENDELL J., KLEANTHOUS A. (2007), Deeper luxury: Quality and style when the world matters, WWF-United Kingdom, Surrey, UK.

BELK R.W. (1988), "Possessions and the extended self”, Journal of Consumer Research, vol. 15, n. 2, pp. 139-68.

BIAN Q., FORSYTHE S. (2012), "Purchase intention for luxury brands: A cross cultural comparison", Journal of Business Research, vol. 65, n. 10, pp. 1443-1451.

CERVELLON M.C., CAREY L. (2011), "Consumers' perceptions of green: Why and how consumers use eco-fashion and green beauty products", Critical Studies in Fashion and Beauty, vol. 2, n. 1, pp. 117-98.

CERVELLON M.C., SHAMMAS L. (2013), "The value of sustainable luxury in mature markets a customer-based approach", Journal of Corporate Citizenship, vol. 52, n. 12, pp. 90-101.

CHANG H.H., CHEN S.W. (2008), "The impact of online store environment cues on purchase intention: trust and perceived risk as a mediator", Online Information Review, vol. 32, n. 6, pp. 818-41.

CHEN Y.S., CHANG C.H. (2012), "Enhance green purchase intentions”, Management Decision, vol. 50, n. 3, pp. 502-520.

Chen Y.S., Lin C.L., Chang C.H. (2014), "The influence of greenwash on green word-of-mouth (green WOM): the mediation effects of green perceived quality and green satisfaction", Quality \& Quantity, vol. 48, n. 5, pp. 2411-2425.

CHOI D., JOHNSON K.K. (2019), "Influences of environmental and hedonic motivations on intention to purchase green products: An extension of the theory of planned behavior", Sustainable Production and Consumption, vol. 18, pp. 145-155.

DAVIES I.A. STREIT C.M. (2013), "Not sexy, no edge and irrelevant! exploring the paucity of sustainable fashion", Proceedings of the Academy of Marketing, Coventry, 6-8 July.

DUGAN E. (2008), "The rich keep spending, but on ethical products", The Independent, 9 June.

GODEY B., PEDERZOLI D., AIELLO G., DONVITO R. (2013), "A cross-cultural exploratory content analysis of the perception of luxury from six countries", Journal of Product and Brand Management, vol. 22, pp. 229-237.

GRISKEVICIUS V., TYBUR J.M., VAN DEN BERGH B. (2010), "Going green to be seen: status, reputation and conspicuous conservation”, Journal of Personality and Social Psychology, vol. 98, n. 3, pp. 343-355. 
HAIR J.F., HOWARD M.C., NITZL C. (2020). "Assessing measurement model quality in PLS-SEM using confirmatory composite analysis”, Journal of Business Research, vol. 109, pp. 101-110.

HAIR J.F., HULT G.T.M., RINGLE C.M., SARSTEDT M. (2017). A Primer on Partial Least Squares Structural Equation Modeling (PLS-SEM), 2nd Ed., SAGE, Thousand Oaks, California.

HALLER M., HADLER M. (2008), "Dispositions to act in favor of the environment: Fatalism and readiness to make sacrifices in a cross-national perspective", Sociological Forum, vol. 23, n. 2, pp. 281-311.

HENNIGS N., WIEDMANN K.P., KLARMANN C., BEHRENS S. (2013), "Sustainability as part of the luxury essence: Delivering value through social and environmental excellence", Journal of Corporate Citizenship, vol. 52, pp. 25-35.

HENNINGER C.E., ALEVIZOU P.J., TAN J., HUANG Q. AND RY- DING D. (2017), "Consumption strategies and motivations of Chinese consumers - the case of UK sustainable luxury fashion”, Journal of Fashion Marketing and Management, vol. 21, pp. 419-434

HENSELER J., DIJKSTRA T.K., SARSTEDT M., RINGLE C.M., DIAMANTOPOULOS A., STRAUB D.W., KETCHEN JR., D.J., HAIR J.F., HULT G.T.M., CALANTONE R.J. (2014), "Common Beliefs and Reality about PLS: Comments on Rönkkö amd Evermann (2013)”, Organizational Research Methods, vol. 17, pp. 182-209.

HU S., HENNINGER C.E., BOARDMAN R., RYDING D. (2018), "Challenging current fashion business models: entrepreneurship through access based consumption in the second-hand luxury garment sector within a circular economy", In Gardetti M.A., Muthu S.S. (eds), Sustainable Luxury Cases on Circular Economy and Entrepreneurship, Springer, Singapore.

JOY A., SHERRY J.F., VENKATESH A., WANG J., CHAN R. (2012), "Fast fashion, sustainability and the ethical appeal of luxury brands", Fashion Theory, vol. 16, n. 3, pp. 273-296.

KAPFERER J.N. (2014), "The artification of luxury: From artisans to artists", Business Horizons, vol. 57, n. 3, pp. 371-380.

KO E., MEGEHEE C.M. (2012), "Fashion marketing of luxury brands: recent research issues and contributions", Journal of Business Research, vol. 65, n. 10, pp. 1395-1398.

LEONIDOU C.N., SKARMEAS D. (2017), "Gray Shades of Green: Causes and Consequences of Green Skepticism”, Journal of Business Ethics, vol. 144, pp. 401-415.

LIM W.M., TING D.H., BONAVENTURE V.S., SENDIAWAN A.P., TANUSINA P.P., (2013), "What happens when consumers realise about green washing? A qualitative investigation", International Journal of Global Environmental Issues, vol. 13, n. 1, pp. 14-24.

MITCHELL V.W. (1999), “Consumer perceived risk: conceptualizations and models”, European Journal of Marketing, vol. 33, n. 1, pp. 163-95.

MONKHOUSE L.L., BARNES B.R., STEPHAN U. (2012), "The influence of face and group orientation on the perception of luxury goods: a four markets study of East Asian consumers", International Marketing Review, vol. 29, pp. 647-672.

MORAES C., CARRIGAN M., BOSANGIT C., FERREIRA C., MCGRATH M. (2017), "Understanding ethical performances in luxury consumption through practice theories: a study of fine jewellery purchases", Journal of Business Ethics, vol. 145, pp. 525-543.

NADERI I., STRUTTON D. (2015), "I support sustainability but only when doing so reflects fabulously on me. can green narcissists be cultivated?", Journal of Macromarketing, vol. 35, pp. 70 -83.

PARGUEL B., BENOÎT-MOREAU F., LARCENEUX F. (2011), "How sustainability ratings might deter 'greenwashing': a closer look at ethical corporate communication", Journal of Business Ethics, vol. 102, n. 1, pp. 15-28.

PAUL J., MODI A., PATE, J. (2016), "Predicting green product consumption using theory of planned behavior and reasoned action", Journal of Retailing and Consumer Services, vol. 29, pp. 123-134.

RAMCHANDANI M., COSTE M. (2012), "Asymmetry in multi-cultural luxury communication: a comparative analysis on luxury Brand communication in India and China”, Journal of Global Fashion Marketing, vol. 3, n. 2, pp. 89-97.

RIALTI R., ZOLLO L., FERRARIS A., ALON I. (2019), "Big data analytics capabilities and performance: Evidence from a moderated multi-mediation model", Technological Forecasting \& Social Change, Vol. 149. DOI: 10.1016/j.techfore.2019.119781.

RINGLE C.M., WENDE S., BECKER J.M. (2015). SmartPLS 3. Boenningstedt: SmartPLS GmbH, http://www.smartpls.com.

ROBERTS J.A. (1996), "Green consumers in the 1990s: Profile and implications for advertising”, Journal of Business Research, vol. 36, n. 3, pp. 217-231

ROJAS-MENDEZ J.I., LE NESTOUR M., ROD M. (2015), "Understanding attitude and behavior of Canadian consumers toward organic wine", Journal of Food Products Marketing, vol. 21, pp. 375-396.

SARSTEDT M., HAIR J.F., RINGLE C.M., THIELE K.O., GUDERGAN S.P. (2016), "Estimation issues with PLS and CBSEM: Where the bias lies!", Journal of Business Research, vol. 69, pp. 3998-4010.

SHARMA P. (2010), "Country of origin effects in developed and emerging markets: exploring the contrasting roles of materialism and value consciousness", Journal of International Business Studies, vol. 42, pp. 1-22.

SHUKLA P., PURANI K. (2012), "Comparing the importance of luxury value perceptions in cross-national contexts", Journal of Business Research, vol. 65, n. 10, pp. 1417-1424.

SPARKS P., SHEPHERD R. (1992), "Self-identity and the theory of planned behavior: Assessing the role of identification with “green consumerism”“, Social Psychology Quarterly, vol. 55, n. 4, pp. 388-399.

STERN P.C., DIETZ T., GUAGNANO G.A. (1998), "A brief inventory of values”, Educational and Psychological Measurement, vol. 58 , n. 6, pp. 984-1001.

STRAUGHAN R.D., ROBERTS J.A. (1999), "Environmental segmentation alternatives: a look at green consumer behavior in the new millennium", Journal of Consumer Marketing, vol. 16, n. 6, pp. 558-575

WIEDMANN K.P., HENNIGS N., SIEBELS A. (2007), "Measuring consumers' luxury value perception: a cross-cultural framework", Academy of Marketing Science Review, vol. 11, pp. 1-21

YAU A., DAVIES I. (2014), "Exploring the role of modern Confucian values for promoting sustainable consumption in China", Annual Macromarketing Conference, Royal Holloway University of London, London, pp. 2-5.

ZHANG L., LI D., CAO C., HUANG S. (2018), "The influence of greenwashing perception on green purchasing intentions: The mediating role of green word-of-mouth and moderating role of green concern", Journal of Cleaner Production, vol. 187, pp. 740-750. 


\title{
La formazione e l'evoluzione dei team imprenditoriali: un focus sugli spin-off accademici
}

\author{
Rosangela Feola* Chiara Crudele` Roberto Parente`Massimiliano Vesci***
}

Obiettivi. Il team imprenditoriale è sempre più considerato come il fattore chiave per la creazione di nuove imprese (Harper, 2008; Kamm et al.,1990). Numerosi studi hanno dimostrato che le imprese fondate da team imprenditoriali hanno maggiori probabilità di sopravvivenza ed un tasso di crescita superiore rispetto alle nuove imprese fondate da singoli imprenditori (Eisenhardt e Schoonhoven, 1990, Kamm et al., 1991 Aldrich, Carter e Ruef 2004; Aspelund, Berg-Utby,e Skjevdal 2005; Cooper e Daily 1997; Jin et al. 2017).

Il team imprenditoriale rappresenta un fattore critico di successo anche negli spin off accademici, imprese science-based e operanti in settori ad alta tecnologia, promosse da soggetti appartenenti al mondo della ricerca per valorizzare e portare sul mercato i risultati della ricerca scientifica (Clarysse et al.,2000). Negli spin-off accademici infatti, la presenza di un team imprenditoriale eterogeneo ma complementare in termini di competenze e capacità, rappresenta un'efficace risposta alle tante aree di rischio che tipicamente caratterizzano questa particolare tipologia di impresa innovativa (Gartner, 1985). Numerose ricerche hanno poi che dimostrato che le caratteristiche del team imprenditoriale, soprattutto nella fase di early-stage, costituiscono uno dei principali criteri di valutazione dei fondi di venture capital (Roure e Keeley, 1990; Cyr et al., 2000).

Il ruolo, la composizione e le caratteristiche del team imprenditoriale quali fattori chiave delle performance delle imprese high-tech è stato ampiamente dimostrato da rilevanti studi sul tema (Bjornåli e Gulbrandsen 2010; Clarysse, Knockaert, e Lockett 2007; Colombo e Grilli 2010; Eisenhardt 2013; Ganotakis 2012). In particolare, è stato osservato come alcune caratteristiche del team legate al background di formazione e alle precedenti esperienze rappresentino fattori rilevanti nelle performance delle nuove imprese (Cassar 2014; Ganotakis 2012; Nuscheler, Engelen e Zahra 2018; Visintin e Pittino 2014). Team altamente istruiti hanno maggiori opportunità di successo (Marvel 2013; Marvel e Lumpkin 2007; Wiklund e Shepherd 2003; Shane 2000; Shane e Venkataraman 2000; Ucbasaran, Westhead e Wright 2009). Essi sono anche più in grado di attrarre risorse aggiuntive di natura finanziaria e conoscenza (Baum e Silverman 2004; Bruns and Fletcher 2008; Mason and Stark 2004). In una ricerca sugli spin off italiani, Iacobucci et al. (2010) individuano nella composizione del team un altro aspetto rilevante. La ricerca individua infatti tra le principali cause responsabili dei limitati tassi di crescita proprio lo squilibrio nel team dei fondatori verso skills prettamente tecnologiche a svantaggio di competenze di tipo gestionale e organizzativo.

La sfida per uno spin off accademico che tipicamente opera sulla frontiera della conoscenza scientifica, diviene dunque quello di riuscire a costruire un team articolato sia in senso orizzontale (che copra cioè le varie discipline tecnico/scientifiche nel cui dominio ricadono i prodotti/servizi che si intendono sviluppare), sia in senso verticale (ovvero che integri conoscenze scientifiche, tecniche, gestionali e di business) (Netval, 2014), attraverso il coinvolgimento di soggetti esterni all'impresa. Tale coinvolgimento però, risulta particolarmente complesso nel caso degli spin off accademici a causa di un peculiare problema principal-agent (Parente et al., 2009) che rende il tema del team un aspetto centrale nelle dinamiche di sviluppo di uno spin off accademico.

Diversi autori sostengono che il fabbisogno di risorse e competenze necessarie per lo sviluppo di una nuova impresa vari in relazione alle diverse fasi in cui si può scomporre il processo imprenditoriale di uno spin off (Yusubova, Andries, \& Clarysse, 2019; Clarysse and Moray, 2004).

Yusubova, Andries, e Clarysse, (2019) hanno proposto un processo imprenditoriale suddiviso in diverse fasi di sviluppo in ciascuna delle quali diverse risorse e competenze divengono rilevanti:

1) Concezione e sviluppo: è la fase iniziale del progetto quando l'impresa cerca di sviluppare la sua tecnologia in un prototipo. In questa fase la conoscenza tecnologica è la risorsa fondamentale.

2) Commercializzazione: è la fase di ingresso sul mercato quando le imprese tentano di avviare la produzione e

Research Fellow in Economia e Gestione delle Imprese - Università degli Studi di Salerno - Italy

e-mail: rfeola@unisa.it

- Dottoranda di ricerca in Big Data Management - Università degli Studi di Salerno - Italy e-mail: chcrudele@unisa.it

- Associato di Economia e Gestione delle Imprese - Università degli Studi di Salerno - Italy e-mail: mvesci@unisa.it

** Ordinario di Economia e Gestione delle Imprese - Università degli Studi di Salerno - Italy e-mail: rparente@unisa.it 
stabilire relazioni con $i$ fornitori. In questa fase le elevate competenze tecniche possono indurre il team a enfatizzare eccessivamente gli aspetti tecnologici trascurando quelli commerciali e di business (Ganotakis 2012; Oakey 2003) che divengono cruciali in questo step. Per affrontare queste lacune nella conoscenza, studi precedenti hanno evidenziato l'importanza di imprenditori surrogati, cioè individui diversi dai fondatori originari che forniscono conoscenze commerciali sin dalle prime fasi dello sviluppo di una nuova imprese.

3) Rendimenti sostenibili: l'impresa deve cercare di produrre, vendere e distribuire la sua offerta in volumi più elevati. Di conseguenza, membri esperti e con esperienze precedenti sono necessari per sviluppare e consolidare una struttura organizzativa e un modello di business vincente.

Tuttavia, nonostante l'importanza del team imprenditoriale per la nascita e sviluppo degli spin off accademici, pochi studi hanno indagato il processo attraverso il quale i fondatori ampliano il team iniziale attraverso l'integrazione di competenze e conoscenze provenienti da altri soggetti (Mathieu et al. 2014). Partendo da tali premesse il paper si propone di analizzare il processo di formazione di un team imprenditoriale negli spin off accademici. In particolare, il lavoro si propone di analizzare in che modo nelle diverse fasi di sviluppo di uno spin off, il team imprenditoriale evolve al fine di integrare le conoscenze e le competenze necessarie passare da una fase ad un'altra del percorso imprenditoriale.

\section{Metodologia.}

Disegno della ricerca. Il lavoro adotta un approccio di ricerca di tipo qualitativo, basato sulla metodologia del "multiple case study", con l'obiettivo di esaminare in profondità la formazione e l'evoluzione delle conoscenze negli spin-off accademici (Eisenhardt 1989). L'uso di più casi ci consente di applicare una logica di replica che tratta $i$ casi come una serie di esperimenti (Yin 1994). Mentre un singolo caso di studio offre approfondimenti su un esempio particolare, un approccio a più casi è generalmente considerato più solido e fornisce una visione contestuale più ricca e può quindi costituire la base per una spiegazione più generale e una comprensione approfondita del processo di sviluppo del team imprenditoriale nelle imprese science-based (Yin 1989). Il nostro livello di analisi è il processo imprenditoriale e l'unità di analisi è il team di impresa.

Selezione dei casi. La ricerca considera 4 spin off accademici dell'Università degli Studi di Salerno, una tra le Università del Mezzogiorno più attive nella creazione di imprese dalla ricerca (Netval, 2018).

Gli spin-off sono stati selezionati sulla base di specifici criteri. Innanzitutto, tutti gli spin-off dovevano essere attivi nello sviluppo di una nuova tecnologia. In secondo luogo, dal momento che l'obiettivo dello studio è esaminare l'evoluzione del team imprenditoriale, sono state selezionate solo iniziative tecnologiche che avevano una chiara intenzione di crescere. Infine, per garantire uniformità dal punto di vista del contesto economico-istituzionale tutti gli spin-off dovevano essere fondati nella stessa regione geografica.

Per la selezione dei casi, le informazioni rispetto ai tre criteri fornite dai founders sono state triangolate con altri dati raccolti da fonti secondarie al fine di accertare la presenza dei criteri di selezione dei casi. I quattro spin-off sono cosi ripartiti: due nelle fasi di concezione e sviluppo (Riatlas ed EproInn), mentre gli altri due (NewMatt e ImmunePharma) hanno già affrontato questa fase per ritrovarsi nello stadio successivo di commercializzazione. La ricerca è ancora in corso, e l'ultima fase (rendimenti sostenibili) non è ancora stata trattata nel lavoro, in quanto gli spin-off intervistati non hanno raggiunto un livello più avanzato della commercializzazione, che richiede di produrre, vendere e distribuire l'offerta in volumi più elevati.

Raccolta dei dati e procedura di analisi. I dati primari degli spin-off sono stati raccolti durante $i$ mesi di aprilemaggio 2019 attraverso una prima serie di interviste semi strutturate "face-to-face" con i loro fondatori; le interviste di follow-up sono ancora in corso. Durante questo primo round, sono state condotte in totale 4 interviste ognuna delle quali è durata in genere tra i 30 e 45 minuti. Per la seconda serie di interviste, stiamo attualmente implementando la medesima procedura, intervistando i fondatori / top manager degli spin-off per ottenere un resoconto aggiornato dell'evoluzione dei team negli spin-off. Round di interviste multipli sono necessari per catturare $i$ cambiamenti del fenomeno nel tempo e soprattutto per ridurre qualsiasi problema di bias dovuti all'analisi temporale retrospettiva (Pettigrew 1990). Per garantire la triangolazione dei dati (Yin 2014), abbiamo raccolto dati aggiuntivi sui casi da fonti di dati secondarie come rapporti annuali, siti Web, pubblicazioni, brochure e manuali. Abbiamo usato questi dati secondari per ottenere una buona comprensione del contesto e per verificare se vi fossero incongruenze tra $i$ dati dell'intervista e quelli secondari sull'evoluzione dei quattro spin-off. Dalla triangolazione dei dati non sono emerse ad oggi incongruenze. Le interviste sono state registrate e trascritte come parte del processo di analisi dei dati. Per ogni spin-off selezionato, è stato chiesto a ognuno dei top manager (fondatore o CEO) della storia di sviluppo dell'azienda e in particolare di come il team si è evoluto nel tempo. Questo ci ha aiutato a comprendere il contesto in cui i team si sono formati ed evoluti. Al fine di ottenere informazioni più dettagliate in merito al processo imprenditoriale e a come si è evoluto il team imprenditoriale nelle diverse fasi di questo processo, abbiamo posto domande a risposta aperta, in particolare sui diversi individui, i loro background e le loro competenze, e sul perché e come sono stati coinvolti nell'impresa. Per ciascun caso, è stata effettuata una ricostruzione retrospettiva di tutte le fasi di sviluppo che lo spinoff aveva attraversato fino a quel momento. In seguito, per ogni singolo caso è stato, (1) documentato le esigenze di conoscenza per la specifica fase di sviluppo, (2) rilevato come si è evoluto il team di impresa nelle diverse fasi e (3) analizzato in che modo questi cambiamenti nella composizione del team sono correlati ai cambiamenti identificati nei bisogni di conoscenza nelle diverse fasi di sviluppo del processo imprenditoriale. Al momento, essendo il lavoro nella fase di follow-up, man mano che le informazioni sui casi di studio vengono aggiornate, stiamo elaborando e perfezionando come cambiano le esigenze di conoscenza e come di conseguenza si modifica l'evoluzione del gruppo 
imprenditoriale nella sua composizione e ruoli (Eisenhardt 1989).

Risultati preliminari. Questa sezione presenta i principali risultati dei casi di studio ottenuti durante la prima fase del progetto di ricerca e che sono stati ottenuti nella prima fase di raccolta delle informazioni relative alle esigenze di conoscenza e all'evoluzione del team imprenditoriale nelle fasi di (1) concezione e sviluppo, (2) commercializzazione. La Tabella 1 offre una panoramica dei casi utilizzati nel nostro studio.

Tab. 1: Panoramica sui casi di studio del lavoro

\begin{tabular}{|l|l|l|l|}
\hline \multicolumn{1}{|c|}{ Nome dello spin-off } & \multicolumn{1}{|c|}{$\begin{array}{c}\text { Anno di } \\
\text { costituzione }\end{array}$} & Descrizione & Fase \\
\hline NewMatt & 2018 & $\begin{array}{l}\text { Progettazione di strutture (es. oggetti di design } \\
\text { interni e accessori, dispositivi meccanici, } \\
\text { lampade, elementi di moda) attraverso la stampa } \\
\text { 3D. }\end{array}$ & Commercializzazione \\
\hline Riatlas & 2017 & $\begin{array}{l}\text { Realizzazione di un sistema intelligente in grado } \\
\text { di rilevare alcuni parametri vitali del paziente, } \\
\text { attraverso dei dispositivi indossabili. }\end{array}$ & Concezione e sviluppo \\
\hline EproInn & 2014 & $\begin{array}{l}\text { Realizzazione di una tecnologia di conversione } \\
\text { delle auto tradizionali in veicoli ecologici e } \\
\text { solari. }\end{array}$ & Concezione e sviluppo \\
\hline ImmunePharma S.r.l. & 2015 & $\begin{array}{l}\text { Progettazione e realizzazione di un kit di natura } \\
\text { diagnostica nel campo del carcinoma } \\
\text { polmonare. }\end{array}$ & Commercializzazione \\
\hline
\end{tabular}

Fonte: ns. elaborazione

I primi risultati che emergono dalla ricerca evidenziano che in ogni fase dello sviluppo, gli spin-off ampliano la loro base di conoscenza attraverso l'integrazione di competenze via via più specifiche e l'inserimento e la valorizzazione di nuovi membri all'interno del team imprenditoriale. Di seguito presentiamo per $i$ quattro spin-off oggetto dello studio una descrizione dettagliata delle esigenze di conoscenza in ogni fase e le modifiche che vengono apportate a ciascuno dei team imprenditoriali al fine di soddisfare queste esigenze di conoscenza.

Fase di concezione e sviluppo. Durante questa fase di sviluppo, le principali attività di impresa si concentrano sullo sviluppo della tecnologia e sull'identificazione di un potenziale mercato di riferimento. In linea con Wright, Vohora e Lockett (2004), osserviamo due distinti processi. Considerata la natura dell'impresa (spin-off accademici), la tecnologia sviluppata è spesso il risultato della ricerca scientifica condotta dal/dai fondatore/i in un'università/istituto di ricerca o in una società affermata e che ha il potenziale per creare un mercato competitivo completamente nuovo ("technology push"). Nel caso dello spin off Riatlas i fondatori riconoscono un'esigenza di mercato non soddisfatta e provano a sviluppare una soluzione tecnologica per rispondere a tale esigenza ("market pull").

Il fondatore di Riatlas afferma che l'idea nasce da esigenze individuate nell'ambito clinico e dall'esecuzione di progetti di ricerca finanziati.

Il fondatore di NewMatt sottolinea che il suo prodotto nasce dopo un periodo di gestazione/incubazione durante il quale i componenti del team hanno partecipato a competizioni per start-up e spin-off, ricevendo anche dei premi. Il prodotto di NewMatt combina due filoni di conoscenza fondamentali: ingegneria e design. A questi ultimi si aggiunge l'importanza attribuita alla sostenibilità, che porta alla realizzazione, attraverso la stampa $3 D$, di diversi prodotti: dalle lampade, oggettistica, elementi di moda fino al design per interni e accessori.

Per lo spin-off EproInn le principali idee imprenditoriali sono legate all'attività di ricerca portata avanti dal fondatore insieme ad altri colleghi, tra studenti e dottorandi, del Dipartimento di Ingegneria Industriale. Tali idee riguardano principalmente il settore della mobilità sostenibile e dei veicoli ibridi. In particolare, il progetto è quello di convertire le auto tradizionali in veicoli ecologici e solari. L'idea prende avvio da un brevetto che ha portato successivamente alla realizzazione di prototipi. Uno degli obiettivi principali del loro progetto è commercializzare la loro tecnologia ai produttori di autoveicoli, per convertire i veicoli tradizionali in soluzioni ecologiche. Ciò gli permetterebbe di produrre veicoli ecologici senza andare a rivoluzionare le sue linee di produzione, sostenendo un sacrificio in termini di costi ridotto.

ImmunePharma si occupa di diagnosi nell'ambito del carcinoma polmonare, in particolare, sullo sviluppo di un kit di natura diagnostica nel campo del carcinoma polmonare e nasce dalla ricerca di base. La tecnologia alla base dello spin-off deriva da un brevetto precedente la sua stessa costituzione.

Discutiamo di seguito le esigenze di conoscenza osservate in questa fase e le implicazioni per la composizione del team imprenditoriale.

Bisogni di conoscenza nella fase di concezione e sviluppo. In questa fase, al fine di sviluppare e modificare un prodotto prima di entrare sul mercato, le imprese hanno bisogno in primo luogo di conoscenze tecniche per la costruzione e il collaudo di prototipi con gli utenti finali. Infatti, come afferma il fondatore di NewMatt "Le conoscenze per la realizzazione dei prototipi sono basate su due aspetti: strutture e materiali. Le prime, hanno bisogno di uno 
studio matematico, perché hanno concezione innovativa, mentre la conoscenza dei materiali serve per capire quali vanno bene per la stampa 3D oppure per il riciclo e la compatibilità di queste risorse." Anche per EproInn questa fase richiede la presenza di conoscenze prettamente tecniche e tecnologiche, che nel loro caso sono di tipo informaticoelettronico. Per Riatlas le competenze sono principalmente informatiche e di sviluppo software e richiedono forti competenze in tema di Intelligenza Artificiale e machine learning. Infine, per ImmunePharma le principali competenze richieste e implementate in questa fase sono state per lo più di natura biotecnologica.

Lo sviluppo delle competenze tecniche e tecnologiche corrono in parallelo con l'osservazione del mercato e la ricerca di un canale commerciale, punto considerato come cruciale da tutti i casi di studio. Ad esempio, Riatlas identifica come principale problema in questa fase quella dell'ingresso sul mercato: "I problemi sono legati a trovare $i$ canali giusti per entrare sul mercato, soprattutto nel mondo della salute dove società piccole come le start-up, senza referenze, difficilmente vengono selezionate. Sono problematiche legate al business e alle regole che per entrare nel mondo della salute il prodotto deve essere certificato." In linea, il fondatore di NewMatt afferma che "le difficoltà risiedono nel trovare un partner industriale nel territorio circostante [...] la partnership presuppone che l'industriale decida di investire in una start-up innovativa con rientri che non in un primo momento non sono particolarmente rilevanti, ma lo fa per una questione di immagine e per avanzare nello sviluppo delle proprie tecnologie. È un investimento che può fare chi ha una visione più illuminata che non si aspetti di ottenere un risultato immediato $e$ trovare qualcuno all'inizio che la pensi così è stato difficile”.

Composizione del team nella fase di concezione e sviluppo. Alla luce di tali esigenze di conoscenze, nella composizione del team nella fase di concezione e sviluppo, si osserva la presenza di soggetti con competenze principalmente di natura tecnica/tecnologica. Ed è importante sottolineare quanto tutti gli spin-off siano d'accordo che almeno in una fase iniziale sia il fondatore dell'idea a ricoprire la carica di amministratore delegato. Quest'ultimo viene nominato per gestire il top management team e diventa una persona intermedia tra l'incubatore e l'impresa.

Fase di commercializzazione. Dopo che l'idea è stata sviluppata e testata con gli utenti finali, le imprese entrano nella fase di commercializzazione, dove tentano di generare rendimenti offrendo qualcosa di unico e di valore ai loro primi clienti. L'obiettivo del team è lo sviluppo e la preparazione alla commercializzazione della tecnologia. Allo stato attuale della ricerca, in questa fase rientrano solo due degli spin-off analizzati: NewMatt e ImmunePharma.

Bisogni di conoscenza nella fase di commercializzazione. In questa fase di sviluppo, i team imprenditoriali hanno bisogno di ulteriori risorse di conoscenza per sviluppare la tecnologia per la commercializzazione e si lavora per rendere migliori quelle già acquisite. In particolare, emerge che gli spin-off necessitino di una capacità di sviluppo del prodotto aggiuntiva per sviluppare la tecnologia per la commercializzazione. In altre parole, non è alla ricerca di nuove conoscenze complementari, ma deve rafforzare la sua base di conoscenze esistente. Inoltre, nella fase di commercializzazione, $i$ due spin-off nel nostro studio necessitano anche delle conoscenze complementari di marketing $e$ vendita per portare un'innovazione tecnologica sul mercato. Ad esempio, NewMatt ha spiegato che: "Le difficoltà sono farsi conoscere, fare pubblicità è molto difficile”. Allo stesso modo, uno dei fondatori di ImmunePharma ha spiegato: "Nella prima fase dunque, non c'è modo di identificare risorse carenti, perché era prettamente di validazione scientifica, adesso invece è più complicato perché ci si affaccia alla realtà. Ogni prodotto ha un ciclo di vita, quindi se si perde tempo il prodotto perde valore. Bisogna fare tutto in fretta e da questa fase in poi è necessario avere figure esterne specializzate per questo ruolo". Il fondatore di NewMatt ha anche affermato che "non eravamo così bravi a vendere".

Composizione del team nella fase di commercializzazione. Quanto alla composizione del team, per entrambi gli spin-off, la fase di commercializzazione ha richiesto di aggiungere ulteriori conoscenze, e di approfondire e migliorare quelle già acquisite. In particolare, per NewMatt c'è stato bisogno di ampliare la conoscenza commerciale e pubblicitaria, al fine di far conoscere e vendere i propri prodotti. Per ImmunePharma invece, è stato necessario fare ricorso a consulenti esterni per aspetti più prettamente normativi.

Mentre in NewMatt la composizione del team non ha subito rilevanti modifiche, dovuto molto probabilmente al fatto di essere una realtà molto più recente, ImmunePharma col tempo ha visto ridursi il suo team con l'uscita delle persone che non ricoprivano ruoli rilevanti. Infatti, per ImmunePharma in una fase iniziale il team era composto da undici persone, mentre attualmente sono sette, di cui cinque si occupano della parte scientifica, e gli altri due ricoprono il ruolo economico-finanziario. Gli altri membri del tema sono fuoriusciti in quanto si occupavano della parte scientifica, ma non avevano un ruolo rilevante ma solo di supporto.

Limiti della ricerca. La ricerca presenta alcuni limiti "naturali” dovuti allo status in fieri della ricerca e una serie di limiti metodologici che speriamo possano essere spunto per iniziative di ricerca future. Allo stato attuale, $i$ risultati presentati nel presente lavoro dovranno essere complementati con le interviste di follow-up (attualmente in fase di esecuzione) dei quattro spin-off individuati. Solo così potrà essere effettivamente interpretato come cambiano la composizione e il bisogno di conoscenze nelle diverse fasi del processo imprenditoriale. Il secondo limite metodologico riguarda la scelta del metodo di selezione dei casi. Infatti gli spin-off sono stati tutti fondati nel contesto di un incubatore situato in un'area geografica circoscritta. Sebbene, come chiarito nella sezione di metodo, ciò assicuri che queste attività imprenditoriali si trovino ad affrontare contesti istituzionali molto simili, sono necessarie ulteriori ricerche e studi per confrontare come la formazione, la composizione e l'evoluzione dei team imprenditoriali avviene in altri contesti geografici e istituzionali. Ad esempio, altri studi (Bøllingtoft e Ulh $\phi i$ 2005; Grimaldi e Grandi 2005; Bergek e Norrman 2008; Clarysse et al. 2005) hanno identificato come il contesto possa influenzare le caratteristiche del processo di incubazione e conseguentemente anche le dinamiche delle nuove imprese tecnologiche e della 
formazione dei gruppi imprenditoriali. Infine, il terzo limite metodologico è l'assenza all'interno del nostro campione, di spin-off nella fase dei rendimenti crescenti. Questo limite potrà essere risolto in questa seconda fase del progetto di ricerca.

Implicazioni pratiche. Per quanto riguarda le implicazioni pratiche e manageriali, lo studio fornisce una serie di approfondimenti sull'ottimizzazione della composizione del team imprenditoriale mentre si evolve attraverso le diverse fasi di sviluppo del processo imprenditoriale. Nella primissima fase di vita di uno spin-off ad alto impatto tecnologico, le competenze e le conoscenze necessarie sono di carattere tecnico/tecnologico. Per questo motivo testimoni privilegiati possono integrare il top management team fornendo supporto tecnologico nel concepire e testare l'idea dell'impresa. Non appena viene presa la decisione di avviare l'impresa e sviluppare l'opportunità, questi testimoni privilegiati dovrebbero essere sostituiti da nuove professionalità che forniscano al team conoscenze commerciali e di marketing. Inoltre, in questa fase in cui l'impresa cerca di commercializzare il prodotto o il servizio, assumere sviluppatori di prodotti, o coinvolgere lead-users, diventa cruciale per portare il prodotto al cliente.

Originalità del lavoro. Il presente studio è uno dei primi a mostrare in che modo $i$ cambiamenti nella composizione del team possono fornire ulteriori conoscenze per rispondere alle mutevoli esigenze dell'impresa nelle diverse fasi del processo imprenditoriale; i cambiamenti nei bisogni di conoscenza possono aiutare gli spin-off a "liberarsi" delle risorse e delle conoscenze che non sono più rilevanti e ad acquisirne di nuove (Nikiforou et al. 2018). Ancora, lo studio contribuisce alla più ampia letteratura sui team imprenditoriali fornendo una migliore comprensione di come $i$ team cambiano in risposta alle sfide in evoluzione e, in ultima analisi, risponde alle richieste di ulteriori ricerche sulla natura dinamica dei gruppi all'interno della più ampia letteratura sui team imprenditoriali (Mathieu et al. 2014). I nostri risultati suggeriscono che le future ricerche sul tema (sia qualitative che quantitative) dovrebbero tenere attentamente conto non solo delle caratteristiche statiche, ma anche dei cambiamenti evolutivi nel gruppo imprenditoriale nelle diverse fasi di sviluppo dell'impresa.

Parole chiave: team imprenditoriali; spin-off accademici; academic entrepreneurship; trasferimento tecnologico; multiple case study

\section{Bibliografia}

ALDRICH H.E., CARTER N.M., RUEF M. (2004), "Teams”, in Handbook of Entrepreneurial Dynamics: The Process of Business Creation. Eds. Gartner W.B., Shaver K.G., Carter N.M., Reynolds P.D., Thousand Oaks, CA: Sage Publication, pp. 299-310.

ASPELUND A., BERG-UTBY T., SKJEVDAL R. (2005), "Initial Resources' Influence on New Venture Survival: A Longitudinal Study of New Technology-Based Firms”, Technovation, vol. 25, n.11, pp. 1337-1347.

BAUM J.A., SILVERMAN B.S. (2004), "Picking Winners or Building Them? Alliance, Intellectual, and Human Capital as Selection Criteria in Venture Financing and Performance of Biotechnology Startups", Journal of Business Venturing, vol. 19, n. 3, pp. 411-436.

BERGEK A., NORRMAN C. (2008), "Incubator Best Practice: a Framework”, Technovation, vol. 28, p. 1, pp. $20-28$.

BJØRNÅLI E.S., GULBRANDSEN M. (2010), "Exploring Board Formation and Evolution of Board Composition in Academic Spin-Offs", The Journal of Technology Transfer, vol. 35, n. 1, pp. 92-112.

BØLLINGTOFT A., ULHØI J.P. (2005), "The networked business incubator-leveraging entrepreneurial agency?", Journal of Business Venturing, vol. 20, n. 2, pp. 265-290.

BRUNS V., FLETCHER M. (2008), “Banks' Risk Assessment of Swedish SMEs”, Venture Capital, vol. 10, n. 2, pp. 171-194.

CASSAR G. (2014), "Industry and Startup Experience on Entrepreneur Forecast Performance in New Firms", Journal of Business Venturing vol. 29, n. 1, pp. 137-151.

CLARYSSE B., KNOCKAERT M., LOCKETT A. (2007), “Outside Board Members in High Tech Start-Ups”, Small Business Economics, vol. 29, n. 3, pp. 243-259.

CLARYSSE B., MORAY N. (2004), "A process study of entrepreneurial team formation: the case of a research-based spin-off”, Journal of Business Venturing, vol. 19, n. 1, pp. 55-79.

CLARYSSE B., WRIGHT M., LOCKETT A., VAN DE VELDE E., VOHORA A. (2005), "Spinning Out New Ventures: A Typology of Incubation Strategies from European Research Institutions", Journal of Business Venturing, vol. 20, n.2, pp. 183-216.

CLARYSSE B., HEIRMAN A., DEGROOF J.J. (2000), An Institutional and Resource Based Explanation of Growth Patterns of Research Based Spin-Offs in Europe, Frontiers of Entrepreneurship Research.

COLOMBO M.G., GRILLI L. (2010), “On Growth Drivers of High- Tech Start-Ups: Exploring the Role of Founders' Human Capital and Venture Capital”, Journal of Business Venturing, vol. 25, n. 6, pp 610-626.

COOPER A.C., DAILY C.M. (1997), "Entrepreneurial Teams”, in Entrepreneurship 2000, Eds. Sexton D., Smilor R., Chicago, IL: Upstart Publishing, pp. 127-1150.

CYR L.A., JOHNSON D.E., WELBOURNE T.M. (2000), "Human resources in initial public offering firms: do venture capitalists make a difference?", Entrepreneurship Theory \& Practice, vol. 25, n. 1, pp. 77-91. 
EISENHARDT K.M. (1989), "Building Theories from Case study research”, Academy of Management Review, vol. 14, n. 4, pp. 532-550.

EISENHARDT K.M., SCHOONHOVEN C.B. (1990), "Organizational growth: Linking founding team, strategy, environment, and growth among US semiconductor ventures 1978-1988”, Administrative science quarterly, vol. 35, n. 3, pp. 504-529.

EISENHARDT K.M. (2013), “Top Management Teams and the Performance of Entrepreneurial Firms”, Small Business Economics, vol. 40, n. 4, pp. 805-816.

GANOTAKIS P. (2012), "Founders' Human Capital and the Performance of UK new Technology based Firms", Small Business Economics, vol. 39, n. 2, pp. 495-515.

GARTNER W. (1985), “A conceptual framework for describing the phenomenon of new venture creation”, Academy of Management Review, vol. 10, n. 4, pp. 696-706.

GRIMALDI R., GRANDI A. (2005), "Business Incubators and New Venture Creation: an Assessment of Incubating Models", Technovation, vol. 25, n. 2, pp. 111-121.

HARPER D.A. (2008), “Towards a theory of entrepreneurial teams", Journal of business venturing, vol. 23, n. 6, pp. 613-626.

IACOBUCCI D., IACOPINI A., MICOZZI A., ORSINI S. (2010), "Fostering Entrepreneurship in Academic Spinoffs", International Journal of Entrepreneurship and Small Business, vol. 12, n. 4, pp. 513-533.

KAMM J.B., SHUMAN J.C., SEEGER J.A., NURICK A.J. (1990), "Entrepreneurial teams in new venture creation: A research agenda", Entrepreneurship Theory and Practice, vol. 14, n. 4, pp. 7-17.

MATHIEU J.E., TANNENBAUM S.I., DONSBACH J.S., ALLIGER G.M. (2014), "A Review and Integration of Team Composition Models: Moving Toward a Dynamic and Temporal Framework”, Journal of Management, vol. 40, n. 1, pp. 130-160.

MARVEL M.R. (2013), "Human Capital and Search-Based Discovery: A Study of High- Tech Entrepreneurship", Entrepreneurship Theory and Practice, vol. 37, n. 2, pp. 403-419.

MARVEL M.R., LUMPKIN G.T. (2007), “Technology Entrepreneurs' Human Capital and Its Effects on Innovation Radicalness", Entrepreneurship Theory and Practice, vol. 31, n. 6, pp. 807-828.

MASON C., STARK M. (2004), "What Do Investors Look for in a Business Plan? A Comparison of the Investment Criteria of Bankers, Venture Capitalists and Business Angels", International Small Business Journal, vol. 22, pp. 227-248.

NETVAL-NETWORK PER LA VALORIZZAZIONE DELLA RICERCA UNIVERSITARIA (2014), XI Rapporto Netval Sulla Valorizzazione Della Ricerca Pubblica Italiana, Unire i Puntini Per Completare Il Disegno Dell'innovazione, Maria Pacini Fazzi Editore.

NIKIFOROU A., ZABARA T., CLARYSSE B., GRUBER M. (2018), "The Role of Teams in Academic Spin-offs", Academy of Management Perspectives, vol. 32, n. 1, pp. 78-103.

NUSCHELER D., ENGELEN A., ZAHRA S.A. (2018), "The Role of Top Management Teams in Transforming Technology-Based New Ventures' Product Introductions into Growth”, Journal of Business Venturing, vol. 34, n. 1, pp. 122-140.

YIN R.K. (2014), “Case Study Research: Design and Methods", 5th ed., Ca: SAGE, Los Angeles.

YIN R.K. (1989), "Case Study Research: Design and Methods", Ca: SAGE, Newsbury Park.

YUSUBOVA A., ANDRIES P., CLARYSSE B. (2019), "Entrepreneurial Team Formation and Evolution in Technology Ventures: Looking Beyond the Top Management Team”, Journal of Small Business Management, pp. 1-23, https://doi.org/10.1111/jsbm.12539 (online version),

OAKEY R.P. (2003), "Technical Entrepreneurship in High Technology Small Firms: Some Observations on the Implications for Management", Technovation, vol. 23, n. 8, pp. 679-688.

PARENTE R., FEOLA R., PETRONE M. (2011), "Corporate Governance Models as a bridge for linking academic and non-academic entrepreneurs: the case of Italian spin-offs", Industry and Higher Education, vol. 25, n. 2, pp. 119131.

PETTIGREW A. (1990), "Longitudinal Field research on Change: Theory and Practice", Organization Science, vol.1, pp. 267-292.

ROURE J.B., KEELEY R.H. (1990), "Predictors of success in new technology based ventures", Journal of business venturing, vol. 5 , n. 4 , pp. 201-220.

SHANE S. (2000), "Prior Knowledge and the Discovery of Entrepreneurial Opportunities", Organization Science, vol. 11, n. 4 , pp. 448469.

SHANE S., VENKATARAMAN S. (2000), "The Promise of Entrepreneurship as a Field of Research", Academy of Management Review, vol. 25, n. 1, pp. 217-226.

UCBASARAN D., WESTHEAD P., WRIGHT M. (2008), "Opportunity Identification and Pursuit: Does an Entrepreneur's Human Capital Matter?”, Small Business Economics, vol. 30, n. 2, pp. 153-173.

VISINTIN F., PITTINO D. (2014), "Founding Team Composition and Early Performance of University-Based SpinOff Companies", Technovation, vol. 34, n. 1, pp. 31-43.

WIKLUND J., SHEPHERD D. (2003), "Knowledge-Based Resources, Entrepreneurial Orientation, and the Performance of Small and Medium-Sized Businesses”, Strategic Management Journal, vol. 24, n. 13, pp. 13071314. 